22059 INSTITUTO DE QUIMICA UNIVERSIDADE DE SÃO PAULO
UNIVERSIDADE DE SÃO PAULO

INSTITUTO DE QUÍMICA

\title{
Biotransformações na Obtenção de \\ Hidróxi-Selenetos e Hidróxi-Teluretos \\ Quirais
}

Carlos Eduardo da Costa

Tese de Doutoramento

Prof. Dr. João V. Comasseto

Orientador

São Paulo

2006 
- $\because \ldots$.

$\because \quad \cdots$ 


\section{"Biotransformações na obtenção de hidróxi-selenetos e hidróxi-teluretos quirais"}

\section{CARLOS EDUARDO DA COSTA}

Tese de Doutorado submetida ao Instituto de Química da Universidade de São Paulo como parte dos requisitos necessários à obtenção do grau de Doutor em Química - Área: Química Orgânica.

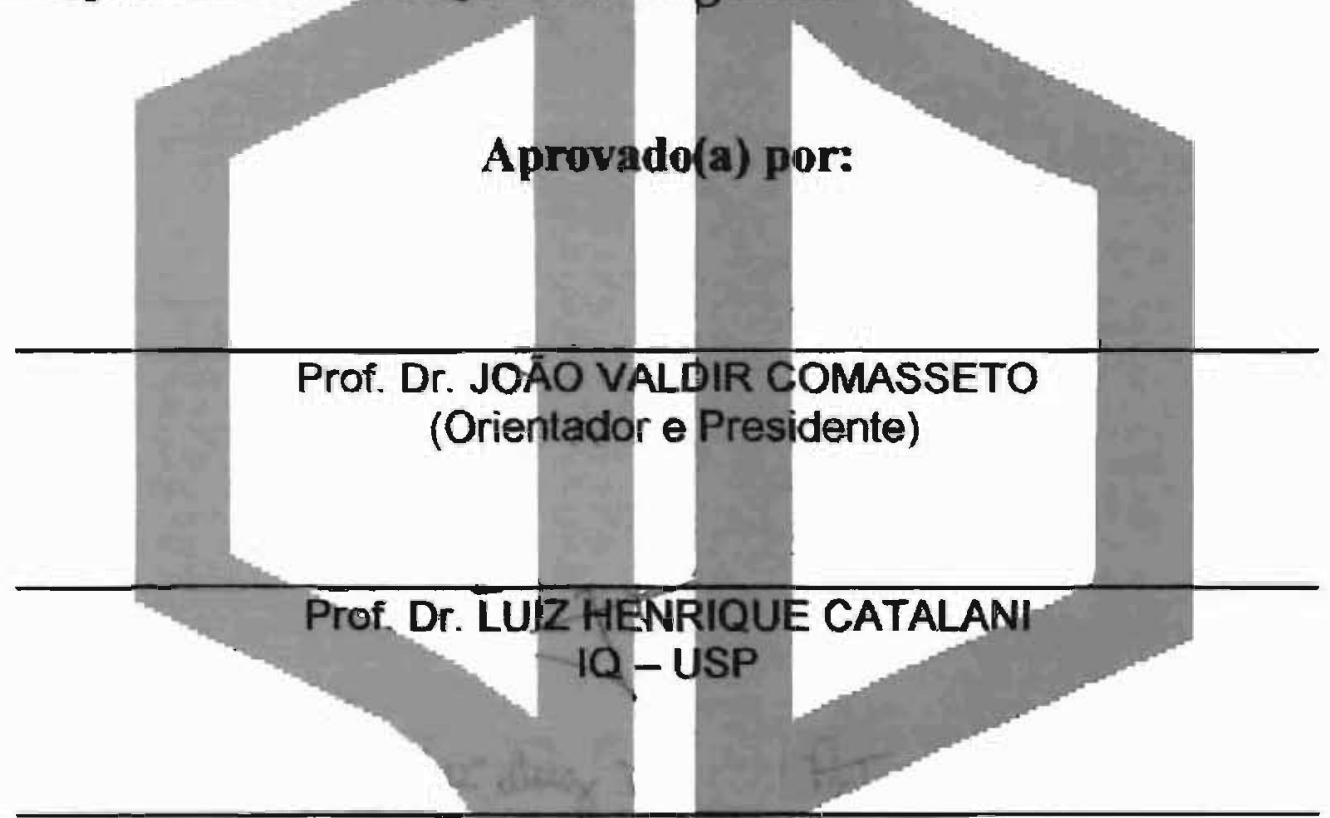

Prof. Dr. ANDRÉ LUIZ MELEIRO PORTO

IQ - SC - USP

Prof. Dr. PAULO/JOSE SAMENHO MORAN

IQ - UNMCAMP

Prof. Dr. ANTONIO LUIZ BRAGA

UFSM 


\section{DEDALUS - Acervo - CQ}

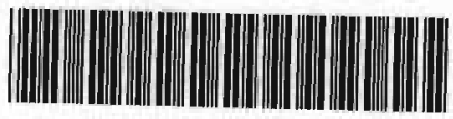

30100012254 
Aos meus queridos pais, José Cesario e Isaura (in memorian), e a minha querida irmã-mãe, Marilene, pelo seu amor e apoio sem restrições. 
A minha amada noiva, Mariana, pelo seu amor e sua compreensão. 

Agradecimentos... 

À Deus e ao meu anjo da guarda, pela constante proteção e por sempre iluminarem meu caminho...

Ao Professor Comasseto pela sua orientação, pelas ótimas condições de trabalho e pela liberdade de desenvolver projetos em seu laboratório. Por todo apoio e encorajamento dado durante todo o tempo e principalmente por ensinar muito mais que química aos seus alunos...

Aos professores, Helena Ferraz, Liliana Marzorati e Hélio Stefani, pela ajuda e convivência durante esses anos. Também aos seus alunos por toda a ajuda, pelos favores e pela amizade. Em especial ao Eduardo da Costa Ramos pelo compartilhamento de experiências e sobre tudo pela amizade incondicional.

As professoras Maria da Graça e Sandra Zanotto, pela breve orientação, pelos trabalhos em colaboração e principalmente pelo apoio e a amizade.

Aos amigos que estão ou estiveram no laboratório durante todo este período: Dennis, Priscila, Rodrigo, Takeo, Maurício, Mirian, F. Kauer, Nathalia, Cristiano, Solange, Artur, Martin, Fabiano, Ivani, Silas, Zinc, João, Bruno, Alcindo, Zé Fogo, Felipe, Nilson, Mulla, Gabriel e Vinícios, pelo bom ambiente de trabalho no laboratório. Ao Lauri por ter me apresentado a "Biocatálise". Em especial ao Giuliano por ter sempre compartilhado suas experiências em síntese e biocatálise e pelos trabalhos em colaboração.

A amiga Sabrina pela amizade e pelas boas e divertidas conversas durante nossos almoços.

Aos colegas e amigos do bloco zero: Pedro, Luís, Leonardo, Roberto, Roberta, Piovan, Thais, Adriana, Alexandre e Edna, por toda a ajuda e favores. Em especial aos professores Leandro e André pela amizade, pelo apoio e pelos trabalhos em colaboração. 
Aos meus alunos de Iniciação Científica: Guilherme, Henrique e Renan por toda a ajuda e ensinamentos. A participação de vocês foi muito importante neste trabalho e principalmente na minha formação.

Ao Alexandre Sardelli e a Dona Rosa pela boa e agradável convivência ao longo desses anos.

A toda a equipe da Central Analítica, especialmente Luzia, Adriana, Mirian e Alessandra pela pronta ajuda na execução das análises.

Ao pessoal da Secretaria de Pós-Graduação, por sempre terem sido muito prestativos.

A FAPESP, pelas bolsas de Iniciação Científica e Doutorado Direto.

Aos meus sogros, Leila e João, pelo apoio, pela amizade e pela cumplicidade em todos os momentos em que compartilhamos. Em especial aos meus cunhados, Vinicius e Mayra que da maneira deles, sei que torcem muito por $\operatorname{mim}$..

Aos meus queridos pais, José Cesario e Isaura (in memorian), a minha irmãmãe, Marilene, ao meu irmão, José Teodoro, e aos meus sobrinhos, Thiago e Guilherme, pelo amor, pelo carinho, pela compreensão, pelo total e irrestrito apoio e pelo compartilhamento de todas a minhas alegrias e frustrações. Muito obrigado!

A minha querida noiva, Mariana Simplício Touzarim, pelo seu amor, carinho e compreensão, que foram e são muito importantes para mim, como aluno de doutorado e como pessoa. Obrigado por tudo! Você é muito importante para $\operatorname{mim} .$. 


\section{Lista de Abreviaturas}



ASL

CALB

CALA

CCD

CG

CRL

DIBAL-H

DMF

DMSO

E

e.e.

E.M.

I.V.

$J$

LDA

$\mathrm{M}^{+}$

MSL

$\mathrm{m} / \mathrm{z}$

PPL

PSL

PLE

RMN ${ }^{1} \mathrm{H}$

RMN ${ }^{13} \mathrm{C}$

$\mathrm{RMIN}^{77} \mathrm{Se}$

RMN ${ }^{125} \mathrm{Te}$

t.a.

THF

TLL
- lipase de Ascaligenes sp.

- lipase de Candida antartica fração B

- lipase de Candida antartica fração A

- cromatografia em camada delgada

- cromatografia a gás

- lipase de Candida rugosa

- ridreto de di-isobutilalumirio.

- N,N-dimetilformamida

- dimetil sulfóxido

- razão enantiomérica

- excesso enantiomérico

- espectro de massas / espectrometria de massas

- infravermelho

- constante de acoplamento em $\mathrm{Hz}$

- diisopropilamideto de lítio

- íon molecular

- lipase de Mucor javanicus

- relação massa-carga

- lipase de pâncreas de porco

- lipase de Pseudomonas sp.

- esterease de fígado de porco

- ressonância magnética nuclear de hidrogênio

- ressonância magnética nuclear de carbono

- ressonância magnética nuclear de selênio

- ressonância magnética nuclear de telúrio

- temperatura ambiente

- tetraidrofurano

- lipase de Thermonyces lanuginosa 
- 
Lista de Estruturas 

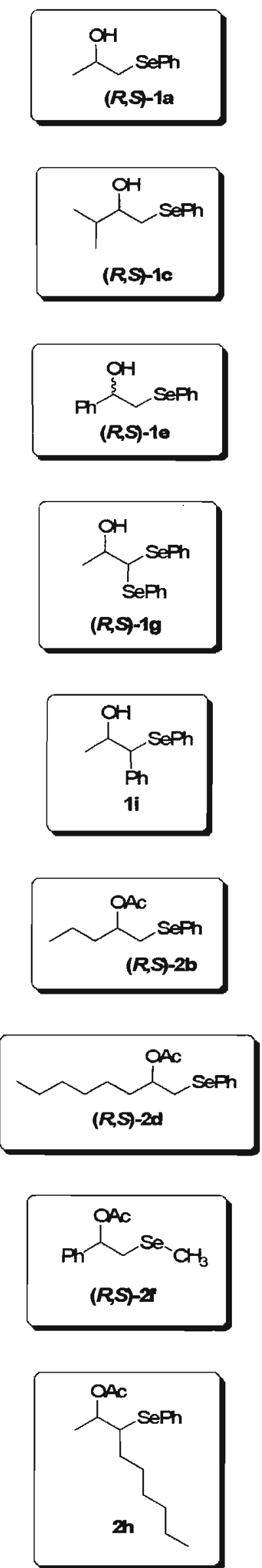
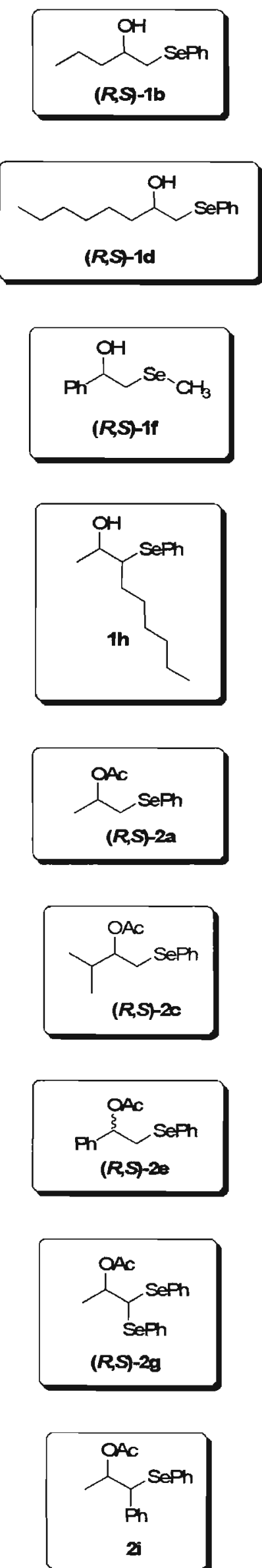

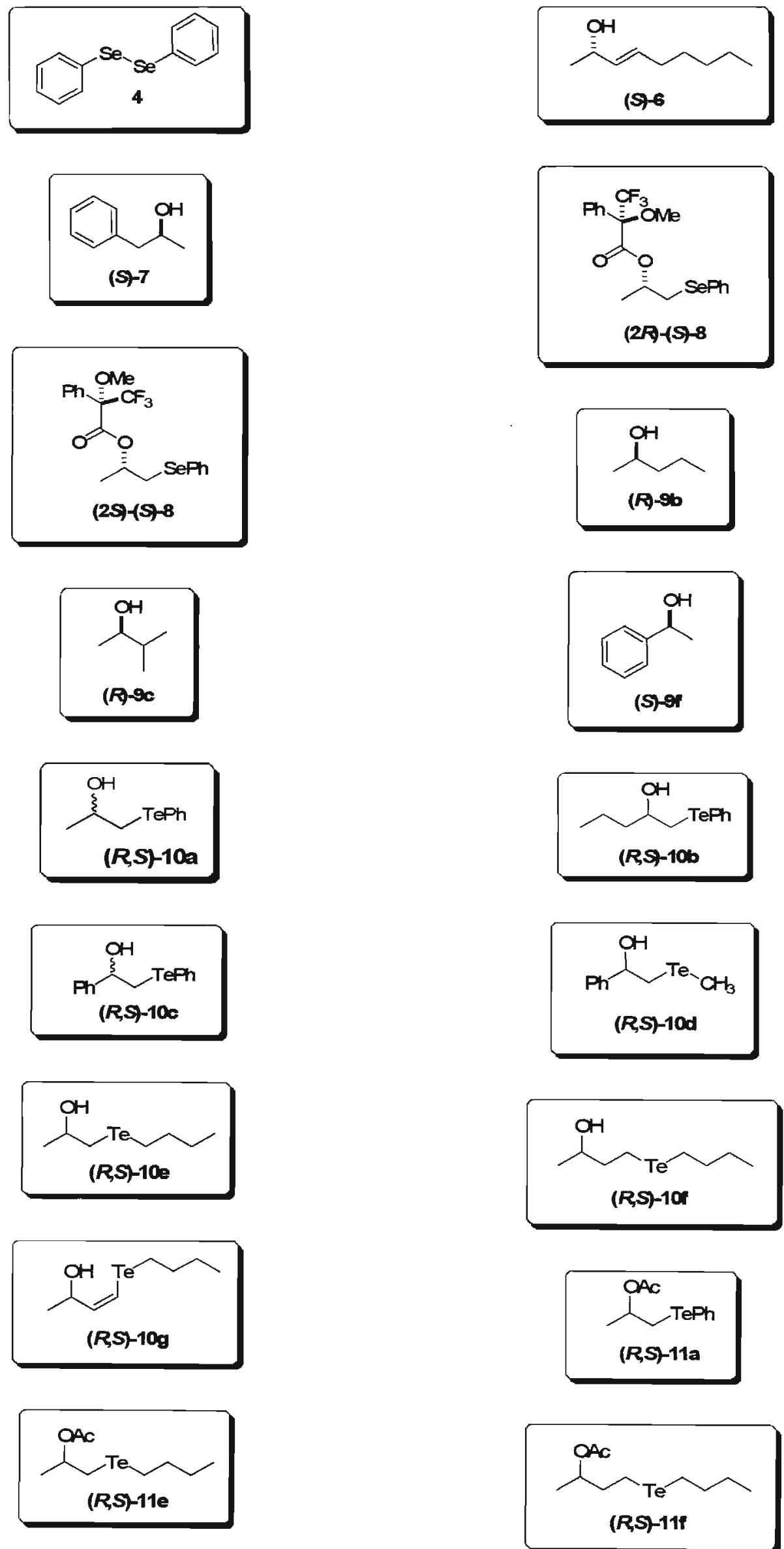


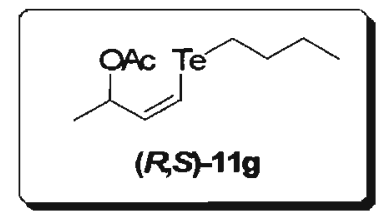

$\left(R-14>^{0}\right.$
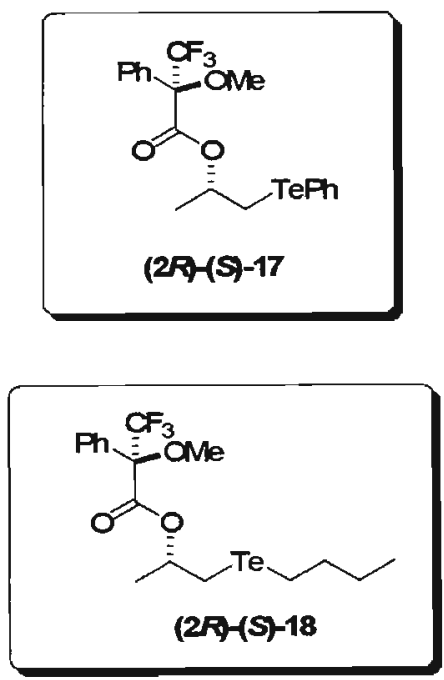
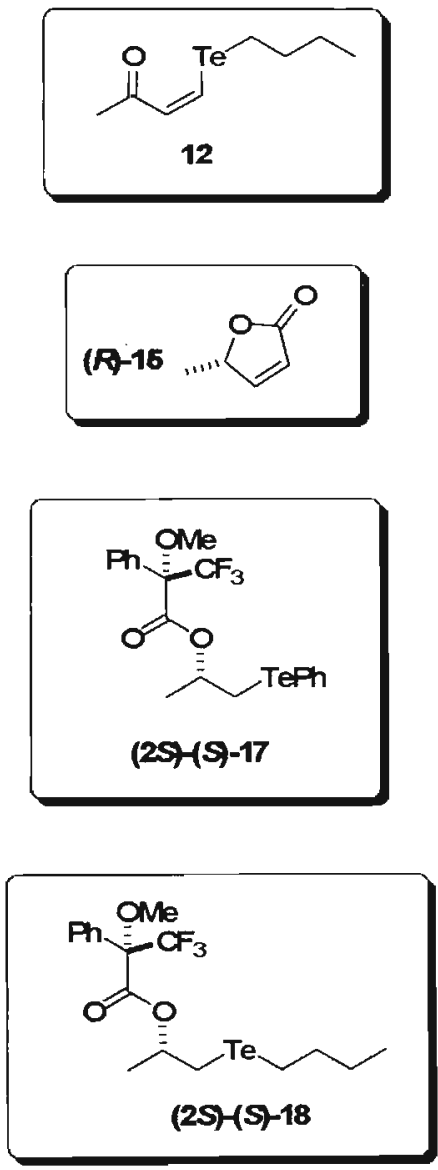
Índice 
$\cdots$ 
Lista de Abreviaturas xiii

Lista de Estruturas xvii

Índice xxiii

Resumo xxvix

Abstract xxxiii

Objetivos xxxvii

1. Introdução 1

1.1. Quiralidade e Atividade Biológica 3

1.2. Biotransformações 9

1.2.1. Enzimas 13

1.2.1.1. Aspectos Mecanísticos 14

1.2.1.2. Aplicação em Síntese Orgânica 17

1.2.1.3. Hidrolases 19

1.2.1.4. Técnicas Especiais em Síntese Orgânica 23

$\begin{array}{ll}\text { 1.3. Selênio e Telúrio } & 27\end{array}$

2. Resultados e Discussão 31

2.1. Hidróxi-Selenetos 33

2.1.1. Síntese Racêmica 35

2.1.2. Biotransformações 38

2.1.2.1. Resolução em Meio Orgânico 38

2.1.2.2. Resolução em Meio Aquoso 45

2.1.2.3. Biotransformações Utilizando Células Inteiras de Fungos $\quad 49$

2.1.3. Aplicação Sintética $\quad 52$

2.1.4. Determinação da Pureza Óptica/Estereoquímica 53

2.1.4.1. Determinação de Excesso Enantiomérico 53

2.1.4.2. Determinação da Configuração Absoluta 54

2.2. Hidróxi-Teluretos

2.2.1. Síntese Racêmica

2.2.2. Biotransformações $\quad 62$

2.2.2.1. Resolução em Meio Orgânico 62

2.2.3. Aplicação Sintética $\quad 67$

2.2.4. Determinação da Pureza Óptica/Estereoquímica 68

2.2.4.1. Determinação de Excesso Enantiomérico 68

2.2.4.2. Determinação da Configuração Absoluta 69 
4. Parte Experimental 75

4.1. Materiais e Métodos 77

4.2. Procedimentos Gerais 83

4.2.1. Preparação do Disseleneto de Difenila 85

4.2.2. Preparação dos Hidróxi-selenetos $(\boldsymbol{R}, S)$-1a e $(\boldsymbol{R}, S)-1 \mathrm{e}$

4.2.3. Preparação do Bis(fenilsseleno)metano 87

4.2.4. Preparação dos Hidróxi-selenetos $(\boldsymbol{R}, S)$-1 $\mathbf{l b}-\mathbf{d} \quad 87$

4.2.5. Preparação do Hidróxi-seleneto $(\boldsymbol{R}, \boldsymbol{S})$-1f $\quad 89$

4.2.6. Preparação do Diisopropilamideto de lítio (LDA) 90

4.2.7. Preparação do Hidróxi-seleneto $(\boldsymbol{R}, \boldsymbol{S})$-1g 90

4.2.8. Preparação dos Fenilsselenoacetais 91

4.2.9. Preparação dos Hidróxi-selenetos $( \pm)-\mathbf{1} \mathbf{h}-\mathbf{i}$

4.2.10. Preparação do Ditelureto de Difenila 93

4.2.11. Preparação dos Hidróxi-teluretos $(\boldsymbol{R}, S)$-10a e $(\boldsymbol{R}, S)$-10c 94

4.2.12. Preparação do Diazometano 95

4.2.13. Preparação do Bis((fenilteluro)metano 96

4.2.14. Preparação do Hidróxi-telureto $(\boldsymbol{R}, \boldsymbol{S})$-10b

4.2.15. Preparação dos Hidróxi-teluretos $(\boldsymbol{R}, S)$-10d e $(\boldsymbol{R}, S)$-10e 97

4.2.16. Preparação do Hidróxi-telureto $(\boldsymbol{R}, \boldsymbol{S})$-10f 98

4.2.17. Preparação da (Z)-butilteluro-enona 99

4.2.18. Preparação do Hidróxi-telureto $(\boldsymbol{R}, S)-\mathbf{1 0 g} \quad 100$

4.2.19. Preparação dos Acetatos dos Hidróxi-calcogenetos 101

4.2.20. Resolução Enzimática em Meio Orgânico 106

4.2.21. Imobilização Enzimática 111

4.2.21.1. Gel de Agar 111

4.2.21.2. Filme de Caseinato de Sódio 111

4.2.21.3. Sílica ou Montmorilonita K-10 (Silicato de Alumínio) 111

4.2.21.4. Poli(oxietileno) - PEO 111

4.2.22. Triagem Enzimática 112

4.2.23. Hidrólise Enzimática 113

4.2.24. Biotransformação Empregando Células Inteiras de Fungos 113

4.2.24.1. Crescimento dos Fungos em Meio Sólido 114

4.2.24.2. Crescimento dos Fungos em Meio Líquido 114 
4.2.24.3. Obtenção das Células Úmidas de Fungos

4.2.24.4. As Biotransformações 114

4.2.25. Preparação do Álcool Alílico - Reação de Eliminação de Selenóxido 115

$\begin{array}{ll}\text { 4.2.26. Preparação das lactonas } & 115\end{array}$

4.2.27. Determinação dos Excessos Enantioméricos 116

4.2.27.1. Hidrólise Química 117

4.2.27.2. Desselenização Redutiva 117

4.2.27.3. Derivatização Utilizando Anidrido Trifluoracético 118

4.2.28. Determinação da Configuração Absoluta 118

4.2.28.1. Preparação do Cloreto de Ácido de Mosher 118

4.2.28.2. Preparação dos Derivados de Mosher 118

4.2.28.3. Desselenização Redutiva 121

4.2.28.4. Eliminação de Selenóxido 122

4.2.28.5. Reação de Lactonização 123

4.3. Espectros Selecionados 125

5. Bibliografia 167

$\begin{array}{ll}\text { 6. Curriculum Vitae } & 173\end{array}$ 



\section{Resumo}



Neste trabalho foi estudado o comportamento de hidróxi-calcogenetos ( $\mathrm{Se}$ e $\mathrm{Te}$ ) frente a biotransformações, empregando enzimas isoladas em meio orgânico ou aquoso e empregando microorganismos (fungos). Estudos comparativos sobre a influência de diversas variáveis, como solvente, temperatura, imobilização enzimática e estrutura do hidróxi-calcogeneto, foram realizados.

Inicialmente os compostos foram sintetizados utilizando métodos descritos na literatura, em seguida foi estudada a resolução de hidróxiselenetos em meio orgânico empregando lipases isoladas (Esquema 1), incluindo um estudo de imobilização da PSL em diversos suportes, além do estudo da influência da variação do solvente, da temperatura, da lipase, etc.

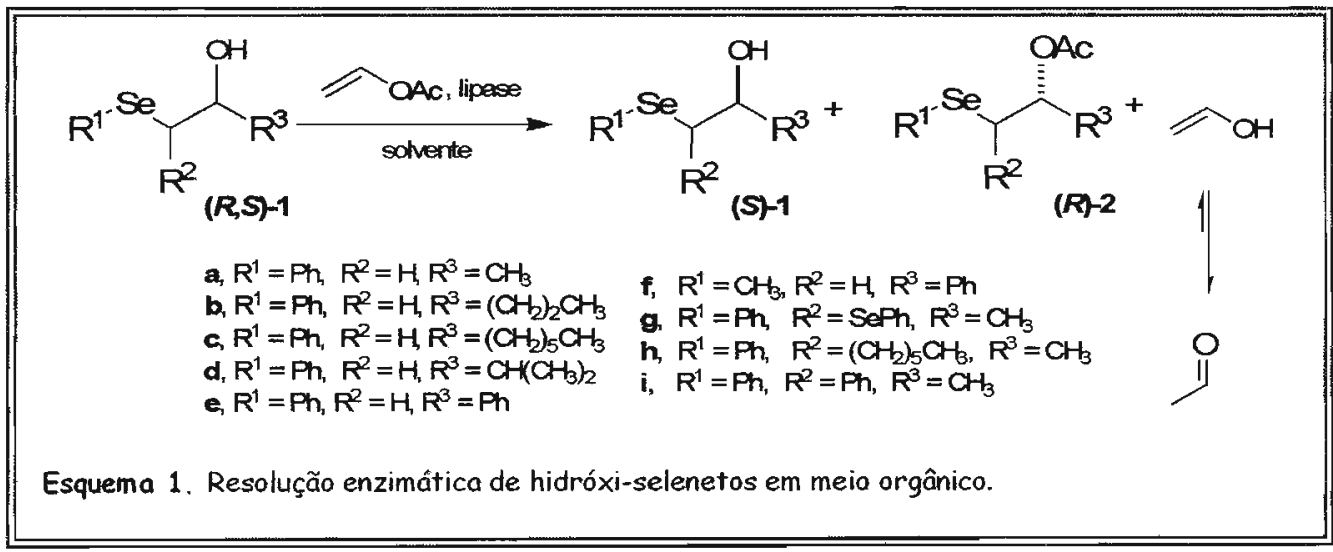

$\mathrm{Na}$ resolução em meio aquoso empregando enzimas isoladas, primeiramente os hidróxi-selenetos foram acetilados quimicamente e depois realizado uma triagem (com dez enzimas de diferentes fontes) empregando indicador de $\mathrm{pH}$ colorimétrico. Posteriormente os acetatos dos hidróxi-selenetos (Esquema 2) foram submetidos à resolução enzimática em meio aquoso empregando as enzimas que foram selecionadas na triagem enzimática.

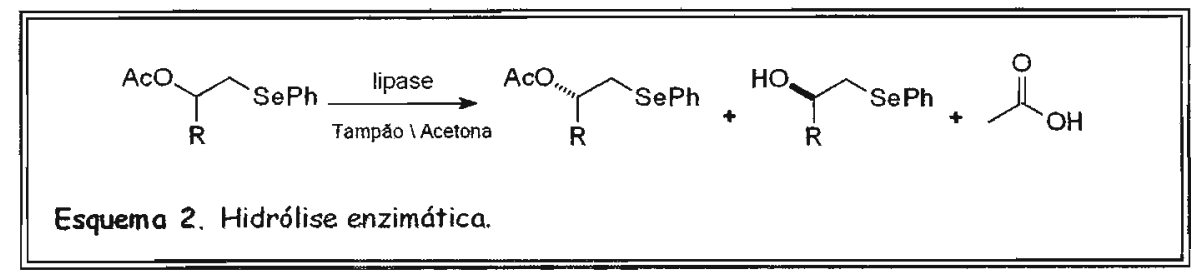

As biotransformações utilizando fungos foram realizadas empregando células inteiras de algumas linhagens de Aspergillus terreus. 
Na seqüência foi realizada a resolução de hidróxi-teluretos em meio orgânico utilizando lipases isoladas (Esquema 3). Nessas resoluções também foi estudada a influência da variação do solvente, da lipase, do tempo, etc.

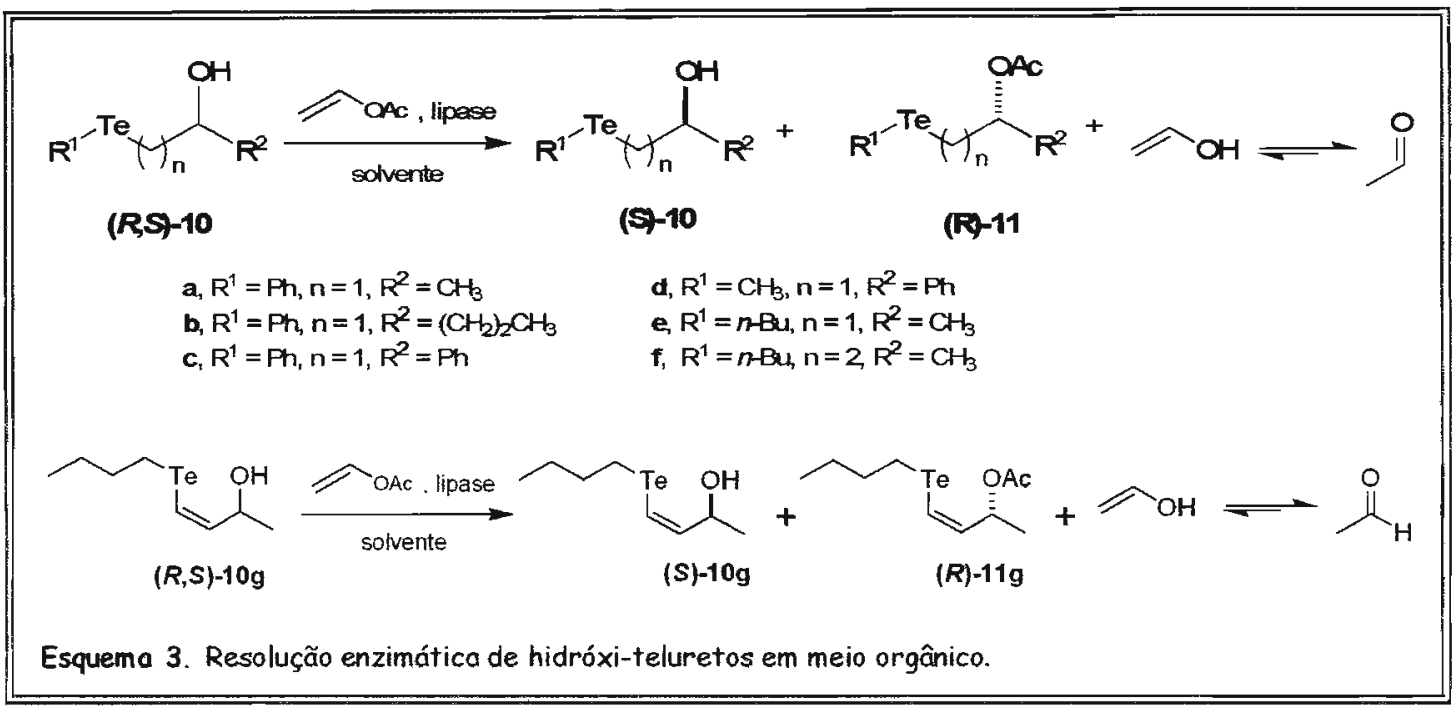

De forma a demonstrar a importância dos compostos resolvidos, um hidróxi-seleneto quiral e dois hidróxi-teluretos quirais foram usados para preparar compostos pertencentes a classes de unidades estruturais de vasta ocorrência em produtos naturais: um álcool alílico e duas lactonas (Esquema 4).

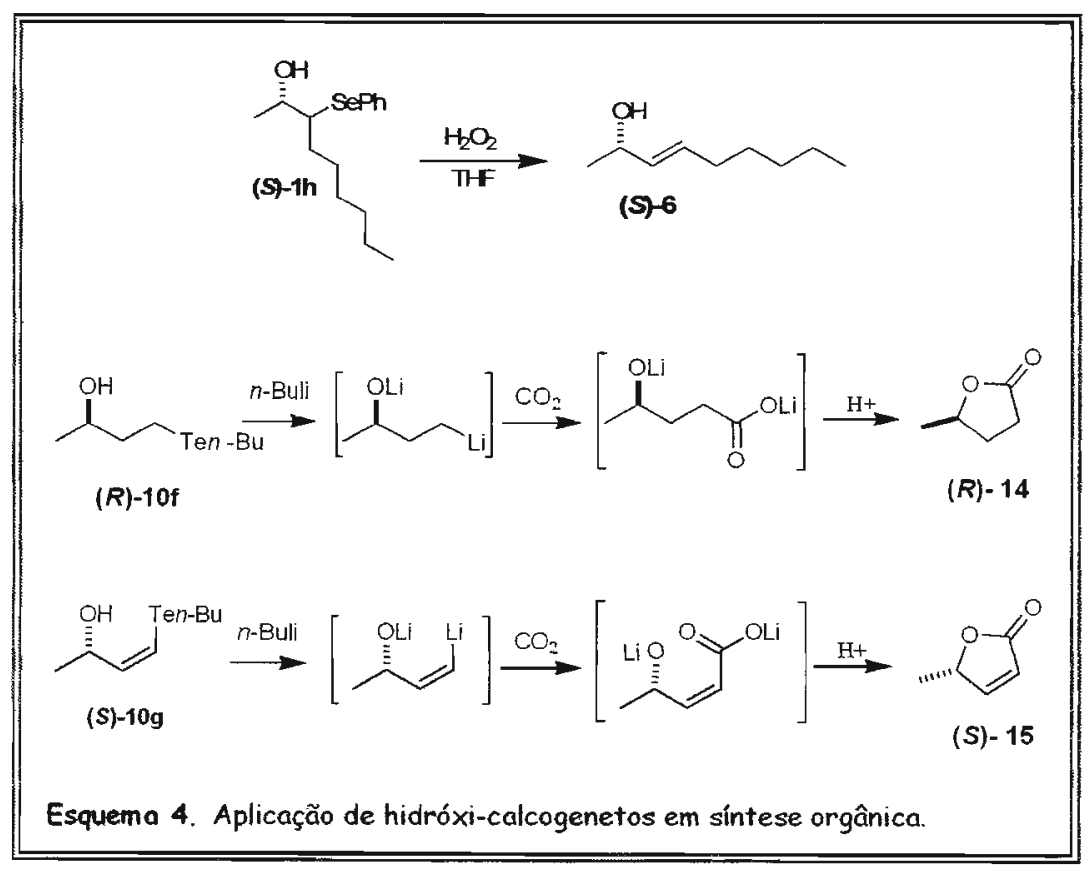


Abstract 

In this work, the behavior of hydroxy chalcogenides ( $\mathrm{Se}$ and $\mathrm{Te}$ ) towards the biotransformations using isolated enzymes in organic media or aqueous media and using microorganisms (fungi) was studied. A comparative study of the effect of temperature, solvent, enzyme immobilization and structure of the substrates on the resolution was performed.

Initially, the compounds had been synthesized using described methods in the literature, after, the resolution of hydroxy selenides in organic media using isolated lipases was carried out (Scheme 1), including a study on the immobilization of PPL on some supports, as well studies on the influence of the variation of the solvent, the temperature, lipase, etc.

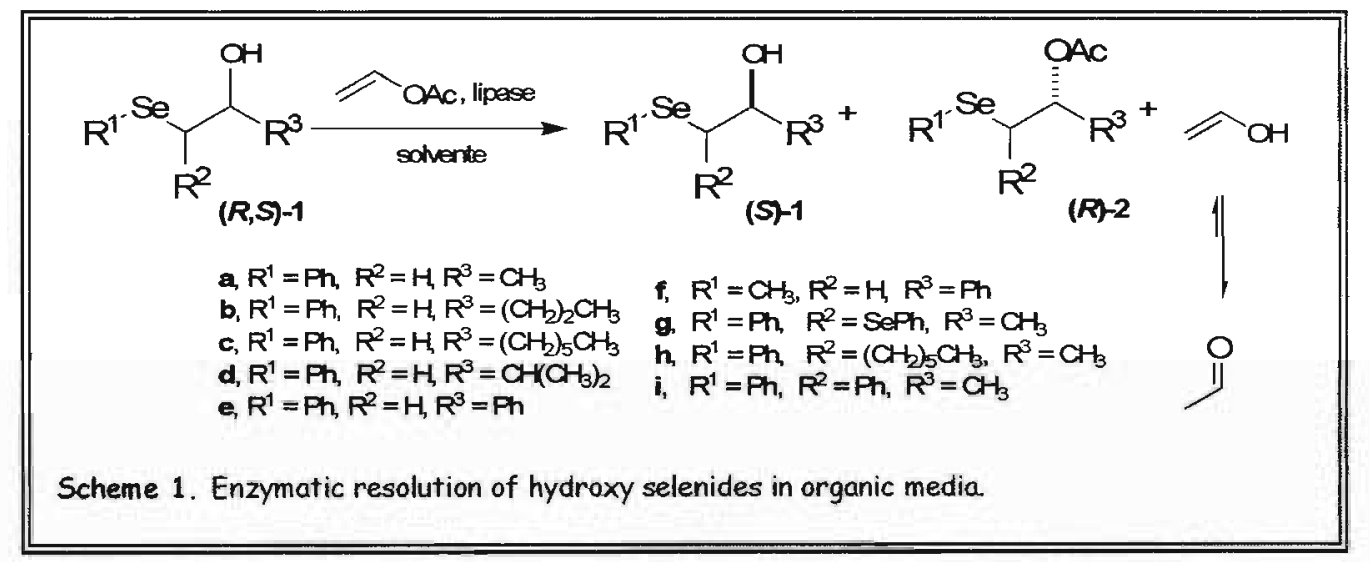

In the resolution in aqueous media using isolated lipases, initially the hydroxy selenides were transformed into their acetates by convertional chemical methods, and then, a screening with ten enzymes from different sources was carried out using $\mathrm{pH}$ indicator. In the following, the enzymatic resolution of the selanyl acetates in aqueous media using the enzymes selected in the screening step was performed (Scheme 2).

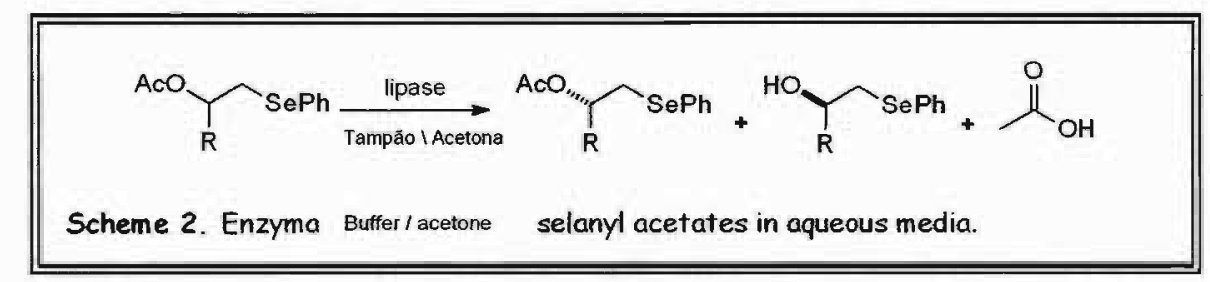

The biotransformations by fungi were performed using whole cells of some Aspergillus terreus strains. 
In the sequence, the resolution of hydroxy tellurides in organic media using isolated lipases was carried out (Scheme 3). In these resolutions, the influence of the variation of the solvent, lipase and the reaction time was also studied.

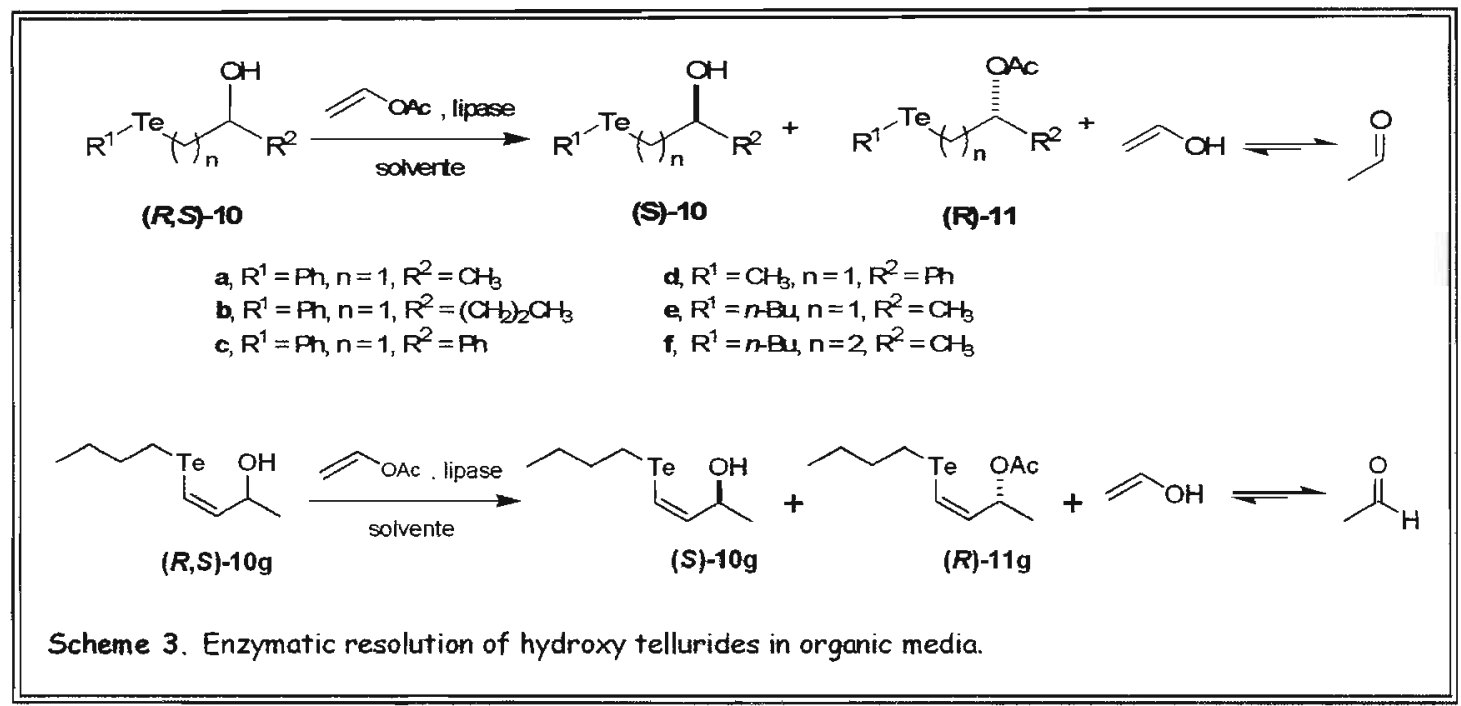

In order to demonstrate the potencial of the resolved compounds, one chiral hydroxy selenide and one chiral hydroxy telluride were used to prepare compounds belonging to classes of building blocks of wide occurrence in natural products: an allylic alcohol and a lactone (Scheme 4).

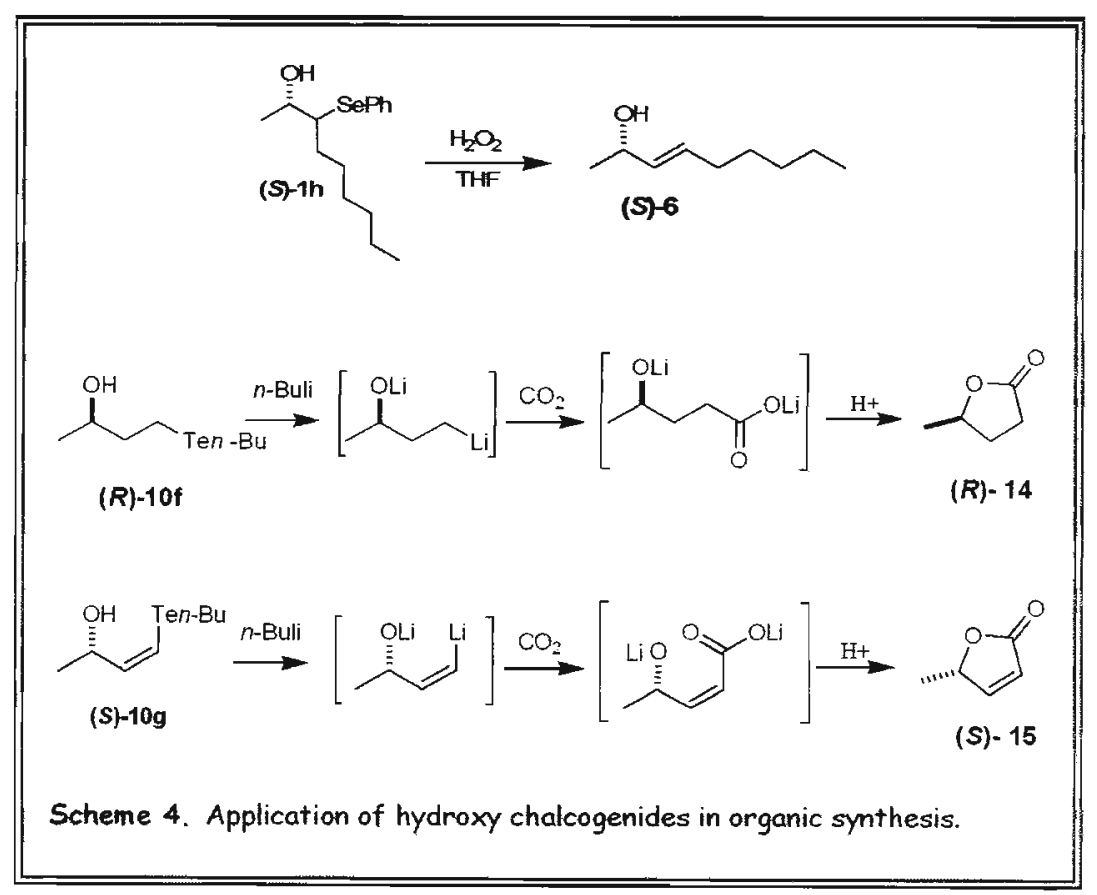


Objetivos 

O objetivo do presente trabalho foi avaliar o comportamento de hidróxiselenetos e hidróxi-teluretos frente a reações de biotransformações, empregando principalmente enzimas isoladas em meio orgânico, de modo a obter compostos orgânicos opticamente puros ou enriquecidos contendo selênio e telúrio, os quais podem ser precursores sintéticos na preparação de compostos bio-ativos. Em adição a estes estudos, foi desenvolvida uma metodologia de preparação de hidróxi-selenetos quirais em meio aquoso, contribuindo significativamente no desenvolvimento de técnicas de obtenção de bloco quirais que agridem cada vez menos o nosso meio ambiente. Dessa forma, daremos continuidade à união dessas ferramentas sintéticas (biotransformações e a química de organo-selenetos e organo-teluretos), aumentando a versatilidade dos compostos de selênio e telúrio em sintese orgânica e o lêque de opções para o químico orgânico sintético na síntese de fármacos, fragrâncias, pesticidas, feromônios, etc. 

1. Introdução 


\section{.}




\subsection{Quiralidade e Atividade Biológica}




\section{.}


A quiralidade é um conceito que ultrapassa o domínio da química. Ela se refere a uma determinada característica geométrica: a sobreposição (ou não) da imagem especular de um objeto sobre ele mesmo. Assim, denominamos um objeto como quiral quando a sua imagem especular não pode ser sobreposta ao objeto original. Existem diversos objetos quirais ao nosso redor, como por exemplo, as conchas marinhas, as nossas mãos (Figura $1.1 .1)$, etc. ${ }^{1}$

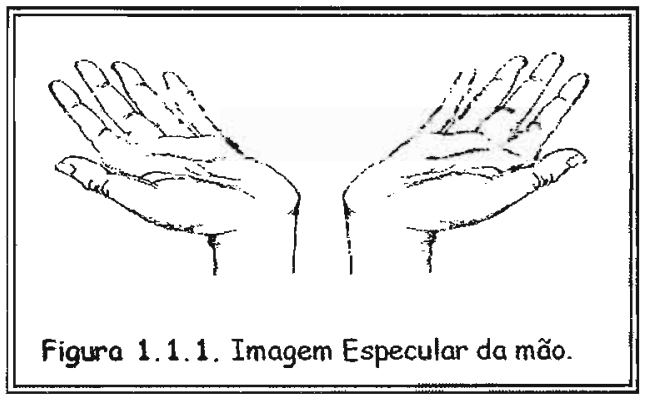

Essa propriedade também é observada em moléculas orgânicas, as quais podem ser quirais ou aquirais (imagem especular pode ser superposta à molécula original). A idéia de molécula quiral remonta ao século XIX quando Louis Pasteur separou os enantiômeros do ácido tartárico. ${ }^{1}$ Geralmente, a quiralidade em moléculas orgânicas é resultado da presença de um centro quiral localizado em um átomo que possui um conjunto de ligantes (ou átomos) num arranjo espacial que não permite a superposição da sua imagem especular. Nesse sentido, em compostos orgânicos, o centro de quiralidade (também chamado de centro assimétrico ou centro estereogênico) geralmente se encontra sobre um átomo de carbono de hibridização $s p^{3}$ que está ligado a quatro átomos ou grupos diferentes (Figura 1.1.2). ${ }^{1}$

Designamos por estereoisômero os isômeros (do grego isoméres = partes iguais) que apresentam diferenças entre si na orientação espacial de seus ligantes. Denominamos de diastereoisômeros os

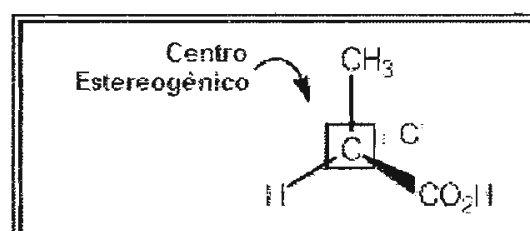

Figura 1,1.2. Centro estereogênico. estereoisômeros que não possuem uma relação objeto-imagem especular, resultante, por exemplo, da presença de mais de um centro estereogênico na estrutura da molécula orgânica. Por outro lado, denominamos de enantiômeros (do grego enantio = opostos) os estereoisômeros que são imagens especulares um do outro (Figura 1.1.3). Uma mistura em partes iguais de dois enantiômeros é denominada mistura racêmica (ou racemato). ${ }^{1}$ 


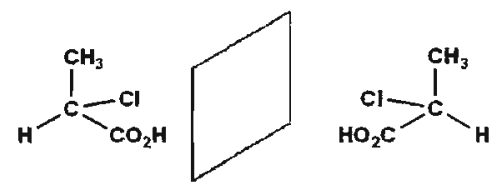

Figura 1.1.3. Enantiômeros.

Os diastereoisômeros possuem propriedades físicas e químicas distintas, enquanto que, os enantiômeros apresentam propriedades físicas e químicas idênticas, exceto quando submetidos à luz planopolarizada, onde um dos enantiômeros desvia a luz polarizada em um sentido e o outro em sentido contrário. Devido à interação entre as soluções dos enantiômeros e a luz polarizada, os enantiômeros são também designados por isômeros ópticos. ${ }^{1}$

Enantiômeros podem apresentar atividades biológicas completamente distintas, como diferenciação de odores, sabores, etc. ${ }^{2,3}$ Dos vinte aminoácidos existentes nos organismos, dezenove são encontrados apenas na forma de um único enantiômero (a forma L), sendo que apenas um, a glicina, não é um composto quiral, o que demonstra a relevância da quiralidade em organismos vivos. ${ }^{4}$

Como exemplo das diferenças de atividades biológicas de enantiômeros, podemos citar a (-)-carvona e a (+)-carvona, responsáveis, respectivamente, aromas da menta e do cominho, duas plantas utilizadas na culinária, e o (+)limoneno e o (-)-limoneno, responsáveis pelos aromas da laranja e do limão,

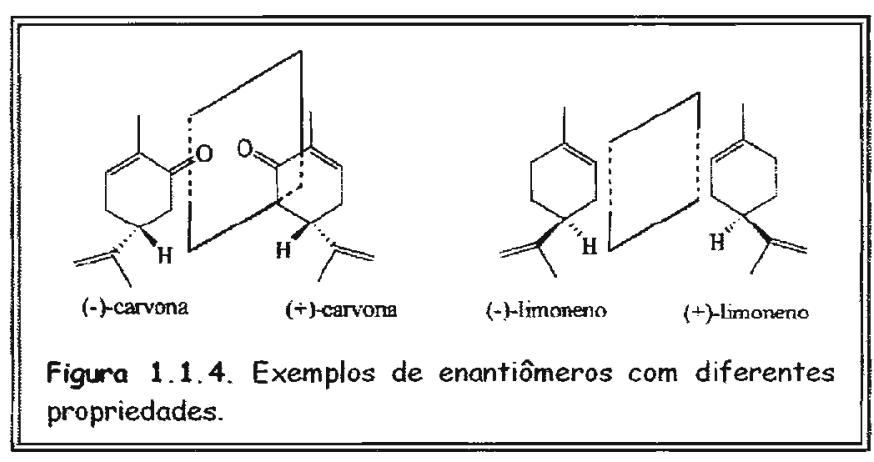
respectivamente (Figura 1.1.4). ${ }^{5}$

Um outro exemplo das diferenças de atividade biológica entre enantiômeros, com conseqüências bem mais sérias do que apenas diferenças

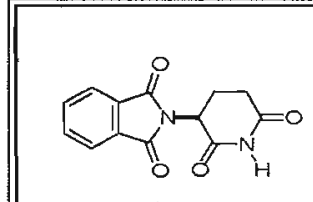

(S)-Talidorrida

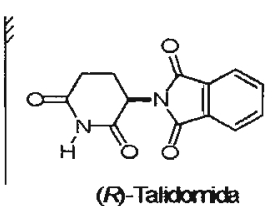

(R)-Talidarida
Figura 1.1.5. Fármaco com atividade biológica distinta para cada enantiômero. de aromas, é o da talidomida (Figura 1.1.5), um fármaco muito utilizado, entre os anos de 1957 e 1962 em todo o mundo, no tratamento de enjôos e náuseas, muito comum no período inicial da gravidez humana. ${ }^{1}$ 
Quando a talidomida foi lançada no mercado sua utilização por grávidas era considerada segura, sendo administrada a mistura racêmica. Entretanto, na época não havia estudos sobre a interação de cada enantiômero com o organismo. Mais tarde foi descoberto que o enantiômero " $R$ " apresenta a atividade sedativa, mas o enantiômero " $S$ " apresenta ação teratogênica (do grego terás = monstro; gene = origem), levando à má formação congênita, afetando principalmente no desenvolvimento dos braços e das pernas do feto. O uso indiscriminado deste fármaco levou ao nascimento de milhares de bebês com gravíssimos defeitos físicos (Figura 1.1.6). ${ }^{1}$

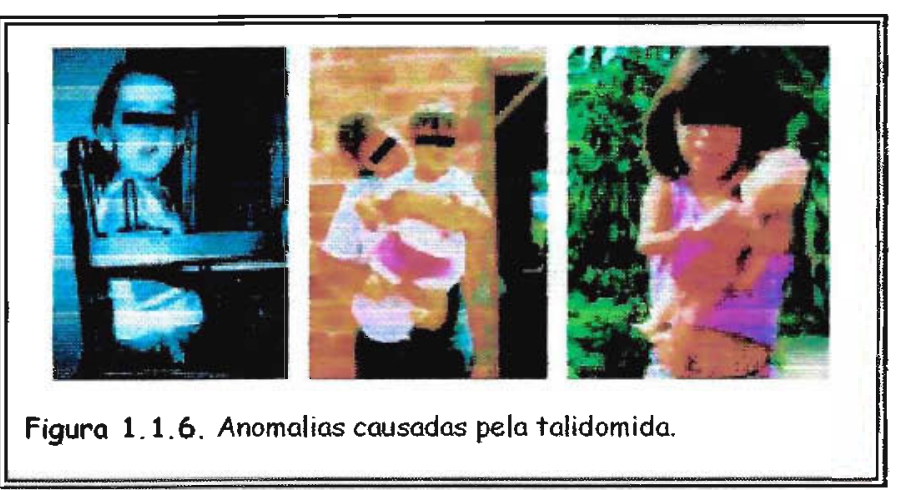

Esse lamentável acontecimento despertou a atenção da comunidade científica e das autoridades farmacêuticas sobre a importância da pureza óptica de fármacos na atividade biológica dos mesmos, visto que a maioria dos fármacos é constituída por substâncias quirais. ${ }^{1}$ Nesse sentido, várias providências foram tomadas a fim de evitar que uma tragédia como esta se repita. Um exemplo das mudanças ocorridas pode ser observado nos Estados Unidos da América, onde o FDA (United States Food and Drug Administration - órgão que regulamenta a comercialização de fármacos naquele país) exige uma experimentação completa de cada enantiômero e da mistura racêmica para que seja aprovada a comercialização de um fármaco.

No Brasil, apesar de diversos fármacos serem comercializados como racematos, os fármacos quirais já são uma realidade na indústria farmacêutica. Em 2000, esse ramo da indústria faturou mais de 130 bilhões de dólares nas vendas de fármacos quirais (em todo o mundo), num mercado que cresce aproximadamente $13 \%$ ao ano. ${ }^{6}$ Neste conexto, a indústria farmacêutica tem um grande interesse em preparar drogas enantiopuras. ${ }^{6}$

Nesse sentido, a indústria tem ajustado seus processos para 0 controle da estereoquímica de novas drogas através de sínteses assimétricas. Deste modo, nenhum aspecto da síntese orgânica recebeu nas últimas 
décadas tanta atenção quanto à preparação de compostos enantiomericamente puros ou enriquecidos. Em 2001, os químicos Willian S. Knowles (Monsanto Company, St. Louis, Missouri/USA), Ryoji Noyori (Nagoya University, Chikusa, Nagoya/Japan) e K. Barry Sharpless (the Scripps Research Institute, La Jolla, California/USA) foram agraciados pela Royal Swedish Academy of Sciences com o prêmio Nobel de Química pelos seus trabalhos em síntese catalítica assimétrica (Figura 1.1.7). ${ }^{7}$

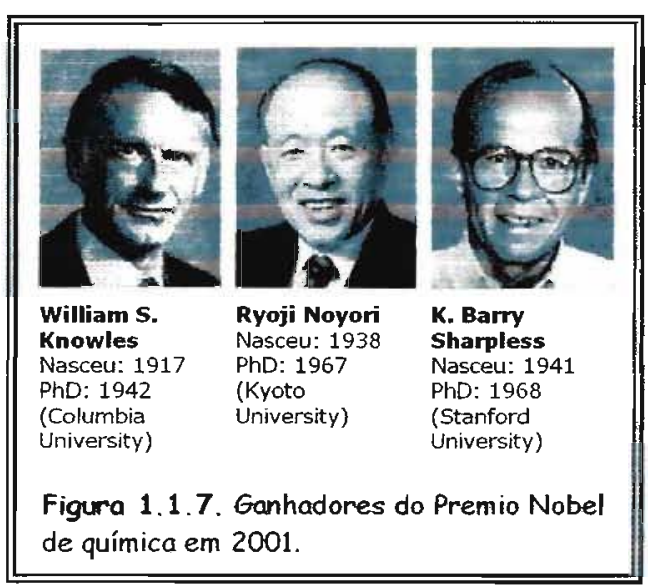

As descobertas destes três químicos tiveram um grande impacto, tanto na pesquisa acadêmica como na indústria farmacêutica, pois possibilitaram o desenvolvimento de novas drogas e outras substâncias biologicamente ativas (fragrâncias, pesticidas, feromônios, etc.) com alta pureza enantiomérica. 


\subsection{Biotransformações}



Nos últimos anos, o desenvolvimento de produtos e/ou processos químicos que reduzem ou eliminem o uso e a geração de substâncias perigosas vem ganhando muita atenção dentro da comunidade científica e fora dela. Isso devido à conscientização da necessidade da preservação do meio ambiente. Nesse sentido a Química Verde vem trabalhando para reduzir e, preferencialmente, eliminar a produção e o uso de substâncias prejudiciais ao meio ambiente e ao homem. ${ }^{8}$

A biotransformação, ou seja, a utilização de microorganismos ou enzimas isoladas (ou na forma de extrato enzimático) em transformações químicas possibilita a redução e/ou a eliminação da utilização de substâncias perigosas em reações químicas. Por exemplo, podem catalisar reações de oxidação que geralmente são realizadas em solvente orgânico (prejudicial ao meio ambiente) e empregando oxidantes que contém metais pesados (ex: PCC - Clorocromato de piridínio). Além disso, os microorganismos, as enzimas e os resíduos gerados durante uma biotransformação são geralmente biodegradáveis, $\circ$ que não compromete $\circ$ meio ambiente. ${ }^{9}$ As biotransformações são geralmente realizadas utilizando água como solvente, ao invés de solventes orgânicos, o que contribui para o uso das mesmas em reações químicas como forma de preservação do meio ambiente. ${ }^{9}$

Somando-se a estas vantagens ambientais, as biotransformações possibilitam a obtenção de compostos enantiomericamente puros ou enriquecidos, ou a transformação de um grupo funcional de maneira seletiva, ou ainda, permitir distinguir um mesmo grupo funcional em ambientes diferentes num mesmo substrato, etc, ${ }^{9}$ diferentemente de reações realizadas usando reagentes químicos convencionais, quando geralmente não se observa seletividade.

Por exemplo, ao tentarmos sintetizar a serina (aminoácido encontrado em organismos vivos - Figura 1.2.1) sob condições convencionais (sem a utilização de reagentes ou catalisadores quirais), será obtida uma mistura de dois compostos, a (S)-serina e a $(R)$-serina (mistura racêmica).Para obtermos somente um dos enantiômeros, precisamos optar por uma síntese assimétrica, que é capaz de produzir, ao

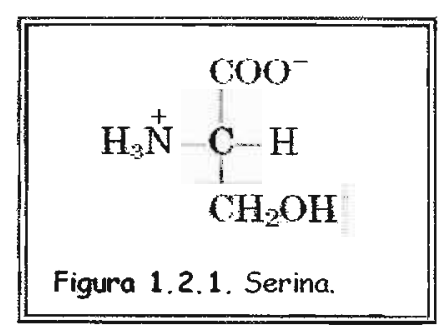


menos, um excesso de uma das formas, ou, a partir da mistura racêmica, aplicar uma técnica de resolução, como por exemplo, a cristalização, que permita a separação dos enantiômeros, ou utilizar um reagente opticamente puro (Figura 1.2.2). ${ }^{10}$

Neste contexto, as biotransformações vêm se destacando rapidamente, devido a suas características ambientamente adequadas e as suas propriedades

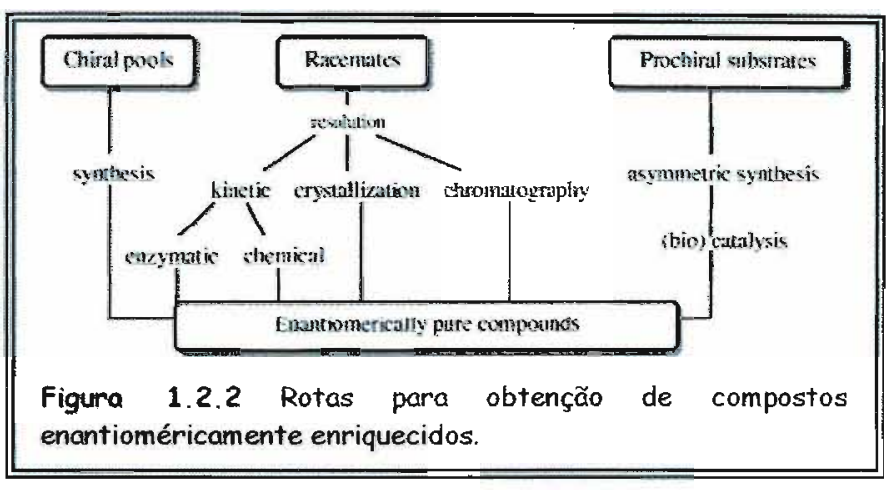
cataliticas e seletivas. Fato esse notado pelo volume crescente de publicações nos últimos anos sobre 0 assunto, ${ }^{11}$ pelo número de indústrias envolvidas direta ou indiretamente em pesquisa e aprimoramento de tecnologias de modificações genéticas, bem como pela aplicação direta de biotransformações, em substituição a processos químicos clássicos.

A utilização de biocatalizadores em transformações sintéticas pela indústria tem crescido rapidamente nas últimas décadas, e a previsão é que a presença de biocatalizadores na indústria cresça muito mais. ${ }^{12}$

Em um estudo sobre processos industriais (amostra de 134 processos), as hidrolases estão presentes em quase metade dos processos, enquanto que as oxi-redutases representam cerca de 25\% (Figura 1.2.3). Nesse estudo, observou-se que geralmente em reações redox são empregadas células inteiras, enquanto que enzimas isoladas (livres ou imobilizadas) são mais comuns em reações que empregam hidrolases: ${ }^{13}$

A chave de todo o processo biocatalítico são as enzimas, ${ }^{9}$ que são

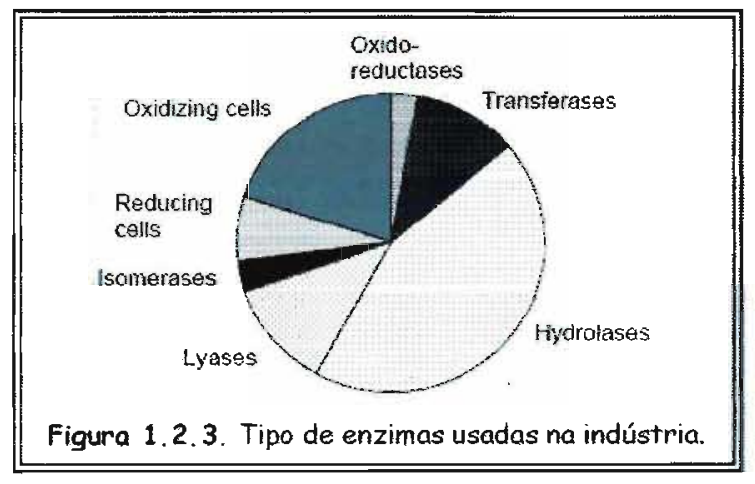
produzidas pelas células e possuem a habilidade de atuar como catalisadores altamente estéreoespecíficos. Esses catalisadores possibilitam a obtenção de compostos enantiomericamente puros ou enriquecidos em condições brandas, gerando muito poucos 
resíduos, os quais são geralmente biodegradáveis, conforme salientado anteriormente, tornando os processos biocatalíticos muito atraentes do ponto de vista estereoquímico e ambiental. Também podemos citar como vantagens do emprego da biocatálise em síntese orgânica, a alta eficiência catalítica das enzimas, que podem aumentar a velocidade de reação na ordem de $10^{8}-10^{10}$, e a tolerância a substratos não naturais. ${ }^{9}$

\subsubsection{Enzimas}

As enzimas governam as reações químicas nos processos biológicos vitais, sendo responsáveis por uma ampla variedade de transformações metabólicas, catalisando quase todos os tipos de reações orgânicas conhecidas. Desta forma, uma grande variedade de processos catalisados por enzimas têm uma reação orgânica sintética equivalente. ${ }^{9}$

As enzimas são proteínas formadas por subunidades de aminoácidos e possuem em suas estruturas grupos polares como $-\mathrm{COOH},-\mathrm{OH},-\mathrm{NH}_{2},-\mathrm{SH}$ e - $\mathrm{CONH}_{2}$ (Figura 1.2.1.1), que atuam como catalisadores. Uma vez elaboradas por uma célula, as enzimas podem atuar independentemente da mesma.

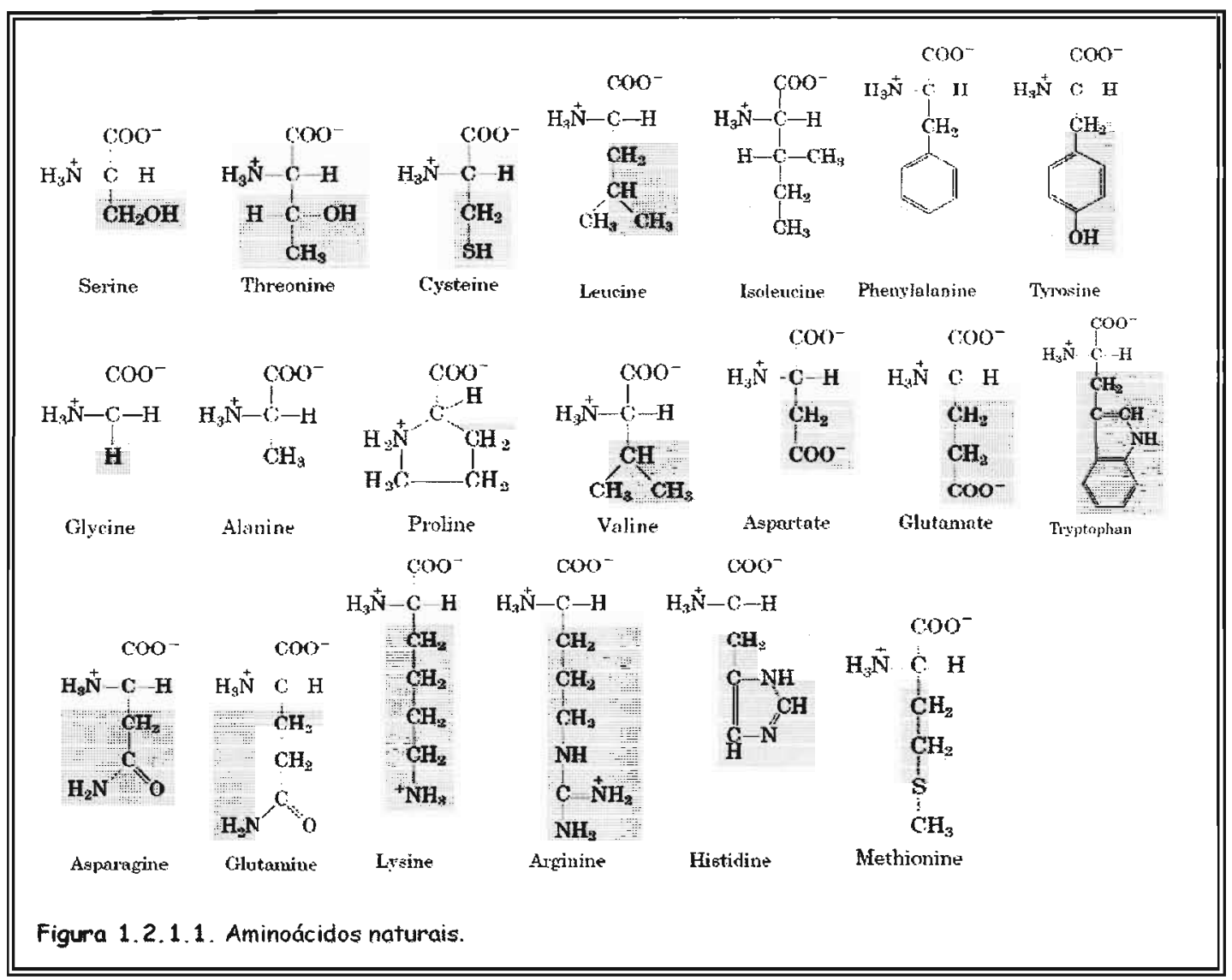


Todas as enzimas possuem estruturas complexas de cadeias polipeptídicas que se mantêm estáveis em meio aquoso, seu ambiente natural. Entretanto, poucas enzimas possuem sua estrutura tridimensional determinada ou seu mecanismo de ação descrito. ${ }^{14}$

As enzimas são classificadas pela "International Union of Biochemistry" em seis classes, de acordo com o tipo de reação que catalizam (Tabela 1.2.1.1). ${ }^{9}$

Tabela 1.2.1.1. Classificação das Enzimas.

\begin{tabular}{|c|c|}
\hline Classificação da Enzima & Tipo de Reação \\
\hline 1. Oxi-redutases & $\begin{array}{l}\text { Oxidação-redução: oxidação de } \mathrm{C}-\mathrm{H}, \mathrm{C}-\mathrm{C}, \mathrm{C}=\mathrm{C} \text {, } \\
\text { remoção ou adição de hidrogênios. }\end{array}$ \\
\hline 2. Transferases & $\begin{array}{c}\text { Transferência de grupos: Aldeídicos, cetônicos, acila, } \\
\text { açucares, etc. }\end{array}$ \\
\hline 3. Hidrolases & $\begin{array}{l}\text { Formação e hidrólise de ésteres, amidas, lactonas, } \\
\text { lactamas, epóxidos, nitrilas, anidridos, etc. }\end{array}$ \\
\hline 4. Liases & $\begin{array}{l}\text { Adição-eliminação de pequenas moléculas em } \mathrm{C}=\mathrm{C} \text {, } \\
\qquad \mathrm{CN}, \mathrm{C}=\mathrm{O} .\end{array}$ \\
\hline 5. Isomerases & Isomerização, como racemização e epimerização. \\
\hline 6. Ligases & $\begin{array}{l}\text { Formação e clivagem de ligações do tipo } \mathrm{C}-\mathrm{O}, \mathrm{C}-\mathrm{S} \text {, } \\
\mathrm{C}-\mathrm{N}, \mathrm{C}-\mathrm{C} \text {, com concomitante clivagem de trifosfato. }\end{array}$ \\
\hline
\end{tabular}

\subsubsection{Aspectos Mecanísticos}

Dentre as teorias que vem sendo desenvolvidas para entender a catálise enzimática, o modelo mais ilustrativo continua sendo o clássico chavefechadura, que foi desenvolvido por Emil Fischer em 1894. O mesmo propõe que o substrato deve ser complementar ao sítio catalítico da enzima, levando a

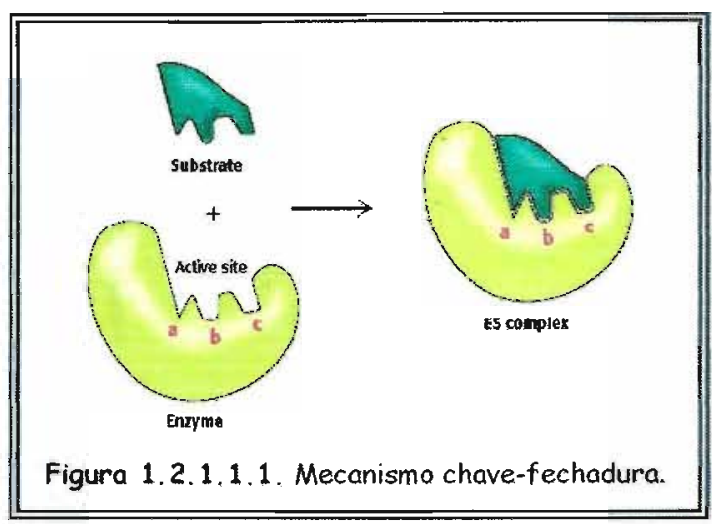
formação do complexo enzimasubstrato, caso contrário a catálise não ocorreria. ${ }^{15}$ Entretanto, este modelo não explica porque algumas enzimas aceitam substratos não naturais (Figura 1.2.1.1.1).

Um modelo proposto por Kosland no final da década de sessenta tenta explicar melhor o mecanismo das enzimas, assumindo que as mesmas 
não são estruturas rígidas. ${ }^{16}$ De acordo com essa proposta, conhecida como encaixe induzido, durante a aproximação entre a enzima e o substrato, várias interações ocorrem, resultando em mudanças conformacionais no sítio ativo da enzima, facilitando assim a formação do complexo "enzima-substrato" (Figura 1.2.1.1.2).

Como já destacado, as reações enzimáticas são muito mais rápidas que as reações químicas convencionais análogas. Tentando explicar essas observações, Dewar postulou uma teoria conhecida como teoria da dessolvatação, ${ }^{17}$ na qual as reações enzimáticas são comparadas àquelas

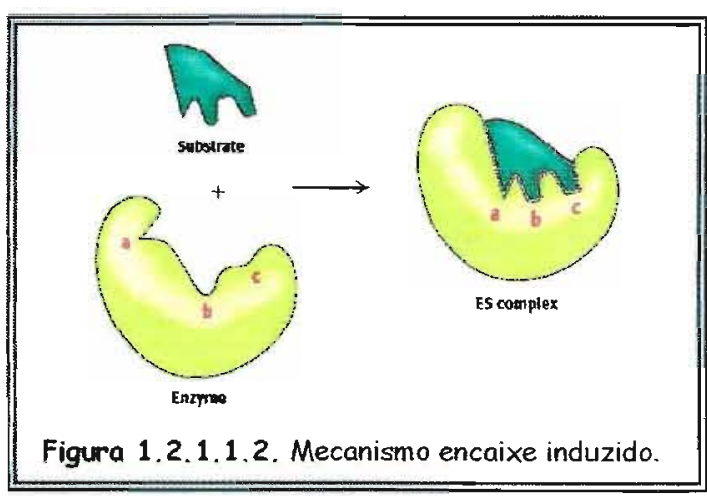
que ocorrem em fase gasosa. De acordo com essa teoria, quando o substrato entra no sítio ativo da enzima, expulsa todas as moléculas de água presentes. Num ambiente anidro as reações ocorrem mais facilmente, levando a um aumento na velocidade da reação. Esta teoria levou à outra, conhecida como teoria da "solvatação-substituição". ${ }^{18}$ A mesma está baseada na suposição de que a enzima não poderia simplesmente expulsar todas as moléculas de água, pois este processo é energeticamente desfavorável. Provavelmente, as moléculas de água são acomodadas em outras partes da enzima, liberando o sítio hidrofóbico da enzima, o que favorece a formação do complexo "enzimasubstrato".

A regra dos três pontos, utilizada por Ongston em 1948, ${ }^{19}$ tenta explicar de forma simplificada a enantiosseletividade enzimática. Partindo-se da premissa que a quiralidade é uma característica espacial, para que a enantiosseletividade seja máxima, o substrato necessita estar firmemente posicionado em três dimensões no sítio enzimático. Para tal, é necessário que

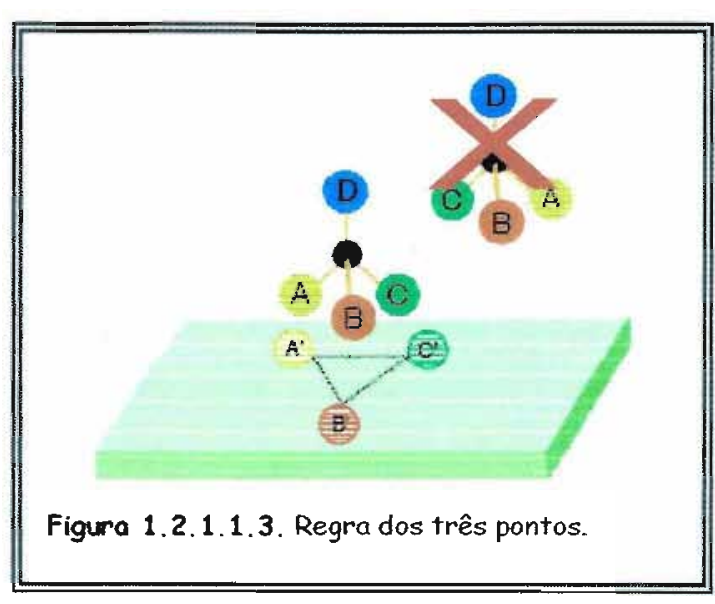


existam pelo menos três pontos de ligação entre o substrato e o sítio ativo da enzima. Como pode ser observado na Figura 1.2.1.1.3, um dos enantiômeros se encaixa bem nos três pontos do sítio ativo da enzima, enquanto que o outro enantiômero se encaixa em apenas dois pontos do sítio ativo, não se encaixando no terceiro ponto.

Em termos físico-químicos, as enzimas, assim como os demais catalisadores, aceleram a velocidade das reações, diminuindo a barreira energética (energia de ativação - Ea) entre reagentes e produtos, devido à estabilidade do complexo "enzima-substrato" formado no estado de transição (Figura 1.2.1.1.4). ${ }^{9,11}$

De forma análoga, a estereosseletividade das enzimas também se origina da diferença de energia entre os estados de transição dos complexos formados entre os enantiômeros de um substrato quiral $\left\{[E A]^{\#},[E B]^{\#}\right\}$, ou das duas formas pró-quirais de um

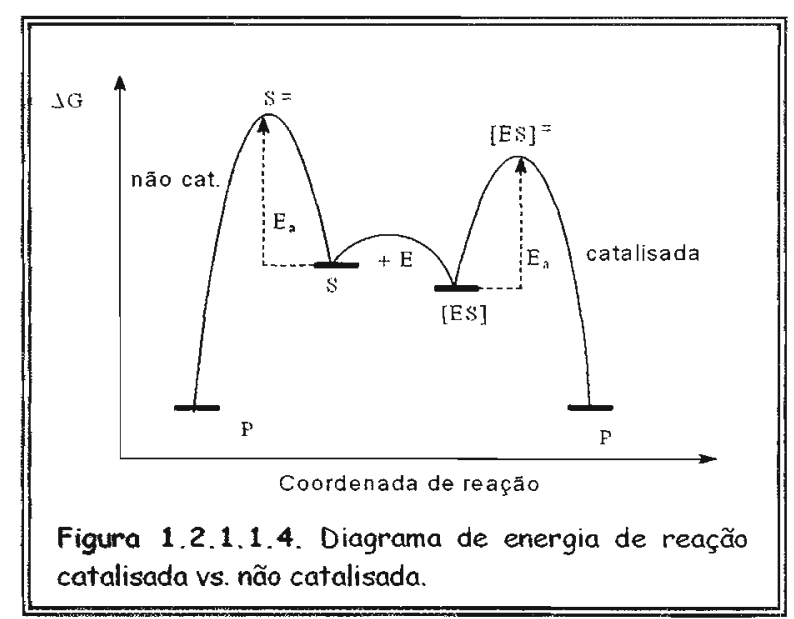
substrato, envolvendo seus grupos ou faces enantiotópicas com o sítio ativo da enzima.

Os complexos diastereoisoméricos "enzima-substrato" formados apresentam diferentes valores de energia livre para seus respectivos estados de transição, conseqüentemente, um enantiômero se formará preferencialmente com relação ao outro. A diferença de energia livre de ativação $\left(\Delta \Delta G^{\#}\right)$ caracteriza a seletividade da enzima na reação, sendo diretamente proporcional à razão entre as velocidades de formação de cada um dos enantiômeros $\left(\mathrm{V}_{\mathrm{A}} / \mathrm{V}_{\mathrm{B}}\right)$, de acordo com a Figura 1.2.1.1.5. Portanto, quanto maior a diferença de energia livre de ativação entre os dois complexos "enzima-substrato" formados $\left(\Delta \Delta \mathrm{G}^{\#}\right)$, maior será a enantiosseletividade enzimática e maior será o excesso enantiomérico obtido. ${ }^{9,11}$ 


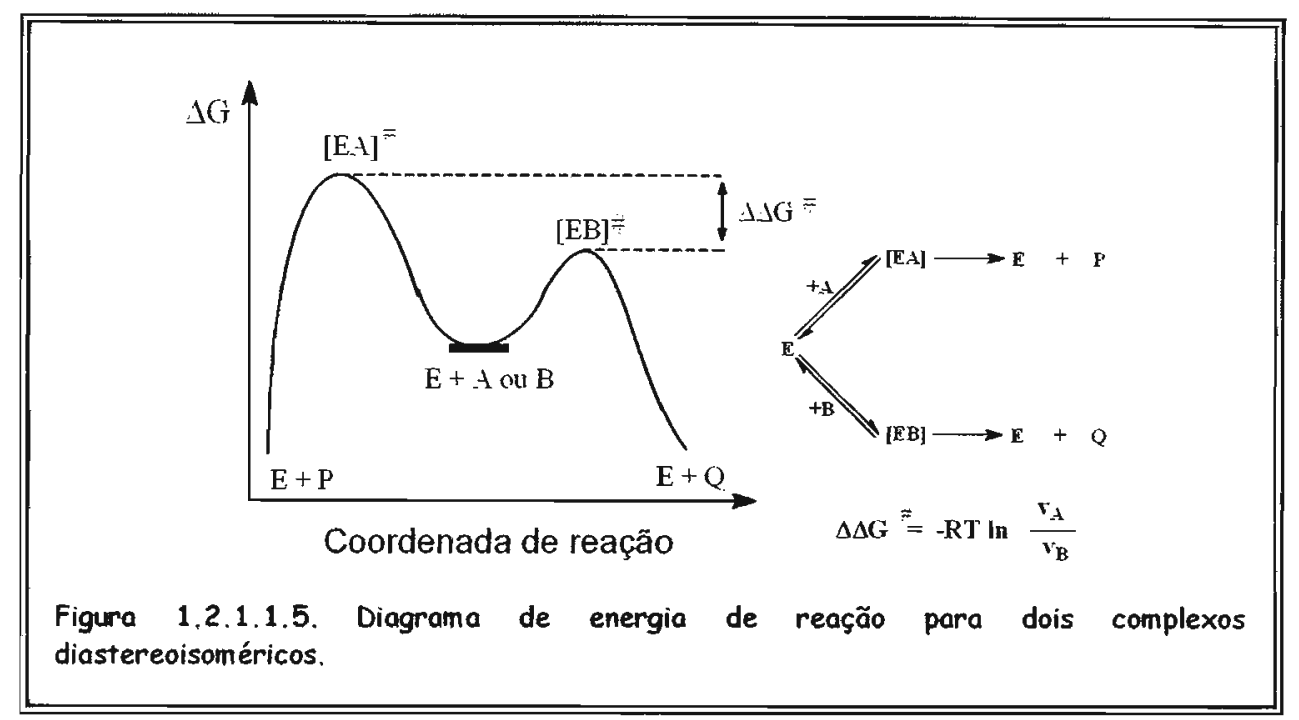

\subsubsection{Aplicação em Síntese Orgânica}

Embora uma das primeiras observações da atividade enzimática date de 1783, apenas em 1960 a estrutura das enzimas começou a ser elucidada, quando Hirs e colaboladores determinaram pela primeira vez a seqüência de aminoácidos de uma enzima, a Ribonuclease $A .{ }^{20}$ Desde então o uso de enzimas em síntese orgânica vem crescendo exponencialmente. Um trabalho publicado em 2000 menciona a existência de mais de 8.000 artigos e patentes que descrevem cerca de 18.500 biotransformações mediadas por enzimas isoladas e por microrganismos. ${ }^{21}$ Parte desses avanços podem ser atribuídos aos progressos da biologia molecular e das técnicas de instrumentação e de triagem enzimática.

Conforme citado, muitas são as vantagens da utilização de enzimas em processos síntéticos, entretanto três propriedades devem ser ressaltadas: ${ }^{9}$

Quimiosseletividade: Capacidade de distinguir diferentes grupos funcionais, atuando em um único tipo de grupo ou função química, não agindo sobre outras funcionalizações presentes na molécula, que em condições normais de catálise química poderiam reagir;

$>$ Regiosseletividade: Enzimas podem distinguir entre grupos funcionais que estão quimicamente situados em regiões diferentes na mesma molécula, graças a sua complexa estrutura tridimensional;

Enantiosseletividade: Como mencionado anteriormente, toda a enzima é constituída por L-aminoácidos e assim podem atuar como catalisadores 
quirais. Como conseqüência, algum tipo de quiralidade presente na molécula é reconhecido e um substrato pró-quiral pode ser transformado em um produto opticamente ativo ou ambos enantiômeros de um composto podem reagir em diferentes velocidades, implicando em uma resolução cinética.

Em algumas biotransformações utilizando enzimas isoladas existe a necessidade de utilizar cofatores, os quais são muitos caros. ${ }^{9}$ En vista disso, microorganismos vêm sendo empregados em reações de oxidação-redução e de epoxidação, evitando utilização de cofatores e/ou coenzimas, visto que os mesmos possuem os cofatores e/ou coenzimas necessários. ${ }^{22,23}$

A escolha entre enzimas isoladas ou microorganismos, livres ou imobilizados, em meio reacional orgânico ou aquoso, depende de vários fatores, tais como a escala em que será realizada a reação, a necessidade da reciclagem de cofatores, e a disponibilidade de infra-estrutura para a manipulação de microorganismos, entre outras. Assim é necessário avaliar as vantagens e as desvantagens de cada processo em cada caso.

As biotransformações em síntese orgânica podem ser realizadas basicamente em três sistemas de solventes distintos: sistema água e cosolvente orgânico miscível; sistema água e solvente orgânico imiscivel (sistema bifásico) e sistema solvente orgânico anidro. A influência do solvente orgârico utilizado pode ser relacionada diretamente com sua constante dielétrica: quanto menor for a constante dielétrica, maiores serão as interações eletrostáticas entre as cargas dos resíduos de aminoácidos que compõem a estrutura protéica da enzima. Esse efeito pode levar a uma redução da flexibilidade e conseqüentemente à redução da atividade catalítica. ${ }^{24}$

A água (seu meio natural) ativa a enzima porque possibilita uma maior flexibilidade. Sua presença é imprescindivel nas reações catalisadas por enzimas. Estudos mostram que existe um mínimo de moléculas de água para cada molécula de enzima. Essa quantidade de água corresponde a uma monocamada de solvatação, proporcionando que a enzima não seja inativada. Mesmo nos sistemas de solventes anidros, existe uma pequena quantidade de água presente no solvente. ${ }^{25}$

$\mathrm{O}$ pH é outro fator muito importante em reações biocatalizadas, com a variação do $\mathrm{pH}$ ocorrem mudanças na conformação protéica da enzima, devido 
à ionização dos resíduos de aminoácidos que compõem a estrutura enzimática. O fator $\mathrm{pH}$ é específico para cada enzima e a conformação obtida com a variação do pH pode ou não corresponder à conformação ativa da enzima, o que pode se tornar um fator crítico em certas reações. ${ }^{26}$

\subsubsection{Hidrolases}

As enzimas hidrolíticas são muito uilizadas em sintese orgânica. Nesta classe estão incluídas as amidases, proteases, esterases, nitrilases, fosfatases e epoxido hidrolases, sendo de particular e grande interesse as lipases. ${ }^{9}$

O mecanismo de hidrólise enzimática de amidas e ésteres é muito similar ao observado para a hidrólise química convencional utilizando base. Um grupo nucleofílico do sítio ativo da hidrolase ataca o grupo carboxílico do éster ou amida do substrato. Este nucleófilo pode ser o grupo hidróxi da serina ou o grupo carboxi do ácido aspártico ou ainda o grupo tiol da cisteína.

O mecanismo elucidado em detalhes é o da serina. Dois aminoácidos localizados próximos a serina (geralmente uma aspartina e uma histidina) auxiliam na catálise e juntos formam a triade catalítica. O arranjo espacial destes grupos favorece

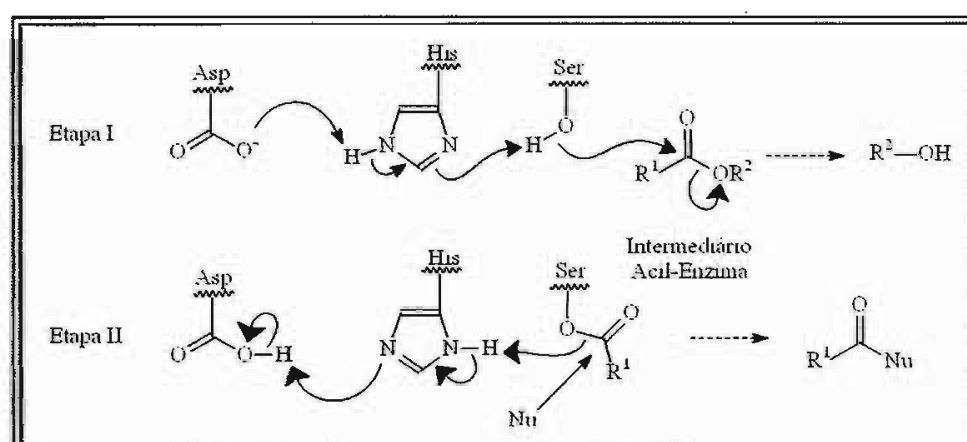

Esquema 1.2.1.3.1. Mecanismo de serina-hidrolase. aumento da nucleofilicidade do grupo hidróxi da serina, que pode então atacar um grupo carboxila de um substrato do tipo $\mathrm{R}^{1}-\mathrm{CO}-\mathrm{OR}^{2}$ (Esquema 1.2.1.3.1 Etapa 1). Dessa forma o intermediário acil-enzima é formado liberando o grupo de saída $\left(\mathrm{R}^{2}-\mathrm{OH}\right)$. Em seguida um nucleófilo (em geral a água) ataca o intermediário acil-enzima, regenerando a enzima e formando um ácido carboxílico do tipo $\mathrm{R}^{1}$-CO-OH (Esquema 1.2.1.3.1 - Etapa II). ${ }^{9}$

Em baixas concentrações de água, outros nucleófilos podem competir com a água no ataque ao intermediário acil-enzima, levando a formação de outros compostos, aumentando a aplicação de hidrolases em sintese orgânica (Esquema 1.2.1.3.2). Quando enzimas hidrolíticas são empregadas na hidrólise 


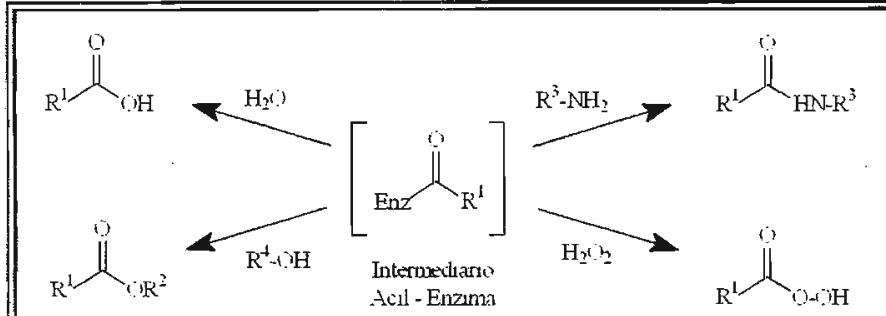

Esquema 1.2.1.3.2. Formaçãa de outros compostos.

de racematos, podemos observar a discriminação dos enantiômeros. Isto ocorre devido à quiralidade existente no sítio ativo da enzima, com - qual um enantiômero interage com mais facilidade

que o outro, e assim um dos enantiômeros é convertido mais rapidamente, resultando em uma resolução cinética do racemato, conforme destacado anteriormente na figura 1.2.1.1.5.

Em casos ideais, onde a enzima apresenta alta enantiosseletividade, a diferença de velocidade é tão grande que apenas um enantiômero é convertido em produto (excesso enantiomérico $>99 \%$ ) e o outro praticamente não reage. Entretanto, há casos em que a enzima não demonstra alta enantiosseletividade e ambos os enantiômeros são convertidos a produto.

O parâmetro $E$ (razão enantiomérica), desenvolvido por C. J. Sih em $1982,{ }^{9}$ traduz em termos numéricos a seletividade enzimática, descrevendo a relação entre a conversão (c) e os excessos enantioméricos do substrato (e.e.s) e do produto (e.e.p) (Figura 1.2.1.3.1). Assim, esse parâmetro é uma ferramenta muito útil no estudo de resoluções enzimáticas.

$E=\frac{\mathrm{V}_{-A}}{\mathrm{~V}_{\mathrm{B}}}=\frac{\left(\frac{\mathrm{k}_{\text {cat }}}{\mathrm{K}_{\mathrm{m}}}\right)_{\mathrm{A}}}{\left(\frac{\mathrm{k}_{\mathrm{cat}}}{\mathrm{K}_{\mathrm{m}}}\right)_{\mathrm{B}}}$
$\mathrm{K}_{\mathrm{m}}=$ constante de Michaclis-Menter
Figura 1.2.1.3.1. Determinação de $E$.

As reações de hidrólise em meio aquoso são consideradas irreversíveis, pois a concentração de água é alta (55,5 Mol/L). Nestas condiçöes, o parâmetro $E$ pode ser determinado facilmente a partir dos valores de conversão e dos valores de excessos enantioméricos do substrato (e.e.s) e do produto (e.e.p) utilizando a equação da Figura

1.2.1.3.2. Esta equação é derivada do estudo cinético enzimático empregando a equação de Michaelis-Menten e partindo-se do principio que não existe inibição enzimática. ${ }^{9}$ 


\section{Entretanto, na prática, a determinação exata da conversão em resoluções, é prejudicada por erros oriundos da manipulação da amostra. Nestes casos, o emprego da equação da Figura 1.2.1.3.3 é sugerido, visto que nesta

\begin{tabular}{|c|c|}
\hline Para o produto: & Para o substrato: \\
\hline \multirow{2}{*}{$E=\frac{\ln [1-c(1+e . e \cdot \mathrm{p})]}{\ln [1-\mathrm{c}(1-e \cdot e \cdot \mathrm{p})]}$} & \multirow{2}{*}{$E=\frac{\ln \left[1-c\left(1+e \cdot e_{\cdot s}\right)\right]}{\ln \left[1-c\left(1+e \cdot e_{\cdot s}\right)\right]}$} \\
\hline & \\
\hline \multicolumn{2}{|c|}{$\begin{array}{l}\mathrm{c}=\text { conversão; } e \cdot e_{\mathrm{F}}=\text { excesso enautiomérico do produto: } \\
e \cdot e_{\mathrm{s}}=\text { excesso enanticmérico do substrato: } \\
E=\text { razão enautiomérica }\end{array}$} \\
\hline $\begin{array}{l}\text { Figura 1.2.1.3.2. Dept } \\
\text { conversão nas resoluções. }\end{array}$ & cia da seletividade e da \\
\hline
\end{tabular} equação apenas os valores de excesso enantiomérico do substrato (e.e.s) e do produto (e.e.p) são necessários. ${ }^{9}$}

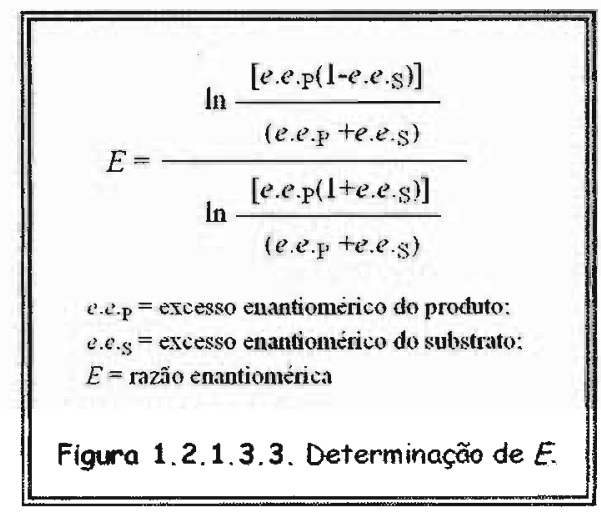

De todas as hidrolases, as lipases são as mais utilizadas em biotransformações. Elas são muito empregadas devido à sua versatilidade catalítica, disponibilidade comercial e baixo custo. Nos organismos elas hidrolisam triglicerídeos em ácidos graxos e glicerol. Apesar de catalisarem reações semelhantes das proteases e esterases o seu mecanismo molecular é diferente.

A mais importante diferença entre as lipases e as esterases é a interação físico-química com o substrato. Enquanto as esterases apresentam dependência direta entre a atividade enzimática e a concentração do substrato (normal Michaelis-Menten), as lipases apresentam baixa atividade enzimática enquanto o substrato permanecer solúvel no meio (Figura 1.2.1.3.4). Porém, quando a concentração do substrato é elevada gradualmente, após o limite de solubilidade do mesmo no meio (formando uma segunda fase), a atividade enzimática

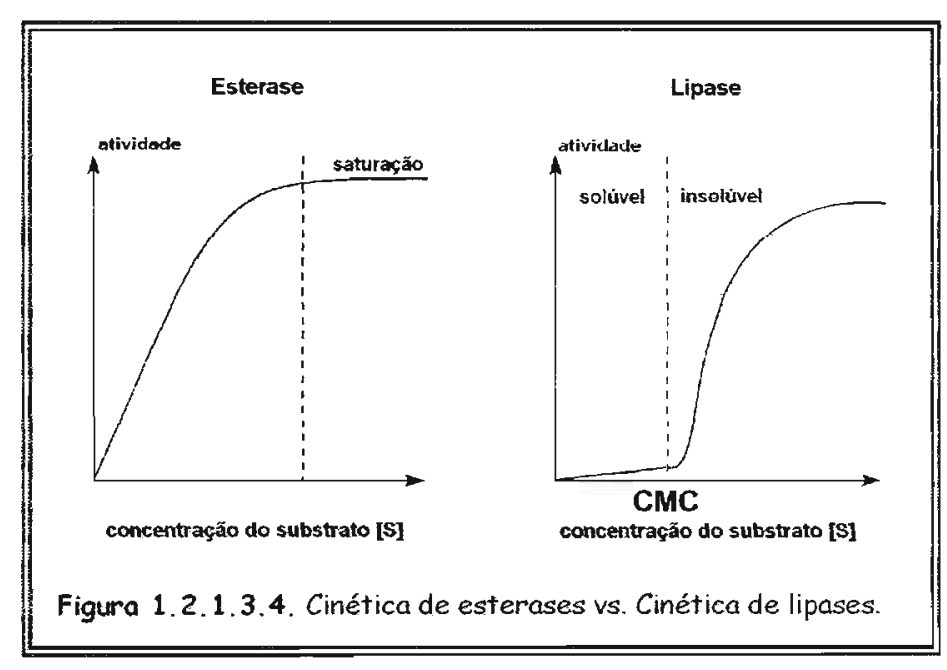


gradualmente. Em outras palavras, lipases não hidrolisam substratos abaixo da concentração micelar crítica (CMC - concentração micelar crítica - Figura 1.2.1.3.4). ${ }^{9}$

Esse comportamento das lipases pode ser explicado por um processo de rearranjo que ocorre com a enzima na interface do sistema bifásico (Figura 2.1.3.5). A lipase dissolvida sem a presença de um sistema bifásico está na forma inativa $\{[E n z]\}$, pois existe uma parte da estrutura da enzima (uma pequena $\alpha$-hélice - a tampa) que cobre o sítio ativo, bloqueando a passagem do substrato (baixa atividade enzimática). Quando a enzima entra em contato com a interface do sistema bifásico, uma reacomodação estrutural dobra a pequena $\alpha$-hélice liberando a entrada do sítio ativo da lipase, ativando a enzima $\left\{[E N Z]^{\ddagger}\right\}$, possibilitando assim o aumento da atividade enzimática com o aumento da concentração do substrato. ${ }^{9}$

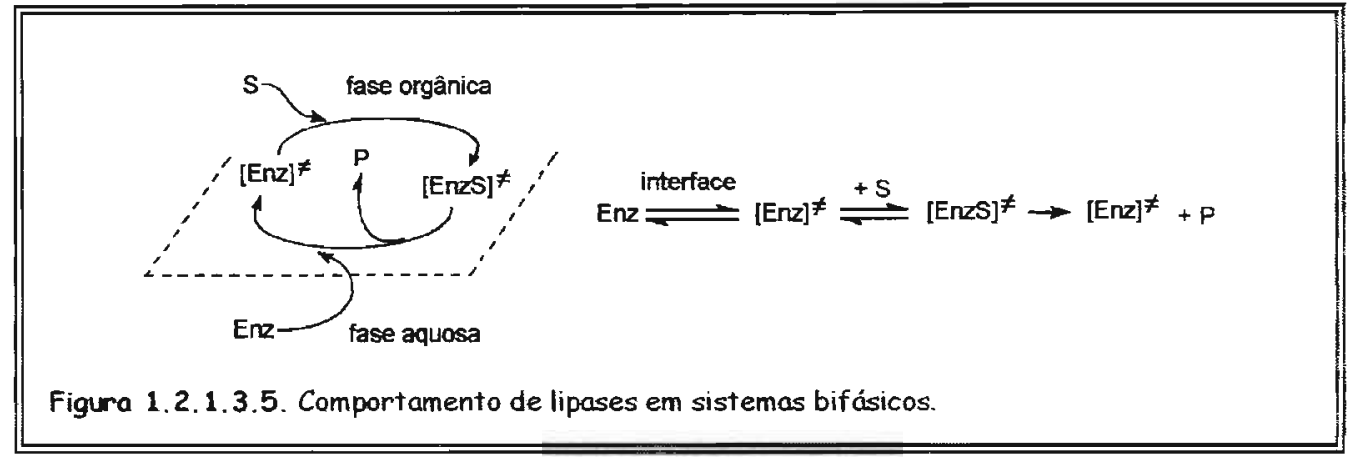

Em solventes orgânicos, as lipases catalisam a transferência de grupos acila de compostos doadores para uma ampla faixa de compostos aceptores diferentes da água. As reações catalisadas por lipases incluem esterificação, transesterificação, ${ }^{27}$ amidação, ${ }^{28}$ sintese de peptídeos ${ }^{29}$ e formação de lactonas. ${ }^{30}$ Dentre estas reações, a transesterificação enantiosseletiva é a de grande interesse aos químicos sintéticos, pois possibilita a fácil preparação de álcoois e ácidos opticamente ativos, os quais são largamente utilizados na síntese de produtos biologicamente ativos.

A resolução de álcoois secundários empregando lipases em meio orgânico é uma prática muito utilizada, pois, além da grande importância em (1) síntese orgânica de álcoois enantiomericamene puros ou enriquecidos, as lipases apresentam maior enantiosseletividade para esses compostos 
(comparando com a resolução de álcoois primários e terciários). ${ }^{10}$ Númerosos exemplos de resolução enzimática de álcoois secundários empregando lipases livres e imobilizadas, com razão enantiomérica superior a cem ( $E>100$ ), podem ser encontrados na literatura, 9,10 inclusive na resolução de alguns compostos orgometálicos. ${ }^{23}$

A estereoseletividade das lipases comumente utilizadas nas resoluções enzimáticas (exemplo: lipase de Candida antartica, lipase de Pseudomonas sp. , lipase de pâncreas de porco, etc.) segue um modelo empírico conhecido como a 'regra de Kazlauskas': 31 lipases preferem o enantiômero com a apresentada na Figura 1.2.1.3.6. ${ }^{32}$

Esta regra empírica está baseada na observação de que muitas lipases preferem catalisar a conversão de um mesmo enantiômero na reação de síntese ou na reação de hidrólise de ésteres. Esta estereosseletividade é explicada pelo arranjo espacial dos resíduos catalíticos da lipase,

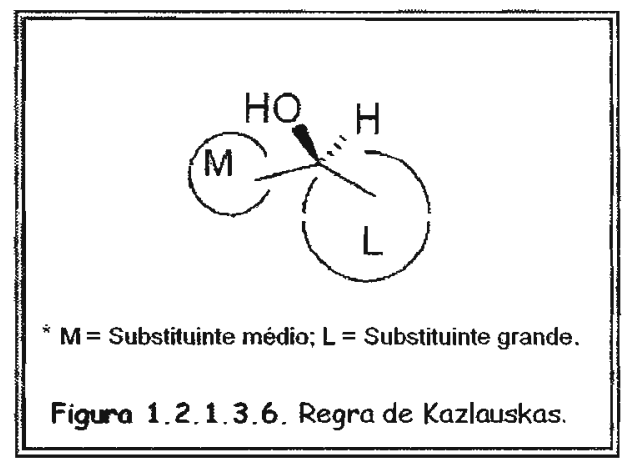
baseado em estudos de raios- $X^{33}$ e via a teoria estereo-eletrônica. ${ }^{34}$ Entretanto, esta regra não prediz o grau de enantiosseletividade da lipase na resolução dos álcoois.

Em geral, altos valores de excesso enantiomérico são observados quando os substituintes ligados ao carbono carbinólico do álcool secundário possuem tamanhos diferentes. ${ }^{9} \mathrm{Em}$ um estudo sobre resoluções de álcoois usando CALB, foi demonstrado que álcoois secundários que possuem um substituinte de tamanho médio maior que um grupo etila ou um substituinte de tamanho grande menor que um grupo $n$-propila apresentam baixos valores na razão enantiomérica (conseqüentemente baixos valores de excesso enantiomérico), salientando a necessidade da diferença de tamanhos entre os substituintes do álcool secundário para uma resolução eficiente. ${ }^{35}$

\subsubsection{Técnicas Especiais em Síntese Orgânica}

Em reações de transesterificação empregando lipases em meio orgânico a concentração do nucleófilo é sempre limitada, diferentemente das 
reações de hidrólise, onde o nucleófilo está sempre em excesso (a água - 55 $\mathrm{Mol} / \mathrm{L}$ ). Como resultado, as transesterificações em meio orgânico utilizando ésteres como doadores de acila, são geralmente reversíveis, chegando ao equilibrio e levando a rendimentos menores que os observados em reações pseudo-irreversíveis (como as hidrólises). A reversibilidade das transesterificações é causada pelas nucleofilicidades relativas do nucleófilo $\left(\mathrm{Nu}^{1}\right)$ e do grupo de saída do doador de acila $\left(\mathrm{Nu}^{2}\right)$, já que ambos competem pelo intermediário "acil-enzima" (Esquema 1.2.1.4.1). ${ }^{9}$

Para contornar este problema, podemos utilizar um excesso do doador Esquema 1.2.1.4.1. Acilação enzimática em meio orgânico. de acila, o que elevaria os custos do processo, e poderia influenciar negativamente na atividade enzimática,

tornando essa alternativa pouco atraente.

Uma alternativa interessante é a utilização de doadores de acila especiais, os quais podem transformar as reações em meio orgânico em reações irreversíveis. Neste contexto, a utilização de enol ésteres em resoluções empregando lipases apresenta bons resultados, pois, doadores de acila como ésteres de vinila ou de isopropenila liberam enóis instáveis como grupo de saída, os quais tautomerizam para formar aldeídos ou cetonas estáveis (Esquema 1.2.1.4.2). Dessa maneira, a resolução se torna irreversível,

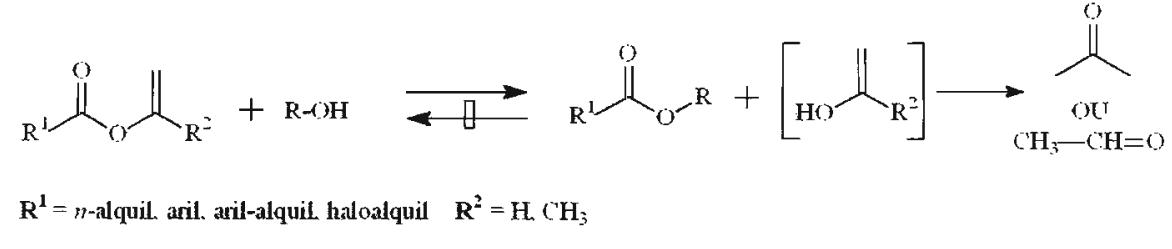

Esquema 1.2.1.4.2. Acilação enzimática em meio orgânico.

contribuindo para o aumento do rendimento e da seletividade enzimática. ${ }^{9}$

Uma outra técnica muito utilizada em biotransformações é a imobilização de enzimas. Tal técnica é uma estratégia empregada para solucionar problemas causados pela utilização de solventes orgânicos elou por 
mudanças bruscas de $\mathrm{pH}$ em biotransformações, além de facilitar a recuperação da enzima após a reação, possibilitando a sua reutilização e diminuindo os custos. ${ }^{9}$

Muitas vezes as enzimas não são estáveis em meio orgânico, ocorrendo sua desnaturação pelo solvente. Em outros casos, mesmo em meio aquoso, pode ocorrer uma auto-oxidação ou uma inativação pela variação do $\mathrm{pH}$. ${ }^{36}$ A imobilização permite a estabilização da enzima, possibilitando a realização de biotransformações em condições adversas às normalmente empregadas com enzimas. Essa técnica consiste na ligação da enzima em um suporte sólido insolúvel ou em ligações cruzadas com reagentes bifuncionais (ou multifuncionais), ou ainda, no confinamento da enzima em uma matriz sólida (gel ou polímero) onde ela permanece cataliticamente ativa (Figura 1.2.1.4.1).

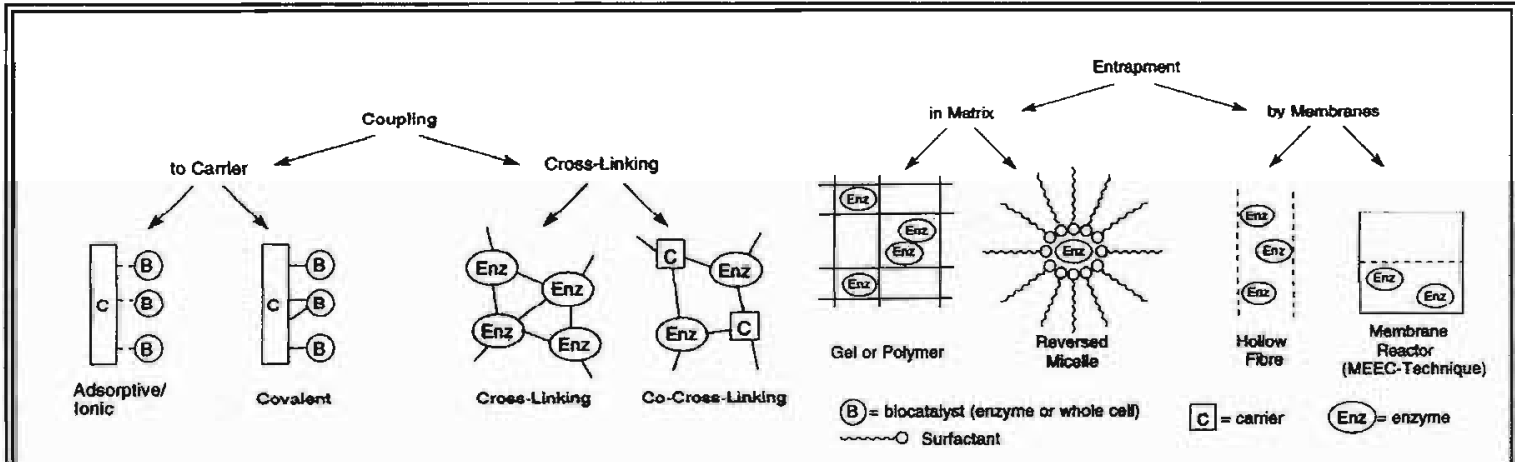

Figura 1.2.1.4. Princípio da técnica de imobilizaçăo enzimática. 

1.3. Selênio e Telúrio 

A versatilidade dos compostos orgânicos de selênio e telúrio em síntese orgânica pode ser notada pela reatividade peculiar apresentada por cada um desses organo-calcogenetos. Essa reatividade está ligada à habilidade desses heteroátomos ( $\mathrm{Se}$ e $\mathrm{Te}$ ) em estabilizar cargas positivas ou negativas adjacentes, à labilidade das ligações C-Se e C-Te e à facilidade de oxidação de selenetos à selenóxidos associada à eliminação de forma "syn". Por exemplo, a estabilização de cargas negativas pelo átomo de selênio permite a reação de $\alpha$-desprotonação dos selenetos vinílicos com bases fortes não nucleofílicas como o LDA, sendo o carbânion vinílico resultante capturado com diferentes eletrófilos. ${ }^{37}$ Também podemos destacar a reação de oxidação de selenetos à selenóxidos seguida de eliminação syn, a qual representa um método versátil na preparação de álcoois alílicos. ${ }^{38}$

É interessante ressaltar que a química de compostos orgânicos de telúrio não é uma extensão da química de compostos orgânicos de selênio, sendo observadas diversas diferenças na reatividade destas classes de compostos. Dependendo das condições reacionais, reagentes alquil-lítio podem efetuar adições do tipo Michael em selenetos vinílicos, clivar a ligação C-Se e promover a $\alpha$-desprotonação, levando a mistura de compostos. ${ }^{37}$ Por outro lado, quando teluretos orgânicos são tratados com reagentes alquil-lítio, não se observam produtos de adição do tipo Michael ou decorrentes da $\alpha$-desprotonação, sendo apenas observados produtos oriundos da clivagem da ligação C-Te. Dessa forma, teluretos orgânicos podem ser considerados precursores de reagentes organometálicos sinteticamente valiosos. ${ }^{39}$

Um aspecto interessante da metodologia de preparação dos teluretos vinílicos a partir de uma olefina ou um alcino (hidroteluração), é a alta estereosseletividade apresentada para produtos com a configuração $Z_{,}{ }^{40}$ diferentemente de outras hidrometalações que levam a produtos de configuração $E$ ou misturas de estereoisômeros. Além disso, a geometria da ligação dupla $(Z)$ dos teluretos virílicos é mantida em reações de troca metalóide-metal, o que torna essa estratégia muito interessante para a síntese de moléculas insaturadas com essa geometria.

Síntese de sistemas deste tipo já foram alvos de estudos, como a preparação da (-)-Macrolactina $A,{ }^{41}$ um agente antiviral e citotóxico, e o 
Siphonodiol, um metabólito bioativo originado de organismos marinhos (Figura 1.3.1), ${ }^{42}$ demonstrando a grande potencialidade dos compostos orgânicos de telúrio em síntese orgânica.

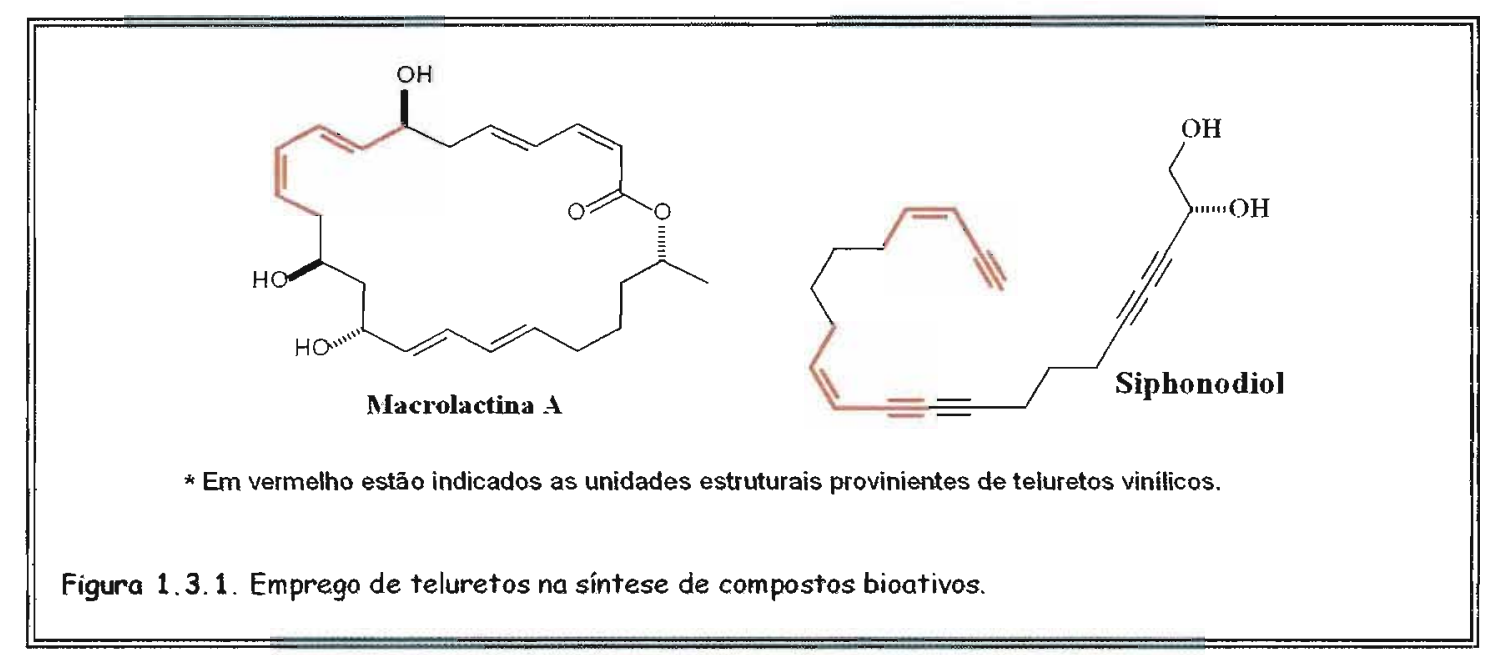

Em vista do potencial sintético dos compostos orgânicos de selênio e telúrio, aliado à importância das sínteses enantiosseletivas (seção 1.1.) é de grande interesse que se desenvolvem métodos de preparação de compostos desses elementos na sua forma enantiomericamente pura. Os mesmos constituiriam importantes blocos de construção quirais, ao se explorar a química orgânica do selênio ${ }^{43}$ e do telúrio ${ }^{44}$, hoje em dia já bem estabelecidas. 
2. Resultados e Discussão 
2.1. Hidróxi-Selenetos 


\subsubsection{Síntese Racêmica}

Os hidróxi-selenetos utilizados nas biotransformações foram preparados empregando metodologias descritas na literatura (Figura 2.1.1.1).

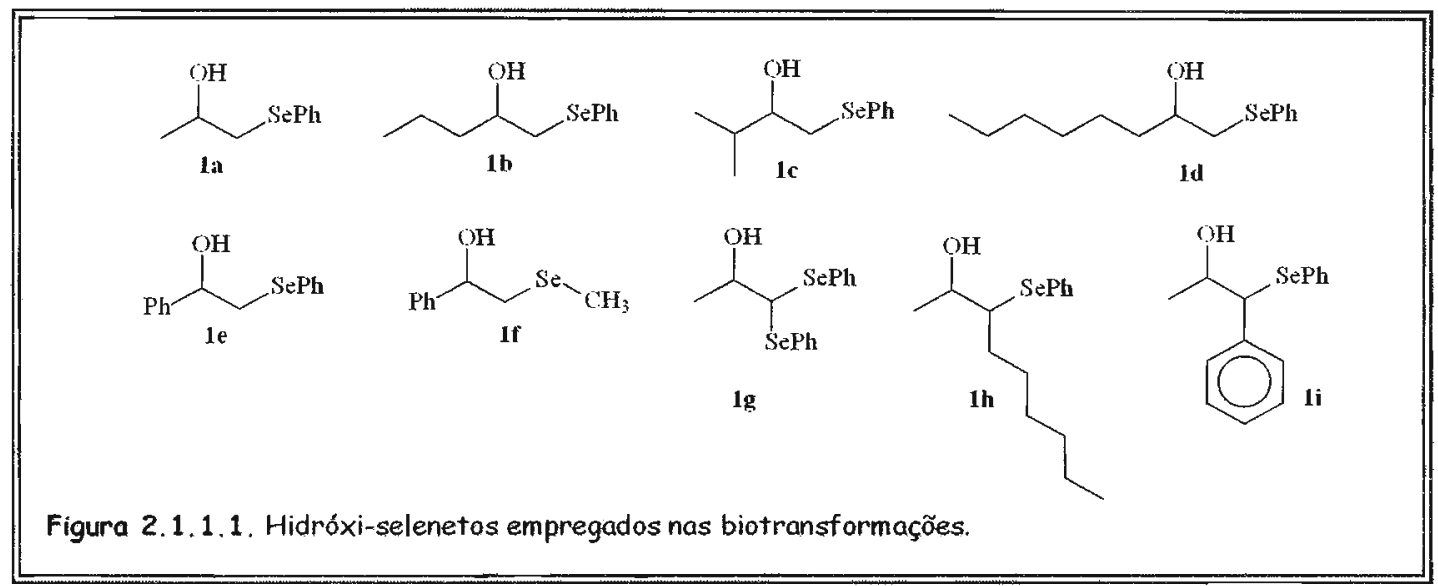

Os hidróxi-selenetos 1a e 1e foram sintetizados, respectivamente, empregando a reação de abertura do óxido de propileno e óxido de estireno com fenil-selenolato de sódio, preparado "in situ" pela redução de disseleneto de diferila com $\mathrm{NaBH}_{4}$ (Esquema 2.1.1.1). ${ }^{38}$

O composto 1f foi preparado de maneira análoga, porém utilizando metil-selenolato de lítio, o qual foi preparado "in situ" pela adição de metil-lítio sobre selênio elementar em THF (Esquema 2.1.1.1). De maneira geral, a abertura de epóxidos mono-substituídos com nucleófilos de selênio são regioespecíficas, originando apenas o álcool secundário, isto é, a abertura ocorre no carbono menos substituído (Esquema 2.1.1.1). ${ }^{38}$

Entretanto, a abertura do óxido de estireno pode originar uma mistura de dois regio-isômeros (álcool

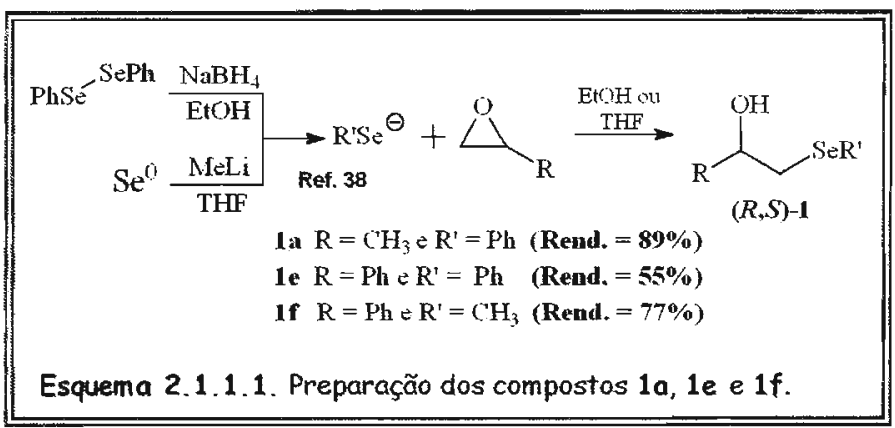
primário e 0 álcool secundário). ${ }^{45}$ A presença dos dois regio-isômeros é explicada pela abertura do óxido de estireno na posição benzílica, gerando o álcool primário (Esquema 2.1.1.2). 


$$
\mathrm{RSe}^{\theta}+\mathrm{C}_{\mathrm{Ph}}^{\stackrel{\mathrm{EtOH}}{\longrightarrow}} \mathrm{Ph}_{\mathrm{Ref} 45}^{\mathrm{H}} \mathrm{SeR}+\overbrace{\mathrm{Fh}}^{\mathrm{H}} \mathrm{SeK}
$$

Esquema 2.1.1.2. Mistura de régia-isômeros.

Os hidróxi-selenetos 1b-d foram sintetizados por reação de adição de fenilseleno-metil-lítio ao aldeído correspondente, levando a formação do hidróxi-seleneto de interesse com elevada pureza. ${ }^{46} 0$ fenilseleno-metil-lítio foi gerado in situ pela reação de troca metalóide-metal entre o bis(ferilseleno)metano e $n$-BuLi. ${ }^{46} \mathrm{O}$ bis(fenilseleno)metano foi preparado pela reação do fenilselenolato de sódio com dibromometano (Esquema 2.1.1.3). ${ }^{38}$

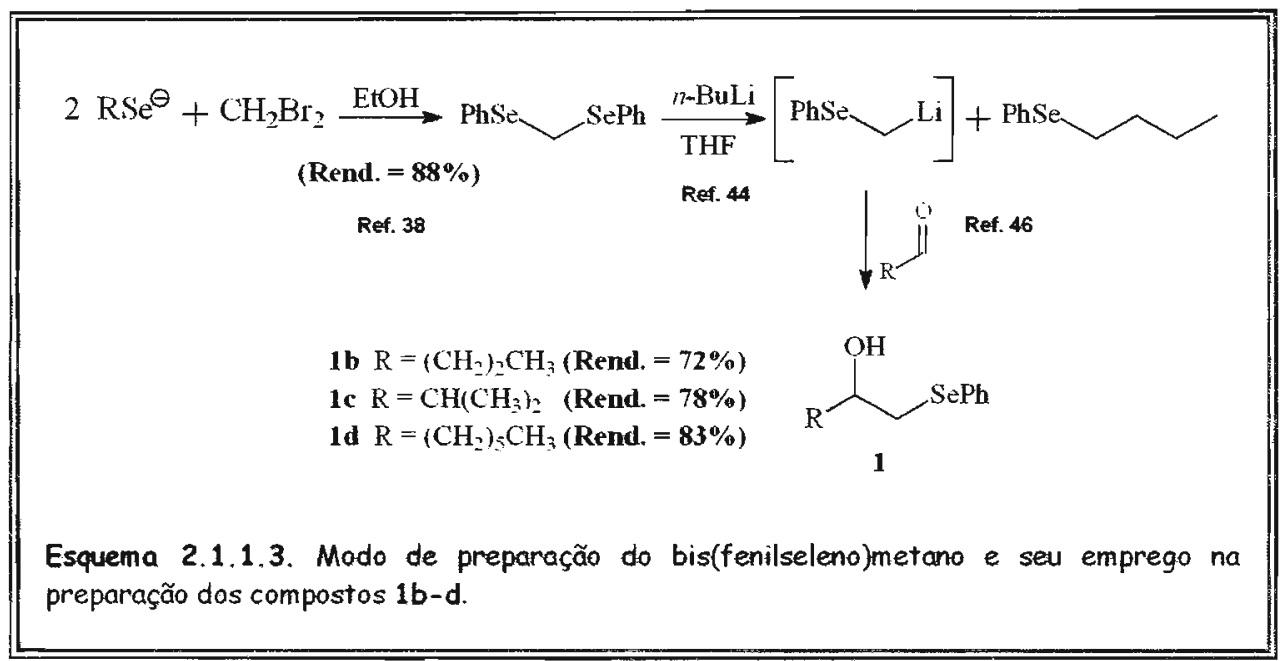

O composto $1 \mathrm{~g}$ foi sintetizado a partir da desprotonação do bis(feniiśseleno)metano empregando o LDA, gerando um carbânion, o qual foi capturado com acetaldeído, produzindo assim o hidróxi-seleneto $(R, S)-1 \mathrm{~g}$ em bom rendimento (Esquema 2.1.1.4). ${ }^{46,47}$

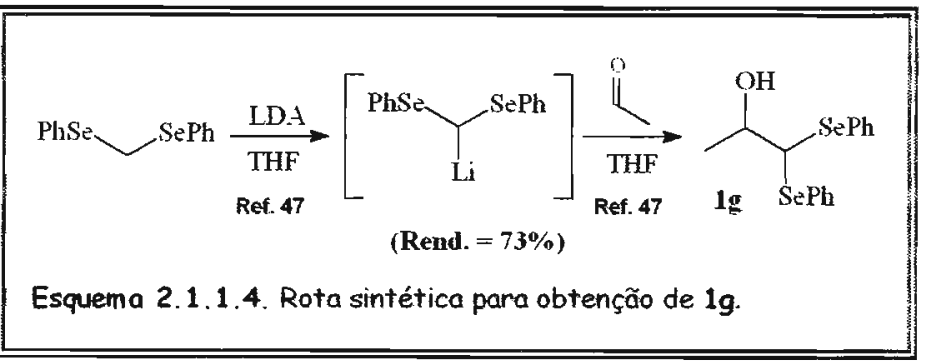

Devido à presença de dois centros estereogênicos nos compostos ( \pm )-1h e ( \pm )-1i, a síntese dos mesmos via a reação de troca metalóidemetal entre selenoacetal substituído e n-BuLi seguida da adição de acetaldeído, gerou os compostos $( \pm)$ - $1 \mathrm{~h}$-i como uma mistura de quatro estereoisômeros (dois pares de enatiômeros - Esquema 2.1.1.5). ${ }^{46}$ 


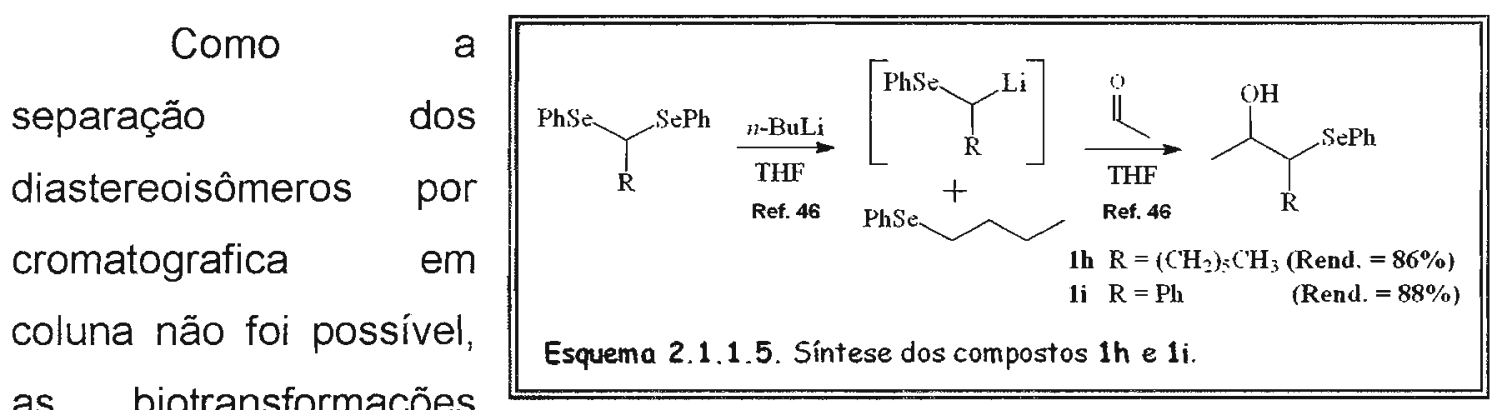

as biotransformações

foram realizadas utilizando-se essa mistura estereoisomérica.

A síntese dos selenoacetais substituidos empregados nessas reações foi a etapa mais delicada na preparação desses hidróxi-selenetos [( \pm )-1h e ( \pm )1i]. Os selenoacetais foram sintetizados por selenoacetalização do aldeído apropriado com fenil-selenol, utilizando $\mathrm{O}_{2} \mathrm{SO}_{4}{ }^{48} \mathrm{O}$ cuidado nesta etapa de síntese foi com o $\mathrm{H}_{2} \mathrm{SO}_{4}$ utilizado, pois o mesmo é um agente oxidante. Para a obtenção do selenoacetal em bons rendimentos foi necessário utilizar $0 \mathrm{H}_{2} \mathrm{SO}_{4}$ $13 \mathrm{M}$, evitando assim a oxidação do fenil-selenol a disseleneto de difenila (Esquema 2.1.1.6). ${ }^{48}$

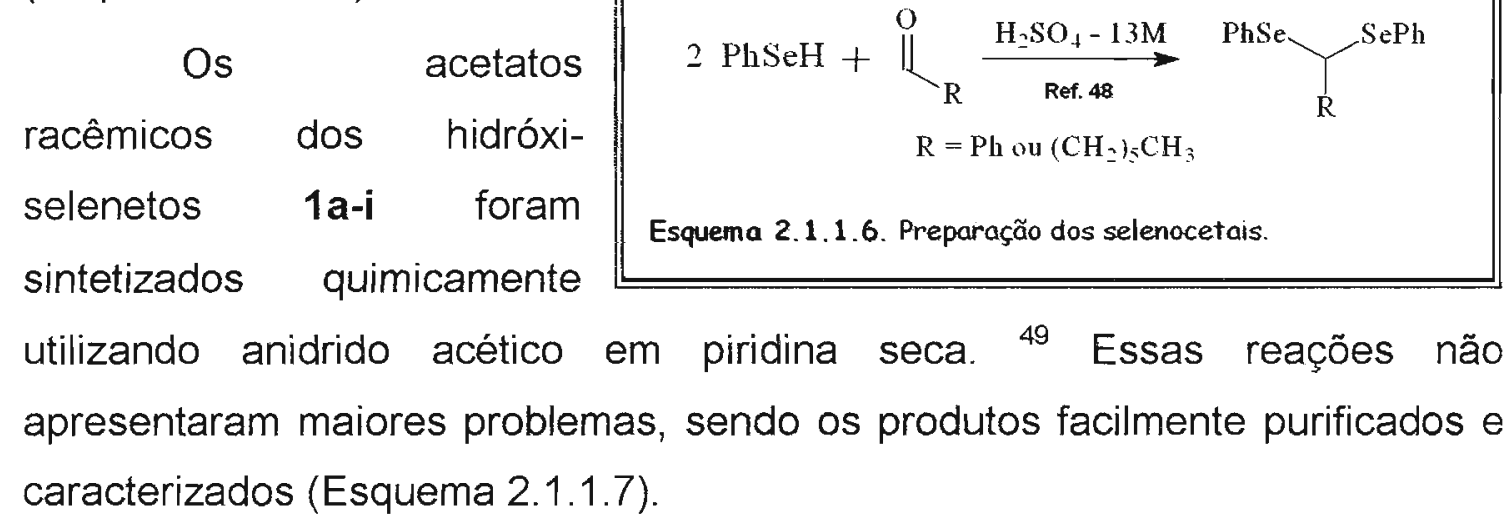

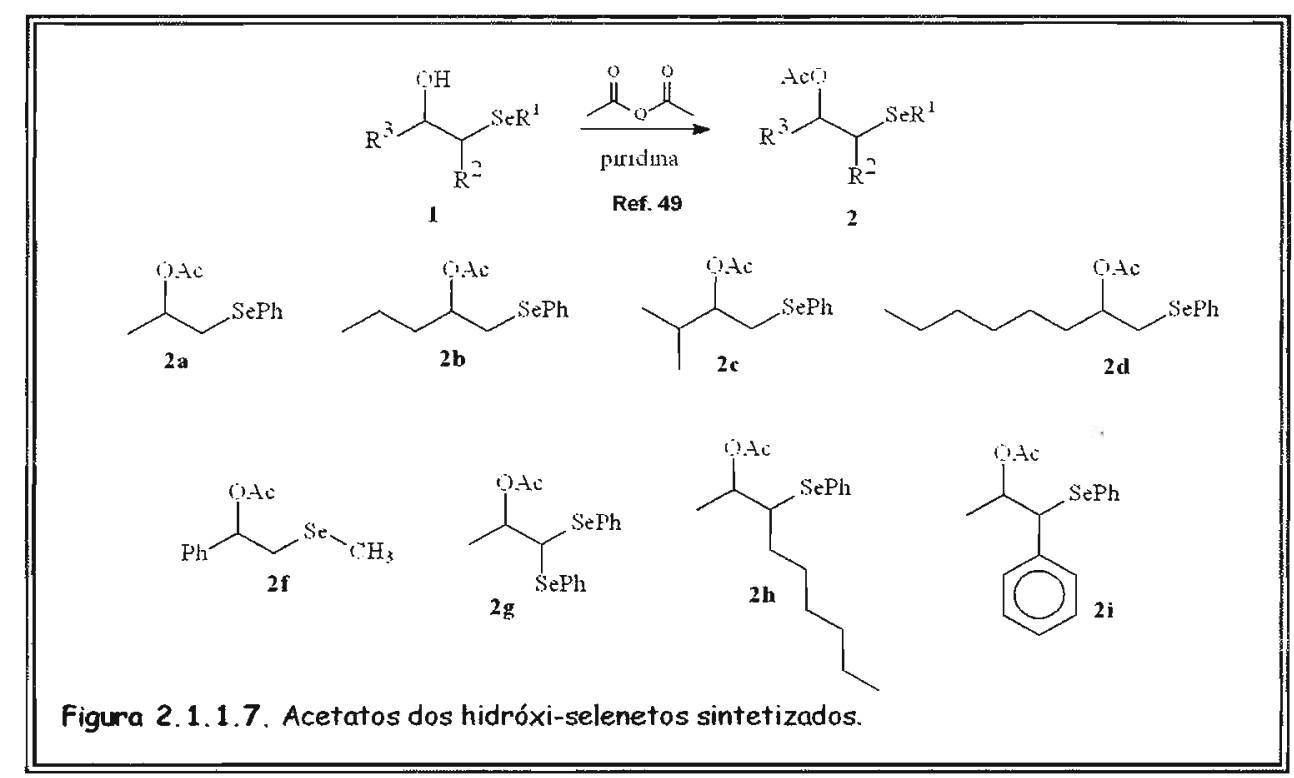




\subsubsection{Biotransformações}

\subsubsection{Resolução em Meio Orgânico}

A resolução enzimática de hidróxi-selenetos foi estudada variando-se 0 tipo de lipase, o suporte da enzima (quando imobilizada), o solvente, a temperatura e a estrutura do hidróxi-seleneto, a fim de avaliarmos a influência desses fatores sobre as resoluções enzimáticas desses compostos em meio orgânico. Dessa forma o $(R, S)$-hidróxi-seleneto 1a foi utilizado como padrão neste estudo (Esquema 2.1.2.1.1).

Três lipases foram escolhidas como biocatalizadores: a PPL (lipase de pâncreas de porco - livre), a PSL (AMANO PS - lipase de Pseudomonas sp. - livre)

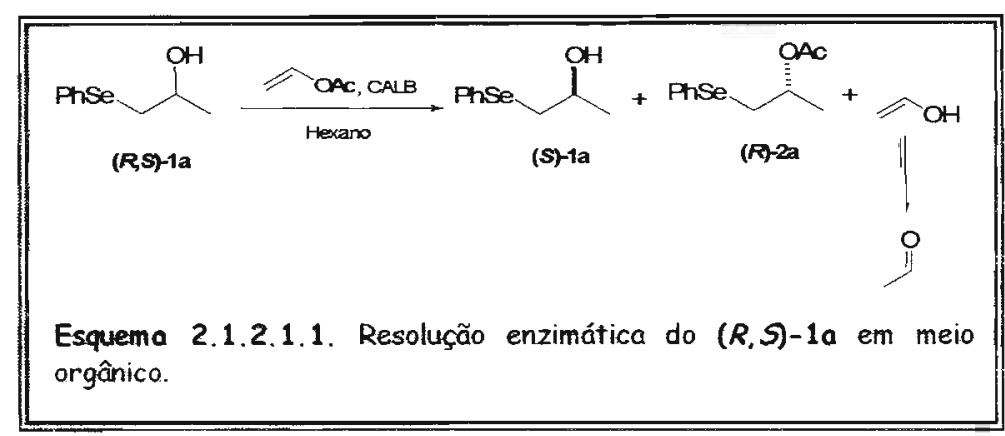
e a CALB (NOVOZYM 435 $5^{\circledR}$ - lipase de Candida antartica - Fração B imobilizada). Na tabela 2.1.2.1.1 estão resumidos os resultados observados na resolução do composto $(\boldsymbol{R}, S)$-1a com essas enzimas em hexano seco e em diferentes temperaturas. Os resultados demonstram que a atividade enzimática depende da temperatura empregada. A temperatura apresentou um considerável efeito na enantiosseletividade da reação, mas não apresentou influência sobre o enantiômero preferencialmente acetilado [enantiômero- $(R)$ ]. A enantio-preferência observada está de acordo com a regra de Kazlauskas (Sessão 1.2.1.3). ${ }^{31}$

As melhores enantiosseletividades foram obtidos utilizando PSL e CALB entre 20 e $40^{\circ} \mathrm{C}$ e a melhor relação entre excesso enantiomérico e conversão foi observado a $32^{\circ} \mathrm{C}$. Na reação com a $\mathrm{PSL}, \circ(\boldsymbol{S})-1 \mathrm{a}$ e o (R)-2a foram obtidos com excessos enantioméricos superiores a $92 \%$ a $32^{\circ} \mathrm{C}$ (Tabela 2.1.2.1.1 - entrada 5), enquanto que a melhor enantiosseletividade foi observada com a CALB. Na reação com a CALB o (S)-1a e o (R)-2a foram obtidos com excessos enantioméricos superiores a $98 \%$ a $32^{\circ} \mathrm{C}$ (Tabela 2.1.2.1.1 - entradas 8 e 9). Controlando o tempo de reação e a temperatura foi 
possivel obter tanto o (S)-1a como o (R)-2a com excessos enantioméricos superiores a 99\% (Tabela 2.1.2.1.1 - Entradas 4-5, 7 e 9-10).

Tabela 2.1.2.1.1. Resolução enzimática do composto $(R, S)$-1a usando diferentes lipases.

\begin{tabular}{cccccccc}
\hline Entrada & Lipase & $\begin{array}{c}\text { Temperatura } \\
/{ }^{\circ} \mathbf{C}\end{array}$ & $\begin{array}{c}\text { Tempo } \\
/ \mathbf{h}\end{array}$ & $\begin{array}{c}\text { Conversão } \\
/ \%\end{array}$ & $\begin{array}{c}\text { e.e. }(\boldsymbol{\%})-\mathbf{1} \mathbf{a}^{\mathbf{b}} \\
/ \%\end{array}$ & $\begin{array}{c}\text { e.e. }(\boldsymbol{R})-\mathbf{2} \mathbf{a}^{\mathbf{c}} \\
/ \%\end{array}$ & $\boldsymbol{E}^{\mathbf{d}}$ \\
\hline 1 & PPL & 20 & 24 & 41 & 63 & 89 & 32 \\
2 & & 32 & 98 & 49 & 81 & 84 & 28 \\
3 & & 40 & 24 & 34 & 46 & 88 & 24 \\
4 & PSL & 20 & 24 & 31 & 45 & $>99$ & $>200$ \\
5 & & 32 & 72 & 52 & $>99$ & 92 & $>125$ \\
6 & & 40 & 24 & 47 & 85 & 95 & 106 \\
7 & CALB & 20 & 6 & 48 & 90 & $>99$ & $>200$ \\
8 & & 32 & 4 & 49 & 98 & 99 & $>200$ \\
9 & & 32 & 6 & 50 & $>99$ & 99 & $>200$ \\
10 & & 40 & 5 & 51 & $>99$ & 98 & \\
\hline
\end{tabular}

${ }^{a}$ As reações foram realizadas com $0.5 \mathrm{mmol}$ do $(R, S)-1 a$ e $1 \mathrm{~g}$ da PPL, 100mg da PSL ou 15mg da CALB em hexano seco (25mL para PPL e PSL ou $10 \mathrm{~mL}$ para CALB). ${ }^{\circ}$ Excesso enantiomérico do hidróxi-seleneto (S)-1a. ${ }^{\circ}$ Excesso enantiomérico do acetato $(R)-2 a$. ${ }^{~ d}$ Razão enantiomérica: este parâmetro descreve a enantiosseletividade da enzima.

A influência do solvente também foi avaliada utilizando o composto $(R, S)-1$ a, com PSL e CALB em experimentos a $32^{\circ} \mathrm{C}$ em solventes orgânicos secos. As conversões foram determinadas após 24 horas para os experimentos

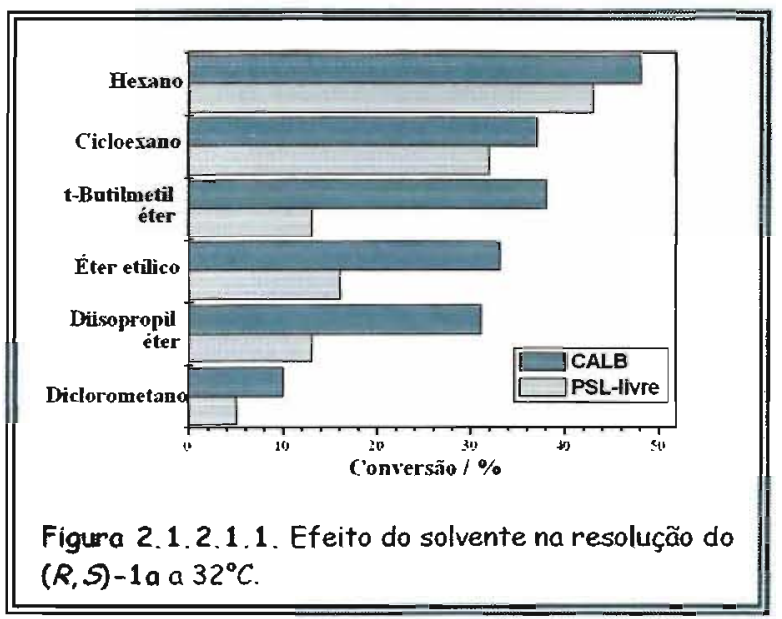
realizados com a PSL e 6 horas para os experimentos realizados com a CALB. Nesses experimentos foi observado que o solvente tem uma grande influência sobre a conversão do substrato (Figura 2.1.2.1.1). Considerando que as demais variáveis (como tempo de reação, substrato, temperatura, etc.) permaneceram constantes, podemos traduzir esse efeito como uma dependência da atividade enzimática em relação ao solvente empregado. 
Apesar da dependência da atividade enzimática com o solvente, não foi observada mudança na enantiosseletividade e nem da enantiopreferência da enzima, sendo sempre acetilado preferencialmente o enantiômero-( $R)-1 \mathbf{a}$.

Em todos os solventes $O(R)-2 a$ foi obtido com excesso enantiomérico superior a $97 \%$ usando a PSL e superior a $99 \%$ usando a CALB. As maiores atividades enzimáticas (isto é, maiores conversões) foram observadas em solventes não polares, como hexano e cilcloexano, enquanto que em solventes polares, como diclorometano, a atividade foi menor (Figura 2.1.2.1.1).

Como salientado, a imobilização enzimática é uma ferramenta muito útil em biotransformações (Sessão 1.2.1.4). Nesses sentido, a PSL foi imobilizada em alguns suportes: gel de agar, silica, filme de caseinato, Montmorilonita K-10 e óxido de poli(etileno) (PEO). Os experimentos utilizando a PSL imobilizada foram conduzidos nas mesmas condições empregadas para a enzima livre. Todos os experimentos de imobilização foram realizados com a supervisão da Profa. Dra. Maria da Graça Nascimento do Departamento de Química da Universidade Federal de Santa Catarina.

Os resultados evidenciaram a dependência da atividade enzimática com o tipo de suporte utilizado (Figura 2.1.2.1.2). Nenhum produto acetilado foi detectado com a PSL imobilizada em gel de ágar ou em Montmorilonita K-10, enquanto que em sílica e em filme de caseinato apresentaram um efeito negativo sobre a atividade enzimática, sendo observadas conversões inferiores às observadas com a lipase livre. Por outro lado, o óxido de poli(etileno) apresentou bons resultados, aumentando sensivelmente a atividade enzimática da PSL (Figura 2.1.2.1.2). Uma racionalização para os resultados observados com a imobilização da PSL em diversos suportes pode ser baseada nos processos de difusão de reagentes e produtos, do suporte para - meio reacional, e também da manutenção da integridade da estrutura ativa da lipase. ${ }^{50}$

A estereoquímica preferencial

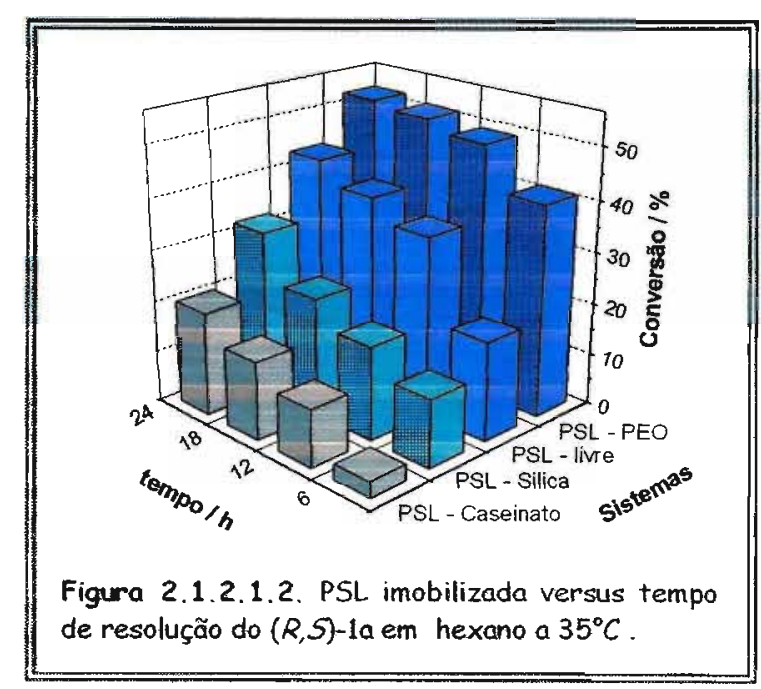


para o enantiômero- $(R)$ na acetilação foi mantida, independente do suporte utilizado. Após 24 horas de reação a $35^{\circ} \mathrm{C}$ em hexano, a resolução utilizando a PSL livre apresentou uma conversão de $45 \%$ e o substrato (S)-1a foi recuperado com excesso enantiomérico de $80 \%$, enquanto que o produto $(R)$ 2a foi obtido com excesso enantiomérico de 97\%. Entretanto, a mesma resolução empregando a PSL imobilizada em PEO apresentou uma conversão de $52 \%$ e o substrato (S)-1a foi recuperado com excesso enantiomérico de $>99 \%$, enquanto que o produto $(\boldsymbol{R})$-2a foi obtido com excesso enantiomérico de $92 \%$.

Analisando os resultados obtidos, verificamos que apesar da melhora do desempenho da PSL com a imobilização em PEO, a CALB (lipase adquirida imobilizada) apresentou os melhores resultados na resolução do hidróxiseleneto $(\boldsymbol{R}, \boldsymbol{S})$-1a. Assim, o sistema CALB em hexano a $32^{\circ} \mathrm{C}$ foi escolhido para avaliar o comportamento da estrutura do hidróxi-seleneto nas biotransformações. Nesse sentido, as resoluções dos hidróxi-selenetos $(R, S)$ 1b-e foram realizadas utilizando a CALB como biocatalizador em hexano seco (Esquema 2.1.2.1.2)

Inicialmente, a resolução do $(\boldsymbol{R}, \boldsymbol{S})-1$ b foi realizada a $32^{\circ} \mathrm{C}$, porém a esta temperatura a reação enzimática foi muito lenta, necessitando mais de quatro dias para uma conversão de 50\% (Tabela 2.1.2.1.2 - entradas 1-3), apesar do aumento da quantidade de lipase utilizada (de $15 \mathrm{mg}$ passamos a utilizar $300 \mathrm{mg}$ por $0,5 \mathrm{mmol}$ de substrato). Como a CALB apresentou conversões maiores a $40^{\circ} \mathrm{C}$ (Tabela 2.1.2.1.1 - entrada 10), optamos por realizar essas resoluções nesta temperatura.

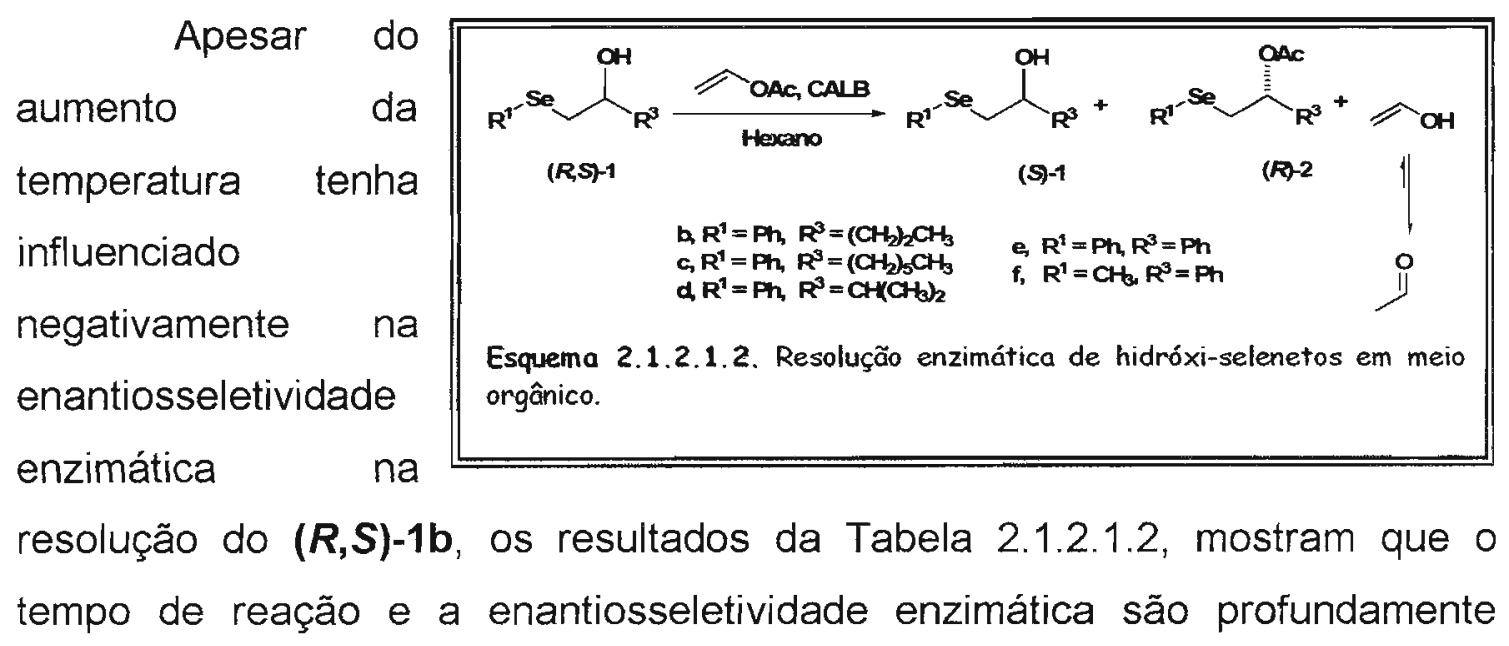


afetadas pelo tamanho do grupo $\mathrm{R}^{3}$ do hidróxi-seleneto (Esquema 2.1.2.1.2). A presença de um substituinte grande [compostos $(R, S)-1 b$ e $(R, S)-1 c]$ ou ramificado [compostos $(\boldsymbol{R}, \boldsymbol{S})$-1d] diminui a enantiosseletividade enzimática nas resoluções dos hidróxi-selenetos. $E$ no caso do composto $(\boldsymbol{R}, \boldsymbol{S})$-1e nenhum produto acetilado foi observado (Tabela 2.1.2.1.2 - entrada 13).

Tabela 2.1.2.1.2. Resolução enzimática ${ }^{\circ}$ do composto $(R, S)$-1a usando CALB.

\begin{tabular}{|c|c|c|c|c|c|c|c|c|}
\hline Entrada & Substrato & $\begin{array}{l}\text { Temp. } \\
{ }^{\circ} \mathrm{C}\end{array}$ & $\begin{array}{c}\text { Tempo / } \\
\text { dias }\end{array}$ & $\begin{array}{c}\text { Conversão } \\
/ \%\end{array}$ & $\begin{array}{c}\text { e.e. do } \\
\text { álcool } / \%{ }^{b}\end{array}$ & $\begin{array}{c}\text { e.e. do } \\
\text { acetato } / \%\end{array}$ & $\begin{array}{l}\text { Config. } \\
\text { Absoluta }\end{array}$ & $E^{e}$ \\
\hline 1 & $(R, S)-1 \mathrm{~b}$ & 32 & 4 & 46 & 66 & 91 & & \\
\hline 2 & & & 12 & 56 & 99 & 78 & & \\
\hline 3 & & & 16 & 58 & $>99$ & 71 & $(S)$ & 41 \\
\hline 4 & & 40 & 2 & 41 & 62 & 88 & & \\
\hline 5 & & & 7 & 58 & 98 & 72 & & \\
\hline 6 & & & 9 & 59 & $>99$ & 70 & $(\boldsymbol{S})$ & 28 \\
\hline 7 & $(R, S)-1 \mathrm{c}$ & 40 & 12 & 29 & 36 & 90 & & \\
\hline 8 & & & 15 & 35 & 47 & 89 & & \\
\hline 9 & & & 20 & 45 & 69 & 86 & $(S)$ & 29 \\
\hline 10 & $(R, S)-1 \mathrm{~d}$ & 40 & 5 & 35 & 22 & 41 & & \\
\hline 11 & & & 7 & 46 & 32 & 37 & & \\
\hline 12 & & & 9 & 59 & 42 & 33 & $(S)$ & 3 \\
\hline 13 & $(R, S)-1 \mathrm{e}$ & 40 & 20 & $<1$ & -- & --- & -- & -- \\
\hline 14 & $(R, S)-1 \mathrm{f}$ & 40 & 10 & 23 & 24 & 79 & & \\
\hline 15 & & & 15 & 32 & 32 & 76 & & \\
\hline 16 & & & 20 & 36 & 41 & 74 & $(R)$ & 10 \\
\hline
\end{tabular}

${ }^{a}$ As reações foram realizadas utilizando CALB $(300 \mathrm{mg})$ em hexano seco $(10 \mathrm{~mL})$ à $40^{\circ} \mathrm{C}\left(\mathrm{ou} 32^{\circ} \mathrm{C}\right)$. ${ }^{b}$ Excesso enantiomérico do álcool 1. "Excesso enantiomérico do acetato 2. Configuração absoluta do álcool 1. " Razão enantiomérica: este parâmetro descreve a enantiosseletividade da enzima.

Nas resoluções dos compostos $(R, S)-1 \mathbf{b}-\mathbf{d}$, foi observada enantiopreferência para o enantiômero- $(R)$, conforme observado para o hidróxiseleneto $(R, S)-1 a$. Esses resultados estão de acordo com os estudos realizados empregando CALB referente à estrutura necessária para que um álcool secundário seja resolvido com sucesso (Seção 1.2.1.3). ${ }^{35}$

De acordo com a regra de Kazlauskas (Seção 1.2.1.3), ${ }^{31}$ nossos resultados demonstram que para os hidróxi-selenetos $(R, S)-1 a-e, ~ o$ grupo fenilselanila comporta-se como um substituinte grande. 
Para avaliar o efeito do tamanho do grupo selanila na resolução dos hidróxi-selenetos, o composto $(\boldsymbol{R}, \boldsymbol{S})$-1f foi sintetizado. Este composto possui um grupo fenila (como o grupo $\mathrm{R}^{3}$ - grupo grande) e um grupo metilselanila (como grupo $\mathrm{R}^{1}$ - Esquema 2.1.2.1.2). A resolução enzimática do $(\boldsymbol{R}, \boldsymbol{S})$-1f apresentou a estereoquímica preferencial para o enantiômero-(S), diferentemente dos demais compostos [compostos $(\boldsymbol{R}, \mathbf{S})$-1a-e / Tabela 2.1.2.1.2 - entradas 1-12] e com baixa enantiosseletividade. De acordo com a regra de Kazlauskas (Seção 1.2.1.3), ${ }^{31}$ o grupo metilselenila comporta-se como um substituinte médio, porém maior que um grupo etila, levando a baixa enantiosseletividade $(E=10)$ observada para a resolução utilizando CALB (Tabela 2.1.2.1.2 - entradas 14-16).

Considerando os resultados obtidos com a resolução dos hidróxiselenetos $(\boldsymbol{R}, \boldsymbol{S})$-1a-f empregando a CALB como biocatalisador e a regra de Kaslauskas (Seção 1.2.1.3), ${ }^{31}$ concluímos que para um $\beta$-hidróxi-seleneto ser eficientemente resolvido pela CALB em meio orgânico é necessário que o substituinte de tamanho médio seja menor que o grupo etila, visto que o grupo selanila se comporta melhor como substituinte grande, como ocorre no composto $(R, S)-1$ a.

Assim, as resoluções dos $\beta$-hidróxi-selenetos $(\boldsymbol{R}, \mathbf{S})$-1g e $( \pm$ )-1h-i (os quais possuem o grupo metila como substituinte de tamanho médio - Esquema 2.1.2.1.3) foram realizadas nas mesmas condições empregadas na biotransformação do composto $(R, S)$-1a, uma maneira de comprovarmos os resultados e as conclusões obtidas nesse estudo.

Nessas

condições o composto

$(R, S)-19$

eficientemente

resolvido pela CALB $(E$ $>$ 200) e o produto acetilado foi obtido

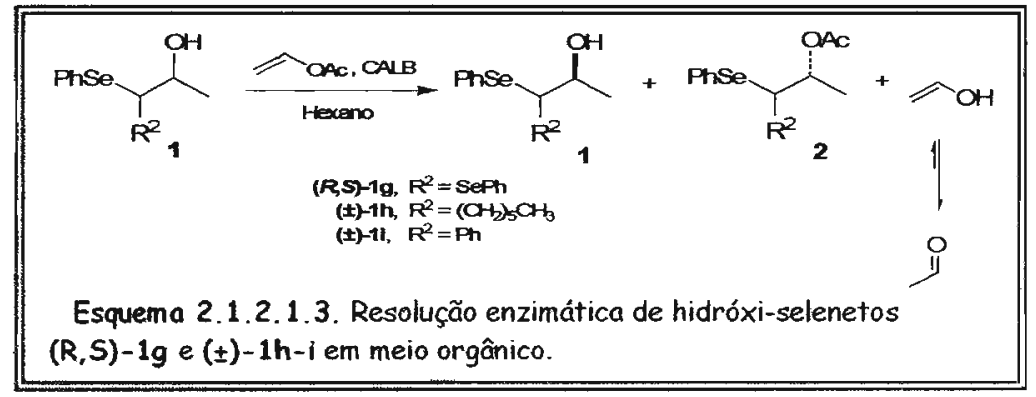

com excessos enantioméricos superiores a 99\% (Tabela 2.1.2.1.3), de maneira análoga ao observado com o hidróxi-seleneto $(\boldsymbol{R}, \mathbf{S})-\mathbf{1 a}$. 
Na resolução dos compostos ( $\mathbf{\pm})$-1h-i, foi empregada a mistura dos quatro estereoisômeros (dois pares de enantiômeros - Esquema 2.1.2.1.3) Nessas resoluções não foi observada nenhuma diastereopreferência.

Como a discriminação de cada um dos quatro enantiômeros via CGQuiral não foi possivel, o grupo ferilselanila foi removido da estutura dos álcoois $(\mathbf{\pm}) \mathbf{- 1 h}-\mathbf{i}$, desfazendo-se assim, um dos centros estereogênicos. Foram utilizadas reações que não modificam a configuração do carbono carbinólico (vide seção 2.1.4.1), possibilitando a determinação da enantiosseletividade enzimática relativa ao centro estereogênico localizado no carbono carbinólico.

Assim, após as reações de eliminação do grupo fenilselanila, foi observada uma alta enantiosseletividade para o centro carbinólico dos compostos ( $\mathbf{\pm}$ )-1h-i, observando-se excessos enantioméricos superiores a $99 \%$ para os produtos acetilados (sem o grupo fenilselanila - Tabela 2.1.2.1.3), também de maneira análoga ao observado com o hidróxi-seleneto $(R, S)-1$ a

Tabela 2.1.2.1.3. Resolução enzimática ${ }^{a}$ dos compostos $1 g$-i usando CALB.

\begin{tabular}{ccccccc}
\hline Entrada & Substrato & $\begin{array}{c}\text { Tempo } \\
/ \mathbf{h}\end{array}$ & $\begin{array}{c}\text { Conversão } \\
/ \%\end{array}$ & $\begin{array}{c}\text { e.e. do substrato } \\
/ \%\end{array}$ & $\begin{array}{c}\text { e.e. do produto } \\
/ \%\end{array}$ & $E^{\mathrm{b}}$ \\
\hline 1 & $(R, S)-1 \mathrm{~g}$ & 25 & 50 & $99^{\mathrm{c}}$ & $>99^{\mathrm{d}}$ & $>200$ \\
2 & $( \pm)-1 \mathrm{~h}$ & 50 & 48 & $93^{\mathrm{e}}$ & $>99^{\mathrm{f}}$ & $>200$ \\
3 & $( \pm)-1 \mathrm{i}$ & 72 & 48 & $92^{\mathrm{g}}$ & $>99^{h}$ & $>200$ \\
\hline
\end{tabular}

${ }^{\text {a }}$ As reações foram realizadas utilizando CALB $(15 \mathrm{mg})$ em hexano $(10 \mathrm{~mL})$ à $32^{\circ} \mathrm{C}$ e utilizando $0,5 \mathrm{mmol}$ do substrato. ${ }^{b}$ Razão enantiomérica: este parâmetro descreve a enantiosseletividade da enzima ${ }^{\circ}$ Excesso enantiomérico do álcool 1g. ${ }^{d}$ Excesso enantiomérico do acetato $2 \mathrm{~g}$. ${ }^{\circ}$ Excesso enantiomérico do álcool após a reação de eliminação de selenóxido (vide seção 2.1.4.1) . ${ }^{~}$ Excesso enantiomérico do acetato após a reação de eliminação de selenóxido (vide seção 2.1.4.1). ${ }^{g}$ Excesso enantiomérico do álcool após a remoção do grupo fenilseleno (vide seção 2.1.4.1). ${ }^{h}$ Excesso enantiomérico do acetato após a remoção do grupo fenilseleno(vide seção 2.1.4.1).

Nas resoluções dos compostos $(R, S)-1 g$ e $(\mathbf{t})$-1h-i, foi observado que a CALB apresenta preferência em acetilar o álcool de configuração $(R)$ (carbono carbinólico), em concordância com os resultados observados anteriormente.

Todos os experimentos realizados neste estudo demonstraram que $\beta$-hidróxi-selenetos que possuem substituinte ligado ao carbono carbinólico menor que um grupo etila, podem ser obtidos opticamente puros empregandose lipases como biocatalisadores em meio orgânico. 


\subsubsection{Resolução em Meio Aquoso}

O emprego de água como solvente em reações orgânicas sempre representa uma contribuição valiosa para a preservação do meio ambiente. Em biotransformações, as vantagens podem ir além do ganho ambiental, pois o meio natural da enzima é o meio aquoso, proporcionando uma melhor conformação e conseqüentemente uma maior atividade enzimática, o que pode contrubuir para um aumento na eficiência na seletividade da enzima.

Assim, com o intuito de encontrarmos um processo de resolução enzimática de hidróxi-selenetos menos agressivo ao meio ambiente e mais eficiente, foram realizados estudos de hidrólise enzimática dos respectivos acetatos dos hidróxi-selenetos $(\boldsymbol{R}, \mathbf{S})$-1b-f (Esquema 2.1.2.2.1).

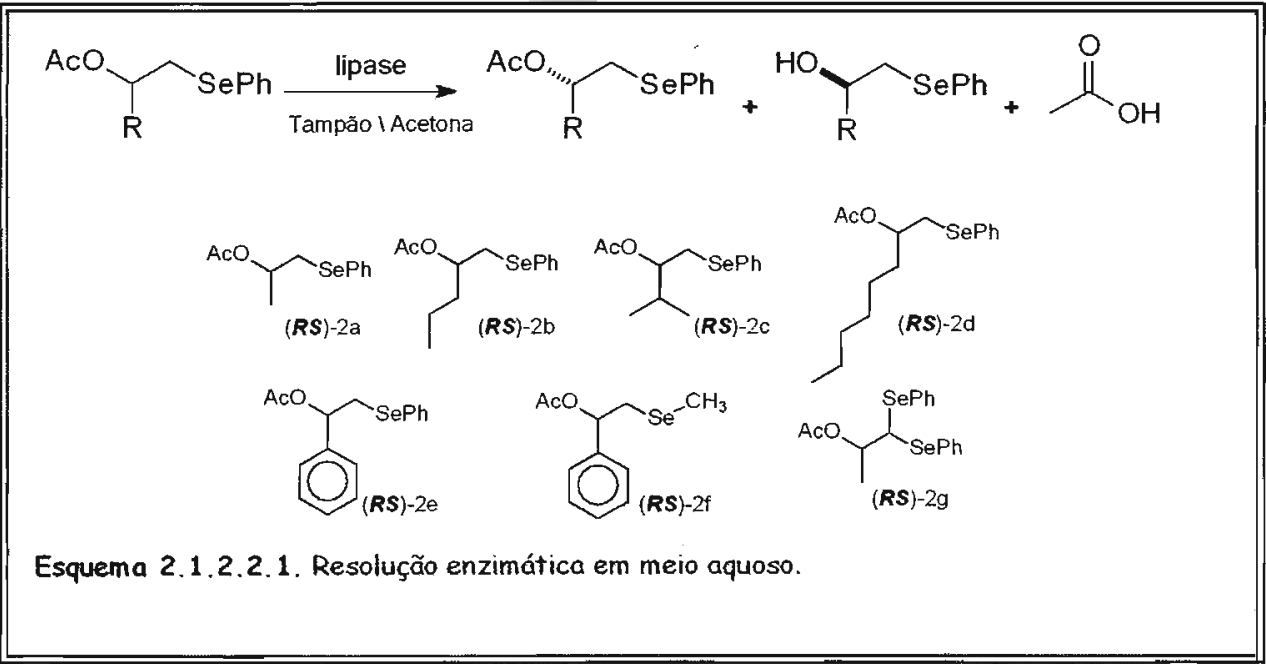

Nesse sentido, realizamos primeiramente uma triagem com dez enzimas comerciais (não imobilizadas) de fontes naturais diferentes, que geralmente apresentam boa atividade em meio aquoso à temperatura ambiente e a pH neutro: [CALA (lipase de Candida antarctica Tipo A - Roche Co.), CALB (lipase de Candida antarctica Tipo B - Roche Co.), CRL (lipase de Candida rugosa - Roche Co.), PSL (lipase de Pseudomonas sp. - Roche Co.), PLE (esterase de fígado de porco - Roche Co.), PPL (lipase de pâncreas de porco - Roche Co.), TLLa (lipase de Thermomyces lanuginosa - Roche Co.), ASL (lipase Alcaligenes sp. - Roche Co.), MJL (lipase de Mucor Javanicus Sigma Co.) e TLL $_{b}$ (LIPOZYME TL $100 L^{\circledR}$ - lipase de Thermomyces lanuginosa - Novozymes Co.)]. 
Para agilizarmos o processo de triagem com as enzimas e os substratos de interesse, optamos por realizar a triagem em placas de "Elisa" (com 96 poços - Figura 2.1.2.2.1) utilizando um indicador de $\mathrm{pH}$ colorimétrico, visto que na reação de hidrólise ocorre a produção de ácido acético (Esquema 2.1.2.2.1), permitindo assim avaliar a conversão no processo de hidrólise pela mudança de cor do indicador. ${ }^{51}$ Dessa maneira foi possivel realizar várias micro-reações ao mesmo tempo e verificar rapidamente quais lipases promoviam a hidrólise dos compostos $(\boldsymbol{R}, \mathbf{S})-\mathbf{2 a}-\mathbf{g}$.

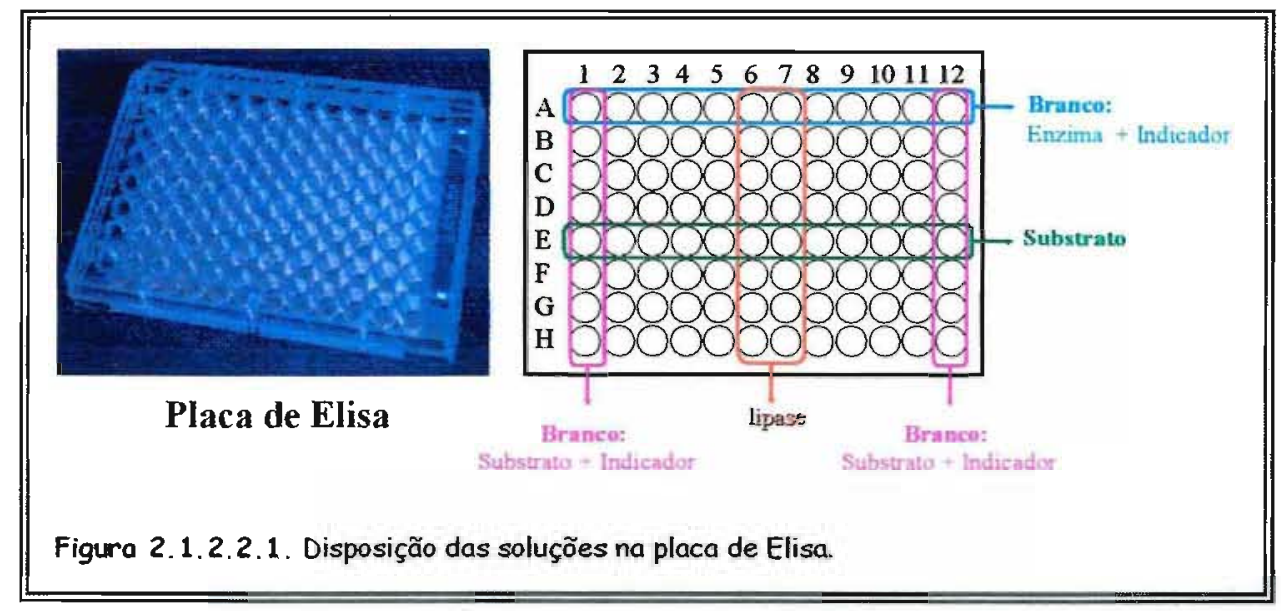

Nesta triagem utilizamos como indicador de $\mathrm{pH}$ azul de bromo timol $(0,005 \%$; azul $=$ meio básico $\backslash$ verde $=$ meio neutro $\backslash$ amarelo $=$ meio ácido $)$, tampão fosfato ( $\mathrm{pH}=7,2 / 20.10^{-3} \mathrm{Mol} \mathrm{L}^{-1}$ ) e duas placa de "Elisa" com 96 poços cada. Todas as micro-reações foram realizadas em duplicatas e sempre acompanhadas com os brancos: enzima + indicador e substrato + indicador, na mesma placa. A disposição das soluções (brancos e reações) na placa seguiu o padrão monstrado na Figura 2.1.2.2.1.

Seis enzimas (CALA, CALB, CRL, PSL, PLE, ASL e MJL) apresentaram atividade hidrolítica para alguns acetatos utilizados na triagem (Figura 2.1.2.2.2). Entretanto, nenhuma enzima apresentou atividade hidrolítica frente aos substratos possuidores de dois ligantes volumosos [ligados ao carbono carbinólico $\backslash(\boldsymbol{R}, \mathbf{S})-2 \mathrm{c}-\mathbf{e}$ - Figura 2.1.2.2.2], provavelmente devido à dificuldade na formação do complexo enzima-substrato no sítio catalítico da enzima, causada pelo volume dos ligantes, conforme observado na resolução em meio orgânico (Seção 2.1.2.1). 
Para determinarmos a razão enantiomérica $(E)$ de cada resolução e os respectivos excessos enantioméricos (e.e.), foram realizadas as hidrólises enzimáticas em maior escala, empregando as enzimas que apresentaram atividade hidrolítica para os acetatos.

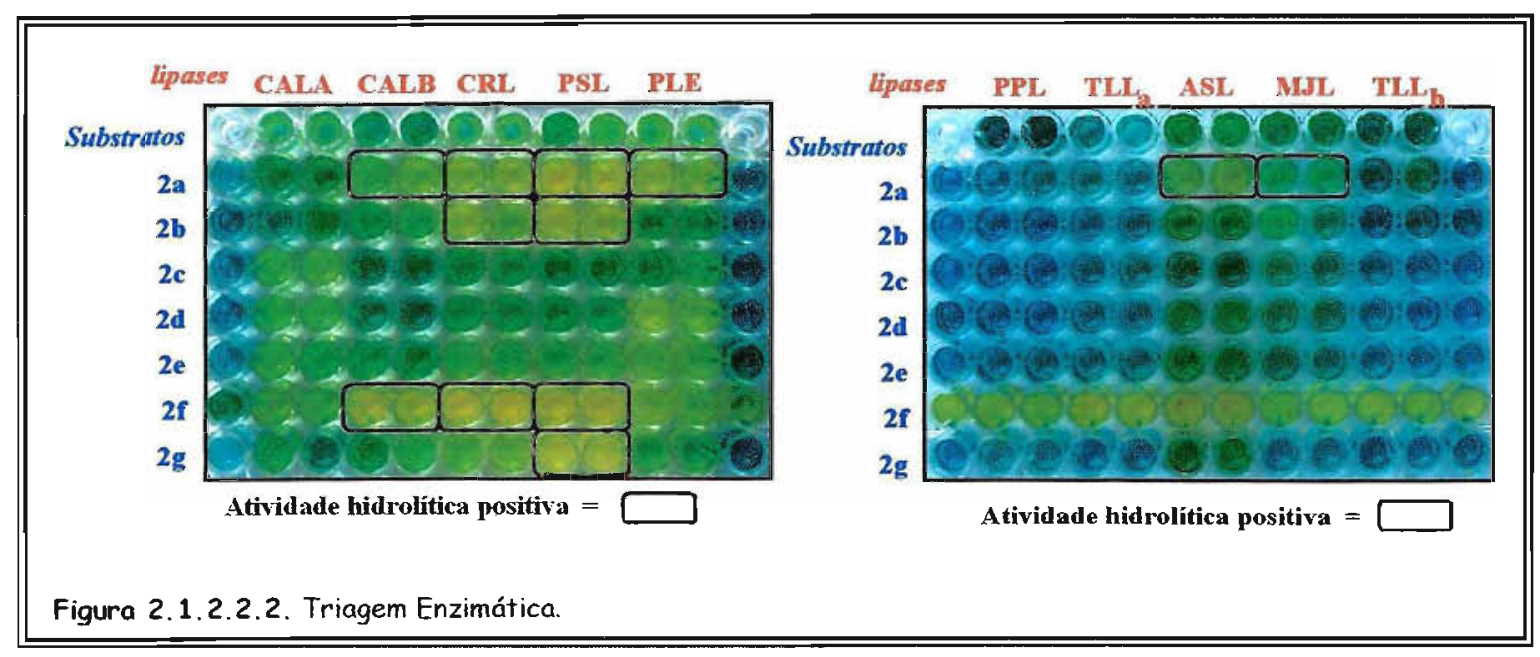

Essas reações foram realizadas em tampão fosfato $(\mathrm{pH}=7,2)$, utilizando $1 \mathrm{mmol}$ do substrato. Na tabela 2.1.2.2.1 estão reunidos os resultados obtidos com a resolução dos compostos $(R, S)-2 \mathrm{a}-\mathrm{b}$ e $(R, S)-\mathbf{2 f}-\mathrm{g}$.

Semelhante aos resultados observados na resolução dos hidróxiselenetos em meio orgânico (seção 2.1.2.1), o enantiômero- $(R)$ foi preferencialmente hidrolisado pelas enzimas, com exceção da hidrólise do $(R, S)-2 f$, na qual o enantiômero-(S) foi preferencialmente hidrolisado (Tabela 2.1.2.1).

A CALB (não imobilizada - Roche CO.) apresentou a melhor enantiosseletividade $(E>200)$ na hidrólise enzimática do $(R, S)-2 a$ resultando na obtenção do $(R)$-1a e (S)-2a com excesso enantiomérico igual ou superior a 99\% (Tabela 2.1.2.2.1 - entrada 1). Resultado muito semelhante ao obtido na resolução deste composto com a CALB (imobilizada - Novozym CO.) em meio orgânico. Por essa razão, optamos em realizar a resolução deste composto $[(\boldsymbol{R}, \boldsymbol{S})-2 \mathrm{a}]$ empregando a CALB imobilizada, pois o uso de enzima imobilizada aumenta a facilidade de manipulação e possibilita a reutilização da mesma, contribuindo para uma diminuição dos custos do processo. 
Tabela 2.1.2.2.1. Hidrólise enzimática a dos acetatos.

\begin{tabular}{|c|c|c|c|c|c|c|c|c|}
\hline Entrada & Substrato & lipase & $\begin{array}{c}\text { Tempo / } \\
\text { horas }\end{array}$ & $\begin{array}{c}\text { Conv. I } \\
\%\end{array}$ & $\begin{array}{c}\text { e.e. do } \\
\text { acetato /\% }\end{array}$ & $\begin{array}{c}\text { e.e. do } \\
\text { álcool } / \%\end{array}$ & $\begin{array}{l}\text { Config. } \\
\text { Absoluta }\end{array}$ & $E^{\mathrm{e}}$ \\
\hline 1 & $(R, S)-2 \mathrm{a}$ & CALB & 96 & 50 & 99 & $>99$ & $(S)$ & $>200$ \\
\hline 2 & & CRL & 96 & 47 & 24 & 27 & $(\boldsymbol{S})$ & 2.2 \\
\hline 3 & & PSL & 12 & 83 & 98 & 20 & $(S)$ & 5.2 \\
\hline 4 & & PLE & 48 & 42 & 28 & 39 & $(S)$ & 3 \\
\hline 5 & & ASL & 12 & 30 & 40 & 92 & $(S)$ & 35 \\
\hline 6 & & MЛ & 96 & 26 & 23 & 66 & $(S)$ & 6,1 \\
\hline 7 & & $\begin{array}{c}\text { CALB } \\
\text { imobilizada }\end{array}$ & 24 & 45 & 95 & $>99$ & $(S)$ & $>200$ \\
\hline 8 & $(R, S)-2 \mathbf{b}$ & CRL & 48 & 13 & 2 & 13 & $(S)$ & 1,3 \\
\hline 9 & & PSL & 12 & 36 & 25 & 45 & $(\boldsymbol{S})$ & 3,3 \\
\hline 10 & $(R, S)-2 \mathrm{f}$ & CALB & 213 & 87 & 20 & 3 & $(R)$ & 1.2 \\
\hline 11 & & CRL & 350 & 91 & 32 & 3 & $(R)$ & 1.3 \\
\hline 12 & & PSL & 144 & 55 & 93 & 75 & $(R)$ & 23 \\
\hline 13 & $(R, S)-2 \mathrm{~g}$ & PSL & 12 & 44 & 17 & 22 & $(S)$ & 1.8 \\
\hline
\end{tabular}

a As reaçōes foram realizadas utilizando $1 \mathrm{mmol}$ do substrato e $10 \mathrm{mg}$ da CALB (livre), $10 \mathrm{mg}$ da CRL, $50 \mathrm{mg}$ da PSL, $10 \mathrm{mg}$ da PLE, $100 \mathrm{mg}$ da ASL, $50 \mathrm{mg}$ da MJL e $10 \mathrm{mg}$ da CALB (imobilizada) em tampão $(10 \mathrm{~mL}-\mathrm{pH}=7,2)$ à $25^{\circ} \mathrm{C}$. ${ }^{b}$ Excesso enantiomérico do acetato 2. ${ }^{\circ}$ Excesso enantiomérico do álcool 1. ${ }^{d}$ Configuração absoluta do acetato 2. ${ }^{e}$ Razão enantiomérica: este parâmetro descreve a enantiosseletividade da enzima.

Neste caso, o uso da enzima imobilizada em meio aquoso, diminuiu o tempo da hidrólise, mantendo a alta enantiosseletividade enzimática observada com a enzima livre (Tabela 2.1.2.2.1 - entradas 1 e 7), demonstrando a versatilidade do uso de enzimas imobilizadas em processos biocatáliticos.

Para o substrato $(\boldsymbol{R}, \mathbf{S})-\mathbf{2 b}$ a maior enantiosseletividade $(E=3,3$ ) foi observada com a PSL (Tabela 2.1.2.2.1 - entrada 8), entretanto com excessos enantioméricos inferiores aos observados com a CALB (imobilizada) em meio orgânico (Seção 2.1.2.1)

No caso do acetato $(\boldsymbol{R}, \boldsymbol{S})-\mathbf{2 f}$ a $\mathrm{PSL}$ apresentou uma razão enantiomérica ( $E=23$ ) melhor que a observada na transesterificação em meio orgânico com a CALB (Seção 2.1.2.1), possibilitando obter o (R)-2f com excesso enantiomérico igual a 93\% e o (S)-1f com excesso enantiomérico igual a $75 \%$ (Tabela 2.1.2.2.1 - entrada 11). Para a reação com o composto $(\boldsymbol{R}, \boldsymbol{S})$ $\mathbf{2 g}$ apenas a PSL apresentou atividade hidrolítica, entretanto com baixa 
enantiosseletividade $(E=1,8)$, gerando compostos com baixos excessos enantioméricos (Tabela 2.1.2.2.1 - entrada 12).

Analisando os resultados obtidos na hidrólise dos seleno-acetatos, podemos observar a semelhança na resolução dos respectivos hidróxiselenetos em meio orgânico, principalmente com relação ao volume dos substituintes e a enantiosseletividade enzimática. Esse resultado evidênciou que a estrutura do seleno-acetato foi um fator importante para uma boa resolução do mesmo empregando enzimas hidrolíticas.

\subsubsection{Biotransformações Utilizando Células Inteiras de Fungos}

Em experimentos anteriormente realizados em nosso laboratório utilizando células inteiras de fungos (Aspergillus terreus), foi observado que as mesmas são capazes de catalisar a desracemização de alguns álcoois secundários (Esquema 2.1.2.3.1).

Esses resultados incentivaram a realização de experimentos com os hidróxi-selenetos, pois na resolução o rendimento máximo é de $50 \%$, enquanto que na desracemização (ou

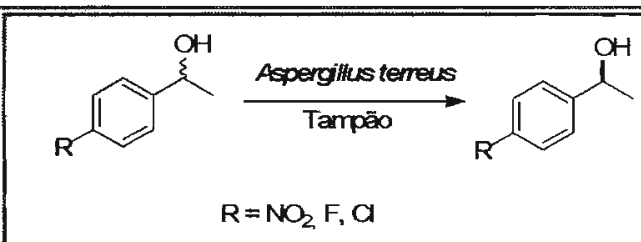

Esquema 2.1.2.3.1. Desracemização utilizando célula inteira de Aspergillus terreus. resolução dinâmica) o rendimento pode chegar a 100\%. Além disso, o uso de fungos poderia permitir a desracemização de alguns compostos que não haviam sido produzidos em excessos enantioméricos satisfatórios quando utilizamos enzimas isoladas.

Uma proposta para o processo de desracemização (ou resolução dinâmica) empregando fungos consiste em duas reações redox catalisadas por enzimas, sendo a primeira reação uma oxidação reversível seguida de uma redução irreversível, gerando apenas um dos enantiômeros (Esquema

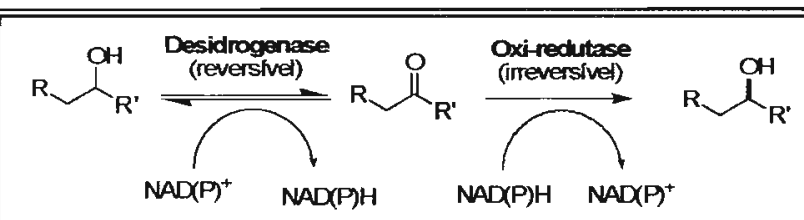

Esquema 2.1.2.3.2. Desracemização utilizando Fungos.
2.1.2.3.2)

Foram empregadas duas linhagens de fungos Aspergillus terreus (URM 3571 e CCT 3320) na desracemização dos hidróxi- 
selenetos $(R, S)-1$ a-c e $(R, S)-1$ e (Figura 2.1.2.3.1).

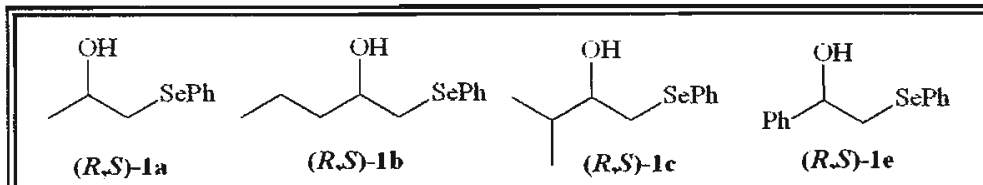

Figura 2.1.2.3.1. Hidróxi-selenetos utilizados.
Nos primeiros testes, foram observados excessos enantioméricos maiores que $99 \%$ na biotransformação do

hidróxi-seleneto $(\boldsymbol{R}, \boldsymbol{S})$-1a utilizando cepas de Aspergillus terreus URM 3571. Os hidróxi-selenetos $(R, S)$-1b-c também foram obtidos com bons excessos enantioméricos (e.e. > 95\%). Um resultado interessante foi a biotransformação do composto $(\boldsymbol{R}, \boldsymbol{S})-1 \mathrm{e}$, pois este não havia sido biotransformado em reações empregando enzimas isoladas (seção 2.1.2.1 e 2.1.2.2).

Entretanto, analisando com mais cuidado os resultados das biotransformações empregando fungos, foi observada a presença de um novo composto: o seleneto de fenil-metila (3) (Tabela 2.1.2.3.1 e Esquema 2.1.2.3.3).

Realizando a biotransformação do hidróxi-seleneto $(R, S)-1$ a em escala maior, foi obtido o hidróxi-seleneto quiral em $50 \%$ de rendimento (e.e.>99\%) e o seleneto de fenil-metila (3) em $40 \%$ de rendimento (Tabela 2.1.2.3.1 entrada 3). Ao empregarmos uma quantidade maior de células (ou um maior tempo de reação) a quantidade de seleneto de fenil-metila aumentou (Tabela 2.1.2.3.1).

Com base nos resultados observados, verificamos que a biotransformação de hidróxi-selenetos empregando fungos não consistia em uma reação de desracemização, como imaginado inicialmente, e sim em uma

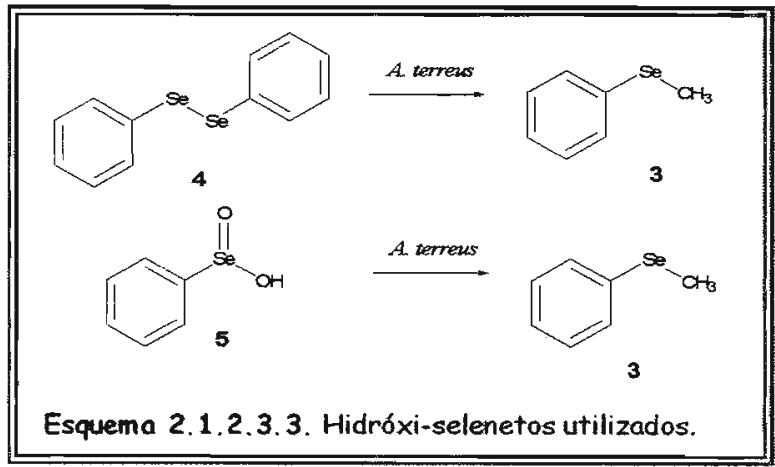
oxidação enantiosseletiva, seguida de uma biometilação, gerando o seleneto de fenil-metila.

Para avaliar a capacidade das cepas de Aspergillus terreus em biometilar organoselenetos, realizamos a biotransformação de outros organoselenetos: difenil disseleneto (4) e o ácido selenínico (5) (Esquema 2.1.2.3.3). Novamente, em ambas as reações, o seleneto de fenil- 
metila (3) foi observado como produto principal da biotransformação, comprovando a capacidade das cepas de Aspergillus terreus em biometilar organosselenetos.

Tabela 2.1.2.3.1. Biotransformações dos hidróxi-selenetos com fungosa ${ }^{a}$.

\begin{tabular}{|c|c|c|c|c|c|c|c|c|c|}
\hline \multirow{2}{*}{ Entrada } & \multirow{2}{*}{ Substrato } & \multirow{2}{*}{$\begin{array}{l}\text { Tempo } \\
\text { / dias }\end{array}$} & \multirow{2}{*}{$\begin{array}{l}\text { Massa de } \\
\text { células / g }\end{array}$} & \multicolumn{2}{|c|}{ A. terreus URM 3571} & \multicolumn{2}{|c|}{ A. terreus CCT 3320} & \multicolumn{2}{|c|}{ Rendimento } \\
\hline & & & & e.e.1/\% & $3 / \%$ & e.e.1 / \% & $3 / \%$ & $1 / \%$ & $3 / \%$ \\
\hline 1 & $(R, S)-1 \mathrm{a}$ & 5 & 1 & $>99$ & 2 & 31 & 2 & --- & --- \\
\hline 2 & & 5 & 3 & 0 & 100 & 98 & 51 & --- & --- \\
\hline 3 & $(R, S)-1 \mathrm{a}^{\#}$ & 6 & 5 & $>99$ & -- & -- & -- & 50 & 40 \\
\hline 4 & $(R, S)-1 \mathrm{~b}$ & 14 & 1 & 30 & 16 & 98 & 18 & -- & --- \\
\hline 5 & & 14 & 3 & 95 & 13 & 0 & 100 & -- & --- \\
\hline 6 & $(R, S)-1 \mathrm{c}$ & 5 & 1 & 1 & 10 & 12 & 20 & -- & --- \\
\hline 7 & & 14 & 5 & 1 & 18 & 95 & 14 & --- & --- \\
\hline 8 & $(R, S)-1 \mathrm{e}$ & 7 & 2 & 24 & 20 & -- & - & --- & --- \\
\hline 9 & & 14 & 2 & 0 & 100 & --- & --- & --- & --. \\
\hline
\end{tabular}

${ }^{a}$ As reações foram realizadas utilizando $20 \mu \mathrm{L}$ do substrato em tampão $(\mathrm{pH}=7,2)$ à $25^{\circ} \mathrm{C}$.

"Foi utilizado $100 \mu \mathrm{L}$ do substrato

Uma peculiaridade da química de compostos orgânicos de selênio é a fácil oxidação de selenetos a selenóxidos (Seção 1.3). Estes, devido à baixa estabilidade sofrem reação de eliminação, gerando alcenos espontaneamente. ${ }^{38}$ Assim, o mecanismo deste processo de biometilação provavelmente envolve a oxidação do seleneto a selenóxido, seguida de uma eliminação. ${ }^{53} \mathrm{~A}$ biometilação pode ocorrer no produto de eliminação (ácido selenenico) ou ocorrer uma nova oxidação (ácido selenínico) e depois a

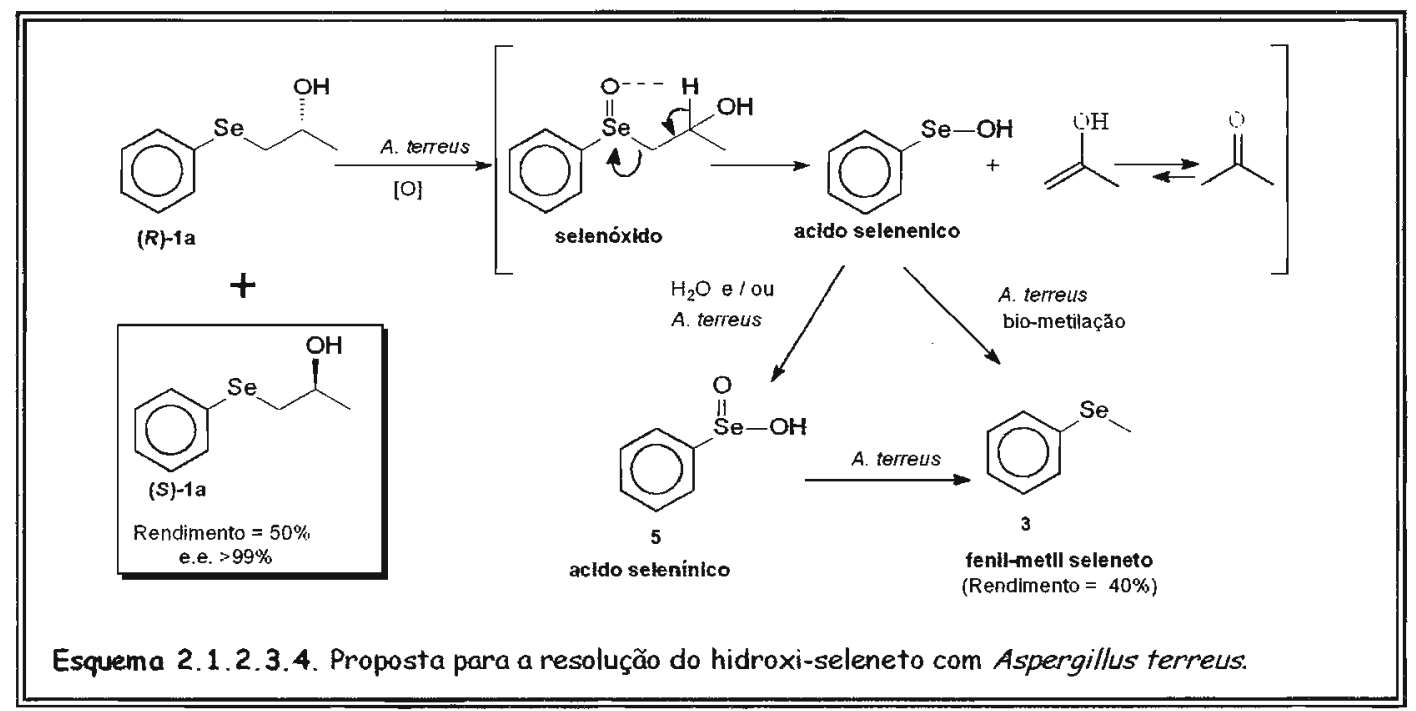


biometilação (Esquema 2.1.3.3.4). No caso dos $\beta$-hidróxi-selenetos, ocorre uma oxidação enantiosseletiva, sendo que um dos enantiômeros é oxidado preferencialmente e em seguida é biometilado, gerando o seleneto de fenilmetila, enquanto que o outro enantiômero é preservado (Esquema 2.1.2.3.4).

Este é o primeiro relato de biometilação envolvendo organo-selenetos e células inteiras de fungos.

\subsubsection{Aplicação Sintética}

Apesar do trabalho desenvolvido ser de cunho metodológico, consideramos relevante sua aplicação sintética. Nesse sentido e em conjunto com os objetivos iniciais do trabalho (aliar a química de selênio com a biocatálise), escolhemos a reação de eliminação de selenóxidos na preparação de álcoois alílicos para exemplificar o potencial de nossa metodologia.

Para isso foi utilizado o hidróxi-seleneto $1 \mathrm{~h}$ obtido pela resolução da sua mistura racêmica empregando CALB em hexano seco (Seção 2.1.2.1 Esquema 2.1.2.1.3).

A reação de eliminação de selenóxidos em hidróxi-selenetos é estéreo seletiva, levando a formação apenas da olefina de configuração " $E$ " ${ }^{38}$ Essa reação também não interfere no centro estereogênico, mantendo-se a

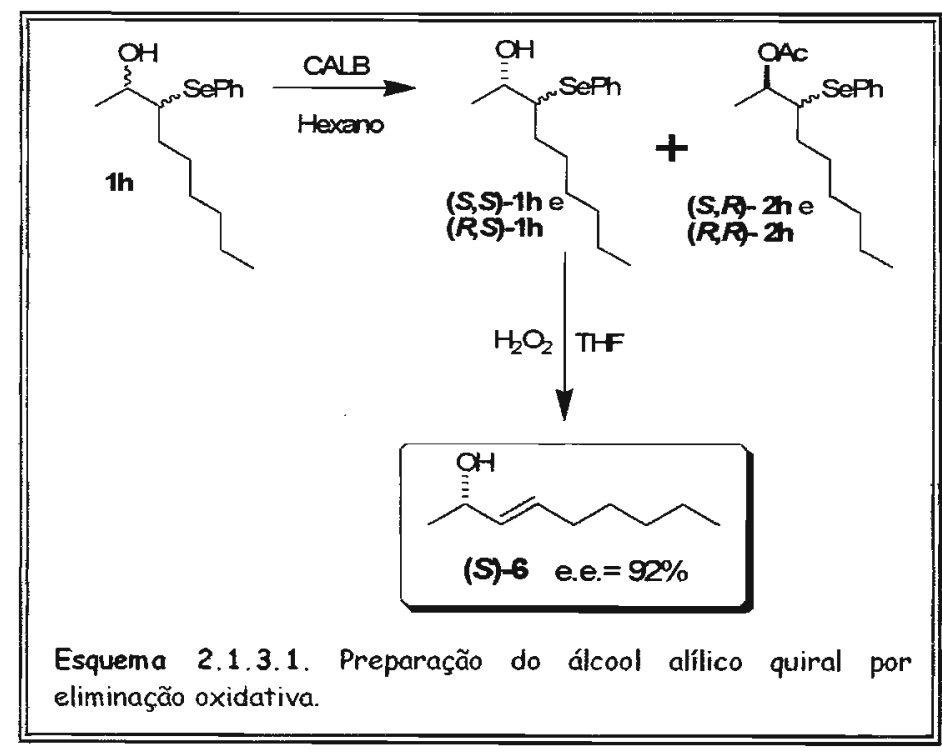

configuração original.

Assim, a preparação do álcool alílico a partir do hidróxiseleneto $1 \mathrm{~h}$ utilizando esta reação gerou apenas o álcool alílico de configuração $E,(S)-6$, com total integridade do centro estereogênico (Esquema 2.1.3.1). 


\subsubsection{Determinação da Pureza Óptica/Estereoquímica}

Em estudos relacionados a enantiômeros, a espectroscopia aliada a outras técnicas análiticas são fundamentais para a determinação da especificidade dos procedimentos utilizados e de suas eficiências. Assim, as técnicas analíticas para determinação de excessos enantioméricos e determinação de configuração absoluta foram essenciais para a condução do trabalho realizado.

\subsubsection{Determinação de Excesso Enantiomérico}

Os excessos enantioméricos (e.e.) dos álcoois 1a-i e dos ésteres 2a-i foram calculados a partir de cromatogramas obtidos em cromatografo a gás equipado com coluna com fase estacionária quiral (CG-Quiral). As análises foram conduzidas comparando os cromatogramas obtidos com cromatogramas de amostras racêmicas (Figura 2.1.4.1).

Para os compostos 1g-i e 2c-í, análises diretas em CG-Quiral não foram possiveis, pois não foi obtida a perfeita discriminação dos enantiômeros destes compostos via CG-Quiral. Nesse sentido, o composto $1 \mathrm{~g}$ foi transformado no hidróxi-

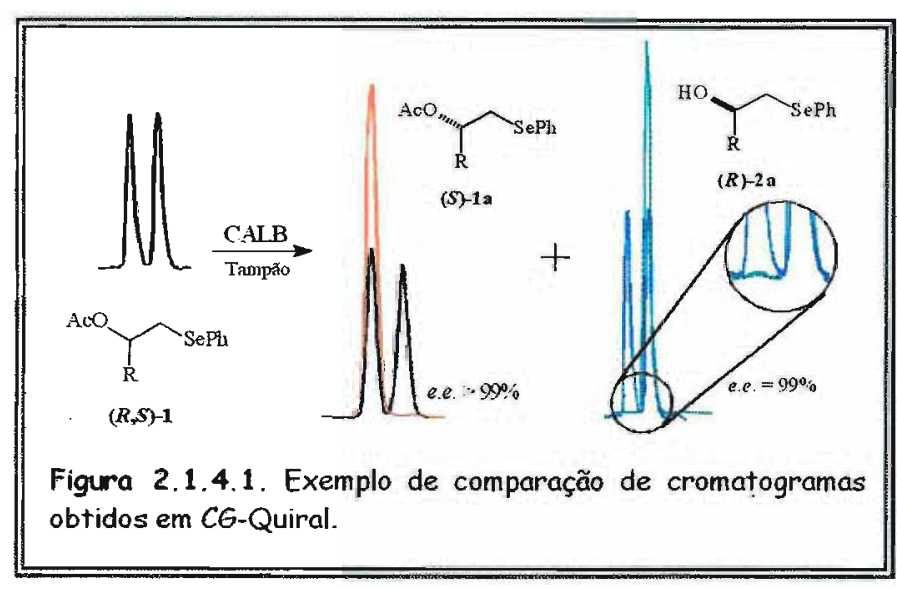
selento 1a através da reação de deselenização redutiva, ${ }^{54}$ a qual não interfere no centro assimétrico, permitindo desta forma a determinação indireta do excesso enantiomérico do composto $\mathbf{1 g}$ (Esquema 2.1.4.1.1).

O hidróxi-seleneto $\mathbf{1 h}$ foi submetido à reação de eliminação de selenóxido gerando o álcool alílico 6, possibilitando assim a determinação do excesso enaniomérico relativo ao carbono carbinólico via CG-Quiral, pois tal reação não modifica a configuração do carbono carbinólico (Seção 2.1.3 Esquema 2.1.4.1.1). ${ }^{38}$ 
De forma similar, o hidróxi-seleneto 1i foi transformado no álcool correspondente 7, pela deselenização redutiva com $n-\mathrm{Bu}_{3} \mathrm{SnH}$ (Esquema 2.1.4.1.1). ${ }^{54}$ Os enantiômeros do composto 7 foram facilmente discriminados utilizando CG-Quiral.

Os ésteres 2c-2i foram hidrolisados, gerando seus respectivos hidroxiselenetos e em seguida submetidos aos procedimentos realizados para determinar os excessos enantioméricos dos respectivos álcoois (Esquema 2.1.4.1).

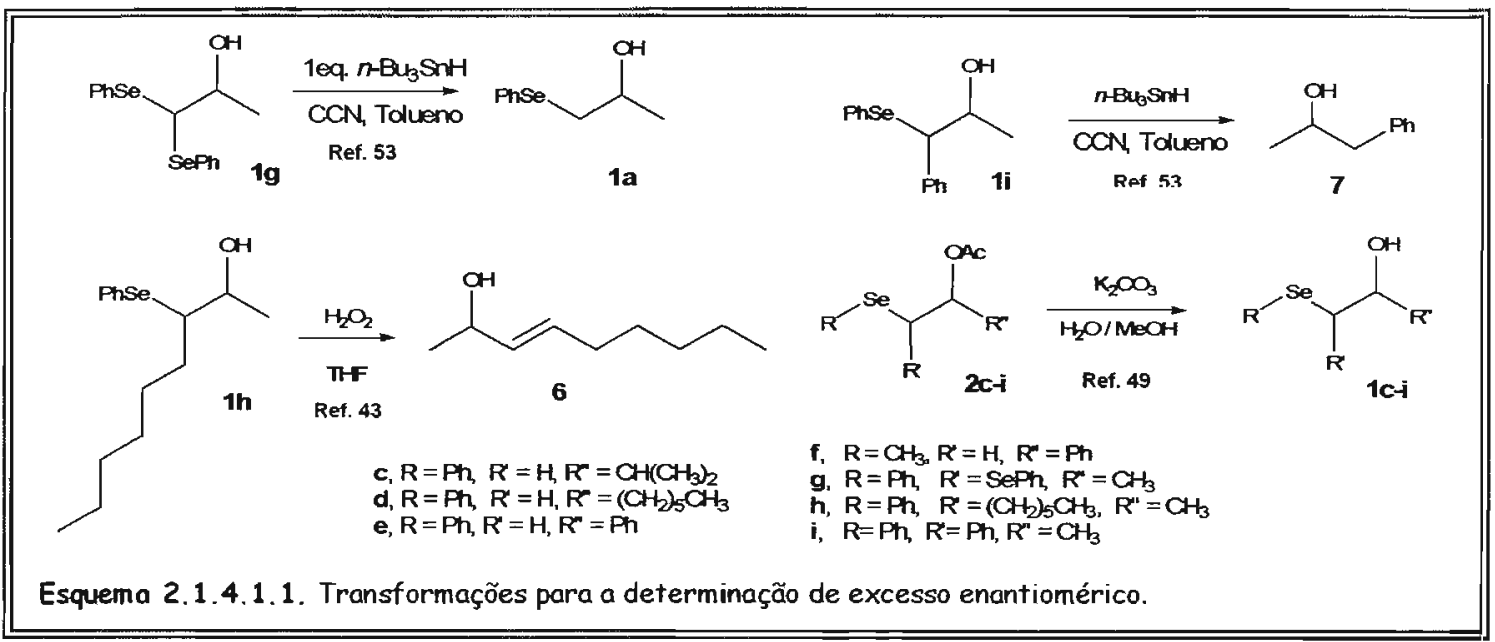

\subsubsection{Determinação de Configuração Absoluta}

A configuração absoluta do hidróxi-seleneto 1a foi determinada por espectroscopia de ressonância magnética nuclear (RMN). O enantiômero do composto 1a (e.e. > 99\%) não acetilado pela lipase foi derivatizado separadamente com os dois enantiômeros do cloreto de $\alpha$-metoxi- $\alpha$ trifluormetil-fenilacetila (MTPA-CI).

$\mathrm{O}$ espectro de ${ }^{1} \mathrm{H}-\mathrm{RMN}$ dos derivados diastereoisômericos formados apresentam deslocamentos químicos diferentes. De acordo com o modelo de Mosher, ${ }^{55}$ as diferenças de deslocamento químico nos espectros de ${ }^{1} \mathrm{H}-\mathrm{RMN}$ dos substituintes ligado ao carbono carbinólico dos diastereoisômeros são originadas pelo efeito anisotrópico do anel aromático em uma conformação preferencial. Este efeito permite determinar a posição dos substituintes ligados ao carbono carbinólico, pois o cone de proteção do anel benzênico (resultado 
do campo magnético gerado pelo movimento dos elétrons da nuvem $\pi$ do anel benzênico) blinda diferentes ligantes em cada diastereoisômero.

Assim, imaginado que o hidróxi-seleneto 1a não acetilado pela lipase tenha a configuração $(S)$, a derivatização gerou os estereoisômeros de configuração $(R, S)-8$ e $(S, S)-8$. No estereoisômero $(R, S)-8$ o cone de proteção irá blindar o substituinte $-\mathrm{CH}_{2} \mathrm{SePh}$, enquanto que no estereoisômero $(\mathrm{S}, \mathrm{S})$-8 o cone de proteção irá blindar o substituinte $-\mathrm{CH}_{3}$ (Figura 2.1.4.2.1). Como resultado, os deslocamentos químicos no espectro de ${ }^{1} \mathrm{H}-\mathrm{RMN}$ do substituinte $-\mathrm{CH}_{2} \mathrm{SePh}$ no estereoisômero $(\boldsymbol{R}, \boldsymbol{S})$-8 deverá cair em campo mais alto que no espectro do estereoisômero $(\mathbf{S}, \mathbf{S})-\mathbf{8}$. Por outro lado, o deslocamento químico no espectro de ${ }^{1} \mathrm{H}$-RMN do substituinte $-\mathrm{CH}_{3}$ no estereoisômero $(\boldsymbol{R}, \mathbf{S})-\mathbf{8}$ deverá cair em campo mais baixo que no estereoisômero $(\mathbf{S}, \mathbf{S})-8$.

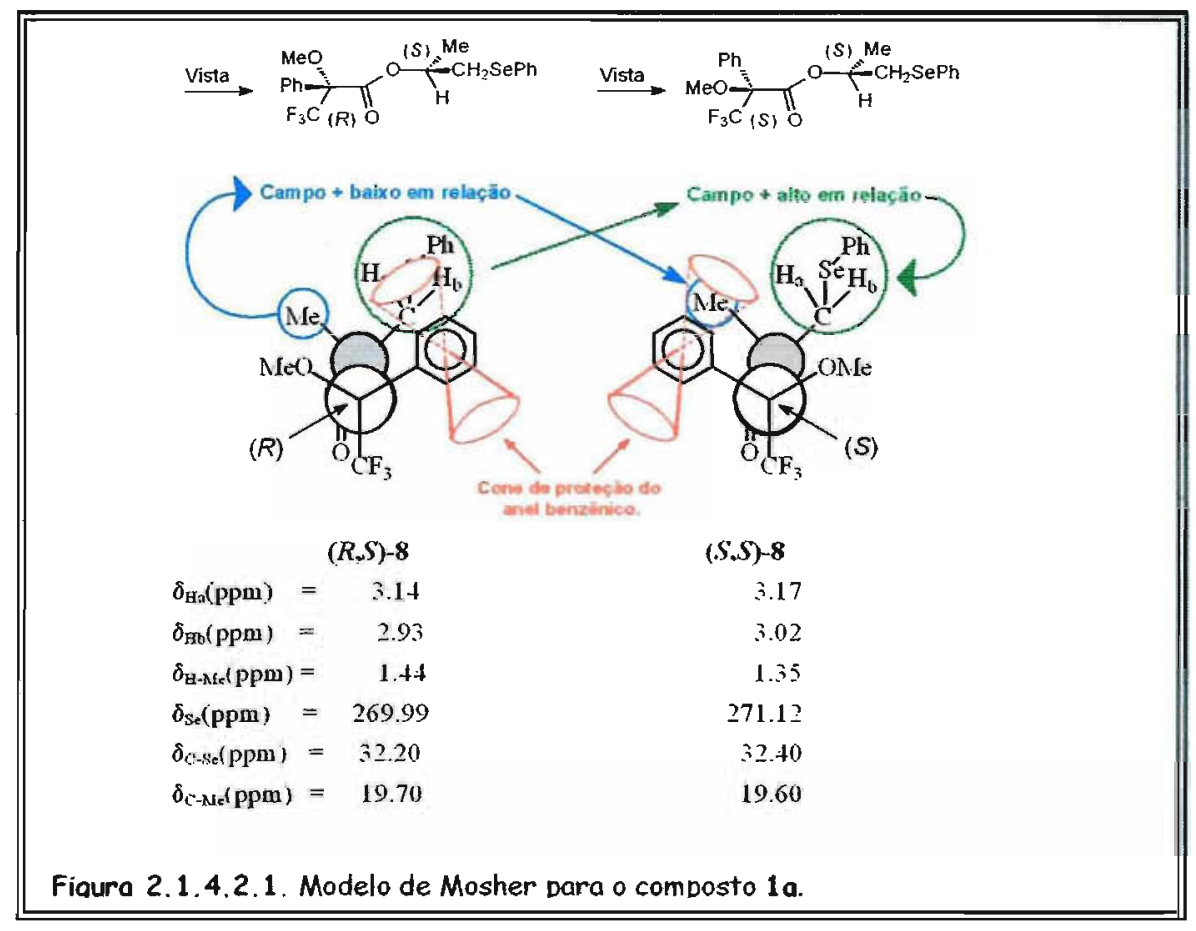

Analizando o espectro de ${ }^{1} \mathrm{H}-\mathrm{RMN}$ dos estereoisômeros obtidos, podemos observar exatamente o padrão de deslocamento químico descrito anteriormente, (Figura 2.1.4.2.1), confirmando a configuração absoluta do nosso hidroxi-seleneto 1 a não acetilado pela lipase como sendo (S).

Os espectros de ${ }^{13} \mathrm{C}-\mathrm{RMN}$ e ${ }^{77} \mathrm{Se}-\mathrm{RMN}$ apresentaram a mesma tendência em seus deslocamentos químicos, confirmando o efeito anisotrópico 
do anel benzênico sobre os substituintes ligados ao carbono carbinólico e a configuração absoluta determinada (Figura 2.1.4.2.1).

A configuração absoluta dos hidróxi-selenetos $\mathbf{1 b}, \mathbf{1 d}$ e $\mathbf{1 f}$ foi determinada de maneira indireta, comparando-se as rotações ópticas $\left\{[\alpha]_{D}\right\}$ dos seus derivados sem o grupo selanila, com os valores da literatura para os mesmos compostos. ${ }^{56,57}$ Para isso, os compostos $\mathbf{1 b}, \mathbf{1 d}$ e $\mathbf{1 f}$ foram derivatizados via reação de deselenização redutiva usando $n$-Bur $\mathrm{SnH}$

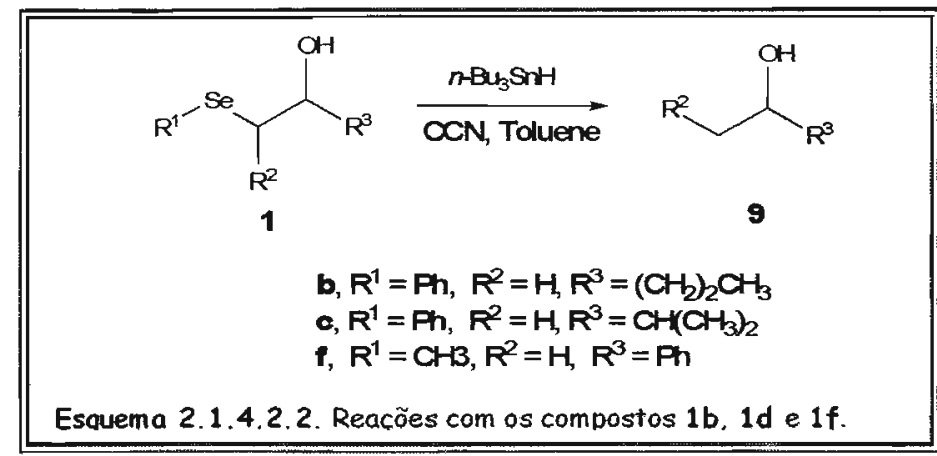

o enantiômero- $(R) .{ }^{58}$
(Esquema 2.1.4.2.2).

A configuração absoluta do composto 1 fifoi determinada diretamente pela comparação da sua rotação óptica com a publicada na literatura para

Para a determinação da configuração absoluta do composto $\mathbf{1 g}$ fol necessário transformá-lo no composto $1 \mathrm{a}$, via reação de deselenização redutiva (Esquema 2.1.4.1.1). Assim sua configuração absoluta foi determinada pela comparação das rotações ópticas dos compostos

A determinação da configuração absoluta dos dois centros estereogênicos dos compostos $1 \mathrm{~h}$ e $1 \mathrm{i}$ não foi realizada, sendo determinada apenas a configuração do centro estereogênico localizado no carbono carbinólico. Assim os compostos 1h e 1i foram transformados em seus respectivos álcoois sem o grupo selanila, conforme realizado na determinação dos excessos enantioméricos (Seção 2.1.4.1 - Esquema 2.1.4.1), e a rotação óptica dos mesmos foram comparadas com os valores descritos na literatura. 58,59 
2.2. Hidróxi-Teluretos 



\subsubsection{Síntese Racêmica}

Partindo dos resultados obtidos com as biotransformações dos hidróxiselenetos (Seção 2.1.2), foram sintetizados alguns hidróxi-teluretos com estruturas particulamente selecionadas para o estudo das biotransformações destes compostos (Figura 2.2.1.1).<smiles>CC(O)C[Te]c1ccccc1</smiles>

$(R, S)$-10;<smiles>CCCC(O)C[TeH2]</smiles>

$(R, S)-10 b$

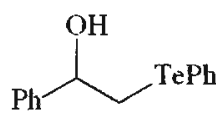

$(R, S)-10 \mathrm{c}$<smiles>C[C]CC(O)c1ccccc1</smiles>

$(R, S)-10 d$<smiles>CCCC[Te]CCC(C)O</smiles>

$(R, S)-10 \mathrm{e}$

$(R, S)-10 \mathrm{f}$<smiles>CCCC[Te]/C=C\C(C)O</smiles>

$(R, S)-10 \mathrm{~g}$

Figura 2.2.1.1. Hidróxi-teluretos sintetizados.

De maneira análoga à reação do disseleneto de difenila com $\mathrm{NaBH}_{4}$ (Seção 2.1.1), a reação de ditelureto de difenila com $\mathrm{NaBH}_{4}$ gera o feniltelurolato in situ, ${ }^{60}$ que reage prontamente com óxido de propileno produzindo o composto $(\boldsymbol{R}, \mathbf{S})-\mathbf{1 0 a}$ (Esquema 2.2.1.1). ${ }^{54}$ Diferentemente da reação do fenilselenolato com óxido de estireno, que gera dois régio-isômeros (Seção 2.1.1.), a reação do feniltelurolato com óxido de estireno produz apenas um régio-isômero: o hidróxi-telureto $(R, S)-10 \mathrm{c}$ (Esquema 2.2.1.1). ${ }^{54}$

Os hidróxi-teluretos $(\boldsymbol{R}, S)$-10d e $(\boldsymbol{R}, S)-10 \mathrm{e}$ foram preparados pela reação do alquil telurolato de lítio apropriado, obtido via reação de alquil lítio com telúrio elementar em THF seco, ${ }^{61}$ com óxido de estireno e óxido de propileno respectivamente (Esquema 2.2.1.1). ${ }^{54}$

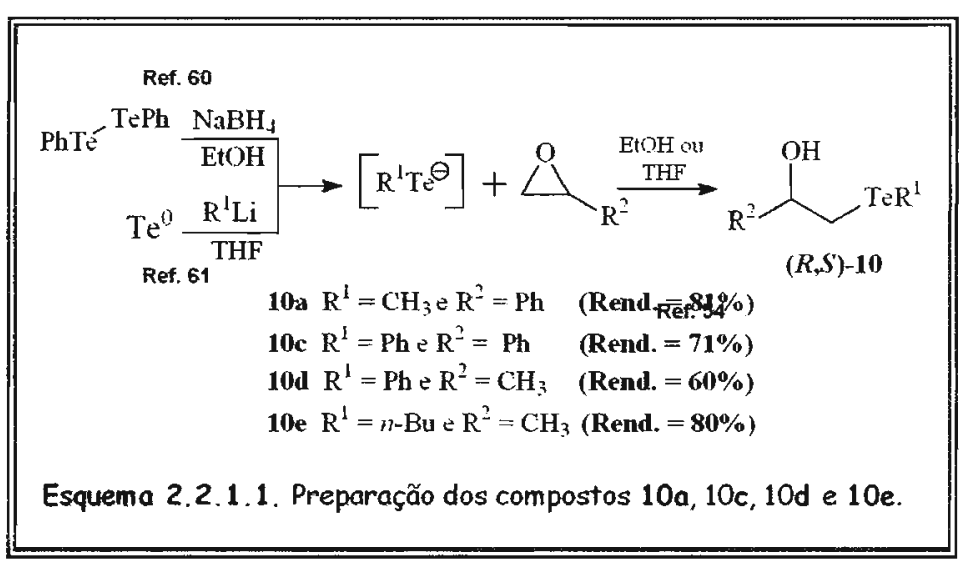

O Telureto $(R, S)-10 b$ foi preparado pela reação de troca telúrio/lítio do bis(fenilteluro)metano com $n$-Buli, gerando o fenilteluro-metil lítio in situ, o qual 
se adiciona à carbonila do butanal (Esquema 2.2.1.2). ${ }^{62} \mathrm{O}$ bis(fenilteluro)metano foi preparado a partir da adição de diazometano $\left(\mathrm{CH}_{2} \mathrm{~N}_{2}\right)$ sobre solução de ditelureto de difenila em éter etílico (Esquema 2.2.1.2). ${ }^{63}$

O hidróxi-

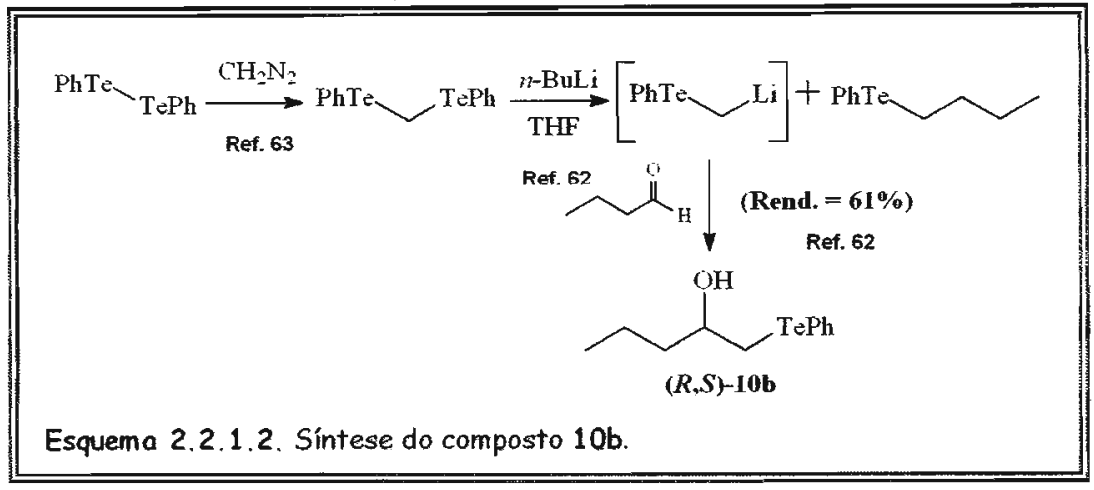

telureto $\quad(R, S)-10 f$ foi preparado através da reação de adição 1,4 do $n$ Butil-telurol à metil vinil cetona, seguida de redução da carbonila com $\mathrm{NaBH}_{4}{ }^{64}$ Alternativamente, o telureto $\left(\boldsymbol{R}_{3} \mathbf{S}\right)-10$ foi obtido em $70 \%$ de rendimento isolado através de reações seqüênciais one-pot (adição 1,4 seguida de redução - Esquema 2.2.1.3). ${ }^{65}$

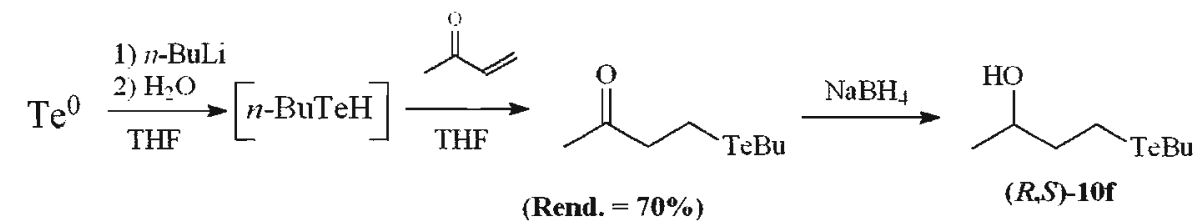

Esquema 2.2.1.3. Obtenção do hidróxi-telureto $(R, S)-10 f$.

Ref. 63 e 64

A hidroteluração direta de álcoois propargílicos produz uma mistura de dois teluretos vinílicos (Esquema 2.2.1.4), ${ }^{66}$ os quais possuem uma polaridade muito próxima, o que dificulta sua separação e conseqüentemente prejudica os rendimentos, inviabilizando a obtenção de álcoois alílicos $\gamma$-butiltelurados, como o composto $(R, S)-10 \mathrm{~g}$. Por outro lado, a hidroteluração de alquinonas produz

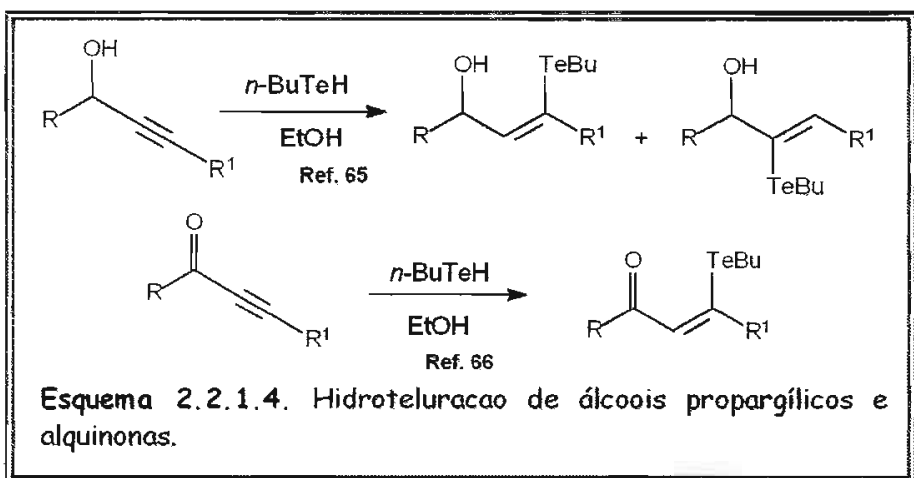

apenas um regioisômero (Esquema 2.2.1.4). ${ }^{67}$ Assim, o telureto vinílico $(R, S)-10 \mathrm{~g}$ foi sintetizado por redução da (Z)- $\beta$-butilteluro-enona (12) $\operatorname{com~} \mathrm{NaBH}_{4}$ em $93 \%$ de rendimento

(Esquema 2.2.1.5) 
Apesar de encontrarmos relatos na literatura de que a redução de compostos carbonílicos $\alpha$, $\beta$-insaturados utilizando $\mathrm{NaBH}_{4}$ leva a uma mistura do álcool alílico e do álcool saturado, ${ }^{68}$ foi observado que $(Z)-\beta$ butilteluro-enonas são reduzidas seletivamente e em bons rendimentos aos álcoois alilicos correspondentes, utilizando $\mathrm{NaBH}_{4}$ ou DIBAL-H como

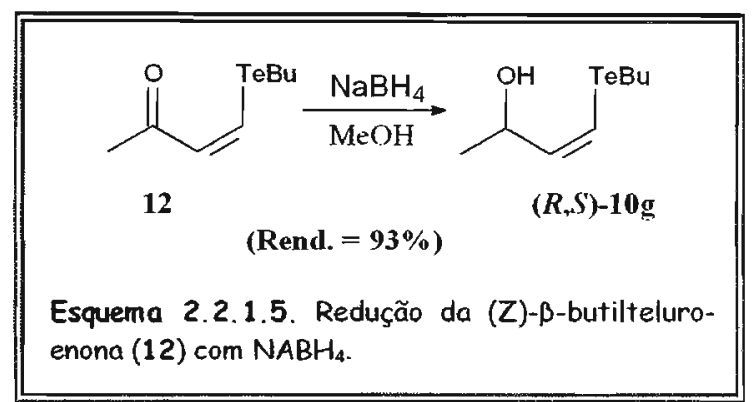
agente redutor, provavelmente devido à presença do grupo $n$-butilteluro na posição $\beta$ das enonas. ${ }^{69}$

O emprego de um procedimento seqüencial em larga escala $(0,1 \mathrm{~mol})$, utilizando um organozinco como intermediário na preparação da alquinona, possibilitou a obtenção da (Z)- $\beta$-butilteluro-enona (12) em bom rendimento (Esquema 2.2.1.6).

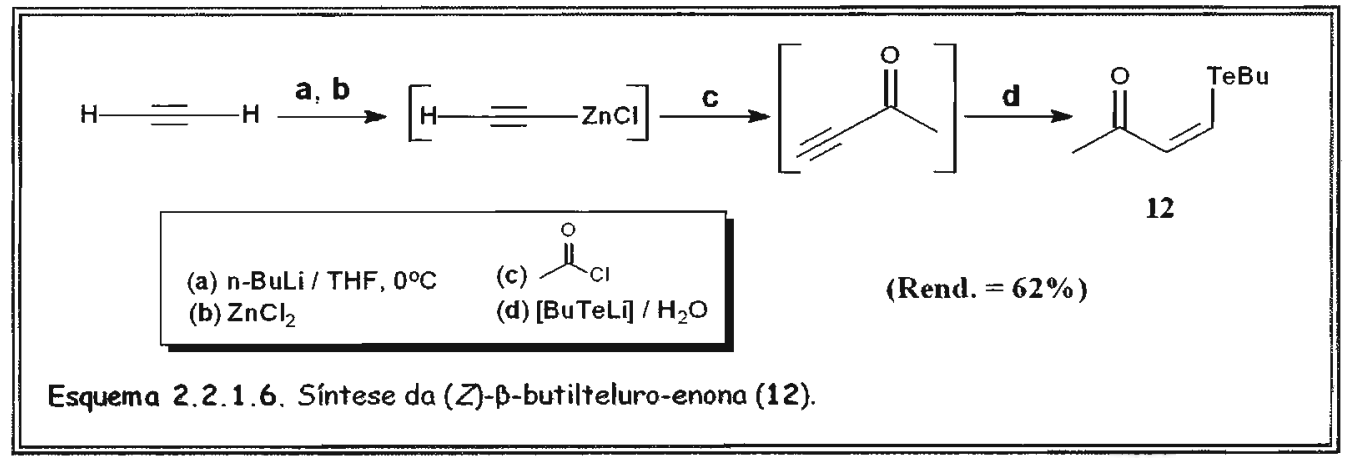

Os respectivos acetatos racêmicos dos hidróxi-teluretos $10 \mathbf{a}-\mathbf{g}$ foram sintetizados quimicamente utilizando anidrido acético em piridina seca, 49 utilizando procedimento análogo ao empregado com os hidróxi-selenetos (Seção 2.1.1). Novamente, essas reações não apresentaram maiores problemas, sendo os produtos facilmente purificados e caracterizados (Esquema 2.2.1.7). 


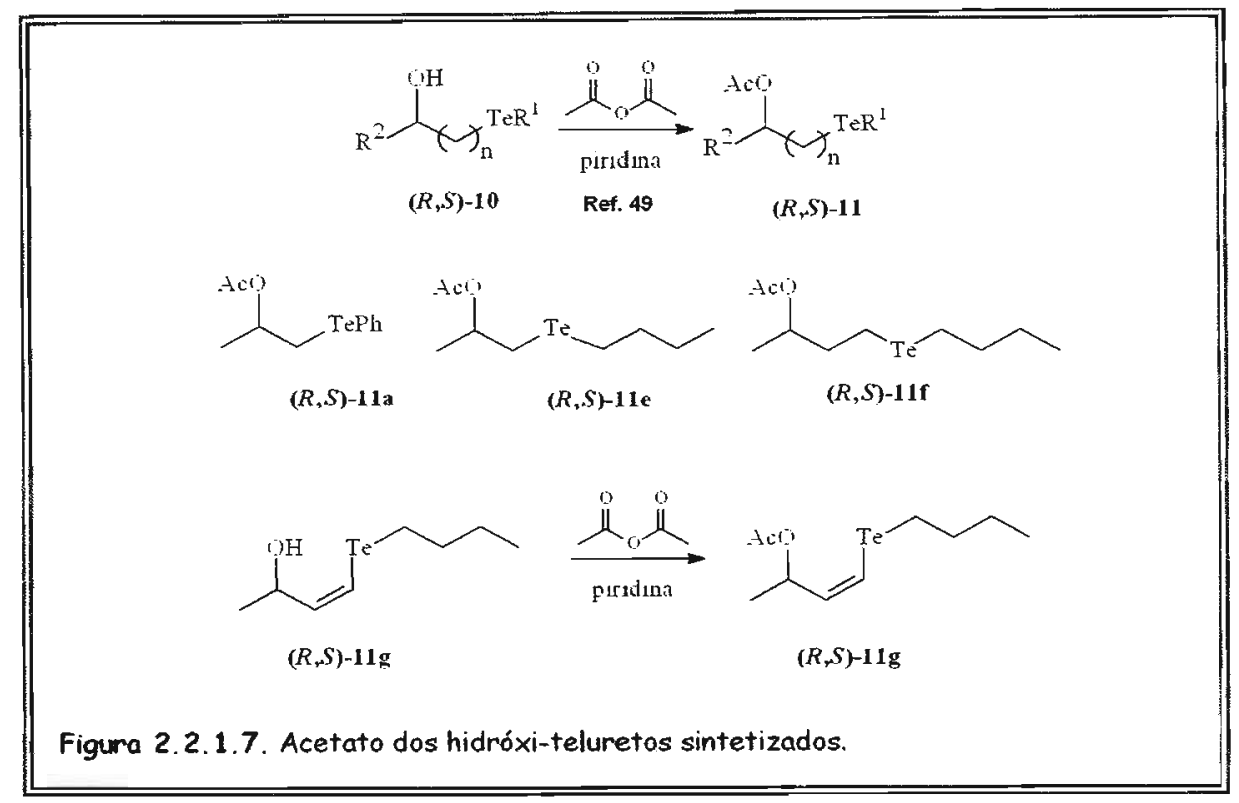

\subsubsection{Biotransformações}

\subsubsection{Resolução em Meio Orgânico}

A avaliação da enantiosseletividade enzimática nas transesterificações dos hidroxi-teluretos em meio orgânico foi realizada inicialmente utilizando o composto $(R, S)$-10a como substrato e acetato de vinila como doador do grupo acila (Esquema 2.2.2.1.1). Quatro lipases foram escolhidas como biocatalisadores: a PPL (lipase de pâncreas de porco - livre), a PSL (AMANO

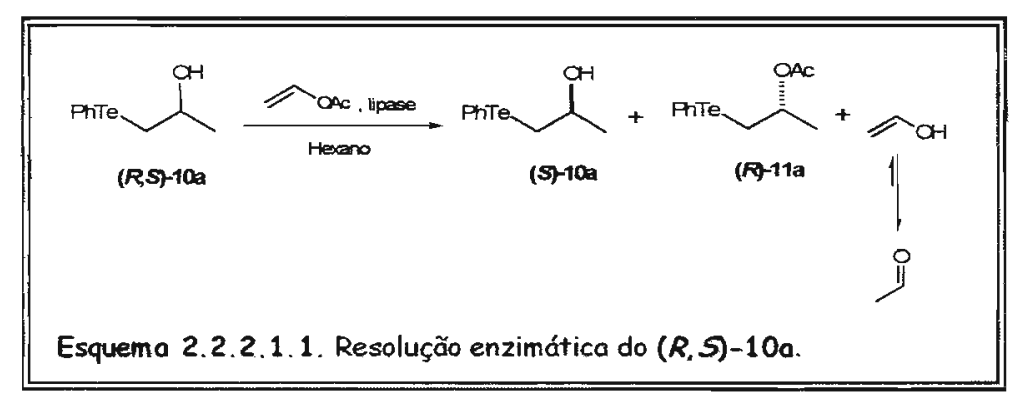
PS - lipase de Pseudomonas sp. livre), CRL (lipase de Candida rugosa - livre) e a CALB (NOVOZYM $435^{\circledast}$ - lipase de

Candida antartica - Fração B - imobilizada).

As maiores enantiosseletividades foram observadas com a PSL e a CALB (Tabela 2.2.2.1.1). Na reação com PSL foi obtido o hidróxi-telureto (S)10a com excesso enantiomérico igual a 94\% (Tabela 2.2.2.1.1 - entrada 4) e o produto $(R)$-11a com excesso enantiomérico igual a 98\% (Tabela 2.2.2.1.1 entrada 3). A melhor enantiosseletividade observada foi na resolução 
empregando a CALB como biocatalisador, onde tanto o produto [(R)-11a] como o substrato [(S)-10a], foram obtidos com excessos enantioméricos superiores a 98\% (Tabela 2.2.2.1.1 - entrada 7).

Tabela 2.2.2.1.2. Resolução enzimática ${ }^{a}$ do composto $(R, S)-10 a$ usando diferentes lipases.

\begin{tabular}{|c|c|c|c|c|c|c|c|}
\hline Entrada & Lipase & $\begin{array}{c}\text { Tempo / } \\
\text { horas }\end{array}$ & $\begin{array}{c}\text { Conversão } \\
/ \%\end{array}$ & $\begin{array}{c}\text { e.e. do }(S)- \\
10 \mathrm{a} / \%^{\mathrm{b}}\end{array}$ & $\begin{array}{l}\text { e.e. do }(R)- \\
11 \mathrm{a} / \%\end{array}$ & $\begin{array}{l}\text { Config. } \\
\text { Absoluta }\end{array}$ & $E^{\mathrm{e}}$ \\
\hline 1 & PPL & 6 & 32 & 44 & 93 & & \\
\hline 2 & & 24 & 41 & 63 & 91 & $(R)$ & 40 \\
\hline 3 & PSI & 6 & 36 & 56 & 98 & & \\
\hline 4 & & 24 & 49 & 94 & 96 & $(R)$ & 174 \\
\hline 5 & CRL & 1 & 21 & 13 & 48 & & \\
\hline 6 & & 3 & 46 & 33 & 41 & $(S)$ & 3.3 \\
\hline 7 & CALB & 2 & 50 & $>99$ & 98 & $(R)$ & $>200$ \\
\hline
\end{tabular}

${ }^{a}$ As reações foram realizadas com $0.5 \mathrm{mmol}$ do $(R, S)-10$ a e $1 \mathrm{~g}$ da PPL, $300 \mathrm{mg}$ da PSL, $75 \mathrm{mg}$ da CRL ou $30 \mathrm{mg}$ da CALB em hexano seco $(10 \mathrm{~mL}) .{ }^{b}$ Excesso enantiomérico do álcool 10a. ${ }^{c}$ Excesso enantiomérico do acetato 11a ${ }^{d}$ Configuração absoluta do acetato 11a ${ }^{e}$ Razão enantiomérica: este parâmetro descreve a enantiosseletividade da enzima.

A enantiopreferência para o enantiômero- $(R)$ foi observada nas resoluções utilizando a PPL, PSL e CALB. Entretanto, a CRL apresentou enantiopreferência para o enantiômero-(S) na resolução do hidróxi-telureto $(\boldsymbol{R}, \mathbf{S})$-10a (Tabela 2.2.2.1.1).

A partir dos resultados observados, a influência do solvente na resolução do hidróxi-telureto $(R, S)$-10a foi estudada empregando a CALB (a maior enantiosseletidade observada em hexano - Tabela 2.2.2.1.2) e a CRL (enantiopreferência inversa das demais lipases em hexano - Tabela 2.2.2.1.2). Os experimentos foram realizados a $30^{\circ} \mathrm{C}$, usando alguns solventes secos comumente empregados em estudos de resolução cinética. As conversões foram determinadas após 3 horas para os experimentos realizados com a CRL e 1 hora para os experimentos realizados com a CALB.

Em comparação a variação do solvente na resolução dos hidróxiselenetos em meio orgânico (Seção 2.1.2.1), a variação do solvente na resolução dos hidróxi-teluretos apresentou uma grande influência sobre a conversão do substrato (Figura 2.2.2.1.1), em outras palavras, sobre a atividade enzimática considerando que as demais variáveis (como tempo de 
reação, substrato, temperatura, etc.) permaneceram constantes, sendo que solventes apolares propiciaram maiores conversões (Figura 2.2.2.1.1).

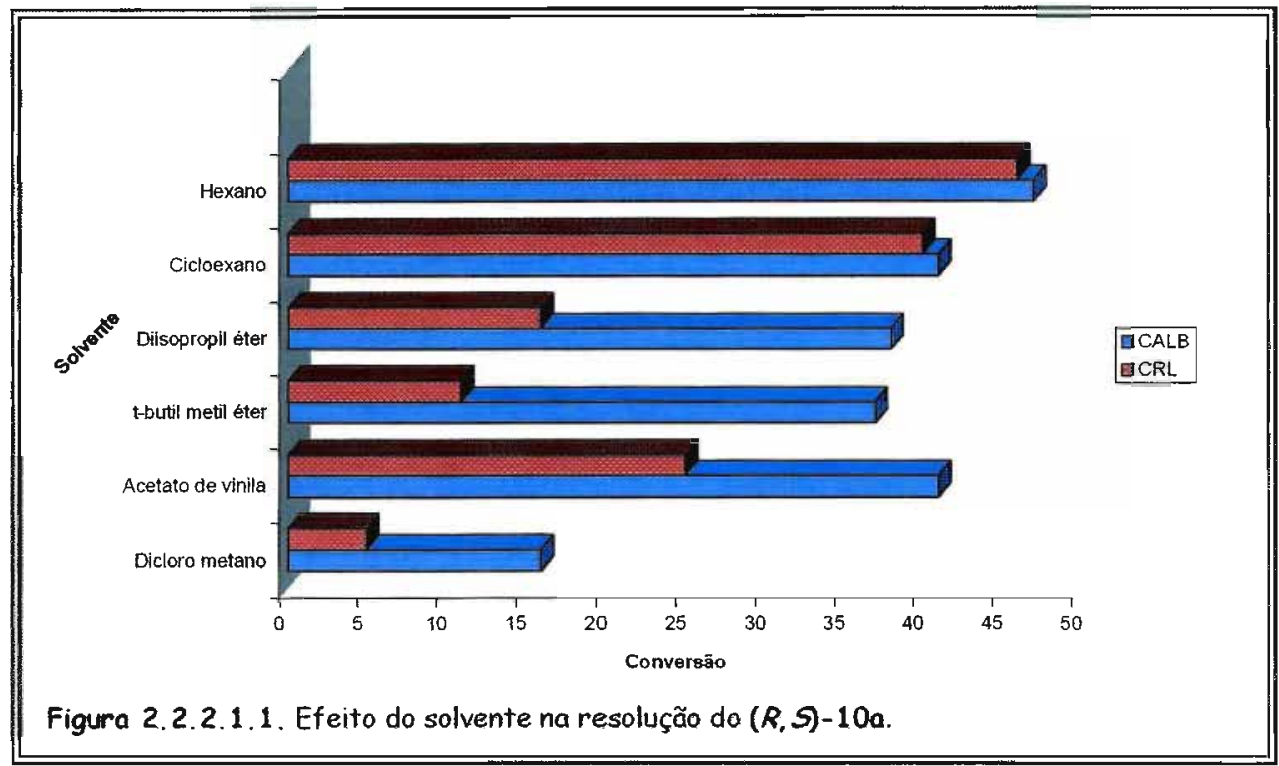

Novamente, o solvente não apresentou nenhuma influência sobre a enantiosseletividade e nem sobre a enantiopreferência da lipase, sendo sempre acetilado preferencialmente o enantiômero-(S) 10a no caso da CRL e o enantiômero-( $R$ ) 10a no caso da CALB. Em todos os solventes o $(R)-11 a$ foi obtido com excesso enantiomérico maior que 99\% empregando CALB ( $E$ >200), enquanto que com a utilização da CRL a enantiosseletiviade observada continuou baixa $(E<4)$.

Após esses experimentos, o sistema CALB, hexano seco a $30^{\circ} \mathrm{C}$ demonstrou ser o melhor sistema para a resolução do hidróxi-telureto $(\boldsymbol{R}, \boldsymbol{S})$ 10a. Desse forma, a resolução cinética enzimática dos hidróxi-teluretos $(R, S)$ 10b-d foram realizadas utilizando este sistema (CALB / hexano / 30 $\mathrm{C}$ ), com o intuito de verificarmos a influência dos grupos ligados ao carbono carbinólico e do grupo organo-teluro nas resoluções enzimáticas.

Em concordância com os resultados observados na resolução dos hidróxi-selenetos (Seção 2.1.2), e com o estudo realizado com a CALB referente à estrutura necessária de álcoois secundários para que sejam eficientemente resolvidos (Sessão 1.2.1.3), ${ }^{35}$ nenhum produto acetilado foi observado nas resoluções dos compostos $(R, S)-10 b-d$, nessas condições. Isso demonstra que o grupo organo-teluro se comporta como um substituinte 
grande na resolução dos hidróxi-teluretos. Assim, para que um hidróxi-telureto seja eficientemente resolvido pela CALB em meio orgânico é necessário que o substituinte de tamanho médio seja menor que o grupo etila.

Assim, as resoluções enzimáticas dos hidróxi-telureto $(R, S)-10 \mathrm{e}-\mathrm{g}$ foram conduzidas empregando a CALB em hexano seco a $30^{\circ} \mathrm{C}$ (Esquema 2.2.2.1.2). Nessas condições esses compostos foram resolvidos, sendo observada a acetilação preferencial do enantiômero- $(R)$ dos compostos $(R, S)$ 10e-f, em concordância com os resultados observados e com a regra de Kazlauskas. ${ }^{31}$

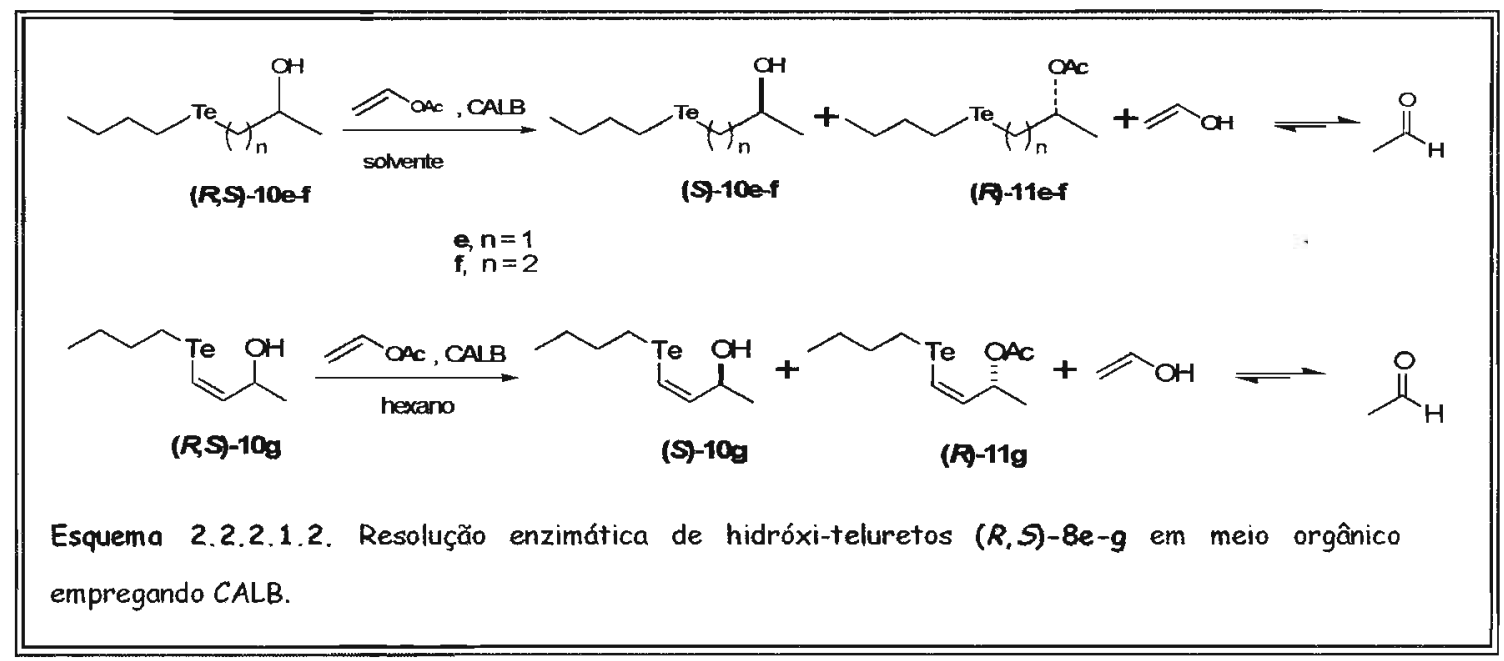

Na resolução do composto $(R, S)-10 \mathrm{e}$, o produto $(R)-11 \mathrm{e}$ foi obtido com excesso enantiomérico maior que $99 \%$ e o substrato (S)-10e com excesso enantiomérico igual a 97\%, demonstrando a alta enantiosseletividade enzimática $(E>200)$ da CALB para este composto (Tabela 2.2.2.1.3).

No caso da resolução do composto $(R, S)-10 f$, também foi observada uma alta enantiosseletividade enzimática $(E=120)$ da CALB, entretanto 0 rendimento isolado do produto enriquecido enantiomericamente foi menor que $5 \%$. Esse baixo rendimento está relacionado com a baixa estabilidade de teluretos alquílicos em hexano, evienciado pela formação de um pó branco (provavelmente teluróxido) no decorrer das reações (utilizando hexano deaerado). Por esse motivo, a resolução do hidróxi-telureto $(R, S)$-10f foi efetuada em THF, pois observamos que teluretos orgânicos apresentam maior estabilidade neste solvente. Entretanto, a enantiosseletividade enzimática em solventes polares é prejudicada, conforme resultados observados 
anteriormente (Figura 2.1.2.1.1 e Figura 2.2.2.1.1). Dessa forma, na resolução do composto $(\boldsymbol{R}, \mathbf{S})$-10f foi empregada uma quantidade maior de lipase, a fim de compensarmos o efeito negativo do solvente empregado (Tabela 2.2.2.1.3).

Nessas novas condições, o produto $(R)-11$ e foi obtido com $36 \%$ de rendimento isolado e com excesso enantiomérico igual a $98 \%$, enquanto que o substrato foi isolado com excesso enantiomérico igual a $99 \%$, evidenciando a alta enantiosseletividade enzimatica ( $E>200$ - Tabela 2.2.2.1.3 - entrada 6) da CALB nessa resolução em THF.

Na resolução do telureto vinílico $(R, S)-10 \mathrm{~g}$, também foi observada alta enantiosseletividade enzimática $(E>200)$. O produto acetilado $11 \mathrm{~g}$ foi obtido com excesso enantiomérico igual a $98 \%$ após 3 horas de reação (Tabela 2.2.2.1.3 - entrada 8).

Tabela 2.2.2.1.3. Resolução enzimática ${ }^{a}$ dos compostos $(R, S)$-10e-g empregando CALB.

\begin{tabular}{|c|c|c|c|c|c|c|c|c|}
\hline Entrada & Substrato & Solvente & $\begin{array}{l}\text { Tempo / } \\
\text { horas }\end{array}$ & $\begin{array}{c}\text { Conversão } \\
/ \%\end{array}$ & $\begin{array}{l}\text { e.e. do álcool } \\
10 / \%\end{array}$ & $\begin{array}{l}\text { e.e. do acetato } \\
11 / \%\end{array}$ & Rend. ' & $E^{\mathrm{e}}$ \\
\hline 1 & $(R, S)-10 \mathrm{e}$ & hexano & 1 & 47 & 87 & $>99$ & & \\
\hline 2 & & & 2 & 49 & 97 & $>99$ & 39 & $>200$ \\
\hline 3 & $(R, S)-10 \mathrm{f}$ & hexano & 1 & 45 & 80 & 96 & & \\
\hline 4 & & & 4 & 49 & 90 & 95 & $<5$ & 120 \\
\hline 5 & & THF & 8 & 48 & 93 & 99 & & \\
\hline 6 & & & 12 & 50 & 99 & 98 & 36 & $>200$ \\
\hline 7 & $(R, S)-11 \mathrm{~g}$ & hexano & 2 & 39 & 62 & $>99$ & & \\
\hline 8 & & & 3 & 45 & 79 & 98 & ---- & $>200$ \\
\hline
\end{tabular}

${ }^{a}$ As reaçōes foram realizadas utilizando CALB (30mg) em hexano seco $(10 \mathrm{~mL})$ ou CALB $(50 \mathrm{mg})$ em THF $(10 \mathrm{~mL})$ à $30^{\circ} \mathrm{C}$. ${ }^{b}$ Excesso enantiomérico do álcool 10. ${ }^{\circ}$ Excesso enantiomérico do acetato $11 .{ }^{d}$ Rendimento isolado do acetato 11. ${ }^{e}$ Razão enantiomérica: este parâmetro descreve a enantiosseletividade da enzima.

Analisando os resultados obtidos com as resoluções dos hidróxiteluretos (Figura 2.2.1.1.) empregando enzimas isoladas em meio orgânico, observamos que os mesmos se comportam de maneira semelhante aos hidróxi-selenetos (Seção 2.1.2.1), em relação à estrutura do hidróxicalcogeneto a ser resolvido. ${ }^{70}$ Assim, $\beta$-hidróxi-teluretos e $\gamma$-hidróxi-teluretos (alquilicos ou vinílicos) que possuem substituinte ligado ao carbono carbinólico menor que um grupo etila, podem ser eficientemente resolvidos empregando lipases em meio orgânico. 


\subsubsection{Aplicação Sintética}

A fim de demonstrarmos o potencial sintético da nossa metologia de obtenção de hidróxi-teluretos enantiomericamente puros, dois teluretos quirais foram empregados na preparação de lactonas. O produto acetilado $(R)-11 f$ (e.e.>99\%) obtido na resolução do composto $(R, S)$-10f empregando CALB em THF seco (Seção 2.2.2), foi utilizado na preparação da (R)- $\gamma$-valerolactona, enquanto que o hidróxi-telureto $(S)-10 \mathrm{~g}(\mathrm{e} . \mathrm{e} .=98 \%$ ) não acetilado na resolução do composto $(\boldsymbol{R}, \boldsymbol{S})-10 \mathrm{~g}$ empregando CALB em hexano seco, foi empregado na preparação da (S)- $\beta$-angelicalactona (Esquema 2.2.3.1).

Inicialmente, foi realizada a hidrólise química do produto acetilado $(\boldsymbol{R})$ 11f, gerando o hidróxi-telureto $(R)$-10f. Na seqüência, a adição de dois equivalentes de $n$-BuLi a $-78^{\circ} \mathrm{C}$, levou a formação do di-ânion, o qual foi capturado com $\mathrm{CO}_{2}$ formando o (R)-hidróxi-ácido 13. A adição de ácido $(\mathrm{HCl}-$ $50 \%)$ levou a ciclização, resultando na $(R)-\gamma$-valerolactona $[(R)-14]$ com excesso enantiomerico igual a $98 \%$. De forma análoga, a (S)-angelicalactona [(S)-15] foi obtida com excesso enantiomérico igual a 98\% (Esquema 2.2.3.1), demonstrando uma aplicação para os hidróxi-teluretos quirais obtidos empregando biotransformações.

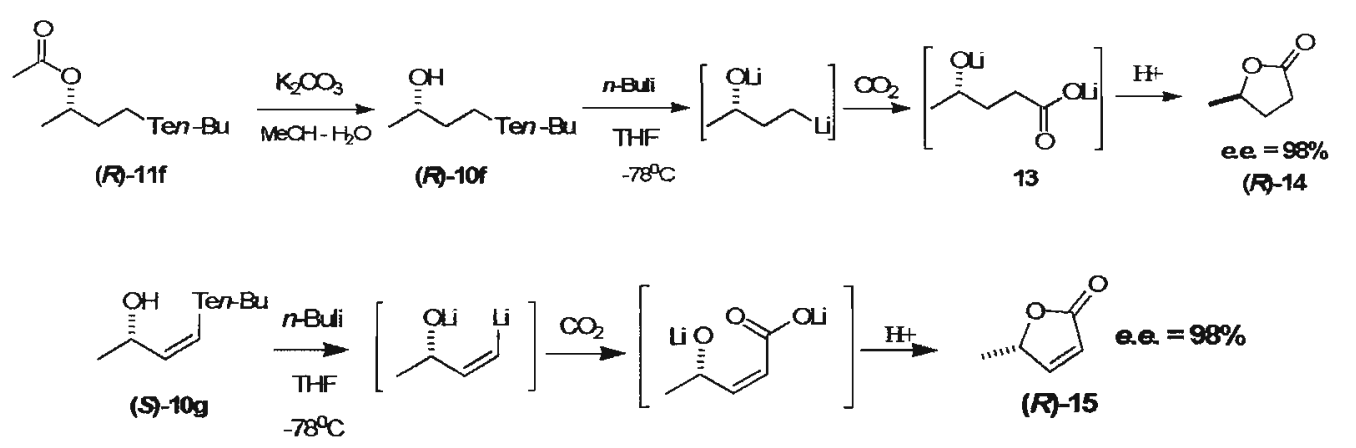

Esquema 2.2.3.1. Sintese da (R)- $\gamma$-valerolactona e da (S)- $\beta$-angelicalactona. 


\subsubsection{Determinação da Pureza Óptica/Estereoquímica}

Como salientado anteriormente no trabalho com hidróxi-selenetos, as técnicas analíticas para determinação de excessos enantioméricos e determinação de configuração absoluta foram essenciais para a condução do trabalho realizado com os hidróxi-teluretos.

\subsubsection{Determinação de Excesso Enantiomérico}

Os excessos enantioméricos dos hidróxi-teluretos 10a, 10e-g e dos seus respectivos ésteres $11 \mathrm{a}, 11 \mathrm{e}-\mathrm{g}$ foram calculados a partir de cromatogramas obtidos em cromatografo a gás equipado com coluna com fase estacionária quiral (CG-Quiral). Conforme realizado no estudo das biotransformações dos hidróxi-selenetos, os cromatogramas obtidos foram sempre comparados com cromatogramas de amostras racêmicas (Seção 2.1.4.1)

Para os compostos 10e e $10 \mathrm{f}$ análises diretas em CG-quiral não foram possiveis, pois não houve discriminação dos enantiômeros em nenhuma coluna disponível no laboratório. Assim, o hidróxi-telureto 10e foi transformado quimicamente em seu respectivo acetato (11e) e depois submetido à análise em CG-Quiral. O hidróxi-telureto $10 f$ foi convertido no seu respectivo trifluoracetato 16, utilizando método convencional (Esquema 2.1.4.1). ${ }^{49}$ Os

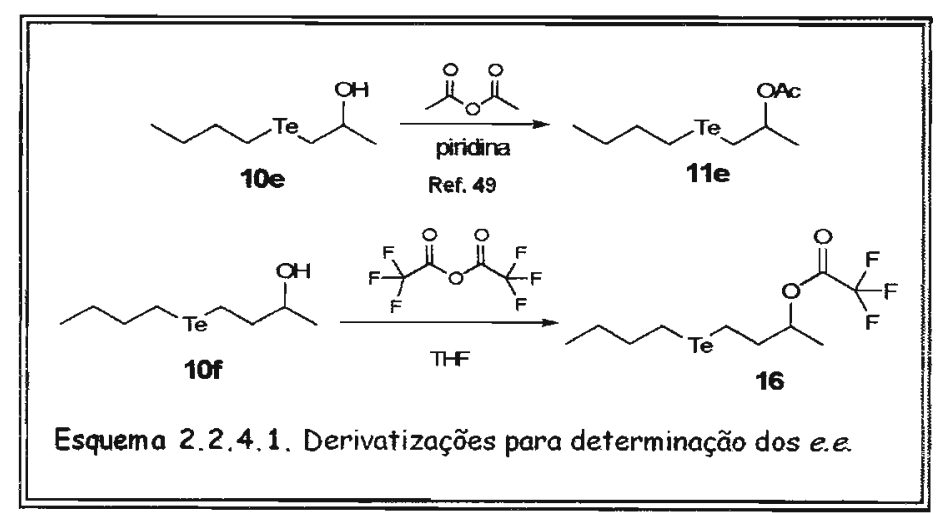
enantiômeros do composto 16 foram facilmente discriminados via CG-quiral, possibilitando a determinação indireta dos excessos enantioméricos do hidróxi-telureto $10 \mathrm{f}$. 


\subsubsection{Determinação da Configuração Absoluta}

De maneira análoga à utilizada na determinação da configuração absoluta do hidróxi-seleneto 1a (Seção 2.1.4.2.), as configurações absolutas dos hidróxi-teluretos 10a e 10e foram determinadas por espectroscopia de ressonância magnética nuclear (RMN). Os enantiômeros dos compostos 8a (e.e. $>99 \%$ ) e 8 e (e.e. $>99 \%$ ) não acetilados pela lipase foram derivatizados com os dois enantiômeros do cloreto de $\alpha$-metóxi- $\alpha$-trifluormetil-fenilacetila (MTPA-Cl).

Os espectros de ${ }^{1} \mathrm{H}-\mathrm{RMN}$ dos derivados diastereoisoméricos formados apresentam deslocamentos químicos diferentes e, de acordo com o modelo de Mosher, ${ }^{55}$ as diferenças de deslocamento químico são originadas pelo efeito anisotrópico do anel aromático em uma conformação preferencial. Este efeito permite determinar a posição dos substituintes ligados ao carbono carbinólico, pois o cone de proteção do anel benzênico (resultado do campo magnético gerado pelo movimento dos elétrons da nuvem $\pi$ do anel benzênico) blinda diferentes ligantes em cada diastereoisômero.

Assim, imaginado que os hidróxi-teluretos $10 \mathrm{a}$ e $10 \mathrm{e}$ não acetilados pela lipase tenham a configuração $(S)$, a derivatização gerou os estereoisômeros $(R, S)-17,(R, S)-18,(S, S)-17$ e $(S, S)-18$. No caso dos estereoisômeros (S,S)-17 e (S,S)-18 o substituinte $-\mathrm{CH}_{3}$ ligado ao carbono carbinólico será blindado pelo cone de proteção, enquanto que nos estereoisômeros $(R, S)-17$ e $(R, S)-18$ o cone de proteção irá blindar o substituinte $-\mathrm{CH}_{2} \mathrm{TeR}$ (Figura 2.2.4.2.1). Assim, os deslocamentos químicos no espectro de ${ }^{1} \mathrm{H}-\mathrm{RMN}$ do substituinte $-\mathrm{CH}_{3}$ ligado ao carbono carbinólico dos estereisômeros $(R, S)$-17 e $(R, S)$-18 aparecerá em campo mais baixo quando comparado os deslocamentos químicos do mesmo substituinte nos estereoisômeros $(\mathbf{S}, \mathbf{S})-17$ e $\mathbf{( S , S ) - 1 8}$. O efeito inverso deverá ser observado para o substituinte $-\mathrm{CH}_{2} \mathrm{TeR}$ (Figura 2.2.4.2.1).

Analizando o espectro de ${ }^{1} \mathrm{H}-\mathrm{RMN}$ dos estereoisômeros, podemos observar exatamente o padrão de deslocamento químico descrito anteriormente (Figura 2.2.4.2.1), confirmando a configuração absoluta dos hidróxi-teluretos $8 \mathbf{a}$ e 8 e não acetilados pela lipase como sendo (S). 
Como observado na determinação da configuração absoluta do hidróxi-seleneto 1a, os espectros de ${ }^{13} \mathrm{C}-\mathrm{RMN}$ e ${ }^{125} \mathrm{Te}-\mathrm{RMN}$ para os estereoisômeros apresentaram o mesmo efeito em seus deslocamentos químicos, confirmando o efeito anisotrópico do anel benzênico sobre os substituintes ligados ao carbono carbinólico e a configuração absoluta determinada (Figura 2.2.4.2.1).

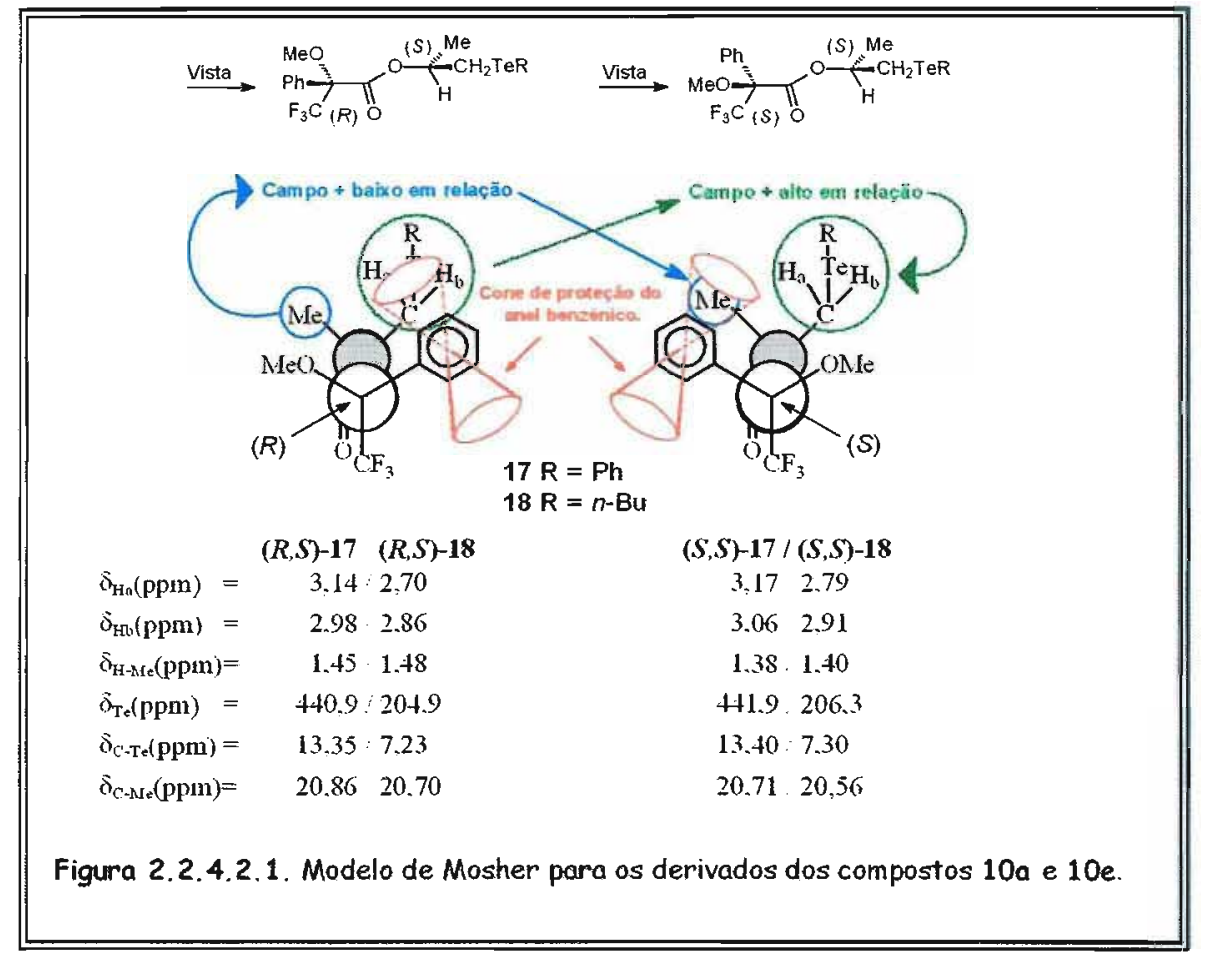

A configuração dos hidróxi-teluretos $10 \mathrm{f}$ e $10 \mathrm{~g}$ foi determinada de maneira indireta. Foi com parado a rotação óptica $\left\{[\alpha]_{D}\right\}$ da $\gamma$-valerolactona $14 \mathrm{e}$ dà $\beta$-angelicalactona 15 preparadas, respectivamente, a partir do hidróxitelureto $10 \mathrm{f}$ e do $10 \mathrm{~g}$ enantiomericamente enriquecidos (Seção 2.2 .3 Esquema 2.2.3.1) com o valor descrito na literatura. ${ }^{71,72}$ Dessa forma, foram determinadas as configurações absolutas dos hidróxi-teluretos $10 \mathrm{f}$ e $10 \mathrm{~g}$, não acetilados preferencialmente pela lipase, como sendo $(S)$. 
3. Conclusões 

A presença do átomo de Se ou de Te na estrutura dos hidróxicalcogenetos não ocasionou a inativação das enzimas, possibilitando a aplicação de biotransformações na resolução cinética dos mesmos, levando à hidróxi-selenetos e hidróxi-teluretos em altos excessos enantioméricos. Alguns destes foram usados na preparação de blocos de construção quiral encontrados em várias classes de produtos naturais, o que demonstra o potencial sintético da metodologia.

O controle de variáveis, tais como o solvente, a lipase, o suporte, a estrutura do álcool, a temperatura e o tempo de reação nas biotransformações de hidróxi-calcogenetos (Se e Te), foi fundamental para uma boa resolução.

Além de permitir a reciclagem das enzimas, o uso de suportes aumentou sensivelmente a atividade e a estabilidade das mesmas, diminuindo o tempo de reação e a quantidade de enzima utilizada nas biotransformações.

O emprego de água como solvente na resolução de selenetos possibilitou a obtenção dos mesmos enriquecidos enantiomericamente sem a necesidade do emprego de solventes orgânicos, valorizando o processo biocatálitico pela redução na utilização de substâncias nocivas ao meio ambiente. Além disso, o uso concomitante de enzimas imobilizadas possibilitou uma diminuição nos tempos de hidrólise, tornando o processo mais atraente.

A triagem enzimática empregando indicador de $\mathrm{pH}$ permitiu realizar uma análise qualitativa prévia sobre a atividade hidrolítica de dez enzimas frente a vários compostos concomitantemente, possibilitando escolher as enzimas mais adequadas para a resolução dos selenetos em meio aquoso.

O emprego de cepas de Aspergillus terreus nas biotransformações de hidróxi-selenetos levou à oxidação enantiosseletiva, seguida de biometilação do produto de eliminação de selenóxido.

A Ressonância Magnética Nuclear como ferramenta para a determinação da configuração absoluta de alguns hidróxi-calcogenetos, permitiu observarmos o efeito anisotrópico do anel aromático sobre os átomos de Se e Te, em comparação ao efeito observado sobre os átomos de $\mathrm{H}$ e $\mathrm{C}$ nesses compostos. 

4. Parte Experimental 

4.1. Materiais e Métodos 

Os solventes foram purificados e secos antes do uso, empregando procedimentos usuais. ${ }^{73}$ Os reagentes comerciais foram convenientemente purificados. O THF e o éter etilico foram destilados sob sódio e benzofenona imediatamente antes do uso. Para evaporar as soluções orgânicas foi utilizado um evaporador rotativo Büchi, operando a pressão reduzida.

As análises por cromatografia a gás (CG) foram efetuadas nos cromatógrafos SHIMADZU GC-2010 e HEWLETT PACKARD - 5730, equipados com um detector de ionização de chama e acoplado a um integrador. O gás de arraste foi o nitrogênio ou hidrogênio (colunas quirais) e as colunas empregadas foram de sílica fundida revestida com goma de poli SPB-35 (35\% difenil / 65\% dimetilsilicone), $\alpha$-ciclodextrina de $30 \mathrm{~m} \times 0,2 \mathrm{~mm} \times$ $0,22 \mu \mathrm{m}$ (ALFA DEX ${ }^{\mathrm{TM}} 120$ ), $\beta$-ciclodextrina de $30 \mathrm{~m} \times 0,2 \mathrm{~mm} \times 0,22 \mu \mathrm{m}$ (BETA DEX $^{T M_{12}}$ ), $\gamma$-clclodextrina de $30 \mathrm{~m} \times 0,2 \mathrm{~mm} \times 0,22 \mu \mathrm{m}\left(\mathrm{GAMA} \mathrm{DEX}^{\mathrm{TM}} 120\right)$, todas da SUPELCO ${ }^{\circledR}$ e a $\beta$-ciclodextrina de $25 \mathrm{~m} \times 0,25 \mathrm{~mm} \times 0,25 \mu \mathrm{m}$ (CRHOMOPACK / CHIRASIL-DEX CB) da Varian ${ }^{\circledR}$.

Nas cromatografias em coluna (CC) foi utilizada sílica gel (60-30mesh) $60 \AA ̊$ da Aldrich Chemical Company, Inc. A sílica Kieselgel 60 PF $_{254}$ da Merck foi utilizada na preparação de placas preparativas. As análises cromatográficas em camada delgada (CCD) foram efetuadas empregando-se as placas comerciais da Merck (E. Merck, tipo 5544, 0,2mm), as quais foram reveladas sob luz ultravioleta ( $\lambda=254 \mathrm{~nm}$ ) e/ou com solução de vanilina em uma mistura de ácido sulfúrico-etanol ( $6 \%$ vanilina $\mathrm{m} / \mathrm{v}, 4 \%$ ácido sulfúrico e $10 \%$ água, v/v, em etanol).

Os espectros no infravermelho foram registrados em um espectrofotômetro Bomen MB-100.

Os espectros de massas de baixa resolução (LRMS) foram obtidos no espectrômetro EM da Hewlett-Packard modelo 5988A acoplado a um cromatógrafo Hewlett-Packard modelo 5890 e as análises elementares foram efetuadas em um equipamento Perkin Elmer Series II, CHNS/O 2400.

Os espectros de ressonância magnética nuclear de ${ }^{1} \mathrm{H}$ (RMN- $\left.{ }^{1} \mathrm{H}\right)$, ressonância magnética nuclear de ${ }^{13} \mathrm{C}$ (RMN $\left.-{ }^{13} \mathrm{C}\right)$, ressonância magnética nuclear de ${ }^{77} \mathrm{Se}\left(\mathrm{RMN}-{ }^{77} \mathrm{Se}\right)$ e ressonância magnética nuclear de ${ }^{125} \mathrm{Te}$ (RMN${ }^{125} \mathrm{Te}$ ) foram registrados em um espectrômetro Varian-Inova $(300 \mathrm{MHz})$ ou 
espectrometro da Bruker (200MHz ou $500 \mathrm{MHz}$ ) utilizando padrão interno tetrametilsilano (TMS), como solvente $\mathrm{CDCl}_{3}$ e nos casos de $\mathrm{RMN}-{ }^{77}$ Se e RMN${ }^{125}$ Te foi utilizado um capilar selado com solução $1 \mathrm{M}$ de difenil dicalcageneto (Se ou Te, correspondentemente) em $\mathrm{CDCl}_{3}$ como padrão interno. Os deslocamentos químicos estão expressos em ppm $(\delta)$ e as constantes de acoplamento $(\mathrm{J})$ em Hertz $(\mathrm{Hz})$. Para indicar a multiplicidade dos sinais foram adotadas as seguintes abreviações: s (singleto), d (dubleto), dd (duplo dubleto), t (tripleto), q (quarteto), quint (quinteto), sext (sexteto) e m (multipleto).

Os desvios ópticos foram determinados em um polarimetro JASCO DIP 3170, sendo que a concentração (c) foi estabelecida em g/100mL.

As enzimas empregadas pertencem ao grupo dos triglicerol acil hidrolases, sendo que a PPL (lipase de pâncreas de porco - livre, 42 urits/mg prot.), a CRL (lipase de Candida rugosa - livre, 1.440 units/mg prot.) e a MJL (lipase de Mucor Javanicus - livre, 536 units/mg) foram adquiridas da Sigma Comp. A CALB (NOVOZYM 435 ${ }^{\circledR}$ - lipase de Candida antartica - Fração B imobilizada, $10.000 \mathrm{U} / \mathrm{g}$ ) e a TLLb (LIPOZYME TL $100 \mathrm{~L}^{\circledR}$ - lipase de Thermomyces lanuginosa - livre, $>100 \mathrm{KU} / \mathrm{g}$ ) foram doadas pela NOVOZYMES CO. e a PSL (AMANO PS - lipase de Pseudomonas sp. - livre, $30.000 \mathrm{u} / \mathrm{g}$ ) foi doada pela Amano S/A. As demais enzimas [CALA (lipase de Candida antarctica Tipo A - livre - >30 U/mg), CALB (lipase de Candida antarctica Tipo B - livre - >120 U/mg), CRL (lipase de Candida rugosa - livre - >250 U/mg), PSL (lipase de Pseudomonas sp. - livre - $400 \mathrm{U} / \mathrm{mg}$ ), PLE (esterase de fígado de porco - livre - $40 \mathrm{U} / \mathrm{mg}$ ), PPL (lipase de pâncreas de porco - livre - 20 U/mg), TLLa (lipase de Thermomyces lanuginosa - livre - >800 U/mg) e ASL (lipase Alcaligenes sp. - livre - >20 U/mg)] foram adquiridas da Roche CO.

As manipulações dos fungos foram efetuadas numa capela de fluxo laminar utilizando os métodos de assepsia adequados para evitar contaminações das colônias. Os meios de cultura foram preparados utilizando água destilada e esterilizados a $120^{\circ} \mathrm{C}$ por vinte minutos. Todo o material utilizado na manipulação de microorganismo (erlenmayers, pipetas, tubos de ensaio, etc.) foi autoclavado e lavado, exceto materiais descartáveis, os quais foram acondicionados em sacos de lixo especiais (tipo hospitalar). 
O descarte dos resíduos foi realizado no laboratório seguindo-se as normas estabelecidas pelo Instituto de Química-USP. Os resíduos orgânicos, incluindo os solventes orgânicos utilizados nos experimentos foram todos descartados em frascos próprios para depois serem encaminhados pelo Instituto de Química para a incineração. O etanol, utilizado para lavagem da vidraria, foi reciclado por destilação em nosso laboratório. Ácidos e bases foram neutralizados antes de serem descartados. Soluções aquosas de sais $\left(\mathrm{NaCl}, \mathrm{NH}_{4} \mathrm{Cl}\right)$ provenientes de lavagem de fase orgânica, após diluição, foram descartadas.

As vidrarias com resíduos de teluretos foram lavadas primeiramente com solução $5 \%$ de hipoclorito de sódio, para que ocorresse a oxidação dos teluretos a teluróxidos, compostos pouco solúveis em água, que foram descartados com os residuos orgânicos. A sílica utilizada nas colunas cromatográficas foi armazenada em tambores apropriados que foram encaminhados pelo Instituto de Química para serem descartados em locais designados para tal fim. 

4.2. Procedimentos Gerais 



\subsubsection{Preparação do Disseleneto de Difenila ${ }^{74}$}

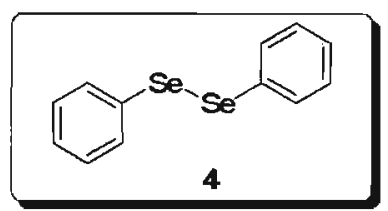

Em um balão de três bocas equipado com um condensador de refluxo, agitador mecânico e um funil de adição, contendo raspas de $\mathrm{Mg}(24,31 \mathrm{~g} ; 1,05$ $\mathrm{mol}$ ) e alguns cristais de iodo $\left(\mathrm{I}_{2}\right)$ em éter etílico seco $(100 \mathrm{~mL})$, foi adicionado uma solução de bromobenzeno (3,925g - $25 \mathrm{mmol})$ em éter etílico seco $(70 \mathrm{~mL})$. A reação começou rapidamente (observada pela descoloração do iodo) e violentamente, necessitando um banho de água e gelo para controlar a reação. Em seguida foi adicionada mais solução de bromobenzeno (85 mmol) em éter etílico seco $(930 \mathrm{~mL})$. Após toda a adição da solução de bromobenzeno, a mistura reacional foi agitada mecanicamente e mantida sobre refluxo até todo o consumo do $\mathrm{Mg}^{0}$. Na seqüência foi adicionado $\mathrm{Se}^{0}$ em pó $(1 \mathrm{~mol})$ em pequenas porções, de modo a manter o refluxo suave, e deixou-se reagir por $30 \mathrm{~min}$. A solução foi então transferida para um kitassato de $500 \mathrm{~mL}$ munido de uma entrada de ar e uma saída para vácuo contendo $\mathrm{KOH}$ e etanol. A solução foi agitada por 12 horas. Em seguida filtrou-se e evaporou-se o solvente. $\mathrm{O}$ produto foi recristalizado em etanol $95 \%$ obtendo-se disseleneto de difenila com pureza analítica. O rendimento total da reação foi de $225 \mathrm{~g}(72 \%)$.

\subsubsection{Preparação dos Hidróxi-selenetos $(R, S)-1$ a e $(R, S)-1 e^{38}$}

Em um balão de duas bocas, equipado com agitação magnética sob nitrogênio, o disseleneto de difenila $(1,56 \mathrm{~g}-5 \mathrm{mmol})$ foi dissolvido em álcool etílico seco $(30 \mathrm{~mL})$. Em seguida foi adicionado lentamente $\mathrm{NaBH}_{4}$ em pequenas porções, até a solução permanecer incolor. Após a formação do selenolato, foi adicionado lentamente sobre a mistura reacional o epóxido (óxido de propileno ou estireno $-11 \mathrm{mmol}$ ). A agitação foi mantida durante uma hora. Ao final desse tempo, a mistura reacional foi lavada três vezes com solução $10 \%$ de $\mathrm{NaCO}_{3}$, extraída com acetato de etila e seca com $\mathrm{MgSO}_{4}$ 
anidro. O solvente foi rotoevaporado e a purificação foi realizada em coluna de sílica utilizando como eluente uma mistura de hexano/acetato de etila (85:15 ou 9:1).

\section{$\hat{l}^{\mathrm{OH}} \operatorname{sen}$}

(R,S)-1a

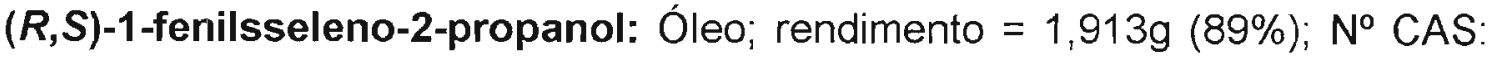
25570-56-3; RMN ${ }^{1} \mathrm{H}\left(300 \mathrm{MHz}, \mathrm{CDCl}_{3}\right), \delta(\mathrm{ppm}): 1,27$ (d; $\left.J=6,19 \mathrm{~Hz} ; 3 \mathrm{H}\right), 2,46$ (s; $1 \mathrm{H}), 2,88$ (dd; $J=12,71 \mathrm{~Hz} ; J=8,31 \mathrm{~Hz} ; 1 \mathrm{H}), 3,10$ (dd; $J=12,71 \mathrm{~Hz} ; J=$ $3,95 \mathrm{~Hz} ; 1 \mathrm{H}), 3,84-3,88(\mathrm{~m} ; 1 \mathrm{H}), 7,23-7,28(\mathrm{~m} ; 3 \mathrm{H}), 7,50-7,56(\mathrm{~m} ; 2 \mathrm{H}) ; \mathrm{RMN}{ }^{13} \mathrm{C}$ $\left(75 \mathrm{MHz}, \mathrm{CDCl}_{3}\right), \delta(\mathrm{ppm}): 22,4 ; 38,5\left(J_{13 \mathrm{C}-77 \mathrm{se}}=64 \mathrm{~Hz}\right) ; 66,1 ; 127,3 ; 129,3$; 129,$2 ; 133,1 ; \mathrm{RMN}^{77} \mathrm{Se}\left(95 \mathrm{MHz}, \mathrm{CDCl}_{3}\right), \delta(\mathrm{ppm})$ : 240,8; I.V. (filme - KBr) Banda de absorção $\left(\mathrm{cm}^{-1}\right)$ : 691, 736, 1371, 1478, 1578, 2927, 2971, 3016, 3056, 3070, 3390; E.M., m/z (\%rel.): 216 (60), $215\left(\mathrm{M}^{+}, 4\right), 172$ (47), 158 (57), 157 (50), 91 (100), 77 (72), 78 (89), 59 (68), 51 (63), 45 (53); Microanálise $\left(\mathrm{C}_{9} \mathrm{H}_{12} \mathrm{OSe}\right)$ Calculado: $\mathrm{C}=50,24 \%$ e $\mathrm{H}=5,62 \%$ e observado: $\mathrm{C}=49,86 \%$ e $\mathrm{H}=5,63 \%$.

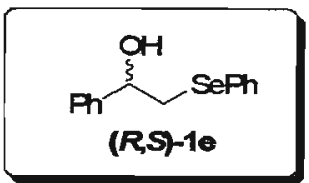

$(\boldsymbol{R}, S)$-1-fenil-2-fenilsseleno-etanol: Óleo; rendimento $=1,523 \mathrm{~g}(55 \%) ; \mathrm{N}^{\circ}$ CAS: 51558-95-3; RMN ${ }^{1} \mathrm{H}\left(300 \mathrm{MHz}, \mathrm{CDCl}_{3}\right), \delta(\mathrm{ppm}): 2,83(\mathrm{~d} ; J=2,78 \mathrm{~Hz} ; 1 \mathrm{H})$, $3,13$ (dd; $J=12,75 \mathrm{~Hz} ; J=9,31 \mathrm{~Hz} ; 1 \mathrm{H}), 3,29$ (dd; $J=12,75 \mathrm{~Hz} ; J=3,77 \mathrm{~Hz} ; 1 \mathrm{H})$, $4,71-4,76(\mathrm{~m} ; 1 \mathrm{H}), 7,24-7,33(\mathrm{~m} ; 8 \mathrm{H}), 7,52-7,55(\mathrm{~m} ; 2 \mathrm{H})$; RMN ${ }^{13} \mathrm{C}(75 \mathrm{MHz}$, $\left.\mathrm{CDCl}_{3}\right), \delta(\mathrm{ppm}): 38,5 ; 72,3 ; 125,8 ; 127,4 ; 127,9 ; 128,5 ; 129,3 ; 133,1 ; 133,2$; 142,5; $\mathrm{RMN}^{77} \mathrm{Se}\left(95 \mathrm{MHz}, \mathrm{CDCl}_{3}\right), \delta(\mathrm{ppm})$ : 251.9; I.V. (filme - $\mathrm{KBr}$ ) Banda de absorção $\left(\mathrm{cm}^{-1}\right)$ : 693, 736, 1085, 1437, 1453, 1477, 1578, 2880, 2932, 2983, 3000, 3029, 3058, 3907; E.M., m/z (\%rel.): $278(25), 277\left(M^{+}, 3\right), 172(100), 157$ (18), 121 (4), 107 (60), 91 (54), 79 (83), 77 (83); 51 (43), 43 (29); Microanálise $\left(\mathrm{C}_{14} \mathrm{H}_{14} \mathrm{OSe}\right)$ - Calculado: $\mathrm{C}=60,66 \%$ e $\mathrm{H}=5,09 \%$ e observado: $\mathrm{C}=60,51 \%$ e $H=5,34 \%$. 


\subsubsection{Preparação do Bis(fenilsseleno)metano ${ }^{38}$}

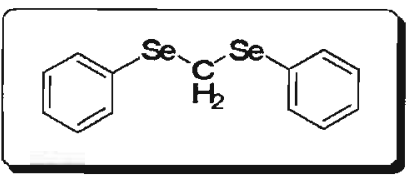

Em um balão de duas bocas equipado com septo e sob nitrogênio disseleneto de difenila $(3,433 \mathrm{~g}-11 \mathrm{mmol})$ foi dissolvido em etanol seco (50 $\mathrm{mL}$ ). Em seguida, $\mathrm{NaBH}_{4}$ foi adicionado em pequenas porções até a solução permanecer incolor. Na seqüência foi adicionado $\mathrm{CH}_{2} \mathrm{Br}_{2}(0,77 \mathrm{~mL}-1,903 \mathrm{~g}-$ $11 \mathrm{mmol})$ em THF ( $4 \mathrm{~mL})$ com uma seringa e a mistura reacional foi agitada por $4 \mathrm{~h}$ a temperatura ambiente. Ao final das $4 \mathrm{~h}$ a mistura reacional foi transferida para um funil de extração contendo solução saturada de $\mathrm{NH}_{4} \mathrm{Cl}(100 \mathrm{~mL})$ e extraída com acetato de etila. A fase orgânica foi lavada com solução saturada de $\mathrm{NaCl}$, seca com $\mathrm{MgSO}_{4}$ e o solvente evaporado. O produto foi purificado por cromatografia utilizando hexano como eluente. O composto foi obtido puro. Rendimento da reação foi de $88 \%(3,157 \mathrm{~g})$.

\subsubsection{Preparação dos Hidróxi-selenetos $(R, S)-1$ b-d ${ }^{46}$}

Em um balão de duas bocas de $50 \mathrm{~mL}$ equipado com septo, sob agitação magnética e sob nitrogênio o bi(fenilsseleno)metano $(0,652 \mathrm{~g}-2 \mathrm{mmol})$ foi dissolvido em THF seco $(8 \mathrm{~mL})$. A mistura foi resfriada com um banho de acetona e gelo seco $\left(-78^{\circ} \mathrm{C}\right)$ e foi adicionado uma solução de $n$-butil lítio $\left(1,43 \mathrm{~mL}-1,4 \mathrm{MolL}^{-1}\right.$ em hexano - $\left.2 \mathrm{mmol}\right)$ em hexano. A mistura reacional foi mantida sobre agitação durante 30 minutos, em seguida foi adicionado o aldeído correspondente $(2 \mathrm{mmol})$. A agitação foi mantida por 10 minutos a $-78^{\circ} \mathrm{C}$ e por 30 minutos a temperatura ambiente. Ao final desse período à mistura reacional foi transferida para um funil de extração (100 mL) contendo solução saturada de $\mathrm{NH}_{4} \mathrm{Cl}(30 \mathrm{~mL})$ e extraída com acetato de etila. A fase orgânica foi lavada com solução saturada de $\mathrm{NaCl}$, seca com $\mathrm{MgSO}_{4}$ e o solvente evaporado. O produto obtido foi pré-purificado numa coluna cromatográfica utilizando primeiramente apenas hexano e depois apenas acetato de etila como eluentes. A fase de acetato de etila foi então evaporada e 
purificada por cromatografia usando uma solução hexano/acetato (9:1) como eluente

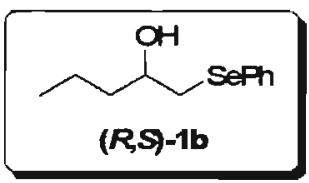

$(R, S)-1$-fenilsseleno-2-pentanol: Óleo; rendimento $=0,350 \mathrm{~g}(72 \%) ; \mathrm{RMN}^{1} \mathrm{H}$ (300MHz, $\left.\mathrm{CDCl}_{3}\right), \delta(\mathrm{ppm}): 0,89(\mathrm{t} ; \mathrm{J}=7,2 \mathrm{~Hz} ; 3 \mathrm{H}), 1,33-1,37(\mathrm{~m} ; 1 \mathrm{H}) ; 1,44-$ $1,54(\mathrm{~m} ; 3 \mathrm{H}) ; 2,18(\mathrm{~s} ; 1 \mathrm{H}), 2,88(\mathrm{dd} ; J=12,73 \mathrm{~Hz} ; J=8,61 \mathrm{~Hz} ; 1 \mathrm{H}), 3,14(\mathrm{dd} ; J=$ $12,73 \mathrm{~Hz} ; J=3,51 \mathrm{~Hz} ; 1 \mathrm{H}), 3,66-3,71(\mathrm{~m} ; 1 \mathrm{H}), 7,24-7,27(\mathrm{~m} ; 3 \mathrm{H}), 7,52-7,53(\mathrm{~m}$, $2 \mathrm{H}) ; \mathrm{RMN}^{13} \mathrm{C}\left(75 \mathrm{MHz}, \mathrm{CDCl}_{3}\right), \delta(\mathrm{ppm}): 14,2 ; 19,2 ; 37,5\left(J_{13 \mathrm{C}-77 \mathrm{Se}}=64 \mathrm{~Hz}\right)$; 39,$0 ; 69,91 ; 127,5 ; 129,4 ; 129,7 ; 133,3 ; \mathrm{RMN}{ }^{77} \mathrm{Se}\left(95 \mathrm{MHz}_{1} \mathrm{CDCl}_{3}\right), \delta(\mathrm{ppm})$ : 234,2 ; I.V. (filme - KBr) Banda de absorção $\left(\mathrm{cm}^{-1}\right)$ : 691, 737, 1436, 1459, 1474, 1578, 2870, 2928, 2958, 3063, 3401; E.M., m/z (\%rel.): $244(60), 243\left(\mathrm{M}^{+}, 4\right)$, 172 (100), 158 (63), 157 (61), 91 (86), 78 (81), 77 (74), 69 (44), 55 (85), 51 (51), 45 (90), 41 (89); Microanálise $\left(\mathrm{C}_{11} \mathrm{H}_{16} \mathrm{OSe}\right)$ - Calculado: $\mathrm{C}=54,32 \%$ e $\mathrm{H}=$ $6,63 \%$ e observado: $\mathrm{C}=54,08 \%$ e $\mathrm{H}=6,85 \%$.

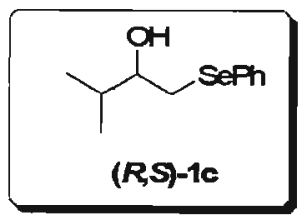

$(R, S)$-1-fenilsseleno-3-metil-2-butanol: Óleo; rendimento $=0,379 \mathrm{~g}(78 \%)$; CAS NR: 68395-98-2; NMR ${ }^{1} \mathrm{H}(500 \mathrm{MHz}): \delta 0,89-0,93(\mathrm{~m} ; 6 \mathrm{H}), 1,74-1,80(\mathrm{~m}$; $1 \mathrm{H}$ ), 2,89 (dd; $J=9,5 \mathrm{~Hz} ; J=12,7 \mathrm{~Hz} ; 1 \mathrm{H}$ ), 3,17 (dd; $J=3,0 \mathrm{~Hz} ; J=12,7 \mathrm{~Hz}$; 1H), 3,40-3,44 (m; 1H), 7,23-7,28 (m; 3H), 7,50-7,54 (m;2H); RMN ${ }^{13} \mathrm{C}$ $\left(125 \mathrm{MHz}_{1} \mathrm{CDCl}_{3}\right), \delta(\mathrm{ppm}): 17,7 ; 18,7 ; 33,3 ; 34,9 ; 74,5 ; 127,2 ; 129,2 ; 129,3$; 133,0; $\mathrm{RMN}^{77} \mathrm{Se}\left(95 \mathrm{MHz}, \mathrm{CDCl}_{3}\right), \delta(\mathrm{ppm}): 240,8$; I.V. (filme - KBr) Banda de absorção $\left(\mathrm{cm}^{-1}\right)$ : 691, 737, 1472, 1578, 1801, 1874, 2874, 2960, 3429; E.M., m/z (\% rel.): 244 (57), 183 (4), 172 (71), 157 (72), 91 (74), 77 (76), 69 (100), 51 (60), 45 (44); Microanálise $\left(\mathrm{C}_{11} \mathrm{H}_{16} \mathrm{OSe}\right)$ - Calculado: $\mathrm{C}=54,32 \%$ e H=6,63\% e observado: $\mathrm{C}=54,75 \%$ e $\mathrm{H}=7,05 \%$. 


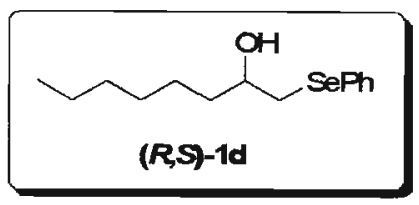

$(R, S)-1-f e n i l s s e l e n o-2-o c t a n o l:$ Óleo; rendimento $=0,473 \mathrm{~g}(83 \%) ; \mathrm{N}^{\circ}$ CAS: $52954-45-7$; RMN ${ }^{1} \mathrm{H}\left(500 \mathrm{MHz}, \mathrm{CDCl}_{3}\right), \delta(\mathrm{ppm}): 0,87(\mathrm{t} ; \mathrm{J}=7,1 \mathrm{~Hz} ; 3 \mathrm{H}), 1,25-$ $1,31(\mathrm{~m} ; 8 \mathrm{H}), 1,51-1,54(\mathrm{~m} ; 2 \mathrm{H}), 2,14(\mathrm{~s} ; 1 \mathrm{H}), 2,87(\mathrm{dd} ; J=8,6 \mathrm{~Hz} ; J=12,7 \mathrm{~Hz}$; $1 \mathrm{H}), 3,14(\mathrm{dd} ; J=3,5 \mathrm{~Hz} ; J=12,7 \mathrm{~Hz} ; 1 \mathrm{H}), 3,63-3,68(\mathrm{~m} ; 1 \mathrm{H}), 7,24-7,27(\mathrm{~m} ; 3 \mathrm{H})$, $7,51-7,54(\mathrm{~m} ; 2 \mathrm{H}) ; \mathrm{RMN}^{13} \mathrm{C}\left(125 \mathrm{MHz}, \mathrm{CDCl}_{3}\right), \delta$ (ppm): 14,0; 22,5; 29,23; 31,7; 36,$6 ; 37,2 ; 69,8 ; 127,2 ; 129,2 ; 133,0 ; \mathrm{RMN}^{77} \mathrm{Se}\left(95 \mathrm{MHz}, \mathrm{CDCl}_{3}\right), \delta(\mathrm{ppm})$ : 237,0 ; I.V. (filme - KBr) Banda de absorção $\left(\mathrm{cm}^{-1}\right)$ : 691, 736, 1024, 1070, 1478, $1578,1712,1799,1873,1946,2855,2928,3056,3070,3399 \mathrm{~cm}^{-1}$; E.M. $\mathrm{m} / \mathrm{z}(\%$ rel.): 286 (68), 172 (96), 158 (71), 129 (23), 91 (78), 77 (70), 69 (96), 55 (100), 51 (48), 45 (42); Microanálise $\left(\mathrm{C}_{14} \mathrm{H}_{22} \mathrm{OSe}\right)$ - Calculado: $\mathrm{C}=58,94 \%$ e H = $7,77 \%$ e observado: $\mathrm{C}=59,31 \%$ e $\mathrm{H}=7,97 \%$.

\subsubsection{Preparação do Hidróxi-seleneto $(R, S)-1 f^{45}$}

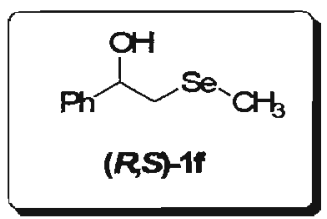

Em um balão de duas bocas equipado com septo, agitação magnética, sob nitrogênio e contendo $\mathrm{Se}^{0}$ em pó $(0,395 \mathrm{~g}-5 \mathrm{mmol})$ em THF seco $(25 \mathrm{~mL})$ foi adicionada lentamente uma solução de MeLi $\left(1,3 \mathrm{MolL}^{-1}\right.$ em hexano) até o ponto de viragem (solução incolor). Em seguida foi adicionado óxido de estireno $(0,57 \mathrm{~mL}-0,600 \mathrm{~g}-5 \mathrm{mmol})$ e foi mantida a agitação sob refluxo durante 24 horas. Ao final deste período a mistura reacional foi transferida para um funil de extração contendo solução saturada de $\mathrm{NH}_{4} \mathrm{Cl}$ e extraída com acetato de etila. A fase orgânica foi lavada com solução saturada de $\mathrm{NaCl}$, seca com $\mathrm{MgSO}_{4}$ e o solvente rotaevaporado. O produto obtido foi prépurificado numa coluna cromatográfica utilizando primeiramente apenas hexano e depois apenas acetato de etila como eluentes. A fase de acetato de etila foi então evaporada e purificada por cromatografia usando uma solução hexanolacetato (9:1) como eluente. 
$(R, S)-1-m e t i l s s e l e n o-2-f e n i l-e t a n o l:$ Óleo; rendimento $=0,828 \mathrm{~g}(77 \%) ; \mathbf{N}^{\circ}$ CAS: 56051-09-3; RMN ${ }^{1} \mathrm{H}\left(200 \mathrm{MHz}, \mathrm{CDCl}_{3}\right), \delta(\mathrm{ppm}): 1,95$ (s; 3H), 2,79 (dd; J $=8,8 \mathrm{~Hz} ; J=12,7 \mathrm{~Hz} ; 1 \mathrm{H}), 2,92(\mathrm{dd} ; J=3,9 \mathrm{~Hz} ; J=12,7 \mathrm{~Hz} ; 1 \mathrm{H}), 4,77(\mathrm{dd} ; J=$ $3,9 \mathrm{~Hz} ; J=8,8 \mathrm{~Hz} ; 1 \mathrm{H}), 7,24-7,39(\mathrm{~m} ; 5 \mathrm{H}) ; \mathrm{RMN}{ }^{13} \mathrm{C}\left(50 \mathrm{MHz}, \mathrm{CDCl}_{3}\right), \delta(\mathrm{ppm})$ : 4,$7 ; 35,8 ; 72,1 ; 125,7 ; 127,7 ; 128,4 ; \mathrm{RMN}^{77} \mathrm{Se}\left(95 \mathrm{MHz}, \mathrm{CDCl}_{3}\right), \delta(\mathrm{ppm}): 30,6$; E.M. $m / z$ (\% rel.): 216 (53), 121(65), 107(94), 91(80), 77(100), 51(66).

\subsubsection{Preparação da Diisopropilamideto de lítio (LDA)}

$$
>\mathbf{N}
$$

Em um balão de duas bocas equipado com septo, com agitação magnética e sob nitrogênio, a diisopropilamina (destilada recentemente $0,202 \mathrm{~g}-2 \mathrm{mmol}$ ) foi dissolvida em THF seco (4mL). A solução foi resfriada a $78^{\circ} \mathrm{C}$ e lentamente foi adicionada a mesma uma solução de $n$-BuLi $(1,43 \mathrm{~mL}$ $1,4 \mathrm{MolL}^{-1} \mathrm{em}$ hexano $-2 \mathrm{mmol}$ ). Após a adição a mistura reacional foi mantida sobre agitação a temperatura ambiente por 30 minutos.

\subsubsection{Preparação do Hidróxi-seleneto $(R, S)-1 g^{47}$}

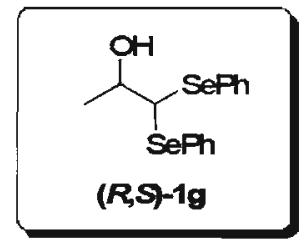

Em um balão de duas bocas equipado com septo, com agitação magnética e sob nitrogênio o bis(fenilsseleno)metano $(0,652 \mathrm{~g}-2 \mathrm{mmol})$ foi dissolvido em THF seco $(8 \mathrm{~mL})$. A solução foi resfriada a $-78^{\circ} \mathrm{C}$ e lentamente foi adicionada à solução de LDA (2mmol). A agitação foi mantida por mais uma hora e em seguida foi adicionado acetaldeído $(0,14 \mathrm{~mL}-0,110 \mathrm{~g}-2,5 \mathrm{mmol})$. Após a adição, a agitação foi mantida por 10 minutos a $-78^{\circ} \mathrm{C}$ e 30 minutos a temperatura ambiente. Ao final deste período a mistura reacional foi transferida para um funil de extração contendo solução saturada de $\mathrm{NH}_{4} \mathrm{Cl}$ e extraída com acetato de etila. A fase orgânica foi lavada com solução saturada de $\mathrm{NaCl}$, seca com $\mathrm{MgSO}_{4}$ e o solvente rotaevaporado. O produto obtido foi pré- 
purificado numa coluna cromatográfica utilizando primeiramente apenas hexano e depois apenas acetato de etila como eluentes. A fase de acetato de etila foi então evaporada e purificada por cromatografia usando uma solução hexano/acetato (9:1) como eluente.

$(R, S)-1,1$-difenilsseleno-2-propanol: Óleo; rendimento $=0,540 \mathrm{~g}(73 \%) ; \mathbf{N}^{\circ}$ CAS: 77461-31-5; RMN ${ }^{1} \mathrm{H}\left(200 \mathrm{MHz}, \mathrm{CDCl}_{3}\right), \delta(\mathrm{ppm}): 1,38$ (d; $\left.J=6,1 \mathrm{~Hz} ; 3 \mathrm{H}\right)$, 2,46 (s;1H), 3,89-3,99 (m;1H), 4,49 (d; $J=3,1 \mathrm{~Hz} ; 1 \mathrm{H}), 7,24-7,30(\mathrm{~m} ; 6 \mathrm{H})$, $7,53-7,62(\mathrm{~m} ; 4 \mathrm{H}) ; \mathrm{RMN}^{13} \mathrm{C}\left(50 \mathrm{MHz}, \mathrm{CDCl}_{3}\right), \delta(\mathrm{ppm}): 20,8 ; 55,3\left(\mathrm{~J}^{1}{ }_{13 \mathrm{c}-77 \mathrm{se}}=\right.$ $86.8 \mathrm{~Hz}) ; 69,2 ; 128,1 ; 128,2 ; 129,2 ; 129,3 ; 129,9 ; 130,3 ; 134,3 ; 135,5$; RMN

${ }^{77} \mathrm{Se}\left(95 \mathrm{MHz}, \mathrm{CDCl}_{3}\right), \delta(\mathrm{ppm}): 355,0 ; 357,9 ;$ E.M. $\mathrm{m} / \mathrm{z}$ (\% rel.): 372 (6), 314 (13), $215(31), 157(62), 117(22), 91$ (77), 77 (93), 51 (72), 43 (100).

\subsubsection{Preparação dos Fenilselenoacetais ${ }^{48}$}

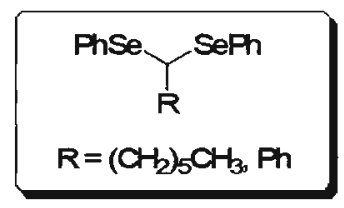

Em um balão de duas bocas equipado com septo, com agitação magnética e sob nitrogênio contendo $\mathrm{PhSeH}(1,570 \mathrm{~g}-10 \mathrm{mmol})$ e o aldeído correspondente $(10 \mathrm{mmol})$ a $0^{\circ} \mathrm{C}$, foi adicionada solução de $\mathrm{H}_{2} \mathrm{SO}_{4}$ (13M $12 \mathrm{mmol}$ ). A agitação foi mantida por 20 minutos e em seguida foi adicionado acetato de etila. A mistura foi lavada com solução $10 \%$ de $\mathrm{NaHCO}_{3}$ e seca com $\mathrm{MgSO}_{4}$. O resíduo foi purificado por coluna cromatografica utilizando hexano como eluente.

\subsubsection{Preparação do Hidróxi-seleneto $(R, S)-1 h-i^{46}$}

Em um balão de duas bocas equipado com septo, com agitação magnética e sob nitrogênio, o selenocetal $(2 \mathrm{mmol})$ de interesse foi dissolvido em THF seco $(8 \mathrm{ml})$. Em seguida, foi adicionada lentamente uma solução de $n$-BuLi $\left(1,43 \mathrm{~mL}-1,4 \mathrm{MolL}^{-1}\right.$ em hexano $\left.-2 \mathrm{mmol}\right)$ a $-78^{\circ} \mathrm{C}$ e mantida a agitação por 30 minutos. Na seqüência, acetaldeido foi adicionado $(0,14 \mathrm{~mL}-0,110 \mathrm{~g}-$ $2,5 \mathrm{mmol}$ ) e a agitação mantida por 20 minutos a $-78^{\circ} \mathrm{C}$ e 1 hora a temperatura ambiente. Ao final deste período a mistura reacional foi transferida para um 
funil de extração contendo solução saturada de $\mathrm{NH}_{4} \mathrm{Cl}$ e extraída com acetato de etila. A fase orgânica foi lavada com solução saturada de $\mathrm{NaCl}$, seca com $\mathrm{MgSO}_{4}$ e o solvente rotaevaporado. O produto obtido foi pré-purificado numa coluna cromatográfica utilizando primeiramente apenas hexano e depois apenas acetato de etila como eluentes. A fase de acetato de etila foi então evaporada e purificada por cromatografia usando uma solução hexano/acetato $(85: 15)$ como eluente.

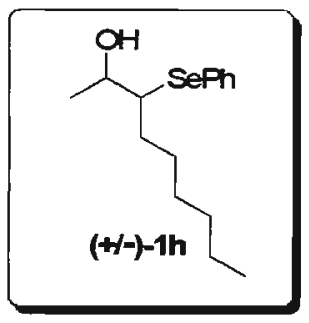

(+/-)-1-hexil-1-(fenilsseleno)-2-propanol: Óleo; mistura diatereoisomérica; rendimento $=0,514 \mathrm{~g}(86 \%) ; \mathrm{RMN}^{1} \mathrm{H}\left(300 \mathrm{MHz}, \mathrm{CDCl}_{3}\right), \delta(\mathrm{ppm}): 0,85-0,93(\mathrm{~m}$; $6 \mathrm{H}), 1,18-1,76(\mathrm{~m} ; 26 \mathrm{H}), 2,08(\mathrm{~s} ; 1 \mathrm{H}), 2,12(\mathrm{~s} ; 1 \mathrm{H}), 2,97-3,03(\mathrm{~m} ; 1 \mathrm{H}), 3,25-3,76$ $(\mathrm{m} ; 1 \mathrm{H}), 3,65-3,76(\mathrm{~m} ; 1 \mathrm{H}), 3,80-3,88(\mathrm{~m} ; 1 \mathrm{H}), 7,20-7,30(\mathrm{~m} ; 6 \mathrm{H}), 7,56-7,60(\mathrm{~m}$; $4 \mathrm{H}) ; \mathrm{RMN}{ }^{13} \mathrm{C}\left(75 \mathrm{MHz}, \mathrm{CDCl}_{3}\right), \delta(\mathrm{ppm}): 14,0 ; 19,8 ; 20,5 ; 22,6 ; 28,1 ; 28,4 ; 29,0$; 29,$1 ; 31,1 ; 31,6 ; 31,7 ; 31,9 ; 57,8 ; 58,0 ; 68,9 ; 69,3 ; 127,5 ; 127,6 ; 129,0 ; 129,1$; 129,6; 134,4; 134,9; E.M. m/z (\% rel.): 300 (30), 255 (6), 172 (5), 158 (59), 157 (24), 91 (16), 78 (49), 77 (40), 69 (100), 55 (96), 51 (20), 45 (63); Microanálise $\left(\mathrm{C}_{15} \mathrm{H}_{24} \mathrm{OSe}\right)$ - Calculado: $\mathrm{C}=60,19 \%$ e $\mathrm{H}=8,08 \%$ e observado: $\mathrm{C}=60,34 \%$ e $\mathrm{H}=8,37 \%$.

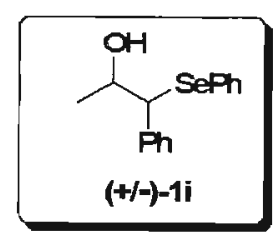

(+/-)-1-fenil-1-(fenilsseleno)-2-propanol: Óleo; mistura diatereoisomérica; rendimento $=0,512 \mathrm{~g}(88 \%) ; \mathrm{N}^{\circ} \mathrm{CAS}: 623575-61-1 ; \mathrm{RMN}^{1} \mathrm{H}\left(200 \mathrm{MHz}, \mathrm{CDCl}_{3}\right)$, $\delta(\mathrm{ppm}): 1,15(\mathrm{~d} ; J=5,7 \mathrm{~Hz} ; 3 \mathrm{H}) ; \delta 1,24$ (d; $J=5,7 \mathrm{~Hz} ; 3 \mathrm{H}) ; 1,95$ (s;2H); 4,07$4,26(\mathrm{~m} ; 4 \mathrm{H}) ; 7,02-7,37(\mathrm{~m} ; 20 \mathrm{H}) ; \mathrm{RMN}{ }^{13} \mathrm{C}\left(75 \mathrm{MHz}, \mathrm{CDCl}_{3}\right), \delta(\mathrm{ppm}): 20,5$; 20,$6 ; 57,3 ; 60,1 ; 69,2 ; 69,6 ; 127,1 ; 127,4 ; 128,3 ; 128,4 ; 128,9 ; 129,0 ; 135,1$; 135,5; E.M. m/z (\% rel.): 292 (11), 247 (4), 158 (30), 157 (15), 135 (86), 117 (51), 91 (62), 78 (32), 77 (39), 57 (73), 51 (25), 43 (100). 


\subsubsection{Preparação do Ditelureto de Difenila ${ }^{75}$}

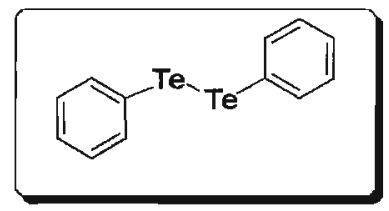

Em um balão de três bocas, equipado com um funil de adição de sólidos, funil de adição, agitador mecânico, contendo raspas de $\mathrm{Mg}^{0}$ (6,07 g $0,25 \mathrm{~mol})$ e alguns cristais de iodo $\left(\mathrm{I}_{2}\right)$ em $\operatorname{THF}(25 \mathrm{ml})$, foi adicionada lentamente uma solução de bromobenzeno $(0,08 \mathrm{~mol})$ em THF $(20 \mathrm{~mL})$. A reação começou rapidamente (observada pela descoloração do iodo) e violentamente, necessitando um banho de água e gelo para controlar a reação. Em seguida foi adicionada mais solução de bromobenzeno $(0,20 \mathrm{~mol})$ em THF seco $(150 \mathrm{~mL})$. Após toda a adição da solução de bromobenzeno, a mistura reacional foi agitada mecanicamente e mantida sobre refluxo até todo $\circ \mathrm{Mg}^{0}$ ser consumido. Após a formação do reagente de Grignard, adicionou-se (sob agitação) $33 \mathrm{~g}(0,25 \mathrm{~mol})$ de telúrio em pó sobre a solução de Grignard. A reação começa em poucos minutos. Logo que algum ditelureto tenha sido formado (caracterizado pela coloração vermelha intensa) resfriamos a solução a zero grau e trocamos o funil de adição por uma tampa de borracha com um tubo de vidro provido de uma torneira ligada a um balão contendo 2,5 litros de oxigênio $\left(\mathrm{O}_{2}\right)$. A cada dez minutos a torneira era aberta para o oxigêrio fluir para dentro do balão. Depois que todo o oxigênio foi consumido (aproximadamente $1 \mathrm{~h}$ ) elevamos a temperatura até a temperatura ambiente e agitamos por mais 1,5h. Ao final de 1,5h despejamos a mistura em um Becker grande e deixamos durante toda à noite em contato com o ar atmosférico. No dia seguinte tratamos a mistura com solução saturada de $\mathrm{NH}_{4} \mathrm{Cl}$, extraímos com éter dietílico, rotaevaporamos o solvente e obtivemos cristais laranja avermelhados de ditelureto de difenila. Os cristais foram recristalizados em álcool $95 \%$ obtendo-se ditelureto de difenila com pureza analítica. O rendimento total da reação foi de $59,36 \mathrm{~g}(58 \%)$. 


\subsubsection{Preparação dos Hidróxi-teluretos $(R, S)-10 a$ e $(R, S)-10 c{ }^{54}$}

Em um balão de duas bocas equipado com septo, com agitação magnética e sob nitrogênio, o ditelureto de difenila $(2,252 \mathrm{~g}-5,5 \mathrm{~mol})$ foi dissolvido em etanol seco (30 mL). Em seguida foi adicionado lentamente $\mathrm{NaBH}_{4}$ em pequenas porções, até a solução permanecer incolor. Após a formação do telurolato, foi adicionado lentamente sobre a mistura reacional o epóxido (óxido de propileno ou estireno - $11 \mathrm{mmol}$ ). A agitação foi mantida durante uma hora. Ao final desse período, a mistura reacional foi lavada três vezes com solução $10 \%$ de $\mathrm{NaCO}_{3}$, extraída com acetato de etila e secada com $\mathrm{MgSO}_{4}$ anidro. O solvente foi rotaevaporado e a purificação foi feita em coluna de sílica utilizando como eluente uma mistura de hexano/acetato de etila (85:15 ou 9:1).

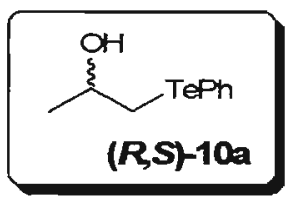

$(R, S)-1$-fenilteluro-2-propanol: Óleo; rendimento $=2,350 \mathrm{~g}(81 \%) ; \mathrm{N}^{\circ}$ CAS: 133617-20-6; $\mathrm{RMN}^{1} \mathrm{H}\left(300 \mathrm{MHz}, \mathrm{CDCl}_{3}\right), \delta(\mathrm{ppm}): 1,30$ (d; $\left.J=6,12 \mathrm{~Hz} ; 3 \mathrm{H}\right), 2,16$ (s; $1 \mathrm{H}), 2,96$ (dd; $J=12,25 \mathrm{~Hz} ; J=7,59 \mathrm{~Hz} ; 1 \mathrm{H}$ ), 3,14 (dd; $J=12,25 \mathrm{~Hz} ; J=$ $4,50 \mathrm{~Hz} ; 1 \mathrm{H}), 3,89-3,95(\mathrm{~m} ; 1 \mathrm{H}), 7,17-7,28(\mathrm{~m} ; 3 \mathrm{H}), 7,72-7,76(\mathrm{~m} ; 2 \mathrm{H})$; $\mathrm{RMN}^{13} \mathrm{C}$ $\left(75 \mathrm{MHz}, \mathrm{CDCl}_{3}\right), \delta(\mathrm{ppm}): 21,5\left(\mathrm{~J}_{13 \mathrm{C}-125 \mathrm{Te}}^{1}=163 \mathrm{~Hz}\right) ; 23,7 ; 67,4 ; 111,2 ; 127,7$; 129,$2 ; 138,4$; RMN ${ }^{125} \mathrm{Te}\left(157 \mathrm{MHz}, 300 \mathrm{~K}, \mathrm{CDCl}_{3}\right), \delta(\mathrm{ppm}): 367.1 ;$ I.V. (filme $\mathrm{KBr}$ ) Banda de absorção $\left(\mathrm{cm}^{-1}\right)$ : 692, 732, 1058, 1320, 1405, 1433, 1451, 1472 , 1573, 2873, 2891, 2924, 2968, 3061, 3371; E.M., m/z (\%rel.): 264 (M+, 21), 222 (19), 207 (18), 130 (10), 91 (26), 77 (100), 59 (96), 51 (60), 45(10); Microanálise $\left(\mathrm{C}_{9} \mathrm{H}_{12} \mathrm{OTe}\right)$ - Calculado: $\mathrm{C}=40,98 \%$ e $\mathrm{H}=4,59 \%$ e observado: $\mathrm{C}=40,63 \%$ e $\mathrm{H}=4,46 \%$.

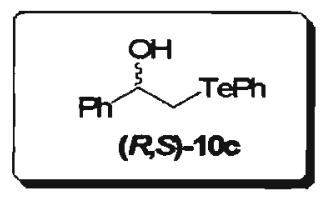

$(R, S)-1$-fenil-2-fenilteluro-etanol: Óleo; rendimento $=2,510 \mathrm{~g}(70 \%)$; $\mathrm{N}^{\circ} \mathrm{CAS}$ 55136-89-5; RMN ${ }^{1} \mathrm{H}\left(300 \mathrm{MHz}, \mathrm{CDCl}_{3}\right), \delta(\mathrm{ppm}): 2,59(\mathrm{~d} ; J=3,51 \mathrm{~Hz} ; 1 \mathrm{H}), 3,26$ (dd; $J=12,13 \mathrm{~Hz} ; J=8,11 \mathrm{~Hz} ; 1 \mathrm{H}$ ), 3,32 (dd; $J=12,13 \mathrm{~Hz} ; J=4,99 \mathrm{~Hz} ; 1 \mathrm{H}$ ), 4,84- 
$4,90(\mathrm{~m} ; 1 \mathrm{H}), 7,15-7,35(\mathrm{~m} ; 8 \mathrm{H}), 7,69-7,72(\mathrm{~m} ; 2 \mathrm{H}) ; \mathrm{RMN}{ }^{13} \mathrm{C}\left(75 \mathrm{MHz}, \mathrm{CDCl}_{3}\right)$, $\delta(\mathrm{ppm}): 20,6 ; 73,6 ; 111,5 ; 125,6 ; 127,7 ; 127,8 ; 128,4 ; 129,2 ; 138,3 ; 143,4 ;$ I.V (filme - KBr) Banda de absorção $\left(\mathrm{cm}^{-1}\right) 697,734,1047,1434,1452,1475$, 1493, 1574, 2874, 2930, 2989, 3029, 3059, 3407; E.M., m/z (\%rel.): 326 (14), $325\left(\mathrm{M}^{+}, 2\right), 220(16), 205(15), 121(18), 103(33), 91(50), 77(100), 51(58)$ Microanálise $\left(\mathrm{C}_{14} \mathrm{H}_{14} \mathrm{OTe}\right)$ - Calculado: $\mathrm{C}=51,60 \%$ e $\mathrm{H}=4,33 \%$ e observado: $\mathrm{C}=51,43 \%$ e $\mathrm{H}=4,25 \%$.

\subsubsection{Preparação do Diazometano ${ }^{76}$}

\section{$\mathrm{CH}_{2} \mathrm{~N}_{2}$}

Utilizando um aparato de destilação sem juntas esmerilhadas, as diversas partes do conjunto (condensador de tubo reto longo, balão, funil de adição, frascos coletores) foram conectadas com rolhas. $O$ condensador foi conectado a uma alonga e esta a dois frascos coletores conectados em série, o primeiro com $500 \mathrm{~mL}$ de capacidade e o segundo com $100 \mathrm{~mL}$; ambos os frascos foram resfriados com uma mistura de gelo picado e sal. No segundo frasco foi adicionado éter etílico $(40 \mathrm{~mL})$ e um tubo de vidro foi conectado de modo que a ponta deste permanecesse abaixo do éter (isto servirá para que qualquer traço de diazometano que escape do primeiro frasco seja capturado neste segundo frasco coletor). Esta preparação foi executada numa capela com exaustão potente em virtude da toxicidade do diazometano. Assim, em um balão de destilação (250 mL) foi depositada uma solução contendo hidróxido de potássio (10 g; $180 \mathrm{mmol})$, água $(15 \mathrm{~mL})$ e etanol $(96 \%-50 \mathrm{~mL})$. A solução no balão de destilação foi aquecida com banho de água $\left(60-65^{\circ} \mathrm{C}\right)$. Em seguida, uma solução de $N$-metil- $N$-nitrosotolueno-p-sulfonamida (43 g; 200 $\mathrm{mmol})$ em éter etílico $(250 \mathrm{~mL})$ foi adicionada lentamente, de forma que a velocidade de adição fosse igual a velocidade de destilação. Após a adição, novas porções de éter etílico foram adicionadas até que o destilado não ficasse mais amarelado (indicando a presença de diazometano). Após a destilação, as soluções de éter dos frascos coletores continham cerca de 5,9 a $6,1 \mathrm{~g}$ de diazometano (rendimento $=70-73 \%$ ). 


\subsubsection{Preparação do Bis(fenilteluro)metano ${ }^{63}$}

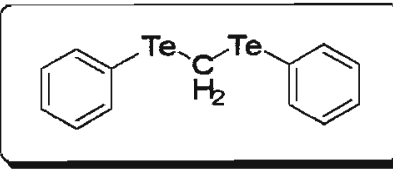

Em um kitassato de $250 \mathrm{~mL}$ sob nitrogênio, equipado com agitação mecânica e com um funil de extração, ditelureto de difenila $(2,047 \mathrm{~g}-5 \mathrm{mmol})$ dissolvido em éter dietilico foi tratado gota a gota com solução de diazometano (em éter dietílico) a $0^{\circ} \mathrm{C}$ até o desaparecimento da cor vermelha do ditelureto de difenila. O produto foi obtido por evaporação do solvente e purificado em coluna cromatográfica utilizando hexano como eluente.

\subsubsection{Preparação do Hidróxi-telureto $(R, S)-10 b^{62}$}

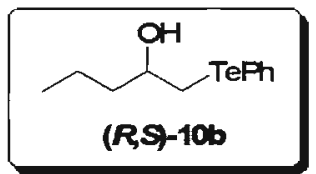

Em um balão de duas bocas equipado com septo, com agitação magnética e sob nitrogênio, o bis(fenilteluro)metano $(0,847 \mathrm{~g}-2 \mathrm{mmol})$ foi dissolvido em THF seco $(8 \mathrm{~mL})$. A mistura foi resfriada a $-78^{\circ} \mathrm{C}$ e foi adicionado $n$-BuLi $\left(1,43 \mathrm{~mL}-1,4 \mathrm{MolL}^{-1} \mathrm{em}\right.$ hexano $\left.-2 \mathrm{mmol}\right)$. A mistura reacional foi mantida sobre agitação durante 30 minutos, em seguida, foi adicionado o butanal $(0,18 \mathrm{~mL}-0,144 \mathrm{~g}-2 \mathrm{mmol})$ e foi mantida a agitação por mais 10 minutos a $-78^{\circ} \mathrm{C}$ e 30 minutos a temperatura ambiente. Ao final desse período a mistura reacional foi transferida para um funil de extração (100 mL) contendo solução saturada de $\mathrm{NH}_{4} \mathrm{Cl}(30 \mathrm{~mL})$ e extraída com acetato de etila. A fase orgânica foi lavada com solução saturada de $\mathrm{NaCl}$, seca com $\mathrm{MgSO}_{4}$ e o solvente evaporado. O produto obtido foi pré-purificado numa coluna cromatográfica utilizando primeiramente apenas hexano e depois apenas acetato de etila. A fase de acetato de etila foi então evaporada e purificada por cromatografia usando uma solução hexano/acetato (9:1) como eluente.

$(\boldsymbol{R}, S)$-1-fenilteluro-2-pentanol: Óleo; rendimento $=0,355 \mathrm{~g}(61 \%) ; \mathrm{RMN}^{1} \mathrm{H}$ $\left(500 \mathrm{MHz}, \mathrm{CDCl}_{3}\right), \delta(\mathrm{ppm}): 0,89(\mathrm{t} ; J=7,32 \mathrm{~Hz} ; 3 \mathrm{H}), 1,32-1,37(\mathrm{~m} ; 1 \mathrm{H}), 1,40-$ $1,47(\mathrm{~m} ; 1 \mathrm{H}), 1,50-1,61(\mathrm{~m} ; 2 \mathrm{H}), 2,14(\mathrm{~s} ; 1 \mathrm{H}), 2,98(\mathrm{dd} ; J=12,26 \mathrm{~Hz} ; J=$ 
$7,94 \mathrm{~Hz} ; 1 \mathrm{H}), 3,16(\mathrm{dd} ; J=12,26 \mathrm{~Hz}, J=4,03 \mathrm{~Hz} ; 1 \mathrm{H}), 3,69-3,74(\mathrm{~m} ; 1 \mathrm{H}), 7,17-$ $7,29(\mathrm{~m} ; 3 \mathrm{H}), 7,73-7,76(\mathrm{~m}, 2 \mathrm{H}) ; \mathrm{RMN}^{13} \mathrm{C}\left(125 \mathrm{MHz}, \mathrm{CDCl}_{3}\right), \delta(\mathrm{ppm}): 13,9 ; 19,2$; 20,$4 ; 40,1 ; 70,8 ; 111,2 ; 127,8 ; 129,3 ; 138,5 ;$ E.M., m/z (\%rel.): 292 (40), 222 (40), 207 (45), 130 (18), 91 (43), 77 (93), 69 (63), 45 (100), 43 (64); Microanálise $\left(\mathrm{C}_{11} \mathrm{H}_{16} \mathrm{OTe}\right)$ - Calculado: $\mathrm{C}=45,27 \%$ e $\mathrm{H}=5,53 \%$ e Observado: $\mathrm{C}=45,62 \%$ e $\mathrm{H}=5,66 \%$.

\subsubsection{Preparação dos Hidróxi-teluretos $(R, S)-10 d$ e $(R, S)-10 e^{54}$}

Em um balão de duas bocas equipado com septo, com agitação magnética e sob nitrogênio, telúrio elementar $(0,638 \mathrm{~g}-5 \mathrm{mmol})$ foi suspenso em THF seco $(20 \mathrm{~mL})$, adicionando-se a seguir lentamente MeLi ou $n$-BuLi até a formação de uma solução límpida amarela. Em seguida, foi adicionado o epóxido correspondente (óxido de estireno ou óxido de propileno $-5 \mathrm{mmol}$ ). A agitação foi mantida por 4 horas. Ao final deste período a mistura reacional foi transferida para um funil de extração contendo solução saturada de $\mathrm{NH}_{4} \mathrm{Cl}$ e extraída com acetato de etila. A fase orgânica foi lavada com solução saturada de $\mathrm{NaCl}$, seca com $\mathrm{MgSO}_{4}$ e o solvente rotaevaporado. O produto obtido foi pré-purificado numa coluna cromatográfica utilizando primeiramente apenas hexano e depois apenas acetato de etila como eluentes. A fase de acetato de etila foi então evaporada e purificada por cromatografia em coluna usando uma solução hexano/acetato (85:15) como eluente.

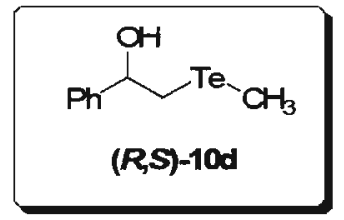

$(\boldsymbol{R}, S)-1-$ metilteluro-2-fenil-etanol: Óleo; rendimento $=0,791 \mathrm{~g}(60 \%) ; \mathrm{RMN}^{1} \mathrm{H}$ $\left(200 \mathrm{MHz}, \mathrm{CDCl}_{3}\right), \delta(\mathrm{ppm}): 1,77(\mathrm{~s} ; 3 \mathrm{H}) ; 2,98-3,03(\mathrm{~m} ; 2 \mathrm{H}) ; 4,78-4,84(\mathrm{~m} ; 1 \mathrm{H})$; $7,27-7,33(\mathrm{~m} ; 5 \mathrm{H}) ; \mathrm{RMN}{ }^{13} \mathrm{C}\left(75 \mathrm{MHz}, \mathrm{CDCl}_{3}\right), \delta(\mathrm{ppm}): 17,3 ; 73,8 ; 125,7 ; 127,8$; 128,$4 ; 143,8 ; \mathrm{RMN}^{125} \mathrm{Te}\left(157 \mathrm{MHz}, 298 \mathrm{~K}, \mathrm{CDCl}_{3}\right), \delta(\mathrm{ppm}): 25,1 ;$ E.M. $\mathrm{m} / \mathrm{z}(\%$ rel.): 226 (32); 160 (61); 140 (9), 121 (71), 103 (73), 91 (44), 77 (100), 65 (14), 43 (80); Microanálise ( $\left.\mathrm{C}_{9} \mathrm{H}_{12} \mathrm{OTe}\right)$ - Calculado: $\mathrm{C}=40,98 \%$ e $\mathrm{H}=4,59 \%$ e observado: $\mathrm{C}=40,71 \%$ e $\mathrm{H}=4,36 \%$. 


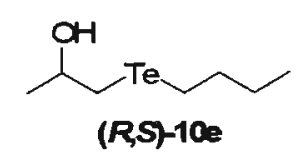

( $R, S)-1$ - $\left(\boldsymbol{n}\right.$-butilteluro)-2-propanol: Óleo; rendimento $=0,794(80 \%)$; N $^{\circ}$ CAS: 4.14902-88-8; $\mathrm{RMN}^{1} \mathrm{H}\left(200 \mathrm{MHz}, \mathrm{CDCl}_{3}\right), \delta(\mathrm{ppm}): 0,92(\mathrm{t} ; J=7,5 \mathrm{~Hz} ; 3 \mathrm{H}), 1,29$ (d; $J=5,7 \mathrm{~Hz} ; 3 \mathrm{H}$ ), 1,32-1,47 (m;2H), 1,72 (quint.; $J=7,5 \mathrm{~Hz} ; 2 \mathrm{H}$ ), 2,54-2,91 (m; $4 \mathrm{H}$ ), 3,86 (sext; $J=5,7 \mathrm{~Hz} ; 1 \mathrm{H}), \mathrm{RMN}^{13} \mathrm{C}\left(50 \mathrm{MHz}, \mathrm{CDCl}_{3}\right), \delta(\mathrm{ppm}): 3,16$; 13,$2 ; 15,6 ; 23,5 ; 24,79\left(J^{1} \mathrm{C}-T_{e}=45,9 \mathrm{~Hz}\right) ; 34,07 ; 67,4 ; \mathrm{RMN}{ }^{125} \mathrm{Te}(157 \mathrm{MHz}$, 298K, $\mathrm{CDCl}_{3}$ ), $\delta(\mathrm{ppm}): 118,5$; E.M. $\mathrm{m} / \mathrm{z}$ (\% rel.): 246 (13); 204 (5); 186 (2), 168 (10), 145 (3), 126 (2), 57 (55), 55 (29) e 41 (100); Microanálise $\left(\mathrm{C}_{7} \mathrm{H}_{16} \mathrm{OTe}\right)$ Calculado $\mathrm{C}=34,49 \%$ e $\mathrm{H}=6,61 \%$ e observado: $\mathrm{C}=34,33 \%$ e $\mathrm{H}=6,32 \%$.

\subsubsection{Preparação do Hidróxi-telureto $(R, S)-10$ f $^{63,64}$}

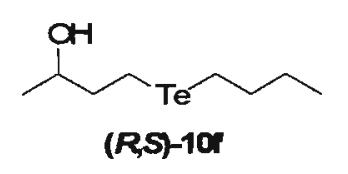

Em um balão de duas bocas equipado com septo, agitação magnética e sob nitrogênio, telúrio elementar $(0,638 \mathrm{~g}-5 \mathrm{mmo})$ foi suspenso em THF seco (10 $\mathrm{mL}$ ), adicionando-se a seguir lentamente $n$-BuLi $\left(3,57 \mathrm{~mL}-1,4 \mathrm{MolL}^{-1} \mathrm{em}\right.$ hexano $-5 \mathrm{mmol}$ ) até a formação de uma solução límpida amarela, a qual foi adicionada água desoxigenada $(10 \mathrm{mmol}-0,18 \mathrm{~mL}$ ). A mistura foi mantida sobre agitação por 5 minutos e foi adicionada de uma só vez a metil vinil cetona (MVK - $5 \mathrm{mmol} ; 0,35 \mathrm{~g} ; 0,4 \mathrm{~mL}$ ). A mistura vermelha resultante foi mantida sobre agitação por 30 minutos e utilizando um funil de adição de líquidos, foi adicionada uma solução de $\mathrm{NaBH}_{4}$ em etanol $(6 \mathrm{mmol}, 0,22 \mathrm{~g} ; 6$ $\mathrm{mL}$ de uma solução $1 \mathrm{molL}^{-1}$ ). A reação foi acompanhada por TLC seguida de diluição em água $(20 \mathrm{~mL})$ e extraida com acetato de etila:hexano 1:1 $(50 \mathrm{~mL})$. As fases foram separadas e a fase aquosa lavada com acetato de etila:hexano (1:1 - 2x $50 \mathrm{~mL}$ ). Na seqüência as fases orgânicas foram combinadas e secas com $\mathrm{MgSO}_{4}$ anidro. $\mathrm{O}$ solvente foi rotaevaporado e a purificação foi realizada por cromatografia em coluna empregando uma solução hexano/acetato (15:1) como eluente. 
$(\boldsymbol{R}, S)-4-\left(\boldsymbol{n}\right.$-butilteluro)-2-butanol: Óleo; rendimento $=0,901 \mathrm{~g}(70 \%) ; \mathrm{N}^{\circ}$ CAS: 861399-10-2; No CAS: 861399-10-2; $\mathrm{RMN}^{1} \mathrm{H}\left(200 \mathrm{MHz}^{\circ} \mathrm{CDCl}_{3}\right), \delta(\mathrm{ppm}): 0,85$ $(\mathrm{t} ; J=7,2 \mathrm{~Hz} ; 3 \mathrm{H}$ ); 1,13 (d; $J=6,3 \mathrm{~Hz} ; 3 \mathrm{H}$ ); 1,31 (sext; $J=7,2 \mathrm{~Hz} ; 2 \mathrm{H}$ ); 1,65 (quint; $J=7,2 \mathrm{~Hz} ; 2 \mathrm{H}) ; 1,76-1,85(\mathrm{~m} ; 2 \mathrm{H}) ; 2,53-2,69(\mathrm{~m} ; 4 \mathrm{H}) ; 3,70-3,81(\mathrm{~m} ; 1 \mathrm{H})$; $\mathrm{RMN}{ }^{13} \mathrm{C}\left(50 \mathrm{MHz}, \mathrm{CDCl}_{3}\right), \delta(\mathrm{ppm}):-2,3 ; 2,7 ; 13,4 ; 23,2 ; 25,0 ; 34,2 ; 41,1 ; 69,1$; RMIN ${ }^{125} \mathrm{Te}\left(157 \mathrm{MHz}, 298 \mathrm{~K}, \mathrm{CDCl}_{3}\right), \delta(\mathrm{ppm}): 251.43 ; \mathrm{MS} \mathrm{m} / \mathrm{z}$ (rel. int.): 260 (13); $258(13) ; 256(7) ; 255(3) ; 254(2) ; 215(3) ; 186(8) ; 72(5) ; 57(73) ; 55(100) ; 45$ (44).

\subsubsection{Preparação da (Z)-butilteluro-enona ${ }^{66,68}$}

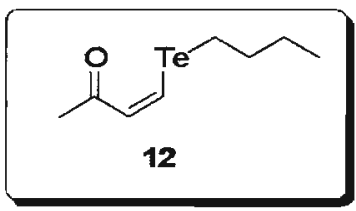

Em um balão de duas bocas equipado com um septo, agitação magnética e sob nitrogênio, foi adicionado THF seco (200 mL). O sistema foi resfriado a $0^{\circ} \mathrm{C}$ e saturado com acetileno, através do borbulhamento de acetileno sobre a solução. Em seguida, $n$-BuLi $\left(38,46 \mathrm{~mL}-1,3 \mathrm{MolL}^{-1} \mathrm{em}\right.$ hexano - $50 \mathrm{mmol}$ ) foi adicionado lentamente por um período de 20 minutos, através de um agulha mergulhada na solução, a fim de evitar a formação de carbeto de lítio, o qual provoca o entupimento da agulha. Na seqüência o sistema foi novamente saturado com acetileno e foi adicionada solução de $\mathrm{ZnCl}_{2}(6,815 \mathrm{~g}-50 \mathrm{mmol})$ em THF $(10 \mathrm{~mL})$ gota-a-gota via seringa. Após a adição, a solução resultante foi aquecida à temperatura ambiente, agitada por 30 minutos e resfriada a $0{ }^{\circ} \mathrm{C}$. Em seguida, foi adicionada lentamente uma solução de cloreto de acetila $(3,925 \mathrm{~g}$ - $50 \mathrm{mmol})$ em THF $(10 \mathrm{~mL})$, mantendose a agitação por 30 minutos a $0{ }^{\circ} \mathrm{C}$ e na seqüência o sistema foi aquecido a temperatura ambiente.

Em um segundo balão de 1L contendo telúrio elementar $(6,6352 \mathrm{~g}-52$ mmol) em THF seco $(150 \mathrm{~mL})$ a $0{ }^{\circ} \mathrm{C}$, foi adicionado $n$-BuLi (40 mL - 1,3 MolL ${ }^{-1}$ em hexano - $52 \mathrm{mmol}$ ) até a formação de uma solução límpida amarelo claro. Em seguida foi adicionada água desoxigenada $(10 \mathrm{~mL})$, mantendo-se a agitação por 10 minutos a temperatura ambiente. A alquinona preparada no 
primeiro balão foi transferida via cânula para o segundo balão, o qual contem o sistema hidrotelurante. O progresso da reação foi monitorado por TLC. Depois de 5 minutos a mistura reacional foi diluída com hexano $(200 \mathrm{~mL})$, lavada com solução saturada de $\mathrm{NaCl}(3 \times 100 \mathrm{~mL})$ e seca com $\mathrm{MgSO}_{4}$. O resíduo foi purificado por cromatografia em coluna empregando uma solução hexano/acetato (20:1) como eluente.

(Z)-4-(butilteluro)but-3-en-2-ona: Óleo; rendimento $=7,868 \mathrm{~g}(62 \%) ;{ }^{1} \mathrm{H}-\mathrm{RMN}$ $\left(\mathrm{CDCl}_{3}, 200 \mathrm{MHz}\right) \delta$ (ppm): 0,92 (t; $J=7,4 \mathrm{~Hz} ; 3 \mathrm{H}$ ), 1,40 (sext; $J=7,4 \mathrm{~Hz} ; 2$ H), 1,80 (quint.; $J=7,4 \mathrm{~Hz} ; 2 \mathrm{H}$ ), 2,24 (s; $3 \mathrm{H}$ ), 2,51 (t; $J=7,4 \mathrm{~Hz} ; 2 \mathrm{H}$ ), 7,53 (d; $J=9,2 \mathrm{~Hz} ; 1 \mathrm{H}), 8,78$ (d; $J=9,2 \mathrm{~Hz} ; 1 \mathrm{H}),{ }^{13} \mathrm{C}-\mathrm{RMN}\left(\mathrm{CDCl}_{3}, 50 \mathrm{MHz}\right) \delta(\mathrm{ppm})$ : 10,$5 ; 13,3 ; 24,9 ; 29,9 ; 33,7 ; 129,5 ; 139,8 ; 197,1 ; \mathrm{RMN}^{125} \mathrm{Te}(157 \mathrm{MHz}, 300 \mathrm{~K}$, $\left.\mathrm{CDCl}_{3}\right), \delta(\mathrm{ppm}): 606,7$; E.M. $m / z(\%$ rel. $): 256\left(\mathrm{M}^{+}+3,8\right) ; 254\left(\mathrm{M}^{+}+1,8\right) ; 252$ (5); 251 (2); 200 (2); 199 (46); 196 (45); 195 (25); 193 (10); 192 (7); 190 (3); 57 (10); 55 (11); 43 (100); I.V. (filme KBr) Banda de absorção $\left(\mathrm{cm}^{-1}\right)$ : 2957; 2922; 2730; 2376; 2064; 1852; 1750; 1644; 1506; 1360; 1334; 1189; 973; 709; 669; Microanálise $\left(\mathrm{C}_{8} \mathrm{H}_{14} \mathrm{OTe}\right)$ - Calculado $\mathrm{C}=37,86 \%$ e $\mathrm{H}=5,38 \%$ e observado: $\mathrm{C}$ $=38,03 \%$ e $\mathrm{H}=5,38 \%$.

\subsubsection{Preparação do Hidróxi-telureto $(R, S)-10 g{ }^{68}$}

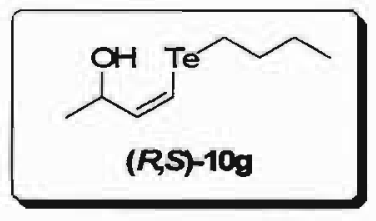

Em um balão de duas bocas equipado com um septo, agitação magnética e sob nitrogênio, a (Z)-butilteluro-enona $(0,253 \mathrm{~g}$ - $1 \mathrm{mmol})$ foi dissolvida em metanol $(5 \mathrm{~mL})$ a $0^{\circ} \mathrm{C}$. Para a solução resultante, uma solução de $\mathrm{NaBH}_{4}$ em etanol ( $1 \mathrm{mmol}-3 \mathrm{~mL}$ etanol) foi adicionada gota-a-gota. A reação foi monitorada por TLC. Depois do consumo de todo o material de partida, a mistura reacional foi diluída com hexano:éter etílico $(1: 1-15 \mathrm{~mL})$, lavada com água $(3 \times 10 \mathrm{~mL})$ e solução saturada de $\mathrm{NaCl}(2 \times 10 \mathrm{~mL})$. O solvente foi evaporado e o resíduo foi purificado por cromatografia em coluna empregando uma solução de hexano:acetato de etila (5:1) como eluente. 
$(R, S)-(Z)-4-\left(\right.$ butilteluro)but-3-en-2-ol: Óleo; rendimento $=0,205 \mathrm{~g}(80 \%) ; \mathbf{N}^{\circ}$ CAS: 835594-73-5; ${ }^{1} \mathrm{H}-\mathrm{RMN}\left(\mathrm{CDCl}_{3}, 300 \mathrm{MHz}\right) \delta$ (ppm): 0,92 (t; $J=7,2 \mathrm{~Hz} ; 3$ $\mathrm{H}$ ), 1,27 (d; $J=6,3 \mathrm{~Hz} ; 3 \mathrm{H}$ ), 1,39 (sext; $J=7,2 \mathrm{~Hz} ; 2 \mathrm{H}$ ), 1,78 (quint.; $J=7,2$ $\mathrm{Hz} ; 2 \mathrm{H}$ ), 1,94 (s; $1 \mathrm{H}$ ), 2,65 (t; $J=7,2 \mathrm{~Hz} ; 2 \mathrm{H}$ ), 4,34 (quint; $J=6,6 \mathrm{~Hz} ; 1 \mathrm{H}$ ), $6,28$ (dd; $J=6,6 \mathrm{~Hz} ; 9,9 \mathrm{~Hz} ; 1 \mathrm{H}), 6,70$ (dd; $J=1,2 \mathrm{~Hz} ; 9,9 \mathrm{~Hz} ; 1 \mathrm{H}$ ); ${ }^{13} \mathrm{C}-\mathrm{RMN}$ $\left(\mathrm{CDCl}_{3}, 75 \mathrm{MHz}\right) \delta(\mathrm{ppm}): 7,2 ; 13,3 ; 22,4 ; 24,9 ; 34,0 ; 70,5 ; 103,4 ; 141,8$; RMN ${ }^{125} \mathrm{Te}\left(157 \mathrm{MHz}, 295 \mathrm{~K}, \mathrm{CDCl}_{3}\right), \delta(\mathrm{ppm}): 280,9 ;$ E.M. $\mathrm{m} / \mathrm{z}$ (\% rel.): $258(13) ; 256$ (12); 201 (15); 199 (15); 71 (100); 57 (60); 55 (40); 53 (35); 45 (22); 43 (81); 41 (55).

\subsubsection{Preparação dos Acetatos dos Hidróxi-calcogenetos ${ }^{49}$}

Em um balão de duas bocas equipado com septo, com agitação magnética e sob nitrogênio, o hidróxi-calcogeneto $(3,6 \mathrm{mmol})$ foi dissolvido em piridina seca $(5 \mathrm{~mL})$. A solução foi resfriada a zero grau $\left(0^{\circ} \mathrm{C}\right)$ e em seguida foi adicionado lentamente anidrido acético $(1,99 \mathrm{~mL}-2,144 \mathrm{~g}-21 \mathrm{mmol})$. Ao final da adição a temperatura foi elevada para a temperatura ambiente. A reação foi acompanhada por CCD. Ao final da reação a mistura reacional foi lavada três vezes com solução $10 \%$ de $\mathrm{HCl}$, três vezes com solução saturada de $\mathrm{CuSO}_{4} \mathrm{e}$ extraída com acetato de etila. A fase orgânica foi lavada com solução saturada de $\mathrm{NaCl}$, seca com $\mathrm{MgSO}_{4}$ e o solvente rotaevaporado. A purificação foi realizada por coluna cromatogratográfica usando uma solução hexano/acetato (95:5) como eluente.

\section{مserh \\ (R,S)-2a}

$(R, S)$-O-acetil-1-fenilsseleno-2-propanol: Óleo; rendimento = 0,842g (91\%); RMN ${ }^{1} \mathrm{H}\left(300 \mathrm{MHz}, \mathrm{CDCl}_{3}\right), \delta(\mathrm{ppm}): 1,33(\mathrm{~d} ; \mathrm{J}=6,30 \mathrm{~Hz} ; 3 \mathrm{H}), 1,94(\mathrm{~s} ; 3 \mathrm{H}), 2,99$ (dd; $J=12,80 \mathrm{~Hz}$ e $J=6,23 \mathrm{~Hz} ; 1 \mathrm{H}$ ), 3,10 (dd; $J=12,80 \mathrm{~Hz}$ e $J=6,13 \mathrm{~Hz} ; 1 \mathrm{H}$ ), $5,04-5,10(\mathrm{~m} ; 1 \mathrm{H}), 7,21-7,30(\mathrm{~m} ; 3 \mathrm{H}), 7,50-7,54(\mathrm{~m} ; 2 \mathrm{H})$; RMN ${ }^{13} \mathrm{C}(75 \mathrm{MHz}$, $\left.\mathrm{CDCl}_{3}\right), \delta(\mathrm{ppm}): 19,8 ; 21,1 ; 33,0 ; 70,3 ; 127,1 ; 129,1 ; 129,9 ; 132,8 ; 170,4 ; \mathrm{RMN}$ ${ }^{77} \mathrm{Se}\left(95 \mathrm{MHz}, \mathrm{CDCl}_{3}\right), \delta(\mathrm{ppm}): 264,3 ;$ I.V. (filme - KBr) Banda de absorção(cm $\left.{ }^{1}\right): 691,738,1242,1371,1438,1453,1478,1578,1737,2932,2980,3057$, 
3071; E.M., m/z (\%rel.): 257 (M+; 1), 215 (1), 198 (12), 181 (4), 157(5), 101 (13), 78 (7), 77 (11), 43 (100); Microanálise $\left(\mathrm{C}_{11} \mathrm{H}_{14} \mathrm{O}_{2} \mathrm{Se}\right)$ - Calculado: $\mathrm{C}=$ $51,37 \%$ e $\mathrm{H}=5,49 \%$ e observado $: \mathrm{C}=51,50 \%$ e $\mathrm{H}=5,54 \%$.

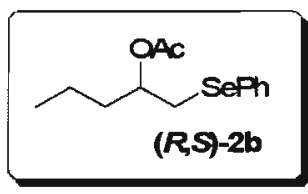

$(R, S)$-O-acetil-1-fenilsseleno-2-pentanol: Óleo; rendimento $=0,944 \mathrm{~g}(92 \%)$; $\mathrm{RMN}^{1} \mathrm{H}\left(500 \mathrm{MHz}, \mathrm{CDCl}_{3}\right), \delta(\mathrm{ppm}): 0,89(\mathrm{t} ; J=7,37 \mathrm{~Hz} ; 3 \mathrm{H}), 1,24-1,36(\mathrm{~m} ; 2 \mathrm{H})$, $1,63-1,68(\mathrm{~m} ; 2 \mathrm{H}), 1.94(\mathrm{~s} ; 3 \mathrm{H}), 3,07(\mathrm{~d} ; J=6,00 \mathrm{~Hz} ; 2 \mathrm{H}), 5.01-5.06(\mathrm{~m} ; 1 \mathrm{H})$, $7.21-7.33(\mathrm{~m} ; 3 \mathrm{H}), 7.51-7.54(\mathrm{~m} ; 2 \mathrm{H}) ; \mathrm{RMN}^{13} \mathrm{C}\left(125 \mathrm{MHz}, \mathrm{CDCl}_{3}\right), \delta(\mathrm{ppm}): 13,8$; 18,$5 ; 21,0 ; 31,6 ; 35,9 ; 73,2 ; 127,1 ; 129,1 ; 130,1 ; 132,8 ; 170,6 ; \mathrm{RMN}^{77} \mathrm{Se}$ $\left(95 \mathrm{MHz}, \mathrm{CDCl}_{3}\right), \delta(\mathrm{ppm}): 260,3$; I.V. (filme $-\mathrm{KBr}$ ) Banda de absorção $\left(\mathrm{cm}^{-1}\right)$ : $692,738,1237,1372,1435,1459,1474,1578,1739,2872$, 2960, 3057; E.M., $\mathrm{m} / \mathrm{z}$ (\%rel.): $286(27), 285\left(\mathrm{M}^{+}, 3\right), 226(51), 157$ (35), 129 (41), 116(49), 91 (52), 78 (45), 77 (51), $69(80), 51(44), 43$ (100); Microanálise $\left(\mathrm{C}_{13} \mathrm{H}_{18} \mathrm{O}_{2} \mathrm{Se}\right)$ Calculado: $\mathrm{C}=54,74 \%$ e $\mathrm{H}=6,36 \%$ e observado: $\mathrm{C}=54,60 \%$ e $\mathrm{H}=6,36 \%$.

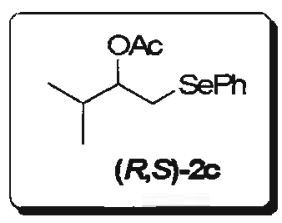

( $R, S)$-O-acetil-1-fenilsseleno-3-metil-2-butanol: Óleo; rendimento $=0,985 \mathrm{~g}$ (96\%;) RMN ${ }^{1} \mathrm{H}\left(200 \mathrm{MHz}, \mathrm{CDCl}_{3}\right), \delta(\mathrm{ppm}): 0,77-0,98(\mathrm{~m} ; 7 \mathrm{H}), 1,95(\mathrm{~s} ; 3 \mathrm{H})$, 3,05-3,09 (m; 2H), 4,85-4,97 (m; 1H), 7,23-7,32 (m; 3H), 7,50-7,55 (m; $2 \mathrm{H})$; $\mathrm{RMN}{ }^{13} \mathrm{C}\left(125 \mathrm{MHz}, \mathrm{CDCl}_{3}\right), \delta(\mathrm{ppm}): 17,3 ; 18,4 ; 18,7 ; 20,8 ; 47,9 ; 77,4 ; 127,0$; 129,$0 ; 129,1 ; 132,9 ; 170,7 ; \mathrm{NMR}^{77} \mathrm{Se}\left(95 \mathrm{MHz}, \mathrm{CDCl}_{3}\right), \delta(\mathrm{ppm}): 265,4$; I.V. (filme - KBr) Banda de absorção $\left(\mathrm{cm}^{-1}\right): 694,739,1021,1301,1474,1578$, 1744, 2874, 2934, 2965, 3032, 3058; E.M. m/z (\% rel.): 286 (20), 226 (44), 171 (10), 157 (24), 91 (45), 77 (42), 69 (96), 43 (100); Microanálise $\left(\mathrm{C}_{13} \mathrm{H}_{18} \mathrm{O}_{2} \mathrm{Se}\right)$ Calculado: $\mathrm{C}=54,74 \%$ e $\mathrm{H}=6,36 \%$ e observado: $\mathrm{C}=54,91 \%$ e $\mathrm{H}=6,31 \%$. 


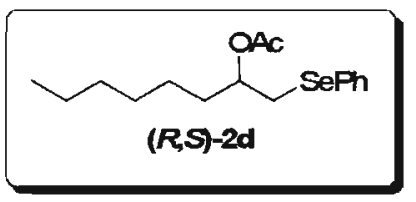

$(R, S)-O-a c e t i l-1-f e n i l s s e l e n o-2-o c t a n o l:$ Óleo; rendimento $=0,965 \mathrm{~g}(82 \%) ; \mathbf{N}^{\circ}$ CAS: 67007-28-7; RMN ${ }^{1} \mathrm{H}\left(500 \mathrm{MHz}, \mathrm{CDCl}_{3}\right), \delta(\mathrm{ppm}): 0,86(\mathrm{t} ; J=7,2 \mathrm{~Hz} ; 3 \mathrm{H})$, $1,23-1,29(\mathrm{~m} ; 8 \mathrm{H}), 1,62-1,70(\mathrm{~m} ; 2 \mathrm{H}), 1,93(\mathrm{~s} ; 3 \mathrm{H}), 3,06(\mathrm{~d} ; \mathrm{J}=6,0 \mathrm{~Hz} ; 2 \mathrm{H})$, 4,99-5,04 (m; 1H), 7,21-7,28 (m; 3H), 7,51-7,54 (m; $2 \mathrm{H})$; RMN ${ }^{13} \mathrm{C}(125 \mathrm{MHz}$, $\left.\mathrm{CDCl}_{3}\right), \delta(\mathrm{ppm}): 14,0 ; 21,0 ; 22,5 ; 25,2 ; 29,1 ; 31,6 ; 33,8 ; 73,4 ; 127,6 ; 129,9$; 132,$8 ; 140,9 ; 170,6 ; \mathrm{RMN}^{77} \mathrm{Se}\left(95 \mathrm{MHz}, \mathrm{CDCl}_{3}\right), \delta(\mathrm{ppm})$ : 264,0; I.V. (filme $\mathrm{KBr}$ ) Banda de absorção $\left(\mathrm{cm}^{-1}\right)$ : 691, 736, 1022, 1239, 1579, 1738, 2858, 2959, 2955, 3016, 3058; E.M. m/z (\% rel.): 328 (15), 268 (44), 171 (25), 158 (6), 91 (46), 77 (38), 69 (89), 43 (100); Microanálise $\left(\mathrm{C}_{16} \mathrm{H}_{24} \mathrm{O}_{2} \mathrm{Se}\right)$ - Calculado: $\mathrm{C}=$ $58,71 \%$ e $\mathrm{H}=7,39 \%$ e observado: $\mathrm{C}=59,12 \%$ e $\mathrm{H}=7,67 \%$.

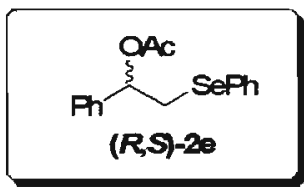

$(R, S)$ - O-acetil-1-fenil-2-fenilsseleno-etanol: Óleo; rendimento $=0,838 \mathrm{~g}$ $(73 \%) ; \mathrm{RMN}^{1} \mathrm{H}\left(300 \mathrm{MHz}, \mathrm{CDCl}_{3}\right), \delta(\mathrm{ppm}): 2,01$ (s; 3H), 3,22 (dd; $J=12,8 \mathrm{~Hz} \mathrm{e}$ $J=5,7 \mathrm{~Hz} ; 1 \mathrm{H}$ ), 3,37 (dd; $J=12,8 \mathrm{~Hz} ; J=7,9 \mathrm{~Hz} ; 1 \mathrm{H}$ ), 5,93 (dd; $J=7,9 \mathrm{~Hz} ; J=$ $5,7 \mathrm{~Hz} ; 1 \mathrm{H}), 7,23-7,55(\mathrm{~m} ; 10 \mathrm{H}) ; \mathrm{RMN}{ }^{13} \mathrm{C}\left(75 \mathrm{MHz}, \mathrm{CDCl}_{3}\right), \delta(\mathrm{ppm}): 21,0 ; 33,4$; 75,$2 ; 126,6 ; 127,2 ; 128,3 ; 128,5 ; 129,1 ; 133,1 ; 140,4 ; 170,0 ;$ RMN ${ }^{77} \mathrm{Se}$ $\left(95 \mathrm{MHz}, \mathrm{CDCl}_{3}\right), \delta(\mathrm{ppm}): 275,6$; Microanálise $\left(\mathrm{C}_{16} \mathrm{H}_{16} \mathrm{O}_{2} \mathrm{Se}\right)$ - Calculado: $\mathrm{C}=$ $60,19 \%$ e $\mathrm{H}=5,05 \%$ e observado: $\mathrm{C}=59,97 \%$ e $\mathrm{H}=5,39 \%$

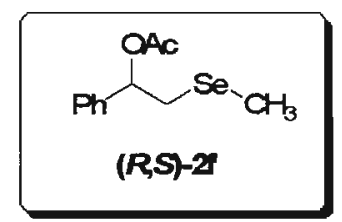

$(\boldsymbol{R}, \boldsymbol{S})$-O-acetil-1-metilsseleno-2-fenil-etanol: Óleo; rendimento $=0,851 \mathrm{~g}$ (92\%); No CAS: 56268-17-8; RMN ${ }^{1} \mathrm{H}\left(200 \mathrm{MHz}, \mathrm{CDCl}_{3}\right), \delta(\mathrm{ppm}): 1,91(\mathrm{~s} ; 3 \mathrm{H})$, 2,09 (s; 3H), 2,87 (dd; $J=6,6 \mathrm{~Hz} ; J=12,9 H z ; 1 \mathrm{H}$ ), 3,00 (dd; $J=7,46 ; J=12,9 \mathrm{~Hz}$; $1 \mathrm{H}), 5,86-5,93(\mathrm{~m} ; 1 \mathrm{H}), 7,26-7,38(\mathrm{~m} ; 5 \mathrm{H}) ; \mathrm{RMN}{ }^{13} \mathrm{C}\left(50 \mathrm{MHz}, \mathrm{CDCl}_{3}\right), \delta(\mathrm{ppm})$ : 5,$0 ; 21,1 ; 30,7 ; 75,4 ; 126,7 ; 128,3 ; 128,5 ; 139,6 ; 170,0 ;$ RMN ${ }^{77} \mathrm{Se}(95 \mathrm{MHz}$, 
$\left.\mathrm{CDCl}_{3}\right), \delta(\mathrm{ppm}): 64,3$; E.M. m/z (\% rel.): 258 (14), 198 (48), 181 (10), 163 (42), $149(6), 104(50), 91(37), 77(48), 43(100)$.

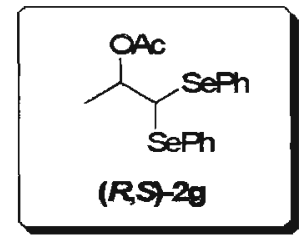

$(\boldsymbol{R}, \mathbf{S})$-O-acetil-1,1-difenilsseleno-2-propanol: Óleo; rendimento $=1,424 \mathrm{~g}$ (96\%); RMN ${ }^{1} \mathrm{H}\left(200 \mathrm{MHz}, \mathrm{CDCl}_{3}\right), \delta(\mathrm{ppm}): 1,45$ (d; J =6,6Hz;3H), 1,88 (s;3H), $4,52(\mathrm{~d} ; J=3,5 \mathrm{~Hz} ; 1 \mathrm{H}), 5,14-5,25(\mathrm{~m} ; 1 \mathrm{H}), 7,22-7,33(\mathrm{~m} ; 6 \mathrm{H}), 7,52-7,55(\mathrm{~m}$; $4 \mathrm{H}) ; \mathrm{RMN}{ }^{13} \mathrm{C}\left(50 \mathrm{MHz}, \mathrm{CDCl}_{3}\right), \delta(\mathrm{ppm}): 18,2 ; 20,8 ; 48,8 ; 72,7 ; 128,1 ; 128,2$; 129,$1 ; 129,2 ; 130,2 ; 130,5 ; 134,2 ; 134,9 ; 170,2 ; \mathrm{NMR}{ }^{77} \mathrm{Se}\left(95 \mathrm{MHz}, \mathrm{CDCl}_{3}\right)$, $\delta$ (ppm): 374,7; 382,4; E.M. m/z (\% rel.): 414 (7), 257 (46), 215 (58), 197 (52), 157 (46), 116 (34), 91 (31), 77 (64), 51 (52), 43 (100); Microanálise $\left(\mathrm{C}_{17} \mathrm{H}_{18} \mathrm{O}_{2} \mathrm{Se}_{2}\right)$ - Calculado: $\mathrm{C}=49,53 \%$ e $\mathrm{H}=4,40$ e observado: $\mathrm{C}=49,41$ e $\mathrm{H}$ $=4,68$.

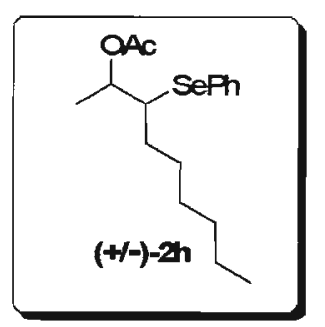

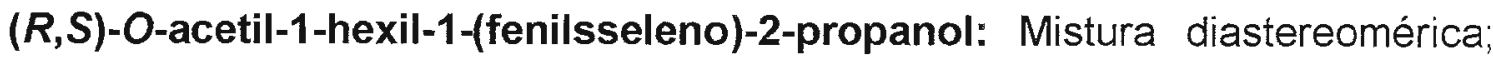
óleo; rendimento $=1,154 \mathrm{~g}(94 \%) ; \mathrm{RMN}^{1} \mathrm{H}\left(300 \mathrm{MHz}, \mathrm{CDCl}_{3}\right), \delta(\mathrm{ppm}): 0,84-0,90$ $(\mathrm{m} ; 6 \mathrm{H}), 1,24-1,29(\mathrm{~m} ; 16 \mathrm{H}), 1,31$ (d; $J=6,3 \mathrm{~Hz} ; 3 \mathrm{H}), 1,36(\mathrm{~d} ; J=6,3 \mathrm{~Hz} ; 3 \mathrm{H})$, $1,50-1,80(\mathrm{~m} ; 4 \mathrm{H}), 1,81(\mathrm{~s} ; 3 \mathrm{H}), 1,99(\mathrm{~s} ; 3 \mathrm{H}), 3,17-3,23(\mathrm{~m} ; 1 \mathrm{H}), 3,27-3,34(\mathrm{~m}$; $1 \mathrm{H}), 5,01-5,16(\mathrm{~m} ; 2 \mathrm{H}), 7,24-7,27(\mathrm{~m} ; 6 \mathrm{H}), 7,55-7,59(\mathrm{~m} ; 4 \mathrm{H}) ; \mathrm{RMN}{ }^{13} \mathrm{C}$ $\left(75 \mathrm{MHz}, \mathrm{CDCl}_{3}\right), \delta(\mathrm{ppm}): 14,0 ; 17,2 ; 17,2 ; 20,9 ; 21,1 ; 22,5 ; 28,0 ; 29,0 ; 31,4$; 31,$6 ; 31,7 ; 50,5 ; 51,7 ; 72,6 ; 73,0 ; 127,2 ; 127,4 ; 128,9 ; 129,9 ; 130,0 ; 134,0$; 134,7; 170,4; E.M. m/z (\% rel.): 342 (2), 282 (4), 157 (20), 91 (4), 77 (30), 69 (100), 55 (94), 51 (18); Microanálise $\left(\mathrm{C}_{17} \mathrm{H}_{26} \mathrm{O}_{2} \mathrm{Se}\right)$ - Calculado: $\mathrm{C}=59,82 \%$ e H $=7,68 \%$ e observado: $\mathrm{C}=60,4 \%$ e $\mathrm{H}=7,82 \%$. 


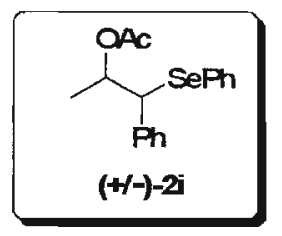

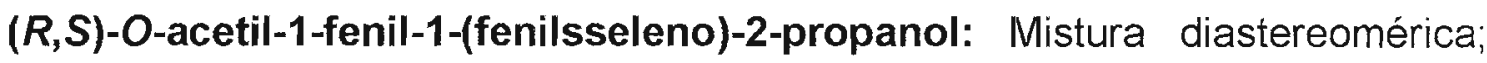
óleo; rendimento $=1,103 \mathrm{~g}(92 \%) ; \mathrm{RMN}^{1} \mathrm{H}\left(200 \mathrm{MHz}, \mathrm{CDCl}_{3}\right), \delta(\mathrm{ppm}): 1,20$ (d; J $=6,1 \mathrm{~Hz} ; 3 \mathrm{H}), 1,30(\mathrm{~d} ; J=6,1 \mathrm{~Hz} ; 3 \mathrm{H}), 1,90(\mathrm{~s} ; 3 \mathrm{H}), 1,98(\mathrm{~s} ; 3 \mathrm{H}), 4,27-4,37(\mathrm{~m}$; $2 \mathrm{H}), 5,33-5,49(\mathrm{~m} ; 2 \mathrm{H}), 7,11-7,28(\mathrm{~m} ; 16 \mathrm{H}), 7,35-7,43(\mathrm{~m} ; 4 \mathrm{H}) ; \mathrm{RMN}{ }^{13} \mathrm{C}$ $\left(125 \mathrm{MHz}, \mathrm{CDCl}_{3}\right), \delta(\mathrm{ppm}): 18,9 ; 20,9 ; 21,1 ; 53,4 ; 53,7 ; 72,4 ; 73,4 ; 127,3 ; 127,7$; 127,$9 ; 128,2 ; 128,4 ; 128,7 ; 128,9 ; 129,1 ; 129,5 ; 135,0 ; 135,4 ; 170,2 ; 170,4$; E.M. $m / z$ (\% rel.): 334 (11), 274 (8), 177 (52), 158 (11), 157 (19), 135 (73), 117 (61), 91 (41), 78 (39), 77 (44), 57 (38), 51 (35), 43 (100); Microanálise $\left(\mathrm{C}_{17} \mathrm{H}_{18} \mathrm{O}_{2} \mathrm{Se}\right)$ - Calculado: $\mathrm{C}=61,26 \%$ e $\mathrm{H}=5,44 \%$ e observado: $\mathrm{C}=61,42 \%$ e $\mathrm{H}=5,56 \%$.

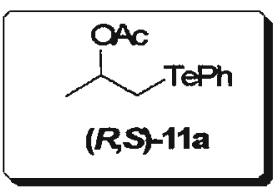

$(R, S)-O$-acetil-1-fenilteluro-2-propanol: Óleo; rendimento $=0,925 \mathrm{~g}(84 \%)$; $\mathrm{RMN}^{1} \mathrm{H}\left(300 \mathrm{MHz}, \mathrm{CDCl}_{3}\right), \delta(\mathrm{ppm}): 1,34(\mathrm{~d} ; \mathrm{J}=6,24 \mathrm{~Hz} ; 3 \mathrm{H}), 1,93(\mathrm{~s} ; 3 \mathrm{H}), 3,08$ $(\mathrm{d} ; J=6,19 \mathrm{~Hz} ; 2 \mathrm{H}), 5,03-5,13(\mathrm{~m} ; 1 \mathrm{H}), 7,17-7,28(\mathrm{~m} ; 3 \mathrm{H}), 7,73-7,76(\mathrm{~m} ; 2 \mathrm{H})$; $\mathrm{RMN}^{13} \mathrm{C}\left(75 \mathrm{MHz}, \mathrm{CDCl}_{3}\right), \delta(\mathrm{ppm}): 14,8\left(\mathrm{~J}_{13 \mathrm{C}-125 \mathrm{Te}}=173 \mathrm{~Hz}\right) ; 21,1 ; 21,2 ; 71,4$; 111,$5 ; 127,8 ; 128,2 ; 138,5 ; 170,3 ; \mathrm{RMN}^{125} \mathrm{Te}\left(157 \mathrm{MHz}, 300 \mathrm{~K}, \mathrm{CDCl}_{3}\right), \delta(\mathrm{ppm})$ : 440,5 ; I.V. (filme - KBr) Banda de absorção $\left(\mathrm{cm}^{-1}\right)$ : 692, 733, 1241, 1372, 1434, 1574, 1735, 2870, 2932, 2979, 3059; E.M. m/z (\%rel.): $306\left(M^{+}, 5\right), 249(2), 222$ (1), 207 (5), 101 (36), 77 (26), 43 (100); Microanálise $\left(\mathrm{C}_{11} \mathrm{H}_{14} \mathrm{O}_{2} \mathrm{Te}\right)$ - Calculado: $\mathrm{C}=43,20 \%$ e $\mathrm{H}=4,61 \%$ e observado: $\mathrm{C}=43,10 \%$ e $\mathrm{H}=4,61 \%$.

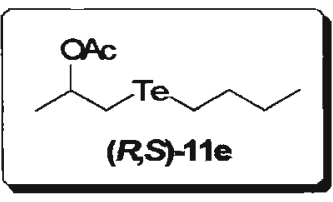

$(\boldsymbol{R}, S)-O$-acetil-1-( $\boldsymbol{n}$-butilteluro)-2-propanol: Óleo; rendimento $=0,875 \mathrm{~g}(85 \%)$; RMN ${ }^{1} \mathrm{H}\left(500 \mathrm{MHz}, \mathrm{CDCl}_{3}\right), \delta(\mathrm{ppm}): 0,92(\mathrm{t} ; J=7,4 \mathrm{~Hz} ; 3 \mathrm{H}), 1,35(\mathrm{~d} ; J=6,2 \mathrm{~Hz}$; $3 \mathrm{H}), 1,36-1,42(\mathrm{~m} ; 2 \mathrm{H}), 1,73$ (sext; $J=7,4 \mathrm{~Hz} 2 \mathrm{H}), 2,04(\mathrm{~s} ; 3 \mathrm{H}), 2,69(\mathrm{t} ; J=$ $7,4 \mathrm{~Hz} ; 2 \mathrm{H}$ ), 2,77 (dd; $J=7,2 ; J=12,2 \mathrm{~Hz} ; 1 \mathrm{H}), 2,83$ (dd; $J=5,6 ; J=12,2 \mathrm{~Hz}$; 
$1 \mathrm{H}), 5,00$ (sext.; $J=6,2 \mathrm{~Hz} 1 \mathrm{H}) ; \mathrm{RMN}^{13} \mathrm{C}\left(125 \mathrm{MHz}, \mathrm{CDCl}_{3}\right), \delta(\mathrm{ppm}): 3,7\left(J_{13 \mathrm{C}}\right.$ $\left.{ }_{125 \mathrm{Te}}=147 \mathrm{~Hz}\right) ; 8,7\left(J^{1}{ }_{13 \mathrm{C}-125 \mathrm{Te}}=173 \mathrm{~Hz}\right) ; 13,4 ; 20,9 ; 21,3 ; 25,0 ; 34,2 ; 72,0$ 170,$4 ;{ }^{125} \mathrm{Te}$ NMR $\left(157 \mathrm{MHz}, 300 \mathrm{~K}, \mathrm{CDCl}_{3}\right), \delta(\mathrm{ppm}): 189,0 ;$ E.M. $\mathrm{m} / \mathrm{z}$ (\% rel.): 288 (6), 258(2), 187 (3), 172 (8), 101 (29), 57 (18), 43 (100); Microanalise $\left(\mathrm{C}_{9} \mathrm{H}_{18} \mathrm{O} 2 \mathrm{Te}\right)$ - Calculado: $\mathrm{C}=37,82 \%$ e $\mathrm{H}=6,35 \%$ e observado: $\mathrm{C}=37,80$ e $\mathrm{H}$ $=6,38$.

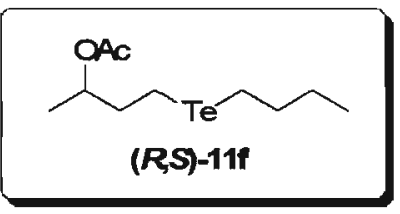

$(\boldsymbol{R}, S)-O$-acetil-4-( $\boldsymbol{n}$-butilteluro)-2-butanol: Óleo; rendimento $=0,993 \mathrm{~g}(92 \%)$; $\mathrm{RMN}^{1} \mathrm{H}\left(300 \mathrm{MHz}, \mathrm{CDCl}_{3}\right), \delta(\mathrm{ppm}): 0,92(\mathrm{t} ; J=7,5 \mathrm{~Hz} ; 3 \mathrm{H}), 1,23$ (d; $J=6,3 \mathrm{~Hz}$; $3 \mathrm{H}$ ), 1,38 (sext.; $J=7,5 \mathrm{~Hz} ; 2 \mathrm{H}$ ), 1,72 (quint.; $J=7,5 \mathrm{~Hz} ; 2 \mathrm{H}$ ), 2,04 (s; $3 \mathrm{H}$ ), 1,87$2,11(\mathrm{~m} ; 2 \mathrm{H}), 2,49-2,67(\mathrm{~m} ; 4 \mathrm{H}) ; \mathrm{RMN}{ }^{13} \mathrm{C}\left(75 \mathrm{MHz}, \mathrm{CDCl}_{3}\right), \delta(\mathrm{ppm}):-3,6 ; 2,8$; 13,$4 ; 19,5 ; 21,3 ; 25,0 ; 34,2 ; 38,8 ; 72,2 ; 170,6 ;{ }^{125} \mathrm{Te} \mathrm{NMR}(157 \mathrm{MHz}, 298 \mathrm{~K}$, $\left.\mathrm{CDCl}_{3}\right), \delta(\mathrm{ppm}): 270,1$; Microanalise $\left(\mathrm{C}_{10} \mathrm{H}_{20} \mathrm{O}_{2} \mathrm{Te}\right)$ - Calculado: $\mathrm{C}=40,05 \%$ e H $=6,72 \%$ e observado: $\mathrm{C}=40,02 \mathrm{e} \mathrm{H}=6,53$.

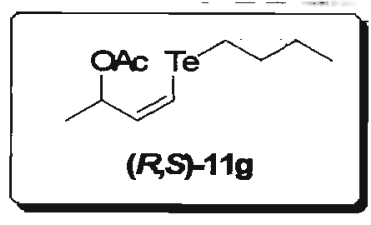

$(\boldsymbol{R}, \mathbf{S})$-(Z)-O-acetil-4-(butilteluro)but-3-en-2-ol: Óleo; rendimento $=1,008 \mathrm{~g}$ (94\%); RMN ${ }^{1} \mathrm{H}\left(300 \mathrm{MHz}, \mathrm{CDCl}_{3}\right), \delta(\mathrm{ppm}): 0,92$ (t; $\left.J=7,5 \mathrm{~Hz} ; 3 \mathrm{H}\right), 1,30$ (d; $J=$ $6,3 \mathrm{~Hz} ; 3 \mathrm{H}$ ), 1,39 (sext; $J=7,5 \mathrm{~Hz} ; 2 \mathrm{H}$ ), 1,78 (quint; $J=7,5 \mathrm{~Hz} ; 2 \mathrm{H}$ ), 2,06 (s; $3 \mathrm{H}$ ), 2,67 (t; $J=7,5 \mathrm{~Hz} ; 2 \mathrm{H}), 5,25-5,37(\mathrm{~m}, 1 \mathrm{H}) ; 6,25$ (dd; $J=7,2 \mathrm{~Hz}$ e $J=9,9 \mathrm{~Hz}$; $1 \mathrm{H}), 6,83(\mathrm{~d} ; J=9,9 ; 1 \mathrm{H}) ; \mathrm{RMN}^{13} \mathrm{C}\left(75 \mathrm{MHz}, \mathrm{CDCl}_{3}\right), \delta(\mathrm{ppm}): 7,2 ; 13,4 ; 19,6$; 21,$26 ; 24,9 ; 34,0 ; 72,9 ; 105,6 ; 138,0 ; 170,1 ;{ }^{125} \mathrm{Te}$ NMR $(157 \mathrm{MHz}, 298 \mathrm{~K}$, $\left.\mathrm{CDCl}_{3}\right), \delta$ (ppm): 293,6 Microanalise $\left(\mathrm{C}_{10} \mathrm{H}_{18} \mathrm{O}_{2} \mathrm{Te}\right)$ - Calculado: $\mathrm{C}=40,32 \%$ e H $=6,09 \%$ e observado: $\mathrm{C}=40,48$ e $\mathrm{H}=5,92$.

\subsubsection{Resolução Enzimática em Meio Orgânico}

Em um Erlenmayer de $50 \mathrm{~mL}$ provido de rolha de silicone ou septo, o $( \pm$ )-hidróxi-calcogeneto $(0,5 \mathrm{mmol})$ foi dissolvido em solvente orgânico seco (10 
$\mathrm{mL}-25 \mathrm{~mL}$ ). Em seguida, foi adicionada a lipase e acetato de vinila ( $3 \mathrm{mmol}$ ). A mistura resultante foi mantida sob agitação contínua (160 r.p.m.) e temperatura constante $\left(10-40^{\circ} \mathrm{C}\right.$ - Figura 3.2.20.1). A reação foi acompanhada por CG-quiral. Ao final da reação (aproximadamente $50 \%$ de conversão) a enzima foi removida por filtração simples ou por centrifugação, e o solvente rotaevaporado. A separação dos produtos foi realizada por coluna cromatogratográfica usando uma solução hexano/acetato (9:1) como eluente.
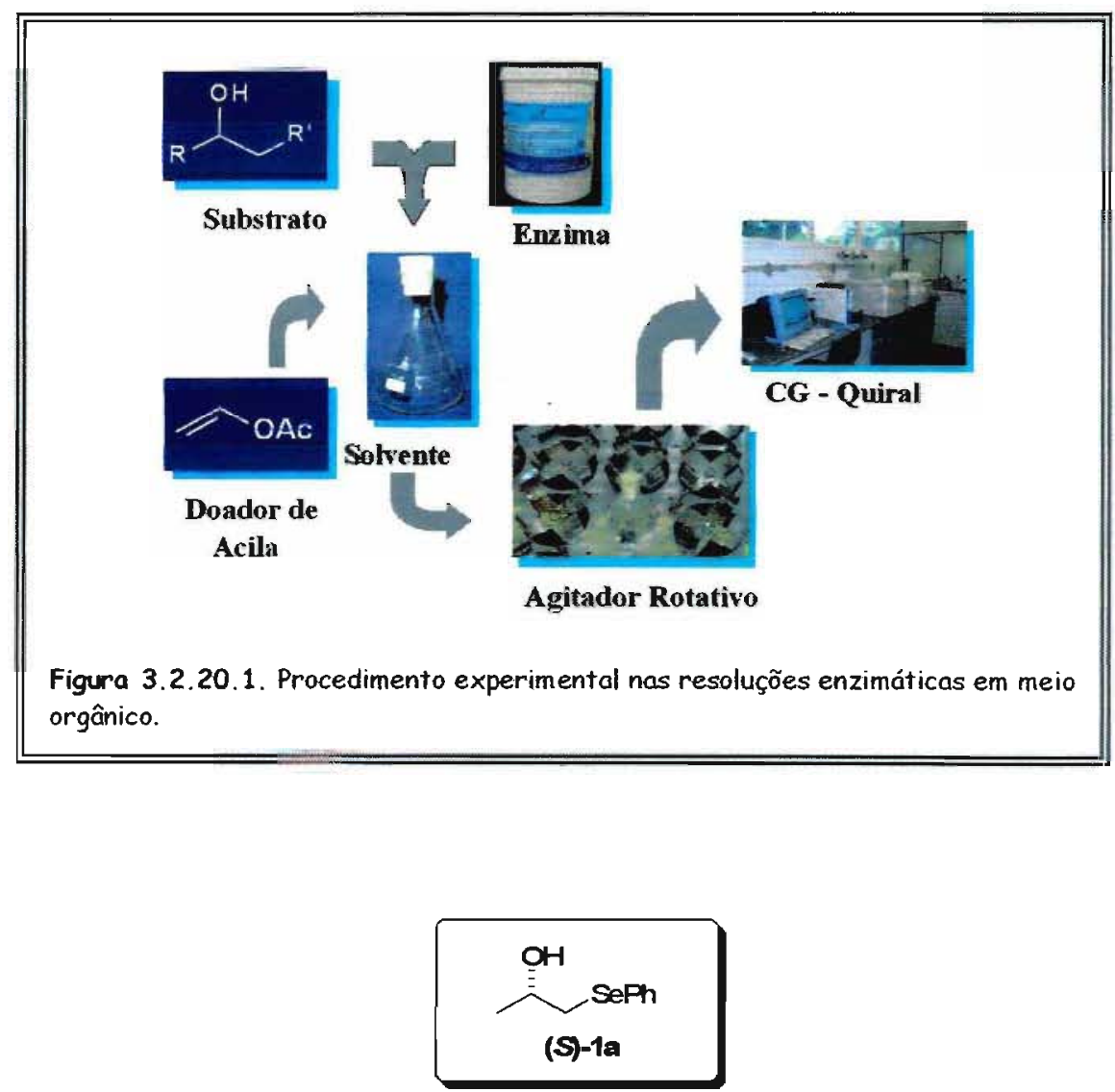

(S)-1-fenilsseleno-2-propanol: Óleo; >99\% e.e.; rendimento = 0,049g (46\%); $[\alpha]_{D}^{22}=+56\left(\mathrm{C} 1,0 ; \mathrm{CH}_{2} \mathrm{Cl}_{2}\right)$.

$$
\underbrace{\text { AAC }}_{(R-2 a} \operatorname{seph}
$$

(R)-O-acetil-1-fenilsseleno-2-propanol: Óleo; >99\% e.e.; rendimento = $0,054 \mathrm{~g}(42 \%) ;[\alpha]_{\mathrm{D}}^{22}=-7\left(\mathrm{c} 1,0 ; \mathrm{CH}_{2} \mathrm{Cl}_{2}\right)$. 


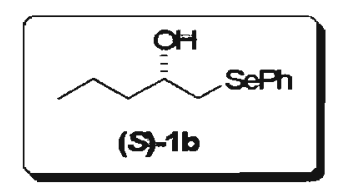

(S)-1-fenilsseleno-2-pentanol: Óleo; >99\% e.e.; rendimento $=0,036 \mathrm{~g}(30 \%)$; $[\alpha]_{D}^{23}=+41\left(\mathrm{C} 1,0 ; \mathrm{CH}_{2} \mathrm{Cl}_{2}\right)$.

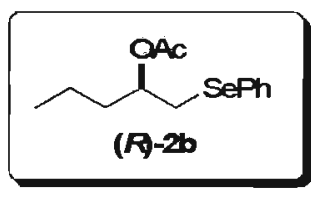

(R)-O-acetil-1-fenilsseleno-2-pentanol: Óleo; $94 \%$ e.e.; rendimento $=0,050 \mathrm{~g}$ $(35 \%) ;[\alpha]_{D}^{28}=+1\left(\right.$ c 1,$\left.0 ; \mathrm{CH}_{2} \mathrm{Cl}_{2}\right)$.

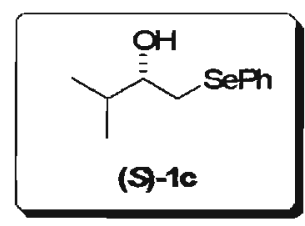

(S)-1-fenilsseleno-3-metil-2-butanol: Óleo; $69 \%$ e.e.; $[\alpha]_{D}{ }^{20}=+47$ (c 1,0; $\mathrm{CH}_{2} \mathrm{Cl}_{2}$ ).

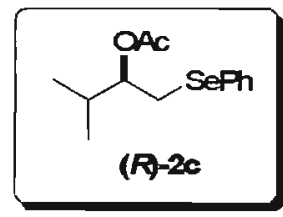

(R)-O-acetil-1-fenilsseleno-3-metil-2-butanol: Óleo; $86 \%$ e.e.; $[\alpha]_{D}{ }^{20}=-12$ (c 1,$0 ; \mathrm{CH}_{2} \mathrm{Cl}_{2}$ ).

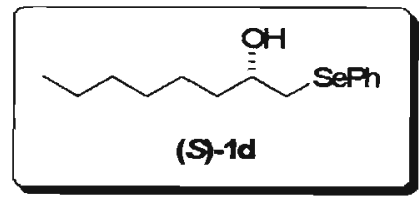

(S)-1-fenilsseleno-2-octanol: Óleo; 70\% e.e.; $[\alpha]_{D}^{22}=+12\left(\mathrm{c} 1,0 ; \mathrm{CH}_{2} \mathrm{Cl}_{2}\right)$; na literatura para o enantiomero $(R)$ : $93 \%$ e.e.; $[\alpha]_{\mathrm{D}}{ }^{19}=-35,5\left(\mathrm{c} 0,986 ; \mathrm{CHCl}_{3}\right) .{ }^{58}$

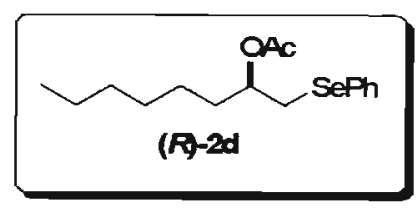

(R)-O-acetil-1-fenilsseleno-2-octanol: Óleo; 33\% e.e.; $[\alpha]_{D}^{22}=+2$ (c 1,0 ; $\mathrm{CH}_{2} \mathrm{Cl}_{2}$ ). 


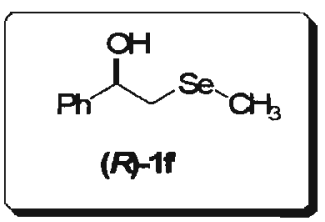

(R)-1-metilsseleno-2-fenil-etanol: Óleo; $41 \%$ e.e.; $[\alpha]_{D}^{22}=-55\left(\right.$ c 1,$0 ; \mathrm{CH}_{2} \mathrm{Cl}_{2}$ ).

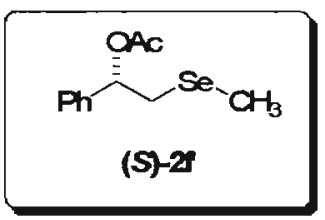

(S)-O-acetil-1-metilsseleno-2-fenil-etanol: Óleo; $74 \%$ e.e.; $[\alpha]_{\mathrm{D}}^{22}=+12$ (c 1,0; $\mathrm{CH}_{2} \mathrm{Cl}_{2}$ ).

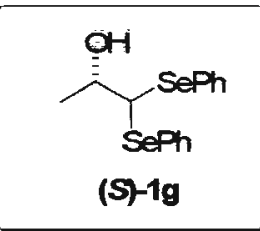

(S)-1,1-difenilsseleno-2-propanol: Óleo; $>99 \%$ e.e.; $[\alpha]_{\mathrm{D}}{ }^{21}=-43$ (c 1,0; $\mathrm{CH}_{2} \mathrm{Cl}_{2}$ ).

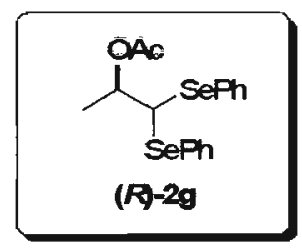

(R)-O-acetil-1,1-difenilsseleno-2-propanol: Óleo; $99 \%$ e.e.; $[\alpha]_{D}{ }^{21}=+1$ (c 1,0; $\mathrm{CH}_{2} \mathrm{Cl}_{2}$ ).

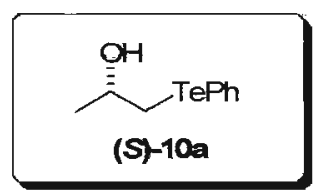

(S)-1-fenilteluro-2-propanol: Óleo; >99\% e.e.; $[\alpha]_{\mathrm{D}}{ }^{28}=+5$ (c 1,0; $\mathrm{CH}_{2} \mathrm{Cl}_{2}$ ).

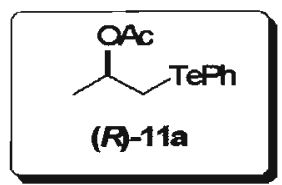

(R)-O-acetil-1-fenilteluro-2-propanol: Óleo; >99\% e.e; $[\alpha]_{D}^{28}=-6$ (c 1,0 ; $\mathrm{CH}_{2} \mathrm{Cl}_{2}$ ). 


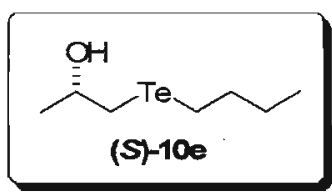

(S)-1-(n-butilteluro)-2-propanol: Óleo; >99\% e.e.; $[\alpha]_{\mathrm{D}}^{23}=+33$ (c 1,0; $\mathrm{CH}_{2} \mathrm{Cl}_{2}$ ).

$$
\overbrace{(R)-110}^{\text {OAC }}
$$

(R)-O-acetil-1-( $n$-butilteluro)-2-propanol: Óleo; $98 \%$ e.e.; rendimento = $0,056 \mathrm{~g}(39 \%) ;[\alpha]_{\mathrm{D}}^{23}=+4\left(\mathrm{c} 1,0 ; \mathrm{CH}_{2} \mathrm{Cl}_{2}\right)$.

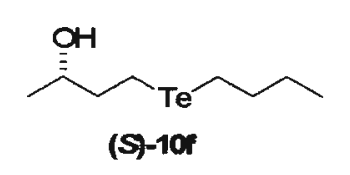

(S)-4-(n-butilteluro)-2-butanol: Óleo; $99 \%$ e.e.; $[\alpha]_{D}^{22}=+7\left(\right.$ c 1,$\left.0 ; \mathrm{CH}_{2} \mathrm{Cl}_{2}\right)$.

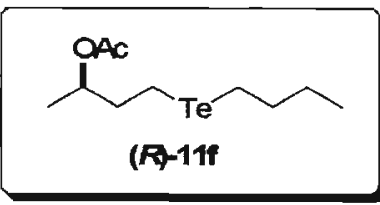

(R)-O-acetil-4-( $\boldsymbol{n}$-butilteluro)-2-butanol: Óleo; $98 \%$ e.e.; rendimento $=0,054 \mathrm{~g}$ $(36 \%) ;[\alpha]_{D}^{22}=+18\left(\right.$ c 1,$\left.0 ; \mathrm{CH}_{2} \mathrm{Cl}_{2}\right)$.

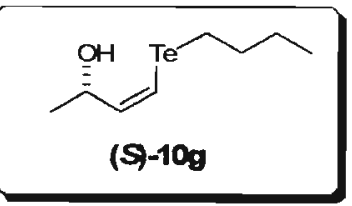

(S)-(Z)-4-(butilteluro)but-3-en-2-ol: Óleo; $98 \%$ e.e.; rendimento $=0,047 \mathrm{~g}$ $(37 \%) ;[\alpha]_{D}^{23}=+6\left(\mathrm{c} 0,75 ; \mathrm{CH}_{2} \mathrm{Cl}_{2}\right)$.

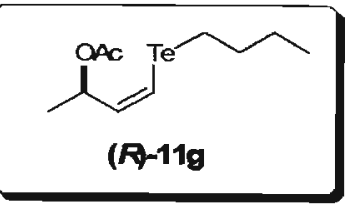

(R)-O-acetil-(Z)-4-(butilteluro)but-3-en-2-ol: Óleo; 95\% e.e.; rendimento = $0,049 \mathrm{~g}(33 \%) ;[\alpha]_{\mathrm{D}}^{23}=-27\left(\mathrm{c} 1,25 ; \mathrm{CH}_{2} \mathrm{Cl}_{2}\right)$. 


\subsubsection{Imobilização Enzimática}

O procedimento para imobilização de lipases depende do suporte a ser empregado:

\subsubsection{Gel de Agar}

Em um tubo de ensaio foi colocado Agar $(0,4 \mathrm{~g})$ e a seguir foi adicionada água destilada $(9 \mathrm{~mL})$. Esta mistura foi levada a um aquecimento de aproximadamente $100^{\circ} \mathrm{C}$, (temperatura no qual o Agar se dissolve). Após o Agar ter sido dissolvido, a mistura foi resfriada à temperatura de $40^{\circ} \mathrm{C}$ (naturalmente). Em seguida foi adicionada uma solução aquosa (ou suspensão em $\mathrm{H}_{2} \mathrm{O}$ ) da enzima (100mg), esperando-se a formação do gel. O gel foi cortado em cubos que foram mantidos em solvente orgânico.

\subsubsection{Filme de Caseinato de Sódio}

Em um pequeno béquer $(25 \mathrm{~mL})$ foram colocados caseinato de sódio $(1,50 \mathrm{~g})$, glicerol $(0,50 \mathrm{~g}$ - plastificante), água destilada $(15 \mathrm{~mL})$ e a enzima (100mg). Em seguida, essa solução foi colocada em uma placa de petri de poliestireno $(\mathrm{d} \approx 8,7 \mathrm{~cm}$ ), para a evaporação do solvente à temperatura ambiente e formação do filme. Após a evaporação, o filme foi retirado, cortado em pequenas porções e mantido em solvente orgânico.

\subsubsection{Silica ou Montmorilonita K-10 (Silicato de Alumínio)}

A imobilização foi realizada misturando-se uma solução (ou suspensão) da enzima (100mg) em água destilada ( $5 \mathrm{~mL}$ ) com uma suspensão de sílica ou Montmorilonita K-10 (500mg) em água destilada (10mL) a temperatura ambiente. A mistura resultante foi agitada mecanicamente por 5 horas. Ao final, essa mistura foi colocada em uma placa de Petri $(d \approx 8,7 \mathrm{~cm}$ ) para a evaporação do solvente à temperatura ambiente.

\subsubsection{Poli(oxietileno) - PEO}

O filme de PEO foi obtido misturando-se uma solução (ou suspensão) da enzima (100mg) em água destilada $(5 \mathrm{~mL})$ com uma solução de PEO (500mg) em água destilada $(20 \mathrm{~mL})$, previamente agitada por 12 horas a 
temperatura ambiente. A mistura resultante foi agitada mecanicamente por 5 horas. Ao final, essa mistura foi colocada em uma placa de petri ( $d \approx 8,7 \mathrm{~cm}$ ) para a evaporação do solvente à temperatura ambiente.

\subsubsection{Triagem Enzimática}

Inicialmente foram preparadas soluções dos acetatos $(30 \mathrm{mg})$ em DMSO (dimetilsulfóxido $-1 \mathrm{~mL}$ ) e das enzimas $(15 \mathrm{mg}$ ) em tampão fosfato ( $1 \mathrm{~mL}$ $-\mathrm{pH}=7,2)$. O tampão foi preparado pela adição de uma solução de $\mathrm{NaH}_{2} \mathrm{PO}_{4}$ $\left(0,002 \mathrm{MolL}^{-1}\right)$ sobre uma solução de $\mathrm{Na}_{2} \mathrm{HPO}_{4}\left(0,002 \mathrm{MolL}^{-1}\right)$ ate atingir $\mathrm{pH}=7,2$, controlada por pHmetro. Também foi preparada a solução do indicador colorimétrico $(0,005 \%$ - azul de bromotimol) em tampão. Em seguida, foram adicionadas as soluções nos pocinhos da placa de Elisa obedecendo ao seguinte padrão (Figura 3.2.22.1): No pocinho $A_{1}$ apenas solução tampão $(180 \mu \mathrm{L})$, nos demais pocinhos da linha $A$ foram adicionadas as soluções enzimaticas (40 $\mu \mathrm{L}$ I branco - uma enzima para cada pocinho) e a solução do indicador $(70 \mu \mathrm{L})$, fazendo-se sempre em duplicata.

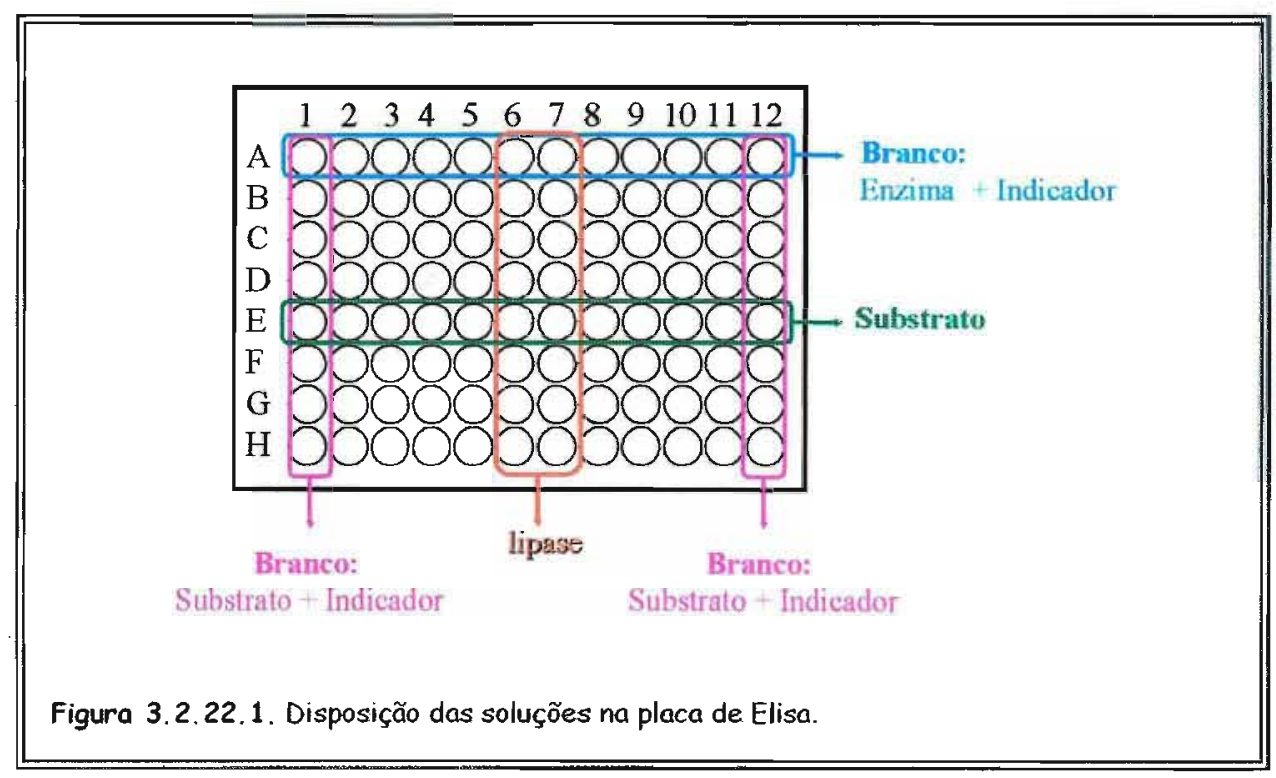

$\mathrm{Na}$ primeira coluna (exceto o pocinho $\mathrm{A}_{1}$ ) foram adicionados os brancos do substrato $(40 \mu \mathrm{L})$ mais a solução do indicador $(70 \mu \mathrm{L})$. Os demais pocinhos foram completados com soluções da enzima e do substrato, respectivos a coluna e linha que ele se encontra, acrescido da solução do 
indicador conforme Figura 3.2.22.1. Em alguns casos a enzima apresentou acidez, acarretando mudança de cor no momento da adição (mudança de pH). Esta mudança de $\mathrm{pH}$ foi corrigida pela adição da solução de $\mathrm{Na}_{2} \mathrm{HPO}_{4}$ ate $\mathrm{pH}$ neutro (cor verde). Ao final das adições o volume foi ajustado com tampão $(180 \mu \mathrm{L})$ e a placa incubada a $37^{\circ} \mathrm{C}$.

\subsubsection{Hidrolise Enzimática}

Em um Erlenmayer de $125 \mathrm{~mL}$ provido de rolha de silicone ou septo, o $( \pm)$-hidróxi-calcogêneto $(0,5 \mathrm{mmol})$ foi dissolvido em acetona $(3 \mathrm{~mL})$. Em seguida, foi adicionado tampão fosfato $(\mathrm{pH}=7,2$ - 10mL) e a enzima (10100mg). A mistura resultante foi mantida sobre agitação continua (160 r.p.m.) e incubada a $32^{\circ} \mathrm{C}$. A reação foi acompanhada por CG-quiral. Ao final da reação (aproximadamente $50 \%$ de conversão) a enzima foi removida por filtração simples ou por centrifugação, e os produtos extraídos com acetato de etila. A fase orgânica foi seca com $\mathrm{MgSO}_{4}$ e o solvente rotoevaporado. A separação dos produtos foi realizada por coluna cromatogratográfica usando uma solução hexano/acetato (9:1) como eluente.

\subsubsection{Biotransformação Empregando Células Inteiras de Fungos}

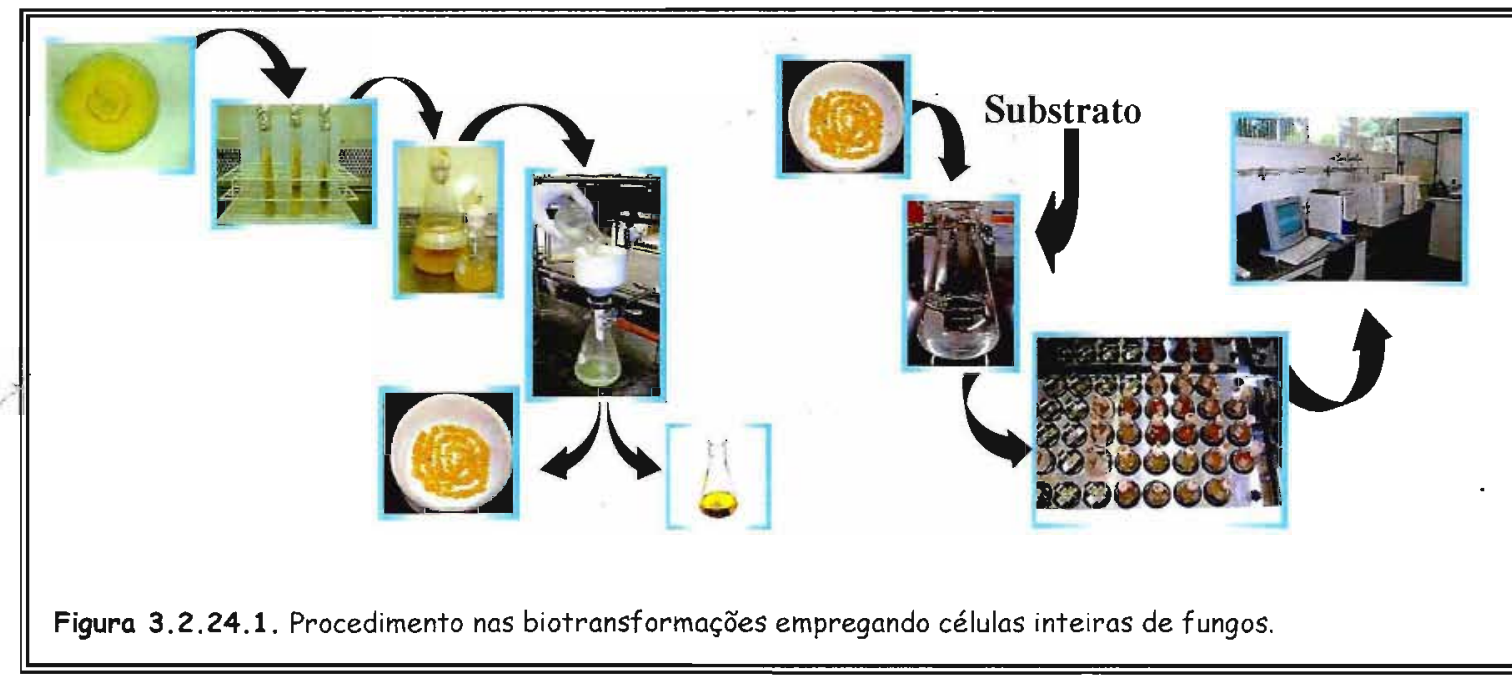

Inicialmente, os fungos foram crescidos em meio sólido e posteriormente em meio líquido, com o objetivo de aumentar a massa celular e 
conseqüentemente à quantidade de enzimas. Após o crescimento em meio líquido, o meio reacional foi filtrado, separando as células do meio de cultura (Figura 3.2.24.1). Em seguida as células foram ressuspensas em tampão, adicionando-se o substrato e mantendo a agitação a $30^{\circ} \mathrm{C}$. Alíquotas de $3 \mathrm{~mL}$ foram retiradas periodicamente para o acompanhamento da reação via CGquiral.

\subsubsection{Crescimento dos Fungos em Meio Sólido}

Os fungos Aspergillus terreus foram adquiridos da Coleção de Culturas Tropicais da Fundação André Tosello. 77 Posteriormente foram feitos repiques em tubos inclinados contendo um meio de cultura constituído por extrato de malte $(2 \mathrm{~g})$, agar $(2 \mathrm{~g})$ e água destilada $(100 \mathrm{~mL})$. Os fungos foram colocados para crescer em estufa a $32^{\circ} \mathrm{C}$.

\subsubsection{Crescimento dos Fungos em Meio Líquido}

Os fungos foram transferidos dos tubos inclinados para frascos Erlenmeyer contendo meio de cultura líquido composto por extrato de malte (2g) e água destilada (100 mL). Em alguns casos foram utilizados Erlenmeyers de 1-3L. O crescimento dos fungos foi realizado em agitador rotativo a $170 \mathrm{rpm}$ e $32{ }^{\circ} \mathrm{C}$ por $72-96$ horas.

\subsubsection{Obtenção das Células Úmidas de Fungos}

Após o crescimento dos fungos, as células foram filtradas em funil Buchner. A quantidade de células empregadas de fungos foi de $1-5 \mathrm{~g}$ de células úmidas.

\subsubsection{As Biotransformações}

As células úmidas de fungos foram resuspensas em solução tampão fosfato Sörensen $\left(\mathrm{Na}_{2} \mathrm{HPO}_{4}\right.$ e $\mathrm{KHPO}_{4} 0,1 \mathrm{MolL}^{-1}$ ) em frascos Erlenmeyer de 250 $\mathrm{mL}$ ( $50 \mathrm{~mL}$ de tampão), 125 (30mL de tampão) ou de $50 \mathrm{~mL}$ (20mL de tampão). Em seguida foi adicionado o substrato $(20 \mu \mathrm{L})$ e mantido em agitador rotativo a 170 rpm e $32{ }^{\circ} \mathrm{C}$ (Figura 3.2.24.1). A reação foi acompanhada por CG-Quiral, retirando-se alíquotas $(3 \mathrm{~mL})$ periodicamente em tubos de centrifuga, adicionando-se $0,5 \mathrm{~mL}$ de acetato de etila, agitando e centrifugando $(6000 \mathrm{rpm}$, 5 minutos). 


\subsubsection{Preparação do Álcool Alílico - Reação de Eliminação de}

\section{Selenóxido ${ }^{38}$}

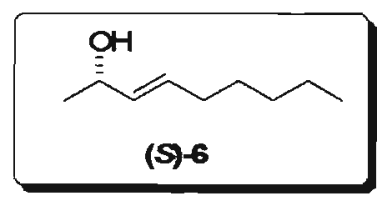

Em um balão, o (S)-1-hexil-1-(fenilsseleno)-2-propanol com 92\% e.e. [(S)-1h] $(0,057 \mathrm{~g}-0,2 \mathrm{mmol})$ foi dissolvido em THF $(5 \mathrm{~mL})$. Em seguida $\mathrm{H}_{2} \mathrm{O}_{2}$ (30\% sol. - 0,6 mmol) foi adicionada lentamente à temperatura ambiente. A mistura reacional foi mantida sob agitação durante 4 horas, diluída com água e extraída com várias porções de éter etílico. A fase orgânica foi lavada com solução concentrada de $\mathrm{Na}_{2} \mathrm{CO}_{3}$ e $\mathrm{NaCl}$ e seca com $\mathrm{MgSO}_{4}$. O resíduo foi purificado por cromatografia utilizando hexano:acetato de etila (9:1).

(S)-3-nonen-2-ol: Óleo; rendimento =0,027g (95\%); No CAS: 173144-01-9; $92 \%$ e.e.; $[\alpha]^{21}{ }_{\mathrm{D}}=-8$ (c 1.5, $\left.\mathrm{CHCl}_{3}\right) ; \mathrm{RMN}^{1} \mathrm{H}\left(200 \mathrm{MHz}, \mathrm{CDCl}_{3}\right), \delta(\mathrm{ppm}): 0,89(\mathrm{t}$; $J=4,50 \mathrm{~Hz} ; 3 \mathrm{H}), 1,25-1,39(\mathrm{~m} ; 8 \mathrm{H}), 1,97-2,04(\mathrm{~m} ; 3 \mathrm{H}), 4,22-4,31(\mathrm{~m} ; 1 \mathrm{H}), 5,50$ (dd; $J=4,35 \mathrm{~Hz} ; J=10,45 \mathrm{~Hz} ; 1 \mathrm{H}$ ), 5,67 (dt; $J=4,40 \mathrm{~Hz} ; J=10,45 \mathrm{~Hz} ; 1 \mathrm{H}$ ); E.M. m/z (\% rel.): $142(1), 124(25), 84(23), 71(100), 68(72), 58(30), 54(55), 43$ (12)

\subsubsection{Preparação das Lactonas}

Em um balão de duas bocas equipado com um septo, agitação magnética e sob nitrogênio, o hidróxi-telureto enantiomericamente enriquecido (1 mmol), foi dissolvido em THF seco $(5 \mathrm{~mL})$. Em seguida, a solução foi resfriada a $-78^{\circ} \mathrm{C}$ e $n$-BuLi $\left(1,69 \mathrm{~mL}-1,3 \mathrm{MolL}^{-1}\right.$ em hexano $\left.-2,2 \mathrm{mmol}\right)$ foi adicionado lentamente. Após 20 minutos, $\mathrm{CO}_{2}$ seco foi borbulhado na solução por 30 min. Na seqüência, a temperatura foi elevada gradualmente à temperatura ambiente. A mistura reacional foi lavada com solução de $\mathrm{HCl}$ $(50 \%)$ e extraída com éter etílico. A fase orgânica foi seca com $\mathrm{MgSO}_{4}$ solvente destilado e o residuo purificado por cromatografia em coluna utilizando pentano:éter etíico (1:1). 


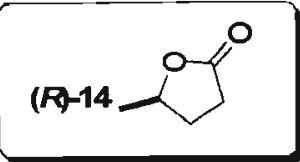

(R)- $\gamma$-valerolactona: Óleo; rendimento $=53 \% ; \mathrm{N}^{\circ}$ CAS: $58917-25-2 ; 98 \%$ e.e.; $[\alpha]_{\mathrm{D}}^{23}=+30\left(\mathrm{c} 1,0 ; \mathrm{CHCl}_{3}\right) ; \mathrm{RMN}^{1} \mathrm{H}\left(300 \mathrm{MHz} \mathrm{CDCl}_{3}\right), \delta(\mathrm{ppm}): 1,43$ (d; $J=6,3$ $\mathrm{Hz} ; 3 \mathrm{H}), 1,78-1,91(\mathrm{~m} ; 1 \mathrm{H}), 2,54-2,59(\mathrm{~m} ; 2 \mathrm{H}), 4,6-4,71(\mathrm{~m} ; 1 \mathrm{H}), \mathrm{RMN}{ }^{13} \mathrm{C}(75$ $\mathrm{MHz}, \mathrm{CDCl}_{3}$ ), $\delta$ (ppm): 21,0;29,1;29,8;77,4;177,6; I.V (filme $\mathrm{KBr}$ ) banda de absorção $\left(\mathrm{cm}^{-1}\right)$ : 2998, 1777, 1432, 1130; E.M. m/z (\% rel.): 41 (47), 43 (34), 56 (100), $85(45), 100(8)$

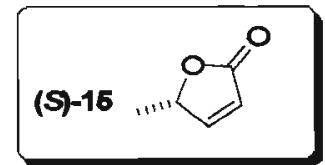

(S)- $\beta$-angelica: Óleo; rendimento $=51 \% ; N^{\circ}$ CAS: $92694-51-4 ; 98 \%$ e.e.; $[\alpha]_{D}^{23}$

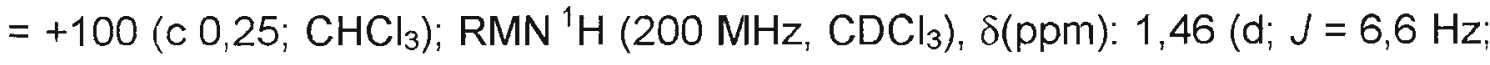
$3 \mathrm{H}), 5,09-5,21(\mathrm{~m} ; 1 \mathrm{H}), 6,11(\mathrm{dd} ; J=5,7 \mathrm{~Hz}$ e $J=2,2 \mathrm{~Hz} ; 1 \mathrm{H}), 7,47$ (dd; $J=5,7$ $\mathrm{Hz}$ e $J=1,7 \mathrm{~Hz} ; 1 \mathrm{H})$; RMN ${ }^{13} \mathrm{C}\left(50 \mathrm{MHz} \mathrm{CDCl}_{3}\right), \delta(\mathrm{ppm}): 18,7 ; 79,6 ; 121,2$; 157,3; E.M. m/z (\% rel.): 43 (58), 55 (100), 69 (12) 83 (40), 98 (34).

\subsubsection{Determinação dos Excessos Enantioméricos}

As condições das análises em CG-Quiral para cada composto foram as seguintes: $(\boldsymbol{R}, S)-1 \mathrm{a}$ : coluna GAMA DEX ${ }^{\mathrm{TM}}$; pressão $=100 \mathrm{Kpa}$; isoterma a $135^{\circ} \mathrm{C} ; t_{R} 1=24,7$ min. e $t_{R} 2=25,2 \min ;(R, S)-1 \mathbf{b}$ : coluna GAMA DEX ${ }^{T M}$; pressão $=80 \mathrm{Kpa}$; isoterma a $140^{\circ} \mathrm{C} ; t_{R} 1=59,5$ min. e $t_{R} 2=61,2 \mathrm{~min}$; (R,S)1c: coluna GAMA DEX ${ }^{\mathrm{TM}}$; pressão $=100 \mathrm{Kpa}$; isoterma a $135^{\circ} \mathrm{C} ; t_{\mathrm{R}} 1=42,0$ min. e $t_{\mathrm{R}} 2=43,0$ min.; $(R, S)-1 \mathrm{~d}$ : coluna GAMA DEX ${ }^{\mathrm{TM}}$; pressão $=100 \mathrm{Kpa}$; isoterma a $150^{\circ} \mathrm{C} ; t_{\mathrm{R}} 1=106,2$ min. e $t_{\mathrm{R}} 2=107,9 \mathrm{~min}$; $(\boldsymbol{R}, \mathbf{S})-1 \mathrm{f}$ : coluna GAMA $\mathrm{DEX}^{\mathrm{TM}}$; pressão $=80 \mathrm{Kpa}$; isoterma a $125^{\circ} \mathrm{C} ; t_{\mathrm{R}} 1=75,6 \mathrm{~min}$. e $t_{\mathrm{R}} 2=77,6 \mathrm{~min}$; $(R, S)-2 a$ : coluna BETA DEX ${ }^{\mathrm{TM}}$; pressão = $115 \mathrm{Kpa}$; isoterma a $125^{\circ} \mathrm{C}_{;} t_{\mathrm{R}} 1=$ 38,0 min. e $t_{R} 2=38,8 \mathrm{~min} ;(\boldsymbol{R}, \mathbf{S})-2 \mathbf{b}$ : coluna BETA DEX ${ }^{\mathrm{TM}}$; pressão = $90 \mathrm{Kpa}$; isoterma $120^{\circ} \mathrm{C} ; t_{R} 1=54,6$ min. e $t_{R} 2=55,1 \mathrm{~min}$; $(R, S)-6$ : coluna ALFA DEX ${ }^{T M}$; pressão $=70 \mathrm{Kpa} ; 50^{\circ} \mathrm{C}-60 \mathrm{~min}, 50-190^{\circ} \mathrm{C}, 1^{\circ} \mathrm{C} / \mathrm{min} ; t_{\mathrm{R}} 1=171,8 \mathrm{~min}$. e $t_{\mathrm{R}} 2=$ 173,7 min.; $(R, S)-7$ : coluna CHIRASIL-DEX CB; pressão $=85 \mathrm{Kpa} ; 60^{\circ} \mathrm{C}-40$ $\min , 60-120^{\circ} \mathrm{C}, 0,5^{\circ} \mathrm{C} / \mathrm{min}, 120^{\circ} \mathrm{C}-15 \mathrm{~min} ; t_{\mathrm{R}} 1=92,0 \mathrm{~min}$. e $t_{\mathrm{R}} 2=95,2 \mathrm{~min}$; 
$(R, S)-10 a:$ coluna GAMA DEX ${ }^{\mathrm{TM}}$; pressão $=70 \mathrm{Kpa} ; 120^{\circ} \mathrm{C}-100 \mathrm{~min}, 120$ $170^{\circ} \mathrm{C}, 0.5^{\circ} \mathrm{C} / \mathrm{min}, 170^{\circ} \mathrm{C}-30 \mathrm{~min} ; t_{\mathrm{R}} 1=119,1 \mathrm{~min}$. e $t_{\mathrm{R}} 2=121,5 \mathrm{~min}$; $(R, S)-$ 10e: coluna GAMA DEX ${ }^{\mathrm{TM}}$; pressão $=90 \mathrm{Kpa} ; 65^{\circ} \mathrm{C}-150 \mathrm{~min}, 65-98^{\circ} \mathrm{C}$, $0,5^{\circ} \mathrm{C} / \mathrm{min} ; t_{\mathrm{R}} 1=198,4 \mathrm{~min}$. e $t_{\mathrm{R}} 2=200,2 \mathrm{~min}$; $(R, S)-10 \mathrm{~g}$ : coluna CHIRASILDEX CB; pressão $=120 \mathrm{Kpa} ; 80^{\circ} \mathrm{C}-120 \mathrm{~min}, 80-160^{\circ} \mathrm{C}, 2^{\circ} \mathrm{C} / \mathrm{min}, 160^{\circ} \mathrm{C}-30 \mathrm{~min}$; $t_{\mathrm{R}} 1=144,1$ min. e $t_{\mathrm{R}} 2=145,2$ min.; $(R, S)-11 \mathrm{a}$ : coluna CHIRASIL-DEX CB; pressão $=90 \mathrm{Kpa}$ isoterma a $120^{\circ} \mathrm{C} ; t_{R} 1=35,3$ min. e $t_{R} 2=39,6$ min.; $(R, S)$ 11e: coluna CHIRASIL-DEX CB; pressão $=125 \mathrm{Kpa} 80^{\circ} \mathrm{C}-120 \mathrm{~min}$., $80-110^{\circ} \mathrm{C}$, $2^{\circ} \mathrm{C} / \mathrm{min}, 110^{\circ} \mathrm{C}-10 \mathrm{~min} ; t_{\mathrm{R}} 1=102,2 \mathrm{~min}$. e $t_{\mathrm{R}} 2=125,1 \mathrm{~min}$. ; $(R, S)-11 \mathrm{f}$ : coluna CHIRASIL-DEX CB; pressão $=80 \mathrm{Kpa} ; 80^{\circ} \mathrm{C}-90 \mathrm{~min}, 80-140^{\circ} \mathrm{C}, 1^{\circ} \mathrm{C} / \mathrm{min}$, $140^{\circ} \mathrm{C}-30 \mathrm{~min} ; \quad t_{\mathrm{R}} 1=126,8 \mathrm{~min}$. e $t_{\mathrm{R}} 2=134,3 \mathrm{~min}$; $(\boldsymbol{R}, \mathbf{S})-11 \mathrm{~g}$ : coluna CHIRASIL-DEX CB; pressão $=120 \mathrm{Kpa} ; 80^{\circ} \mathrm{C}-120 \mathrm{~min}, 80-160^{\circ} \mathrm{C}, 2^{\circ} \mathrm{C} / \mathrm{min}$, $160^{\circ} \mathrm{C}-30 \mathrm{~min} ; t_{\mathrm{R}} 1=142,5 \mathrm{~min}$. e $t_{\mathrm{R}} 2=143,3 \mathrm{~min}$.; $(\boldsymbol{R}, \boldsymbol{S})-14$ : coluna CHIRASILDEX CB; pressão $=100 \mathrm{Kpa} ; 60^{\circ} \mathrm{C}-3 \mathrm{~min}, 60-190^{\circ} \mathrm{C}, 5^{\circ} \mathrm{C} / \mathrm{min}, 190^{\circ} \mathrm{C}-10 \mathrm{~min}$; $t_{\mathrm{R}} 1=10,0 \mathrm{~min}$. e $t_{\mathrm{R}} 2=10,3 \mathrm{~min} ;(\boldsymbol{R}, \boldsymbol{S})-15$ : coluna CHIRASIL-DEX CB; pressão $=100 \mathrm{Kpa} ; 60^{\circ} \mathrm{C}-10 \mathrm{~min}, 60-90^{\circ} \mathrm{C}, 2^{\circ} \mathrm{C} / \mathrm{min}, 90^{\circ} \mathrm{C}-30 \mathrm{~min} ; t_{\mathrm{R}} 1=15,6 \mathrm{~min}$. e $t_{\mathrm{R}} 2$ = 16,0 min.; $(\boldsymbol{R}, \boldsymbol{S})-16$ : coluna CHIRASIL-DEX CB; pressão $=100 \mathrm{Kpa} ; 80^{\circ} \mathrm{C}-90$ $\min , 80-175^{\circ} \mathrm{C}, 1^{\circ} \mathrm{C} / \mathrm{min}, 175^{\circ} \mathrm{C}-30 \mathrm{~min} ; t_{\mathrm{R}} 1=78,6 \mathrm{~min}$. e $t_{\mathrm{R}} 2=83,1 \mathrm{~min}$;

Os valores de $E$ (razão enantiomérica) foram calculados a partir dos excessos enantioméricos dos produtos e substratos, de acordo com a equação de Sirh, Sharpless e Fajans $\{E=\ln [1-c(1+$ e.e.p $)] / \ln [1-c(1-e . e . p)]$, onde $c=$ e.e.s $/(\text { e.e.s }+ \text { e.e.p) }\}^{9,78}$

\subsubsection{Hidrólise Química}

Em um balão o acetato ( $1 \mathrm{mmol}$ ) foi dissolvido em metanol $(5 \mathrm{~mL})$ em seguida foi adicionando $\mathrm{H}_{2} \mathrm{O}(2 \mathrm{~mL})$ e $\mathrm{K}_{2} \mathrm{CO}_{3}(0,2 \mathrm{mmol})$. A mistura foi agitada durante toda a noite à temperatura ambiente. Depois deste período, a mistura foi extraída com acetato de etila e a fase orgânica foi lavada com solução saturada de $\mathrm{NaCl}$ e seca com $\mathrm{MgSO}_{4}$. O produto obtido foi purificado por cromatografia usando uma mistura de hexano acetato (85:15).

\subsubsection{Desselenização Redutiva ${ }^{54}$}

Em um balão de duas bocas equipado com septo, com agitação mậgética e sob nitrogênio, uma quantidade catalítica de CCN [1,1'- 
azobis(cicloexanacarbonitrila)] e o $\beta$-hidróxi-seleneto $(0,2 \mathrm{mmol})$ foram dissolvidos em tolueno seco. Em seguida a solução foi pré-aquecida e o $n$-BuSnH foi adicionado $(0,2 \mathrm{mmol})$. A mistura reacional foi agitada sob refluxo durante 4 horas. Após este período, o sistema foi resfriado a temperatura ambiente, hexano foi adicionado e a mistura foi extraida com acetonitrila. A fase acetonitrila foi evaporada e o resíduo purificado por cromatografia utilizando hexano:acetato (9:1).

\subsubsection{Derivatização Utilizando Anidrido Tri-fluoracético}

Em um vial de $2 \mathrm{~mL}$, o hidróxi-telureto $10 \mathrm{f}(0,05 \mathrm{mmol})$ foi dissolvido em THF (1mL) em seguida foi adicionado anidrido de tri-fluoracético (duas gotas). A mistura reacional foi agitada durante 5 minutos.

\subsubsection{Determinação da Configuração Absoluta}

\subsubsection{Preparação do Cloreto de Ácido de Mosher ${ }^{55,79}$}

Em um balão de duas bocas equipado com septo, com agitação māāḡnética e sob nitrogênio, o ácido (MTPA; 0,5mmol) foi dissolvida o em $5 \mathrm{ml}$ de hexano seco. Em seguida, adicionou-se Cloreto de oxalila ( $5 \mathrm{mmol}$ ) e DMF (1 gota) a temperatura ambiente. Após dois dias, o solvente foi rotaevaporado.

\subsubsection{Preparação dos Derivados de Mosher $^{79}$}

Em um balão de duas bocas equipado com septo, com agitação magnética e sob nitrogênio, o cloreto de ácido (MTPA-Cl; 0,5 mmol) foi dissolvido em $\mathrm{CH}_{2} \mathrm{Cl}_{2}$ seco ( $5 \mathrm{~mL}$ ). Em seguida, foi adicionada uma solução do hidróxi-calcogeneto $(0,1 \mathrm{mmol}), \mathrm{Et}_{3} \mathrm{~N}(1,2 \mathrm{mmol})$ e DMPA $(0,1 \mathrm{mmol})$ em $\mathrm{CH}_{2} \mathrm{Cl}_{2}$ seco $(10 \mathrm{~mL}$ ). A agitação foi mantida por 30 minutos a temperatura ambiente. Depois deste período a solução resultante foi lavada com água, extraída com acetato de etila, lavada com solução saturada de $\mathrm{NaCl}$, seca com $\mathrm{MgSO}_{4}$ e o solvente rotaevaporado. O resíduo foi purificado em placa preparativa utilizando uma mistura hexano:acetato de etila (85:15) como eluente. Entretanto, para o derivado do hidróxi-telureto $\mathbf{8 e}$, devido à 
instabilidade do éster formado, não foi possível realizar a purificação. Assim, após os 30 minutos de agitação o solvente foi evaporado e o resíduo filtrado rapidamente em coluna de sílica utilizando uma mistura hexano:acetato de etila (85:15) como eluente.

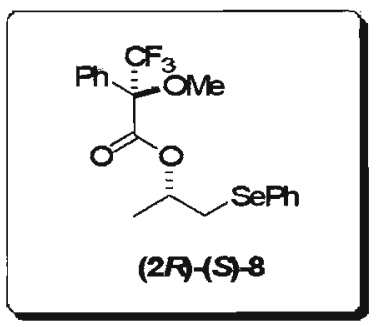

(2R)-(S)-3,3,3-Trifluoro-2-metóxi-2-fenill-propanoato de 1-fenilseleno-2propila: Óleo; rendimento $=0,029 \mathrm{~g}(67 \%) ; \mathrm{RMN}{ }^{1} \mathrm{H}\left(500 \mathrm{MHz}, \mathrm{CDCl}_{3}\right), \delta(\mathrm{ppm})$ : $1,44(\mathrm{~d} ; J=6.29 \mathrm{~Hz} ; 3 \mathrm{H}), 2,93(\mathrm{dd} ; J=12.82 \mathrm{~Hz}$ e $J=6.76 \mathrm{~Hz} ; 1 \mathrm{H}), 3,14(\mathrm{dd} ; J=$ $12,82 \mathrm{~Hz}$ e $J=6,30 \mathrm{~Hz} ; 1 \mathrm{H}), 3,55$ ( $\mathrm{s} ; 3 \mathrm{H}), 5,25-5,31(\mathrm{~m} ; 1 \mathrm{H}), 7,23-7,55(\mathrm{~m} ; 10 \mathrm{H})$; RMN ${ }^{13} \mathrm{C}\left(125 \mathrm{MHz}, \mathrm{CDCl}_{3}\right), \delta(\mathrm{ppm}): 19,7 ; 32,2 ; 55,5 ; 73,1 ; 165,9 ; \mathrm{RMN}^{77} \mathrm{Se}$ (95MHz, $\left.\mathrm{CDCl}_{3}\right), \delta(\mathrm{ppm}): 269,9 ;$ E.M., m/z (\%rel.): $431\left(\mathrm{M}^{+}, 19\right), 275(43), 217$ (11), 198 (68), 189 (100), 157 (64), 105(49), 91 (37), 77 (78), 69 (17), 51 (32).

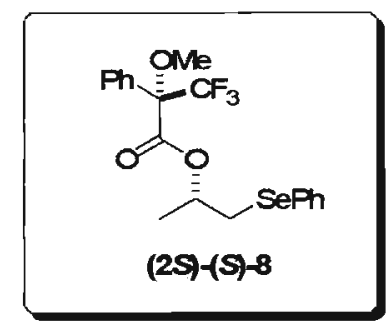

(2S)-(S)-3,3,3-Trifluoro-2-metóxi-2-fenil-prōpanoato de 1-fenilseleno-2propila: Óleo; rendimento $=0,030 \mathrm{~g}(69 \%) ; \mathrm{RMN}^{1} \mathrm{H}\left(500 \mathrm{MHz}, \mathrm{CDCl}_{3}\right), \delta(\mathrm{ppm})$ : $1,35(\mathrm{~d} ; J=6,26 \mathrm{~Hz} ; 3 \mathrm{H}), 3,02(\mathrm{dd} ; J=12,88 \mathrm{~Hz} ; J=6,07 \mathrm{~Hz} ; 1 \mathrm{H}), 3,17$ (dd; $J=$ $12,88 \mathrm{~Hz}$ e $J=6.99 \mathrm{~Hz} ; 1 \mathrm{H}), 3,58(\mathrm{~s} ; 3 \mathrm{H}), 5,24-5,30(\mathrm{~m} ; 1 \mathrm{H}), 7,25-7,57(\mathrm{~m} ; 10 \mathrm{H})$; $\mathrm{RMN}^{13} \mathrm{C}\left(125 \mathrm{MHz}, \mathrm{CDCl}_{3}\right), \delta(\mathrm{ppm}): 20,0 ; 32,8 ; 56,1 ; 73,5 ; 166,4 ; \mathrm{RMN}^{77} \mathrm{Se}$ (95MHz, $\left.\mathrm{CDCl}_{3}\right), \delta(\mathrm{ppm}): 271,1$; E.M., m/z (\%rel.): $431\left(\mathrm{M}^{+}, 13\right), 275$ (36), 217 (11), 198 (65), 189 (100), 157 (68), 105 (54), 91 (42), 77 (88), 69 (20), 51 (39). 


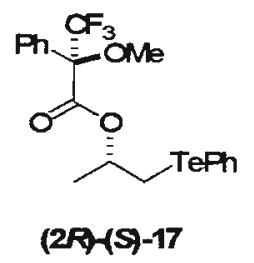

(2R)-(S)-3,3,3-Trifluoro-2-metóxi-2-fenil-propanoato de 1-fenilteluro-2propila: Óleo; rendimento $=0,025 \mathrm{~g}(52 \%) ; \mathrm{RMN}^{1} \mathrm{H}\left(500 \mathrm{MHz}, \mathrm{CDCl}_{3}\right), \delta(\mathrm{ppm})$ : 1,45 (d; $J=6,23 \mathrm{~Hz} ; 3 \mathrm{H}$ ), 2,98 (dd; $J=12,32 \mathrm{~Hz}$ e $J=7,32 \mathrm{~Hz} ; 1 \mathrm{H}$ ); 3,14 (dd; $J=$ $12,32 \mathrm{~Hz}$ e $J=5,84 \mathrm{~Hz} ; 1 \mathrm{H}), 3,56(\mathrm{~s} ; 3 \mathrm{H}), 5,30-5,36(\mathrm{~m} ; 1 \mathrm{H}), 7,27-7,64(\mathrm{~m} ; 10 \mathrm{H})$; RMN ${ }^{13} \mathrm{C}\left(125 \mathrm{MHz}, \mathrm{CDCl}_{3}\right), \delta(\mathrm{ppm}): 13,35 ; 20,86 ; 55,50 ; 74,80 ; 111,38 ; 127,34$ 128,$41 ; 129,39 ; 129,60 ; 130,02 ; 138,50 ; 165,84 ; \mathrm{RMN}^{125} \mathrm{Te}(157 \mathrm{MHz}, 300 \mathrm{~K}$, $\left.\mathrm{CDCl}_{3}\right), \delta(\mathrm{ppm}): 440,9$.

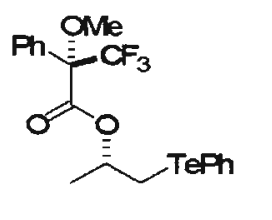

(2S)-(S)-17

(2S)-(S)-3,3,3-Trifluoro-2-metóxi-2-fenil-propanoato de 1-fenilteluro-2-

propila: Óleo; rendimento $=0,024 \mathrm{~g}(50 \%) ; \mathrm{RMN}^{1} \mathrm{H}\left(500 \mathrm{MHz}, \mathrm{CDCl}_{3}\right), \delta(\mathrm{ppm})$ : 1,38 (d; $J=6,21 \mathrm{~Hz} ; 3 \mathrm{H}$ ), 3,06 (dd; $J=12,35 \mathrm{~Hz}$ e $J=7,05 \mathrm{~Hz} ; 1 \mathrm{H}$ ), 3,17 (dd; $J=$ $12,35 \mathrm{~Hz}$ e $J=6,25 \mathrm{~Hz} ; 1 \mathrm{H}), 3,56(\mathrm{~s} ; 3 \mathrm{H}), 5,29-5,34(\mathrm{~m} ; 1 \mathrm{H}), 7,26-7,59(\mathrm{~m} ; 10 \mathrm{H})$; $\mathrm{RMN}^{13} \mathrm{C}\left(125 \mathrm{MHz}, \mathrm{CDCl}_{3}\right), \delta(\mathrm{ppm}): 13,39 ; 20,72 ; 55,63 ; 74,92 ; 111,32 ; 127,71$; 128,$41 ; 129,43 ; 129,60 ; 130,03 ; 138,55 ; 165,94 ;$ RMN $^{125} \mathrm{Te}(157 \mathrm{MHz}, 300 \mathrm{~K}$ $\left.\mathrm{CDCl}_{3}\right), \delta(\mathrm{ppm}): 441,9$.

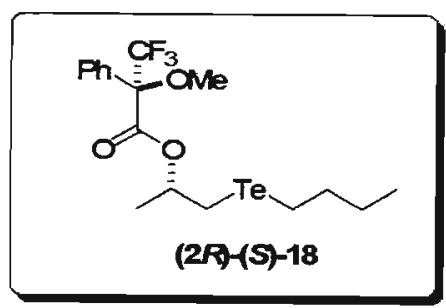

(2R)-(S)-3,3,3-Trifluoro-2-metóxi-2-fenil-propanoato de 1-(n-butilteluro)-2propila: Óleo; $\mathrm{RMN}^{1} \mathrm{H}\left(500 \mathrm{MHz}, \mathrm{CDCl}_{3}\right), \delta(\mathrm{ppm}): 0,90(\mathrm{t} ; J=7,3 \mathrm{~Hz} ; 3 \mathrm{H}), 1,31$ $1,38(\mathrm{~m} ; 2 \mathrm{H}), 1,48(\mathrm{~d} ; J=6,2 \mathrm{~Hz} ; 3 \mathrm{H}), 1,65-1,71(\mathrm{~m} ; 2 \mathrm{H}), 2,57-2,67(\mathrm{~m} ; 2 \mathrm{H})$, $2,70$ (dd; $J=12,3 \mathrm{~Hz}$ e $J=7,9 \mathrm{~Hz} ; 1 \mathrm{H}), 2,86(\mathrm{dd} ; J=12,3 \mathrm{~Hz}$ e $J=5,3 \mathrm{~Hz} ; 1 \mathrm{H}$ ), 
3,57 (s;3H), 5,23-5,30 (m; 1H), 7,38-7,43 (m;3H), 7,53-7,55 (m; $2 \mathrm{H}) ; \mathrm{RMN}^{13} \mathrm{C}$ $\left(125 \mathrm{MHz}, \mathrm{CDCl}_{3}\right), \delta(\mathrm{ppm}): 4,1 ; 7,2 ; 13,4 ; 20,7 ; 24,9 ; 34,1 ; 55,5 ; 75,4 ; 84,5$; 127,$3 ; 128,4 ; 129,5 ; 132,4 ; 165,9 ; \mathrm{RMN}^{125} \mathrm{Te}\left(157 \mathrm{MHz}, 300 \mathrm{~K}, \mathrm{CDCl}_{3}\right), \delta(\mathrm{ppm})$ : 204,9

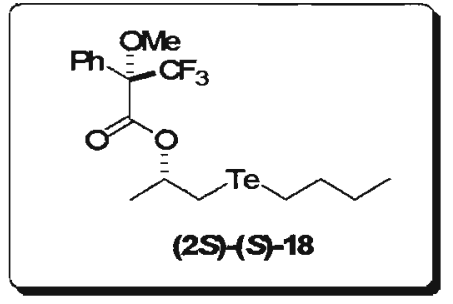

(2S)-(S)-3,3,3-Trifluoro-2-metóxi-2-fenil-propanoato de 1-(n-butilteluro)-2propila: Óleo; $\mathrm{RMN}^{1} \mathrm{H}\left(500 \mathrm{MHz}, \mathrm{CDCl}_{3}\right), \delta(\mathrm{ppm}): 0,91(\mathrm{t} ; \mathrm{J}=7,3 \mathrm{~Hz} ; 3 \mathrm{H}), 1,32-$ $1,39(\mathrm{~m} ; 2 \mathrm{H}), 1,40(\mathrm{~d} ; J=6,2 \mathrm{~Hz} ; 3 \mathrm{H}), 1,68-1,74(\mathrm{~m} ; 2 \mathrm{H}), 2,67-2,70(\mathrm{~m} ; 2 \mathrm{H}), 2,79$ (dd; $J=12,3 \mathrm{~Hz}$ e $J=7,7 \mathrm{~Hz} ; 1 \mathrm{H}), 2,91$ (dd; $J=12,3 \mathrm{~Hz}$ e $J=5,7 \mathrm{~Hz} ; 1 \mathrm{H}$ ), 3,57 (s; $3 \mathrm{H}), \quad 5,23-5,28(\mathrm{~m} ; 1 \mathrm{H}), 7,39-7,45(\mathrm{~m} ; 3 \mathrm{H}), 7,53-7,56(\mathrm{~m} ; 2 \mathrm{H}) ; \quad \mathrm{RMN}{ }^{13} \mathrm{C}$ $\left(125 \mathrm{MHz}, \mathrm{CDCl}_{3}\right), \delta(\mathrm{ppm}): 4,2 ; 7,3 ; 13,4 ; 20,6 ; 25,0 ; 34,1 ; 55,5 ; 75,6 ; 84,5$; 127,$5 ; 128,4 ; 129,6 ; 132,3 ; 166,0 ; \mathrm{RMN}^{125} \mathrm{Te}\left(157 \mathrm{MHz}, 300 \mathrm{~K}, \mathrm{CDCl}_{3}\right), \delta(\mathrm{ppm})$ 206,3 .

\subsubsection{Desselenização Redutiva ${ }^{54}$}

Essas reações foram realizadas seguindo o procedimento descrito na

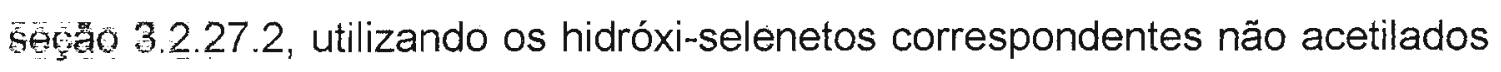
preferencialmente pela lị̣̂̂̀

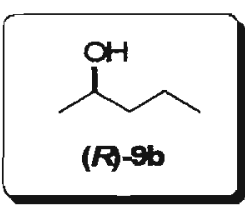

(R)-2-pentanol [obtido do (S)-1-fenilsseleno-2-pentanol (S)-1b]: >99\% e.e.; $[\alpha]_{D}^{19}=-12\left(\mathrm{c} 1,0 ; \mathrm{CHCl}_{3}\right)$; na literatura para o enantiômero $(S): 79 \%$ e.e.; $[\alpha]_{D}=$ $+10,25\left(\mathrm{c} \mathrm{o,98} \mathrm{CHCl}_{3}\right)$. ${ }^{56}$ 


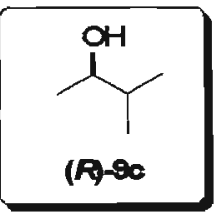

(R)-3-metil-2-butanol [obtido do (S)-1-fenilsseleno-3-metil-2-butanol (S)-1c]: $69 \%$ e.e.; $[\alpha]_{D}^{20}=-2$ (c 2,0; $\mathrm{CHCl}_{3}$ ); na literatura para o enantiômero $(R): 86 \%$ e.e.; $[\alpha]_{D}=-2,74\left(\mathrm{c} 0,986 ; \mathrm{CHCl}_{3}\right) .{ }^{56}$

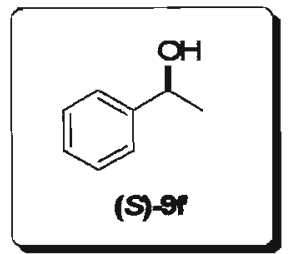

(S)-1-feniletanol [obtido do $(R)$-1-metilsseleno-2-fenil-etanol $(R)$-1f]: $41 \%$ e.e.; $[\alpha]_{D}^{20}=-24$ (c 2,0; $\mathrm{CHCl}_{3}$ ); na literatura para o enantiômero (S): >99\% e.e.; $[\alpha]_{\mathrm{D}}$ $=-55,1\left(\mathrm{c} 1,63 ; \mathrm{CHCl}_{3}\right) .{ }^{57}$

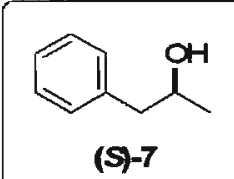

(S)-1-fenil-2-propanol [obtido da mistura diastereoisomérica dos (1R,2S)-1fenil-1-(fenilsseleno)-2-propanol e (1S,2S)-1-fenil-1-(fenilsseleno)-2-propanol]: $92 \%$ e.e.; $[\alpha]_{D}^{21}=+37$ (c 1,0; $\left.\mathrm{CHCl}_{3}\right)$; na literatura para o enantiômero (S): $>99 \%$ e.e.; $[\alpha]_{D}=+41,7\left(\mathrm{c} 1,19 ; \mathrm{CHCl}_{3}\right)$. ${ }^{57}$

\subsubsection{Eliminação de Selenóxido ${ }^{38}$}

Essa reação foi realizada seguindo o procedimento descrito na seção 4.2.25, utilizando os hidróxi-seleneto $1 \mathrm{~h}$ não acetilado preferencialmente pela lipase.

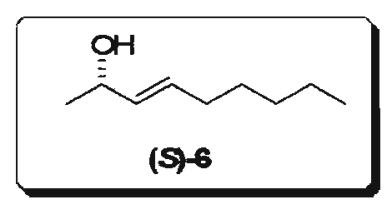

(S)-3-nonen-2-ol [obtido da mistura diastereoisomérica dos (1R,2S)-1-hexil-1(fenilsseleno)-2-propanol e (1S,2S)-1-hexil-1-(fenilsseleno)-2-propanol]: 92\% 
e.e.; $[\alpha]^{21}{ }_{D}=-8\left(\mathrm{c} 1,5, \mathrm{CHCl}_{3}\right)$; na literatura para o enantiômero $(R)$ : $97 \%$ e.e.; $[\alpha]_{D}^{19}=+10,68\left(\right.$ c 1,$\left.03 ; \mathrm{CHCl}_{3}\right) .{ }^{58}$

\subsubsection{Reação de Lactonização}

Essa reação foi realizada seguindo o procedimento descrito na seção 4.2.26, utilizando o telureto $(R)-11 f\left(e_{.} .=98 \%\right)$ acetilado preferencialmente pela lipase e o hidróxi-telureto $(S)-10 g$ (e.e. $=98 \%$ ), não acetilado preferencialmente na resolução.

Assim, inicialmente foi realizada a hidrólise química do telureto $(R)$ 11f, gerando o hidróxi-telureto $(R)$-10f e em seguida a reação de lactonização foi realizada gerando as lactonas de interesse.

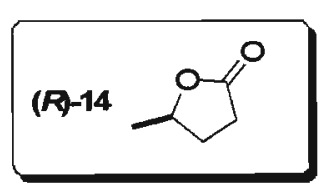

$(R)-\gamma$-valerolactona [obtido do $(R)-4$-( $n$-butilteluro)-2-butanol $(R)-10 f$ ]: $98 \%$ e.e.; $[\alpha]_{D}^{23}=+30$ (c 1,0; $\mathrm{CHCl}_{3}$ ); na literatura para o enantiômero $(S)$ : $74 \%$ e.e.; $[\alpha]_{D}=-26,7\left(\mathrm{C} 1,0 ; \mathrm{CHC}_{3}\right) .{ }^{71}$

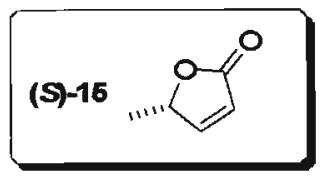

(S)- $\beta$-angelicalactona [obtido do (S)-(Z)-4-(butilteluro)-but-3-en-2-ol (S)-10g] $98 \%$ e.e.; $[\alpha]_{D}^{23}=+100$ (c 0,$25 ; \mathrm{CHCl}_{3}$ ); na literatura para o enantiômero (S): $>99 \%$ e.e.; $[\alpha]_{\mathrm{D}}{ }^{21}=+117\left(\right.$ c 3,60; $\left.\mathrm{CHCl}_{3}\right) .{ }^{72}$ 



\subsection{Espectros Selecionados}





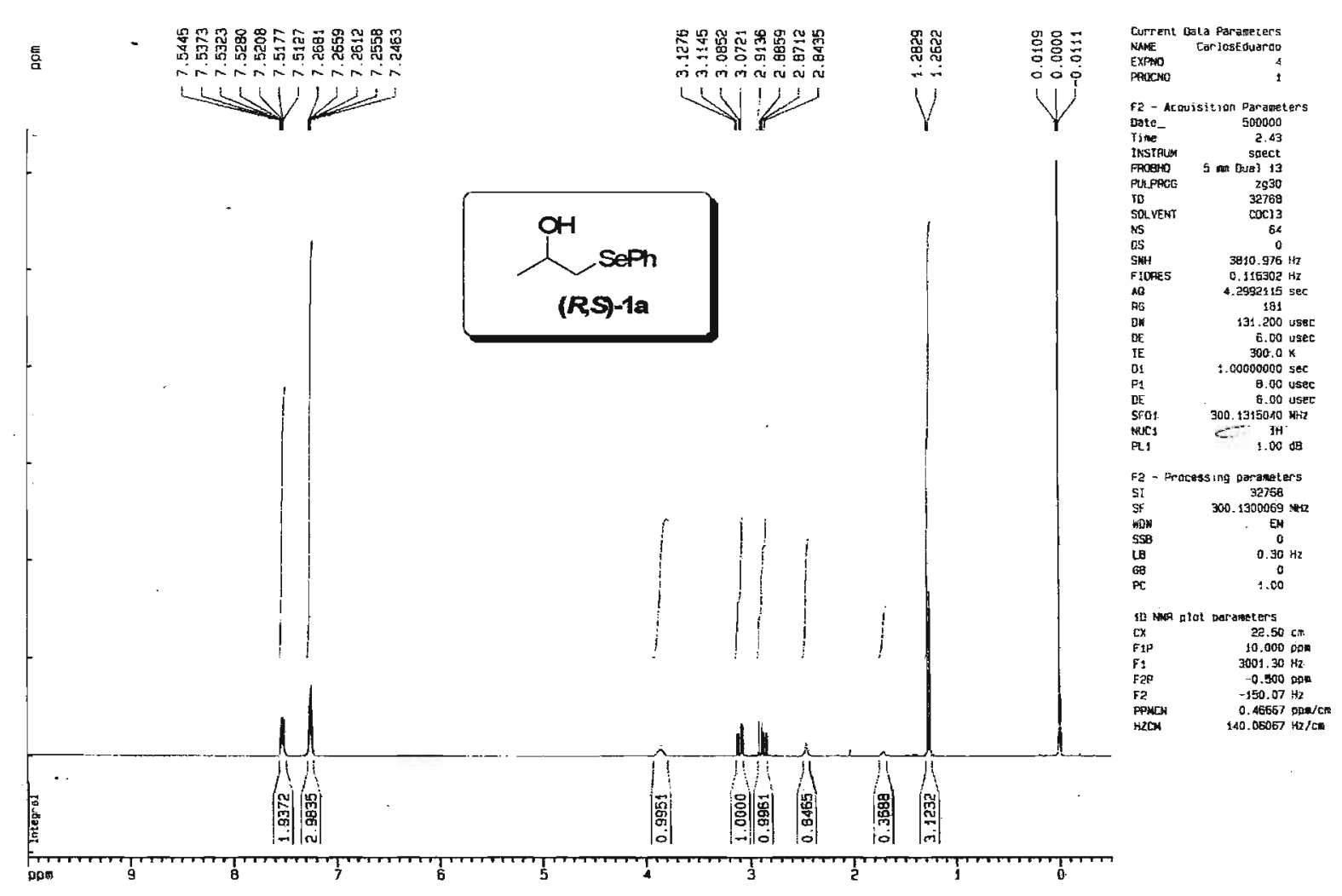

Espectro de RMN 'H do composto $(R, S)-1$-fenilsseleno-2-propanol [(R,S)-1a]

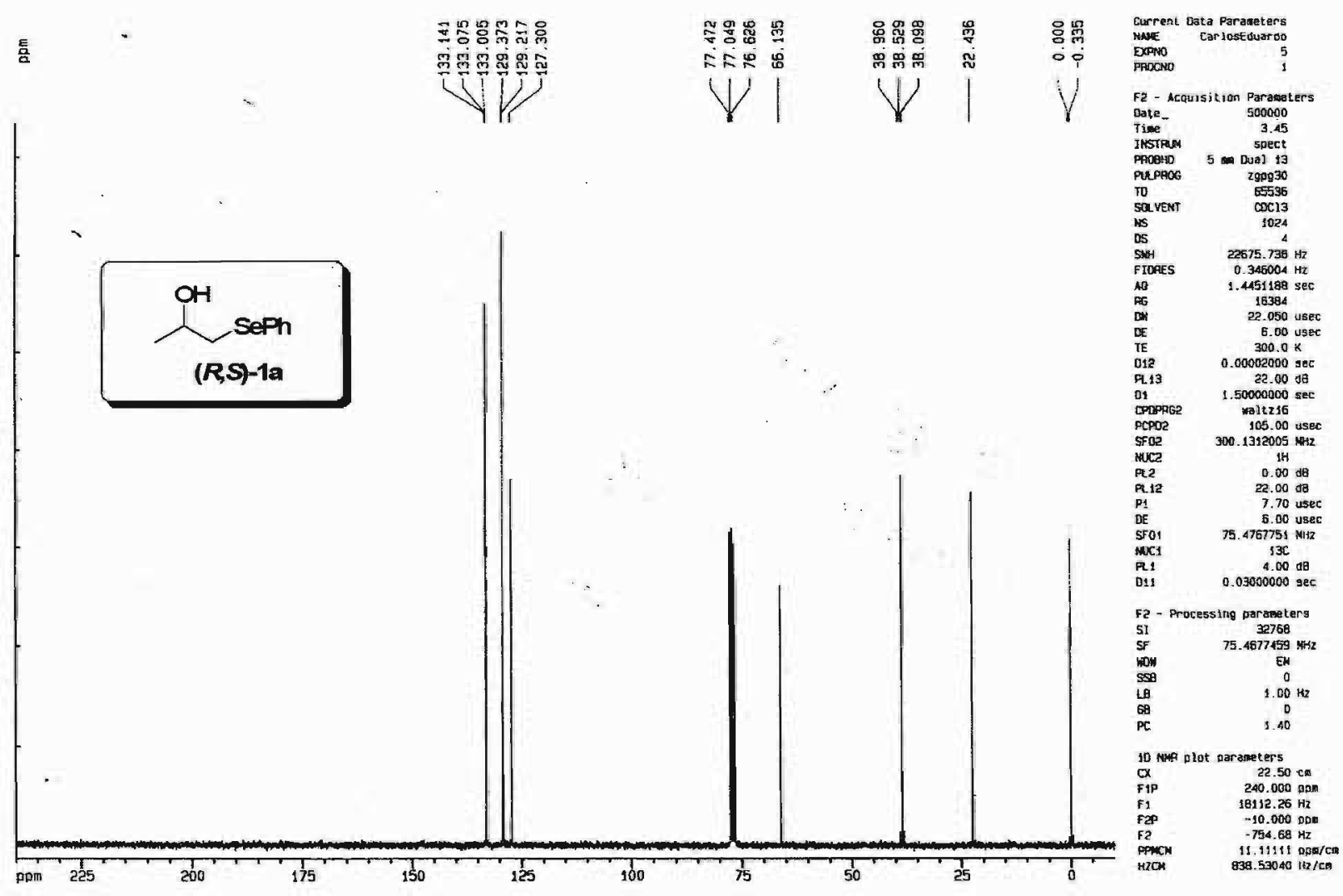

Espectro de $\mathrm{RMN}{ }^{13} \mathrm{C}$ do composto $(R, S)$-1-fenilsseleno-2-propanol $[(R, S)-1 \mathrm{a}]$ 


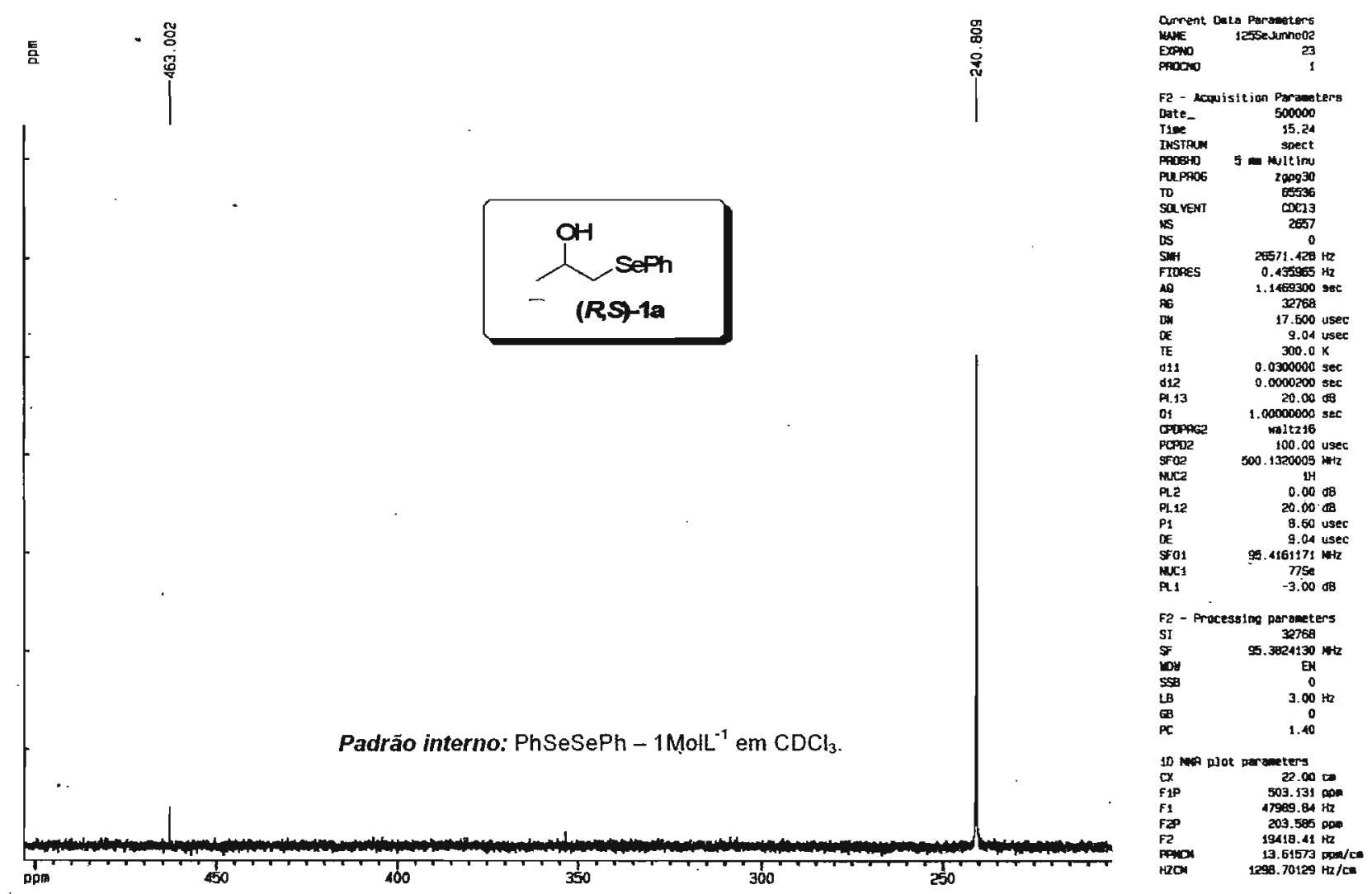

Espectro de $\mathrm{RMN}^{7 \bar{T}}$ Se do composto $(R, S)$-1-fenilsseleno-2-propanol $[(R, S)-1 \mathrm{a}]$

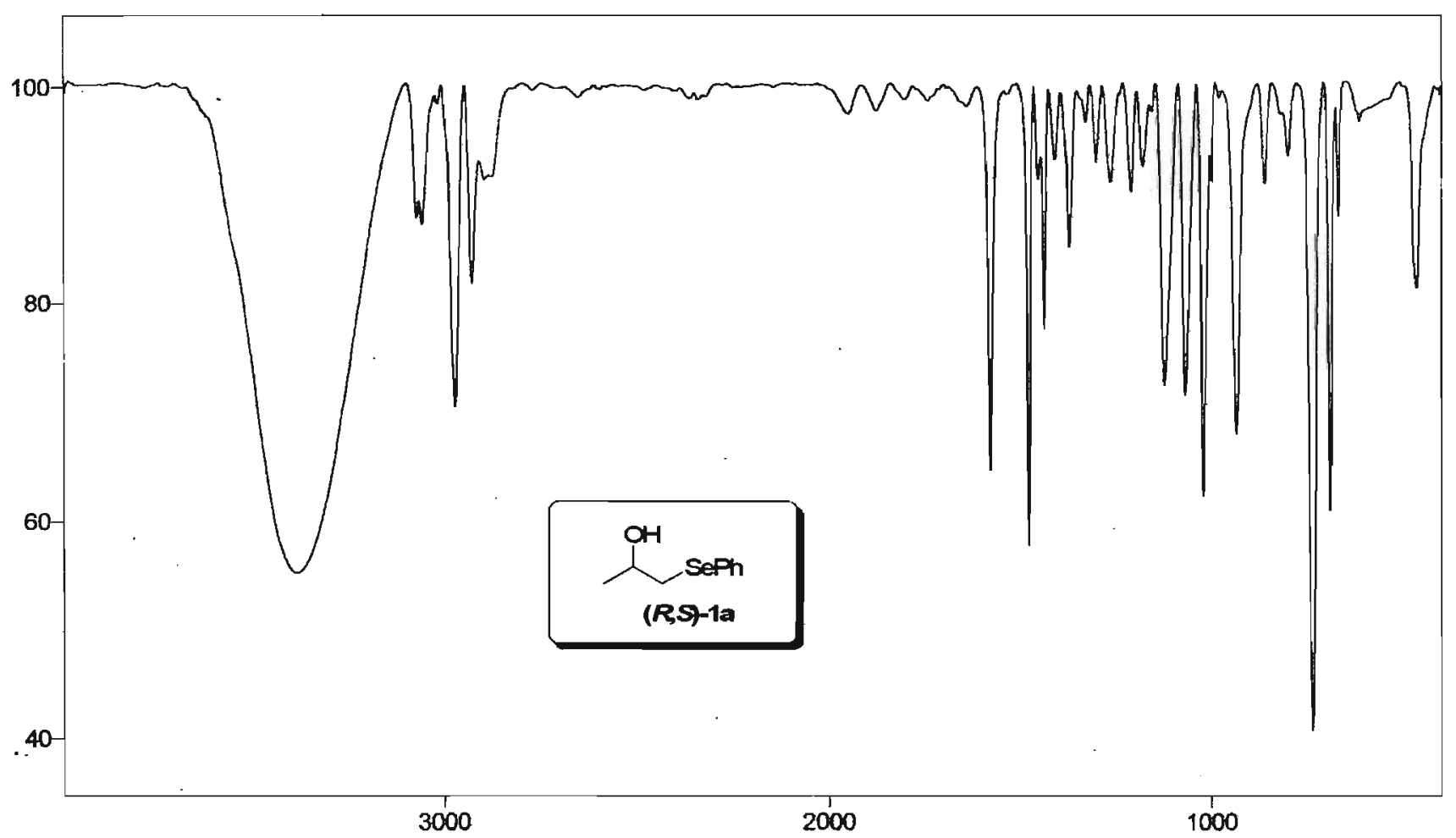

Transmittance / Wavenumber (cm-1)

Espectro de I.V. do composto (R,S)-1-fenilsseleno-2-propanol [(R,S)-1a] 


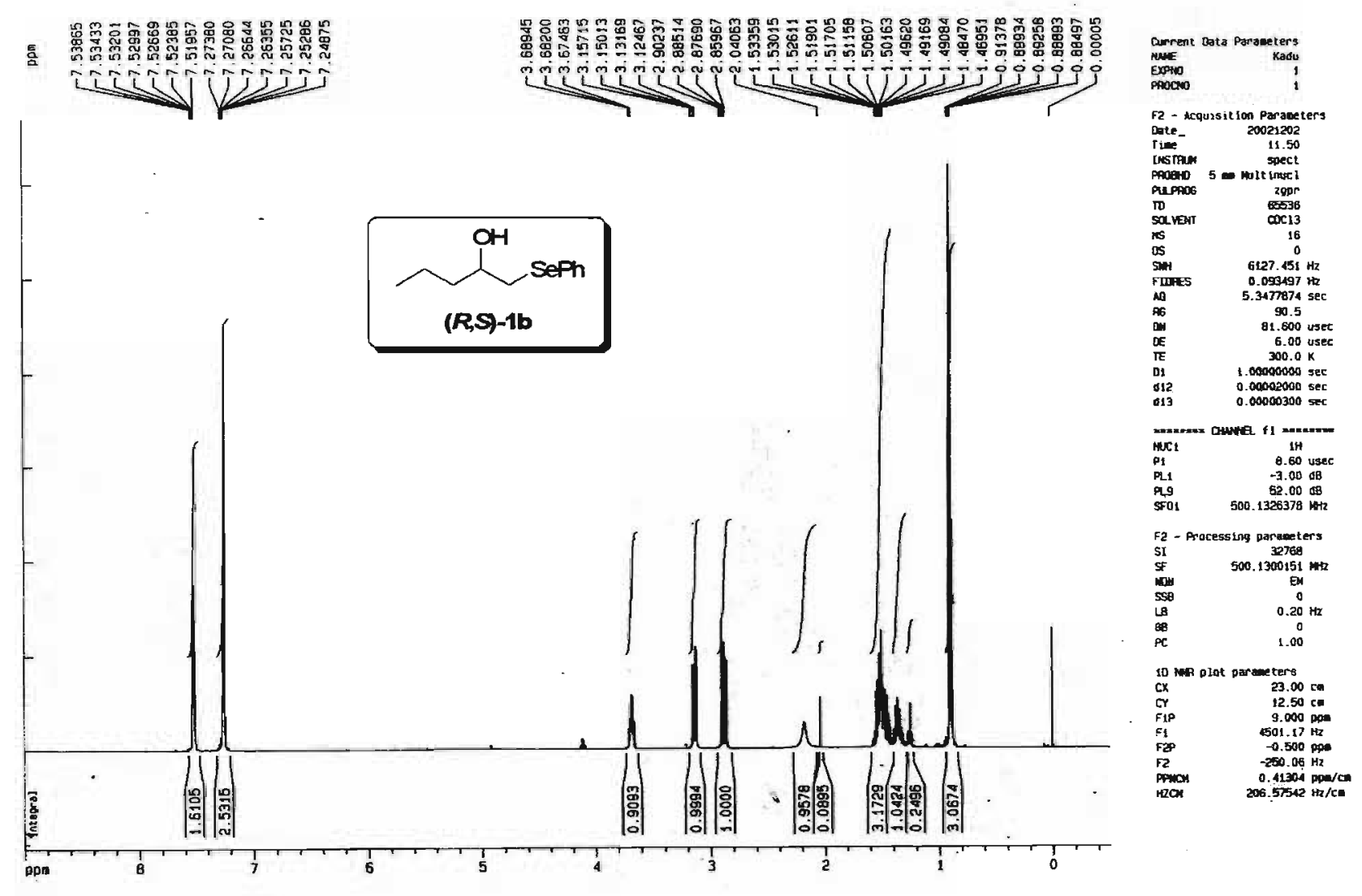

Espectro de RMN ${ }^{1} \mathrm{H}$ do composto $(R, S)-1$-fenilsseleno-2-pentanol $[(R, S)-1 \mathrm{~b}]$

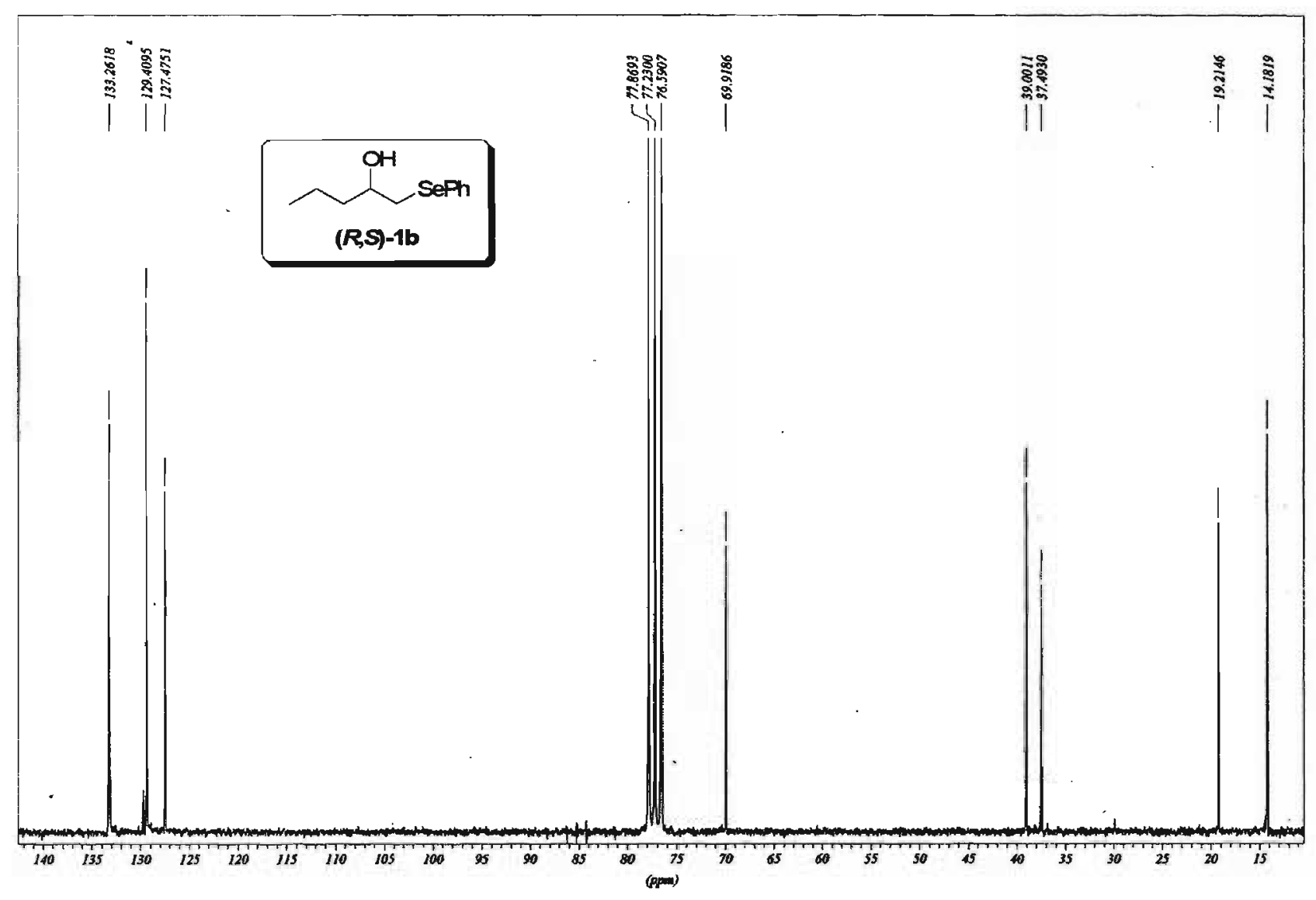

Espectro de RMN ${ }^{13} \mathrm{C}$ do composto $(R, S)$-1-fenilsseleno-2-pentanol [(R,S)-1b] 

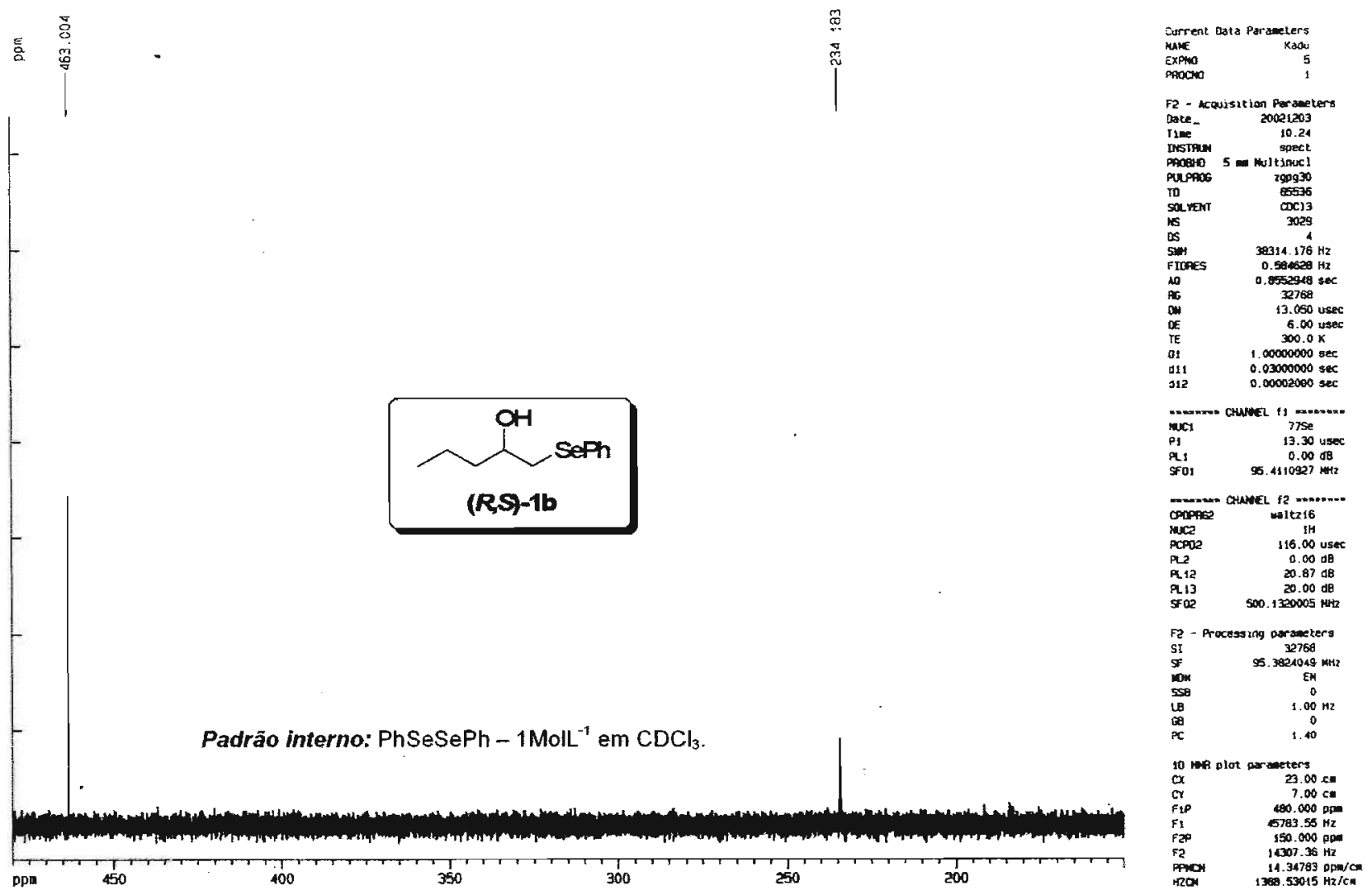

Espectro de RMN ${ }^{77}$ Se do composto $(R, S)$-1-fenilsseleno-2-pentanol $[(R, S)-1 \mathrm{~b}]$

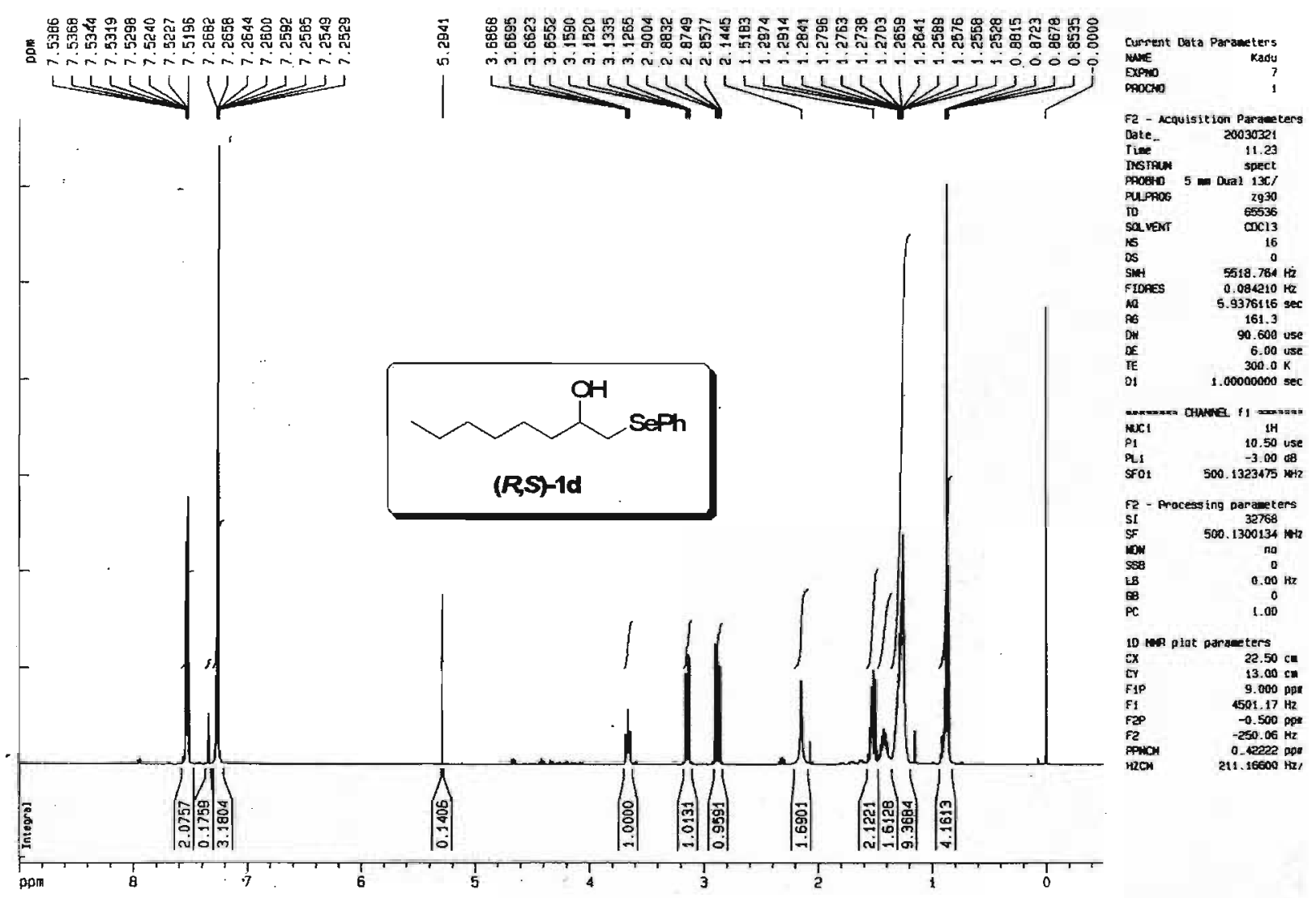

Espectro de $R M N{ }^{1} \mathrm{H}$ do composto $(R, S)$-1-fenilsseleno-2-octanol $[(R, S)-1 \mathrm{~d}]$ 


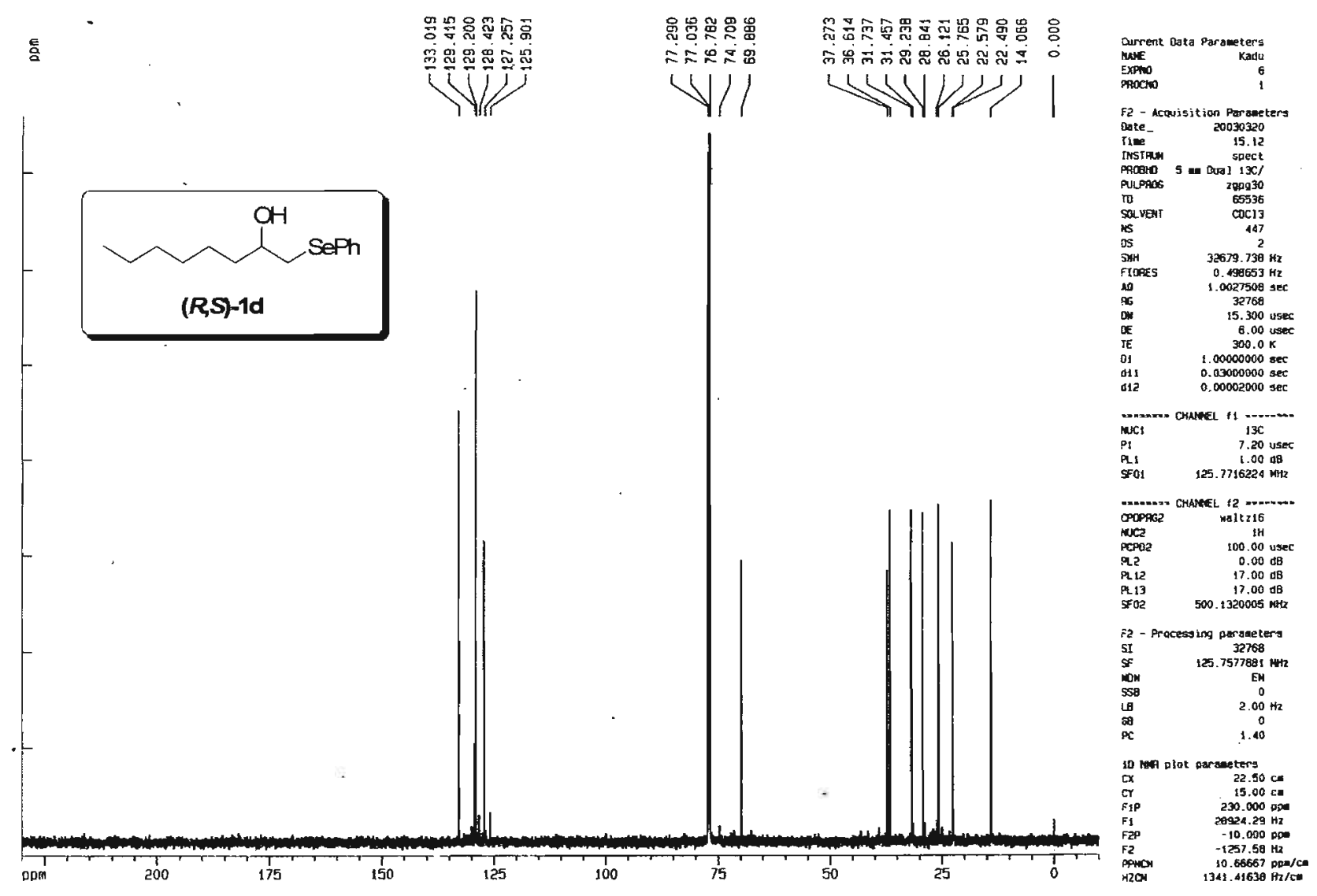

Espectro de RMN ${ }^{13} \mathrm{C}$ do composto $(R, S)$-1-fenilsseleno-2-octanol [(R,S)-1d]

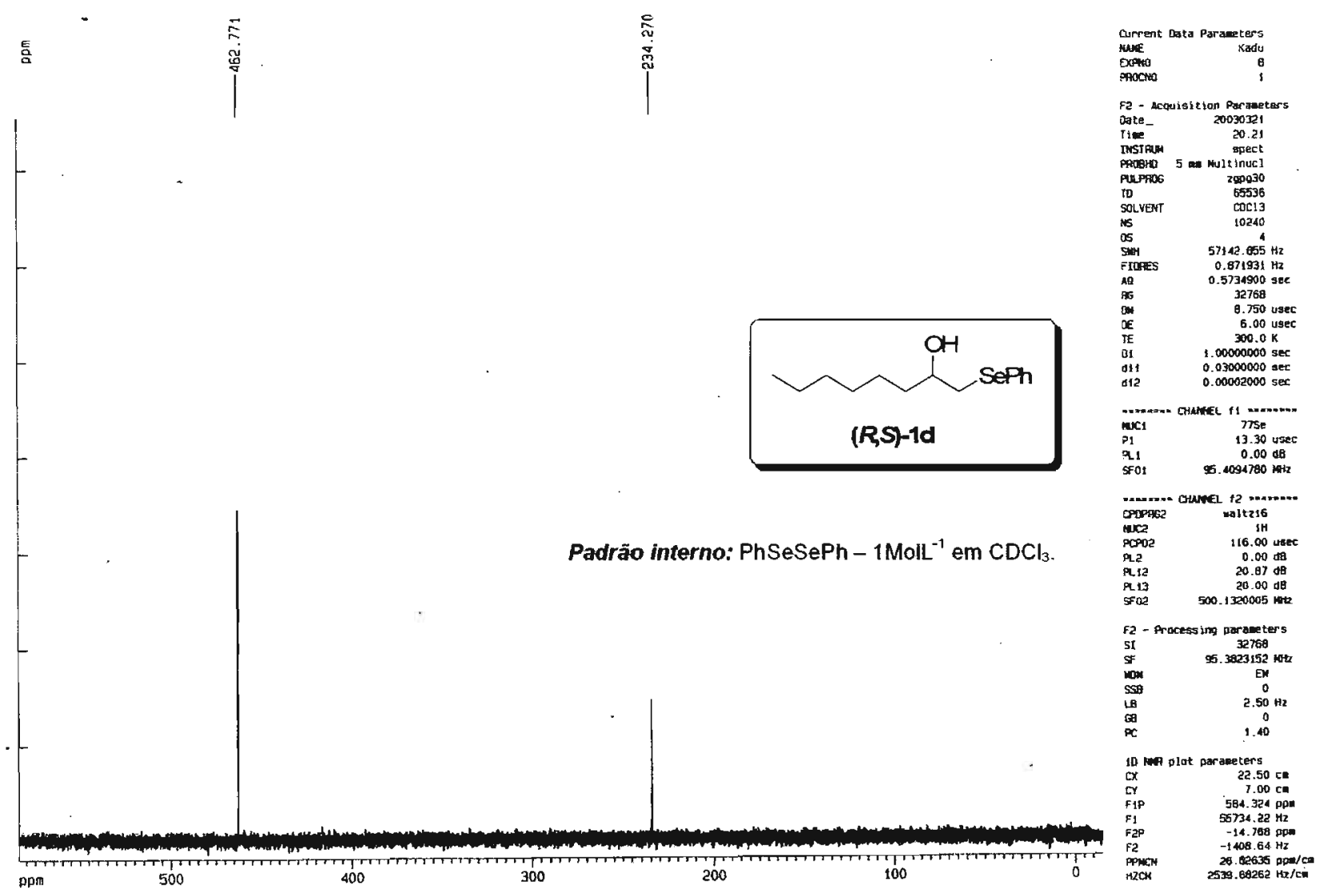

Espectro de $\mathrm{RMN}{ }^{i \top}$ Se do composto $(R, S)$-1-fenilsseleno-2-octanol [(R,S)-1d] 


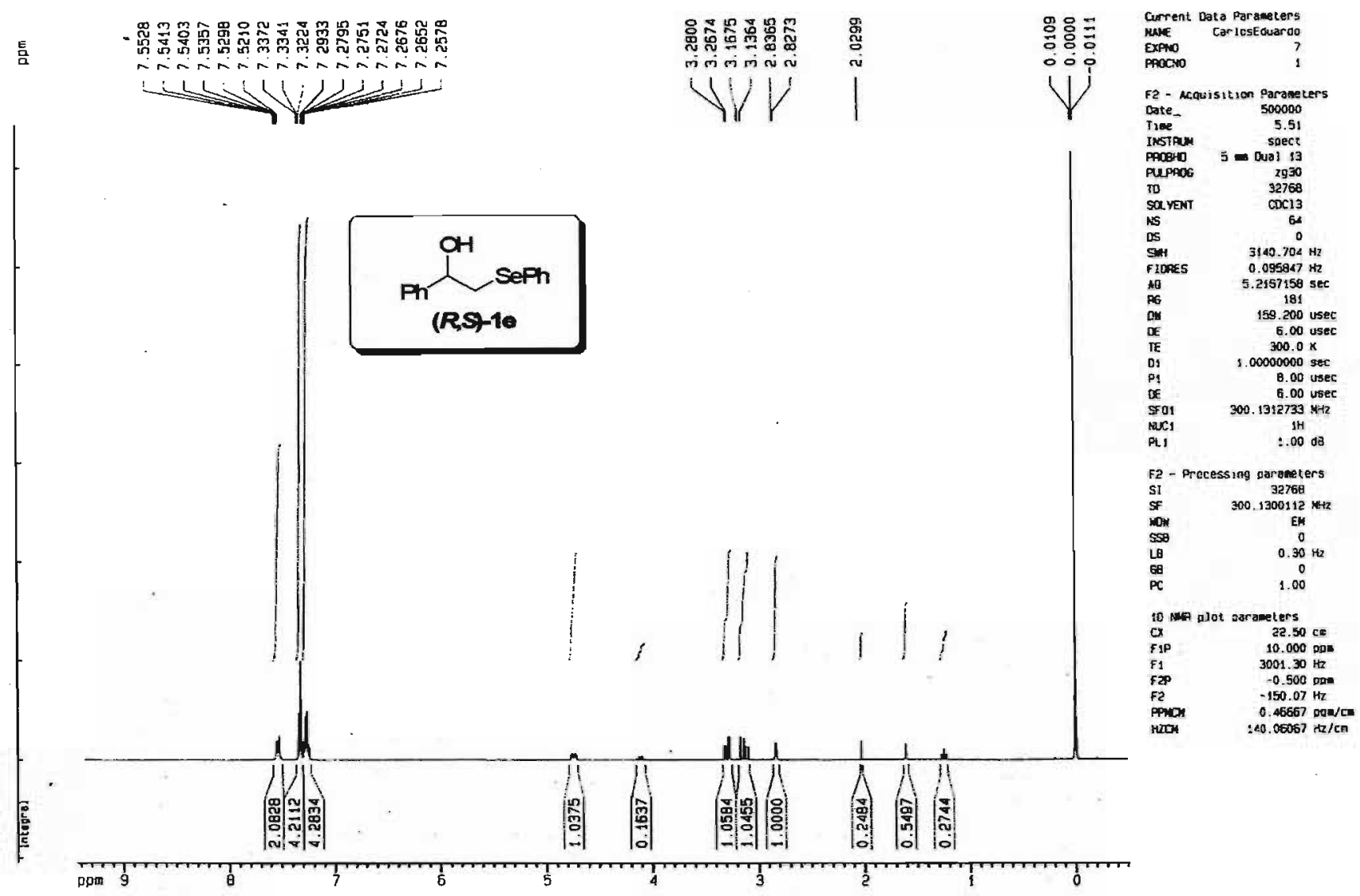

Espectro de RMN 'H do composto $(R, S)$-1-fenil-2-fenilsseleno-etanol [(R,S)-1e]

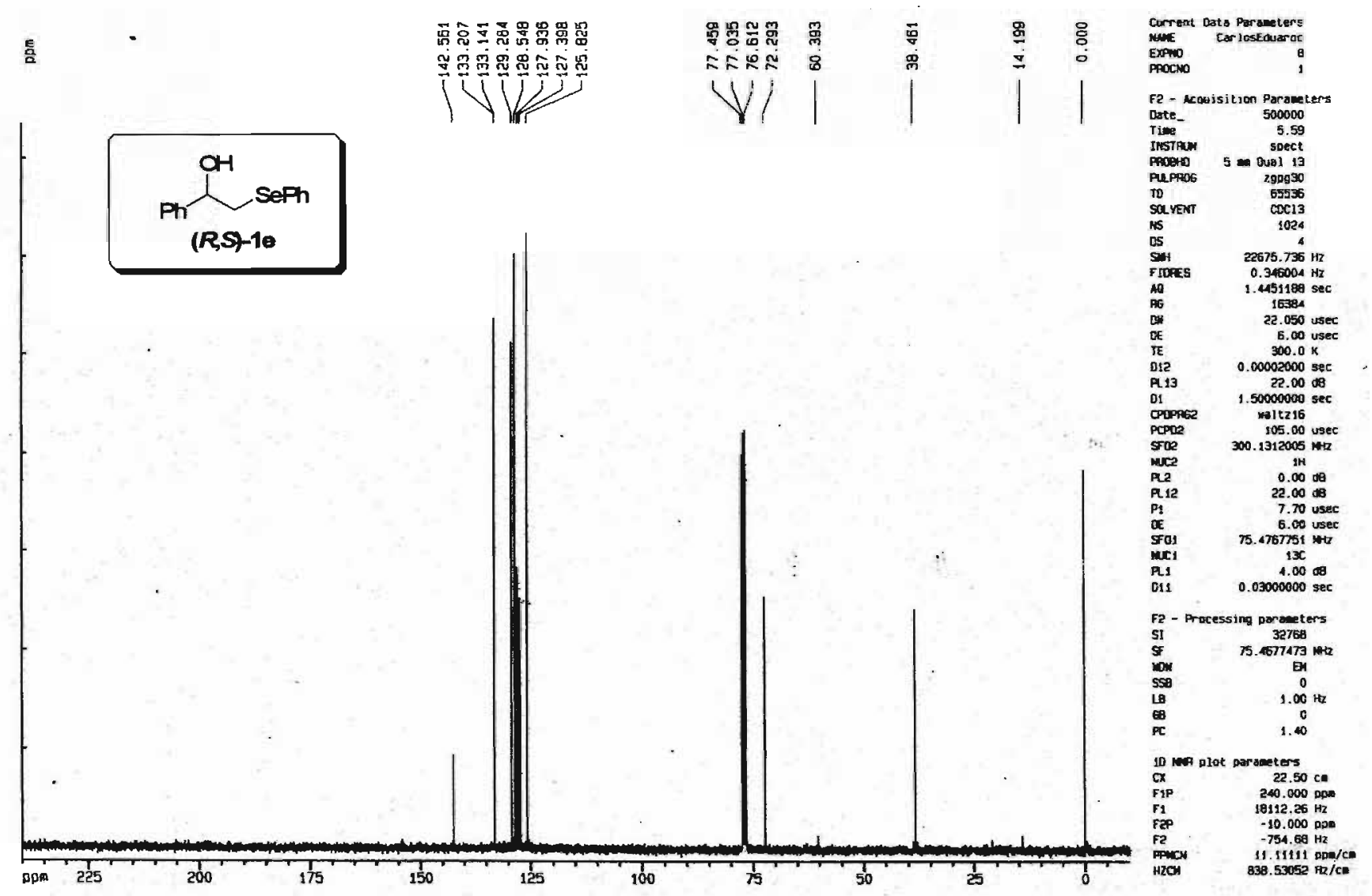

Espectro de $\mathrm{RMN}{ }^{13} \mathrm{C}$ do composto $(R, S)$-1-fenil-2-fenilsseleno-etanol $[(R, S)-1 \mathrm{e}]$ 

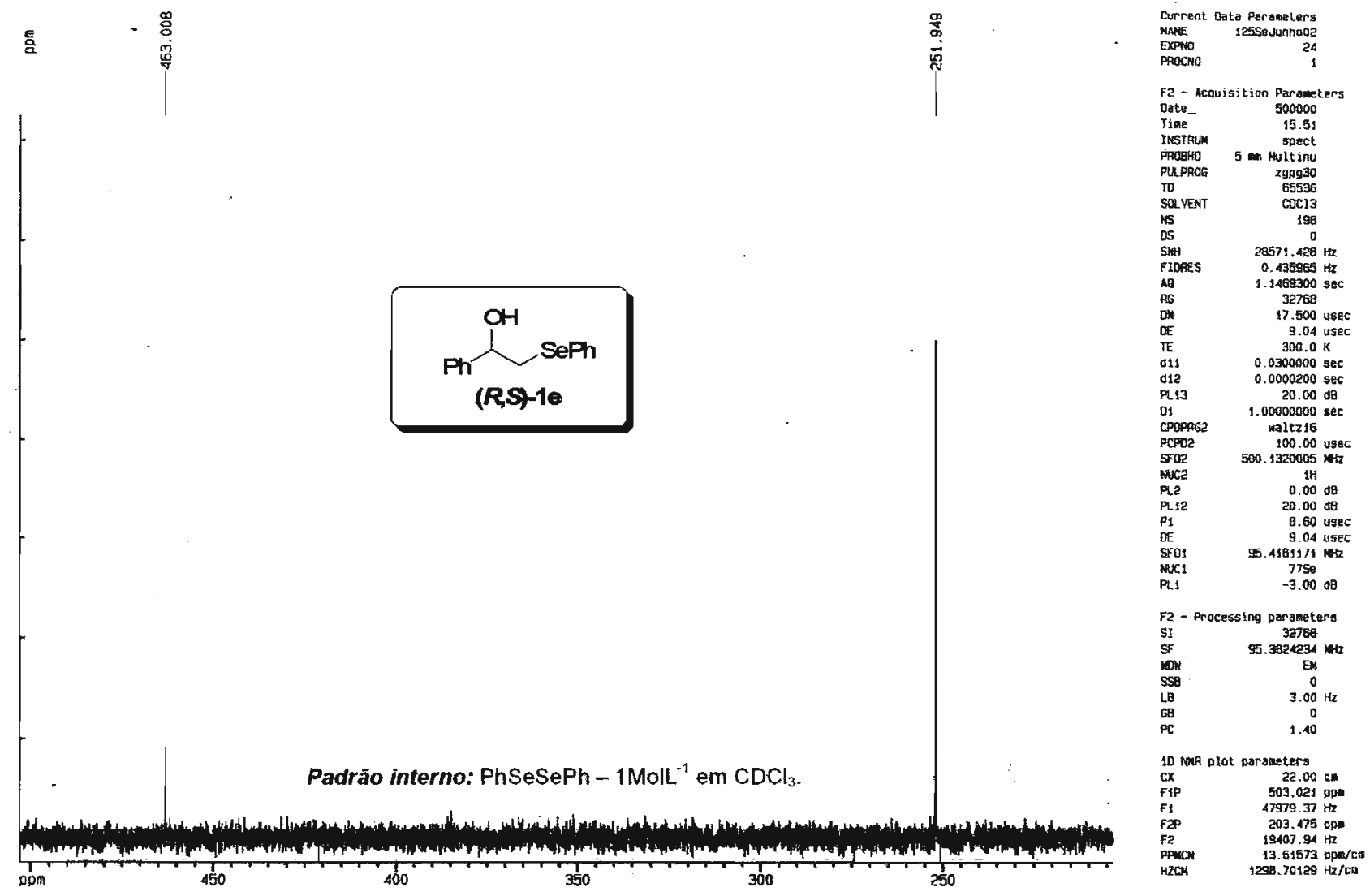

Espectro de RMN ${ }^{77}$ Se do composto $(R, S)-1-f e n i l-2-f e n i l s s e l e n o-e t a n o l ~[(R, S)-1 e]$

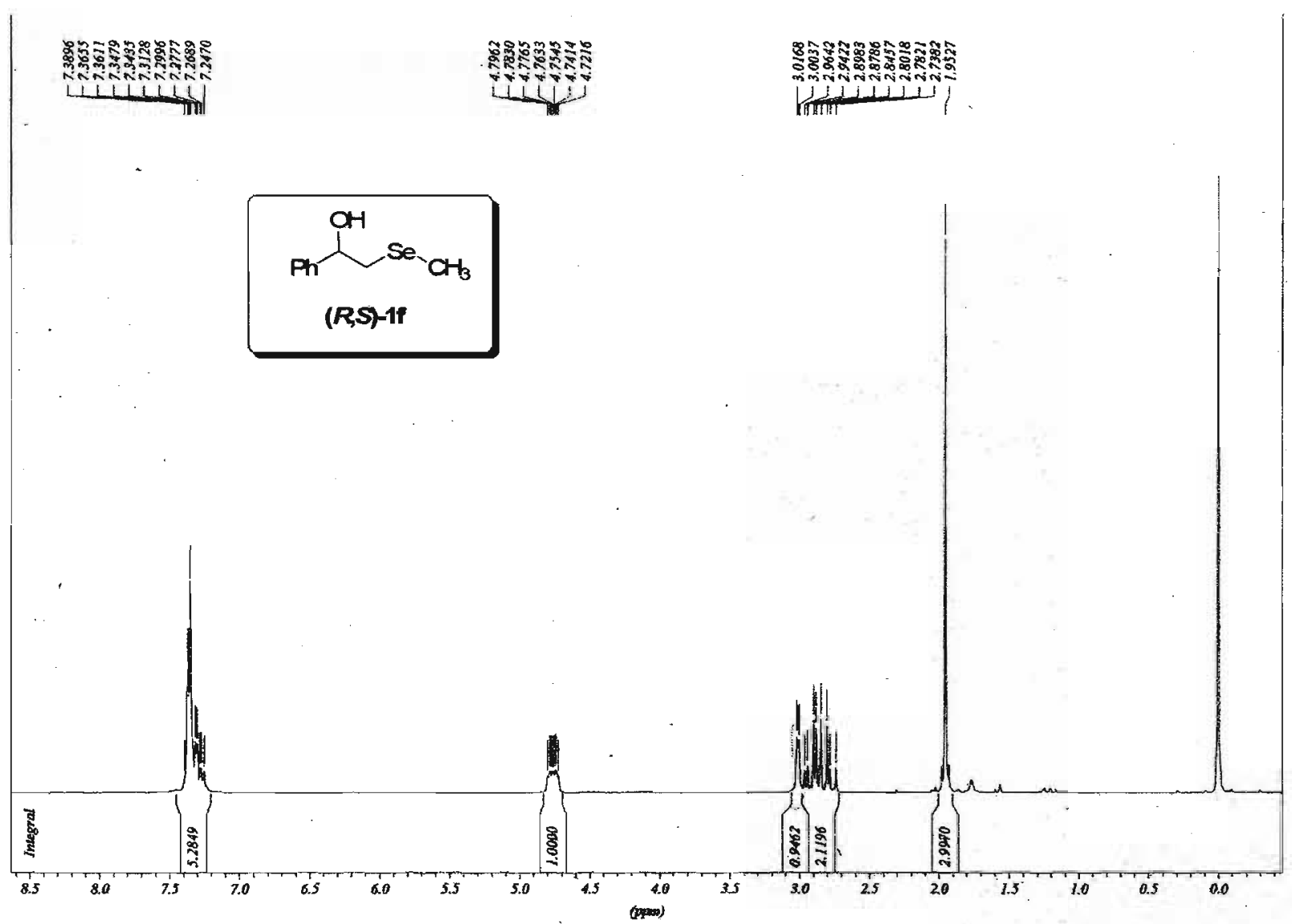

Espectrō de RMiN ${ }^{1} \mathrm{H}$ do composto $(R, S)$-1-metilsseleno-2-fenil-etanol $[(R, S)-1$ f $]$ 


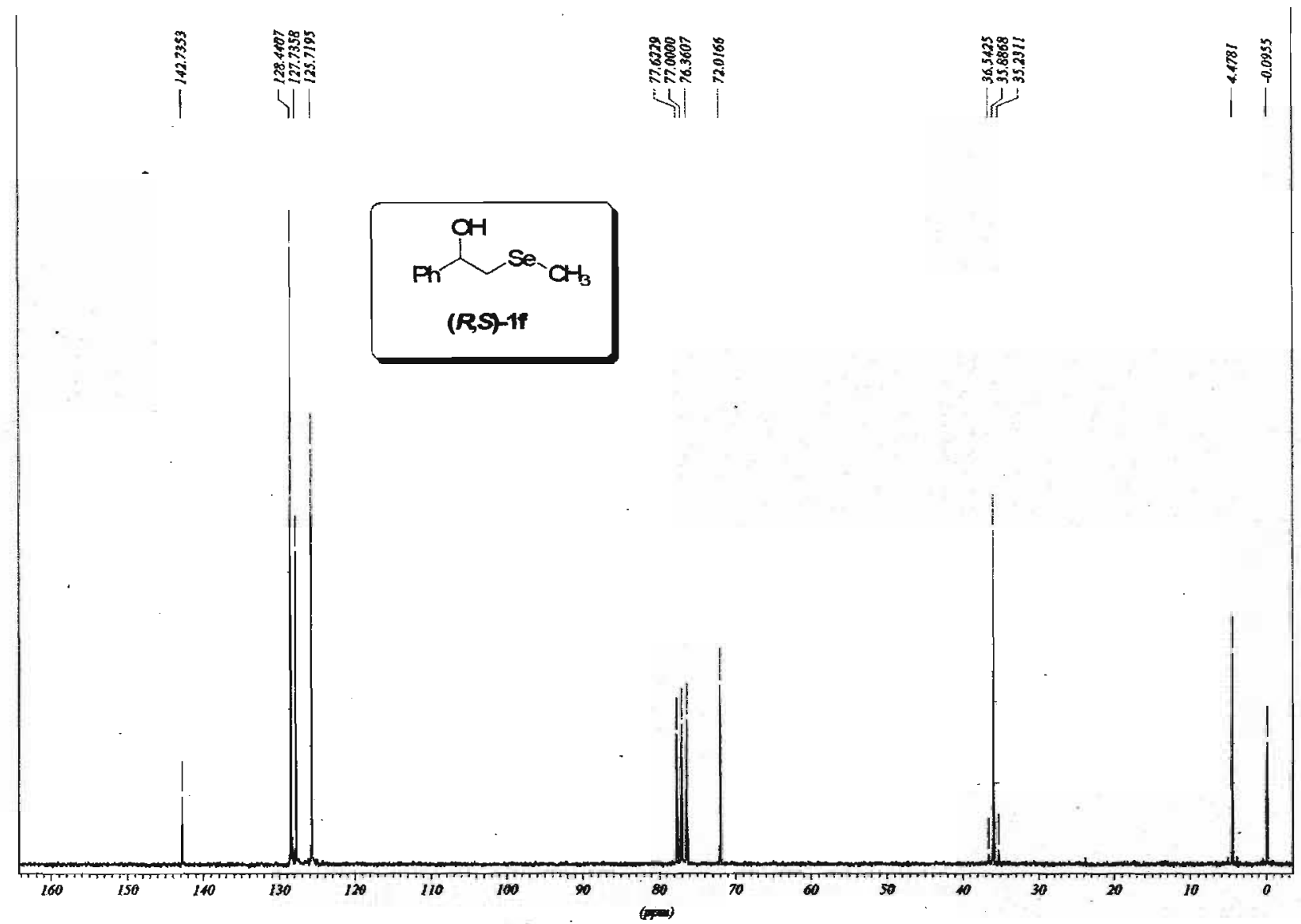

Espectro de $\mathrm{RMN}{ }^{13} \mathrm{C}$ do composto $(R, S)$-1-metilsseleno-2-fenil-etanol [(R,S)-1f]
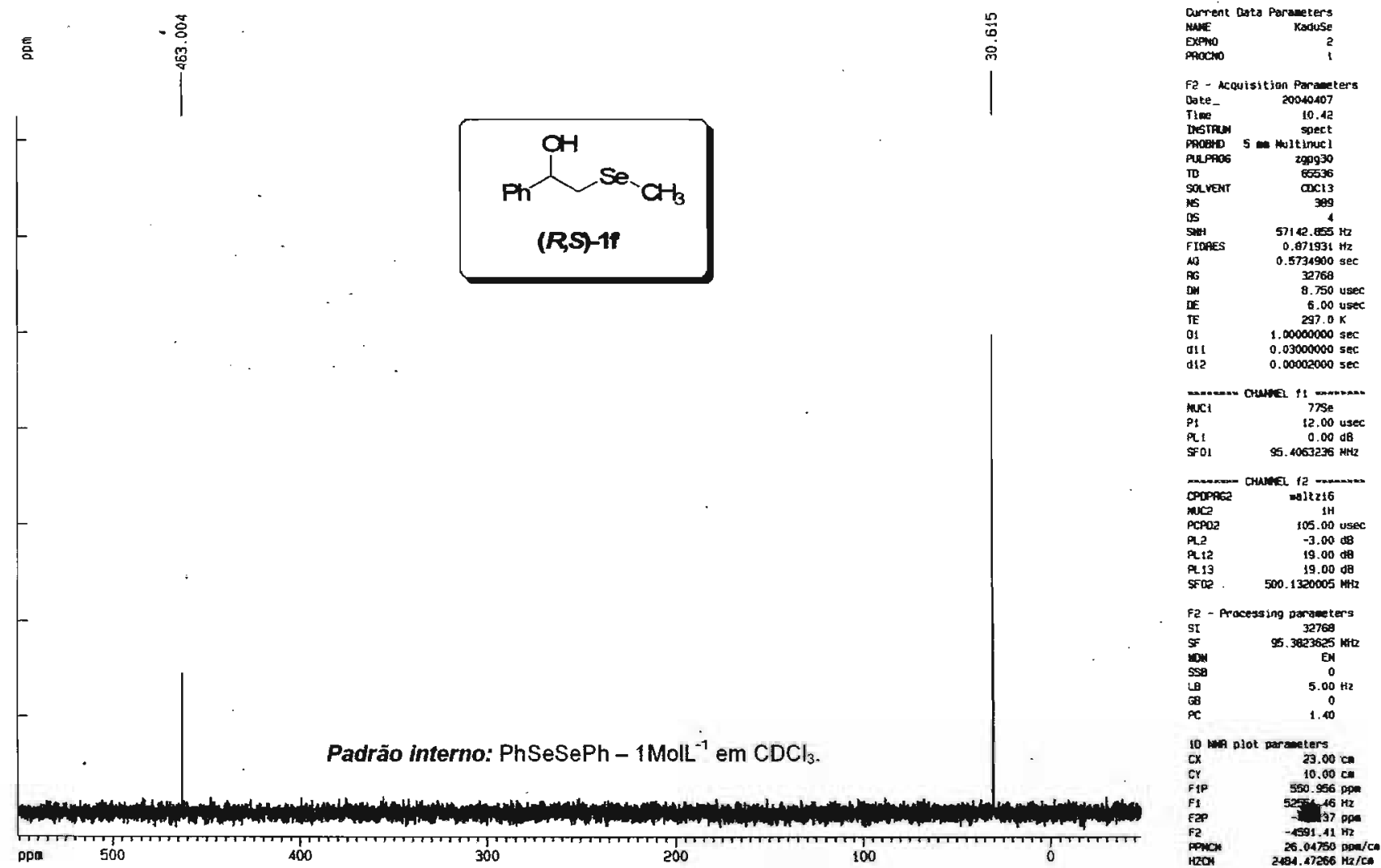

Espectro de $\mathrm{RMN}{ }^{77}$ Se do composto $(R, S)$-1-metilsseleno-2-fenil-etanol $[(R, S)-1 f]$ 


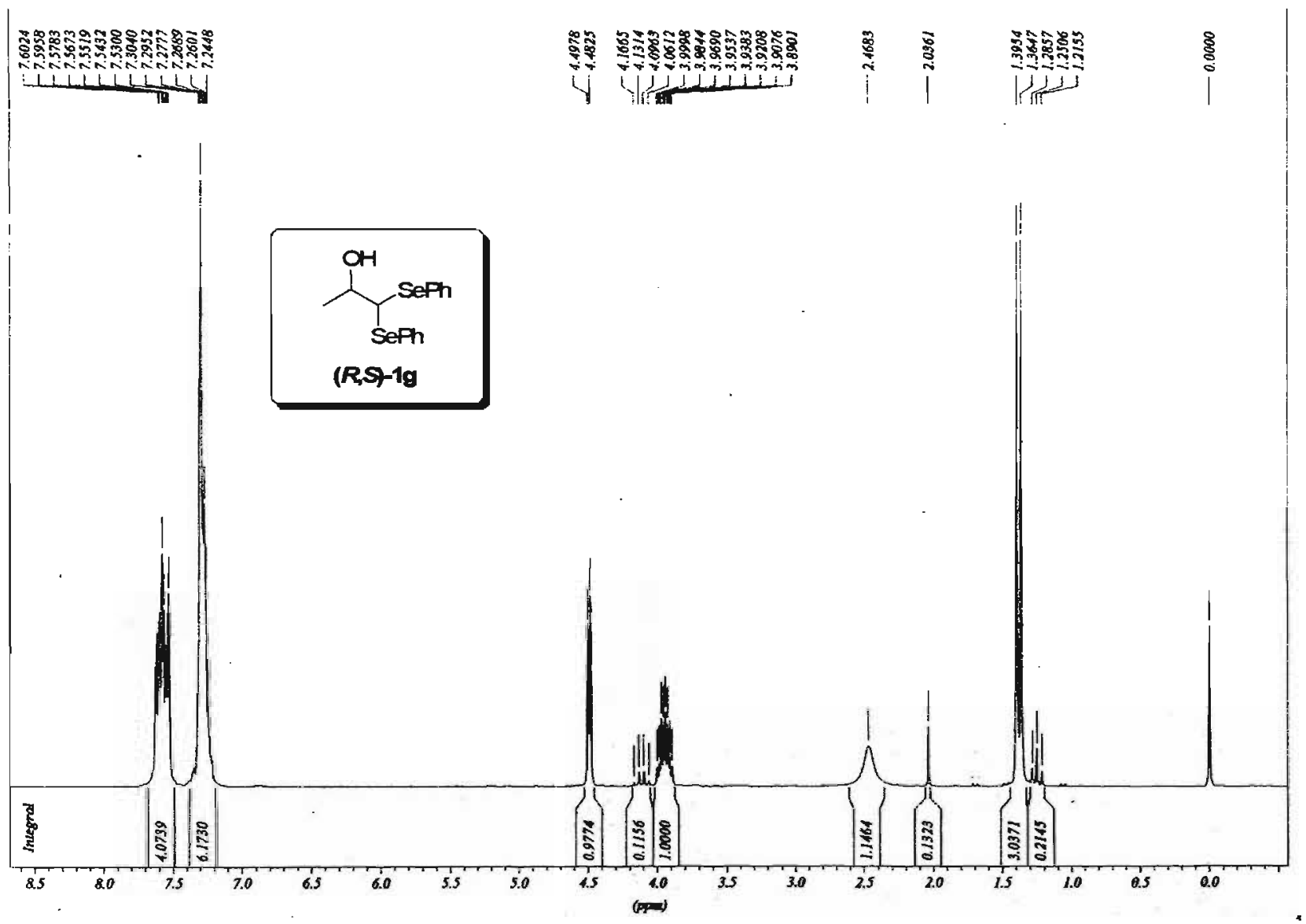

Espectro de $\mathrm{RMN}{ }^{1} \mathrm{H}$ do composto $(R, S)-1,1$-difenilsseleno-2-propanol [(R,S)-1g]

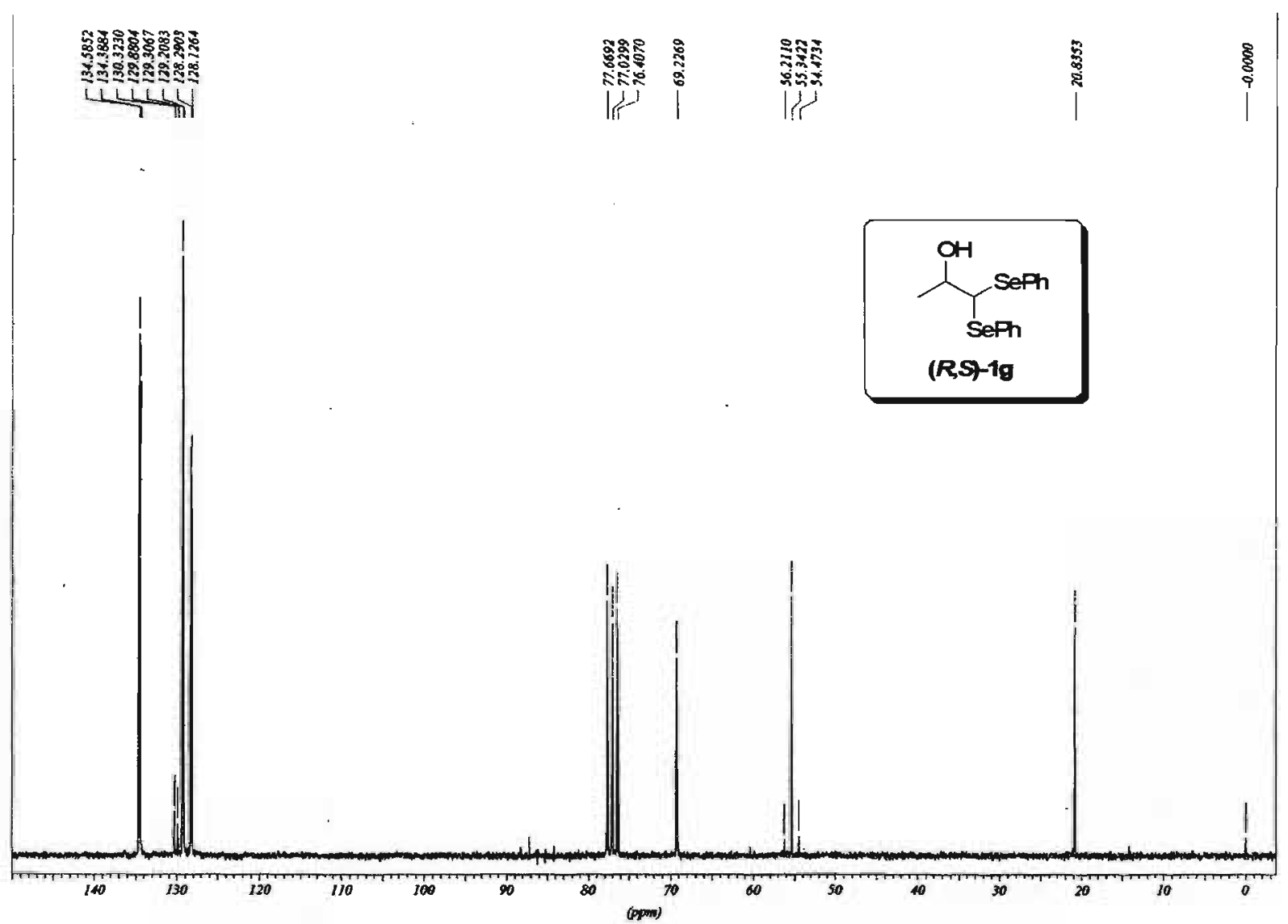

Espectro de RMN ${ }^{13} \mathrm{C}$ do composto $(R, S)$-1,1-difenilsseleno-2-propanol [(R,S)-1g] 


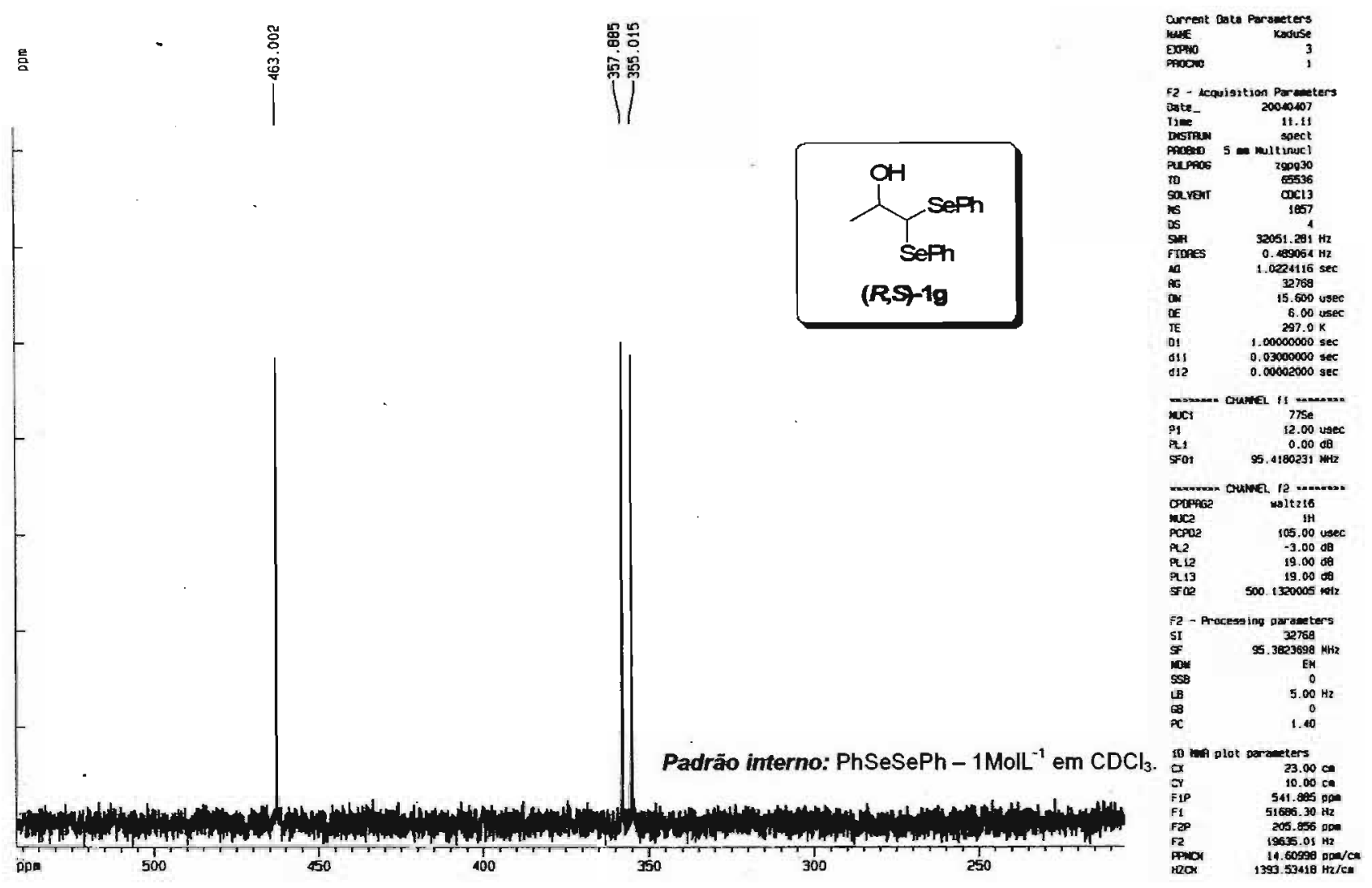

Espectro de RMN ${ }^{i \top}$ Se do composto $(R, S)-1,1$-difenilsseleno-2-propanol [(R,S)-1g]
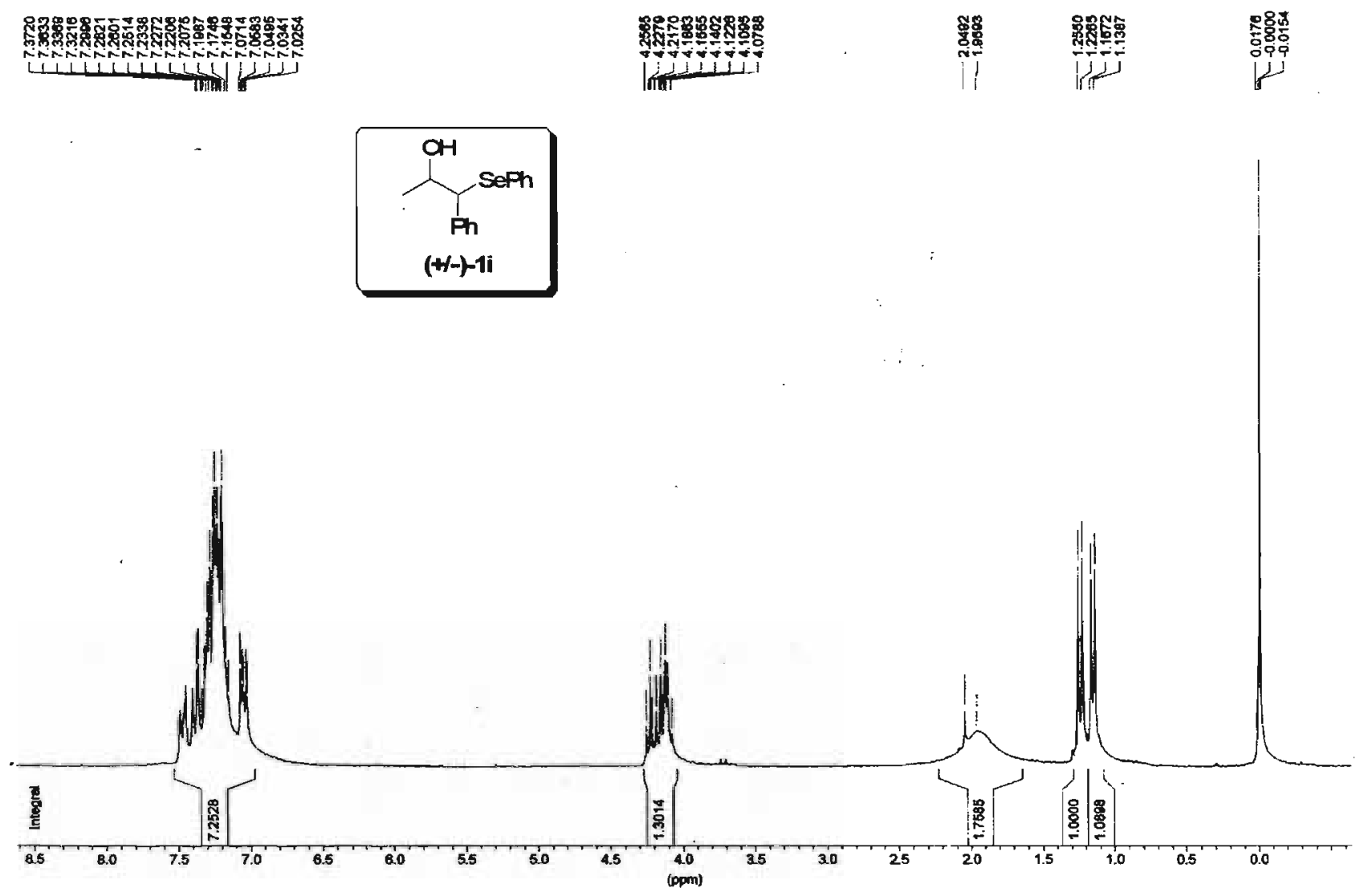

Espectro de RMN ${ }^{1} \mathrm{H}$ do composto ( \pm )-1-fenil-1-fenilsseleno-2-propanol [( \pm )-1i] 


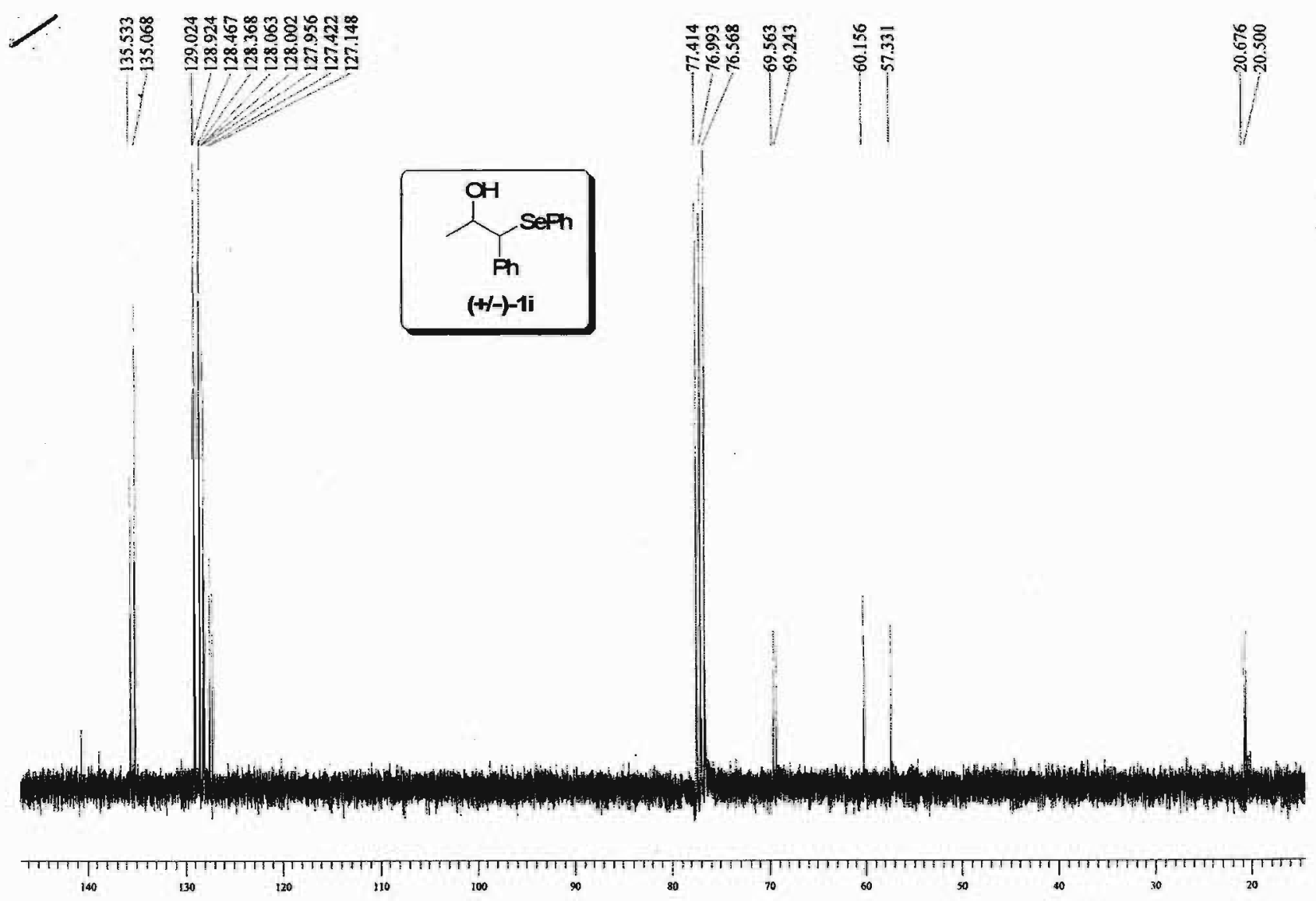

Espectro de RMN ${ }^{13} \mathrm{C}$ do composto ( $\left.\mathbf{\pm}\right)$-1-fenil-1-fenilsseleno-2-propanol [( $\left.\left.\mathbf{\pm}\right)-1 \mathrm{i}\right]$

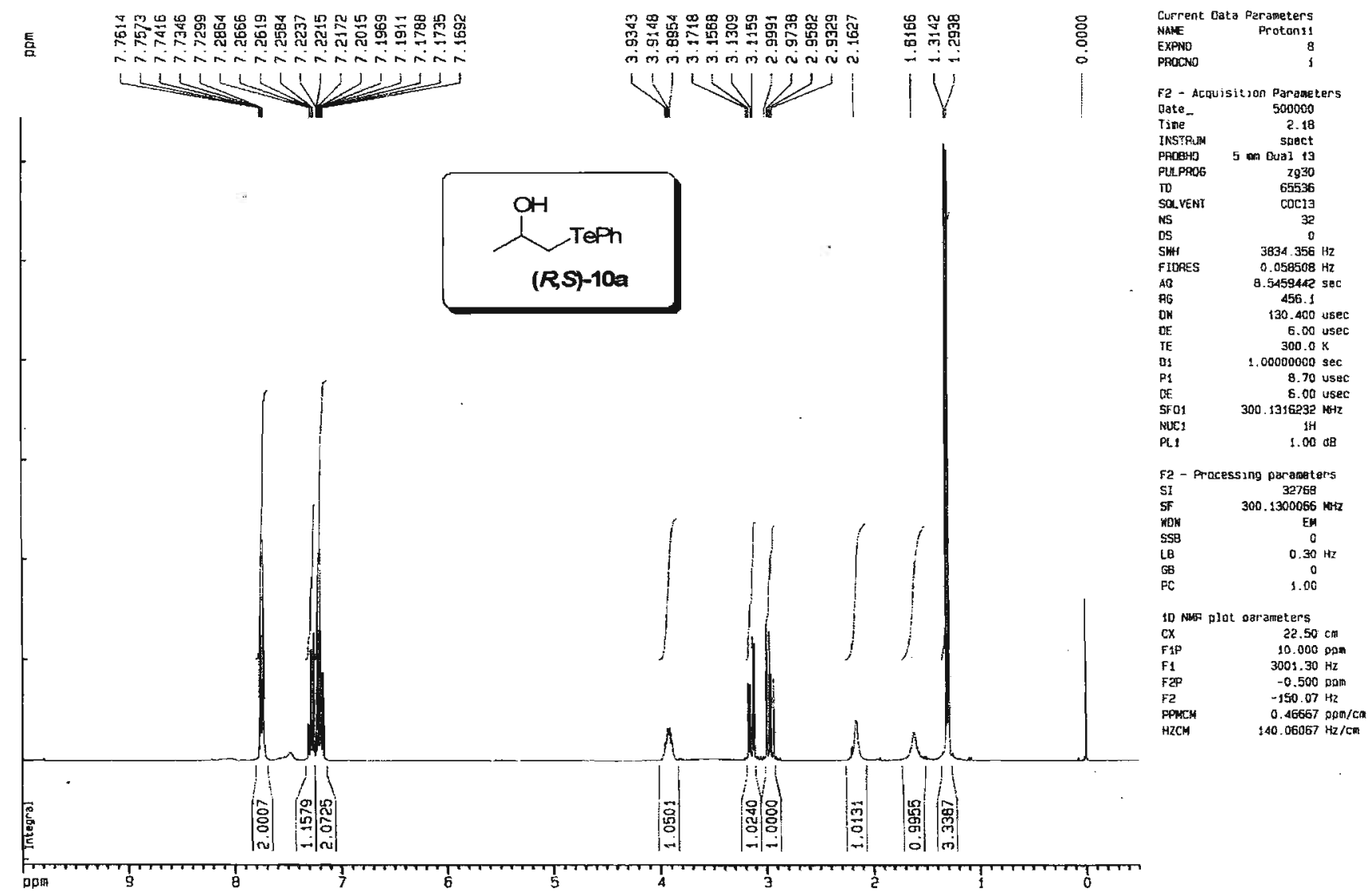

Espectro de RMN ${ }^{1} \mathrm{H}$ do composto $(R, S 81$-fenilteluro-2-propanol $[(R, S)-10 \mathrm{a}]$ 


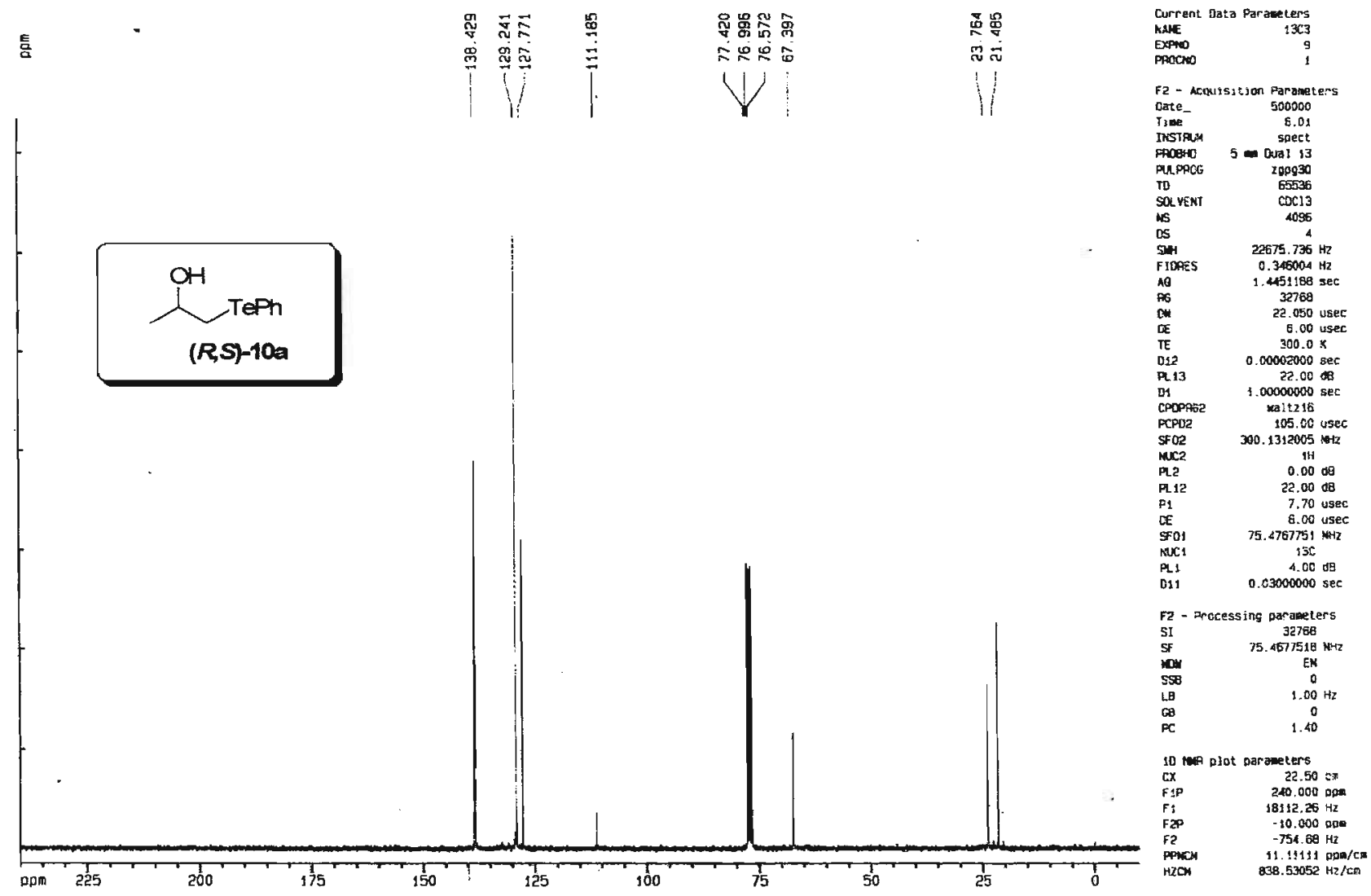

Espectro de $\mathrm{RMN}{ }^{13} \mathrm{C}$ do composto $(R, S)$-1-fenilteluro-2-propanol $[(R, S)-10 \mathrm{a}]$
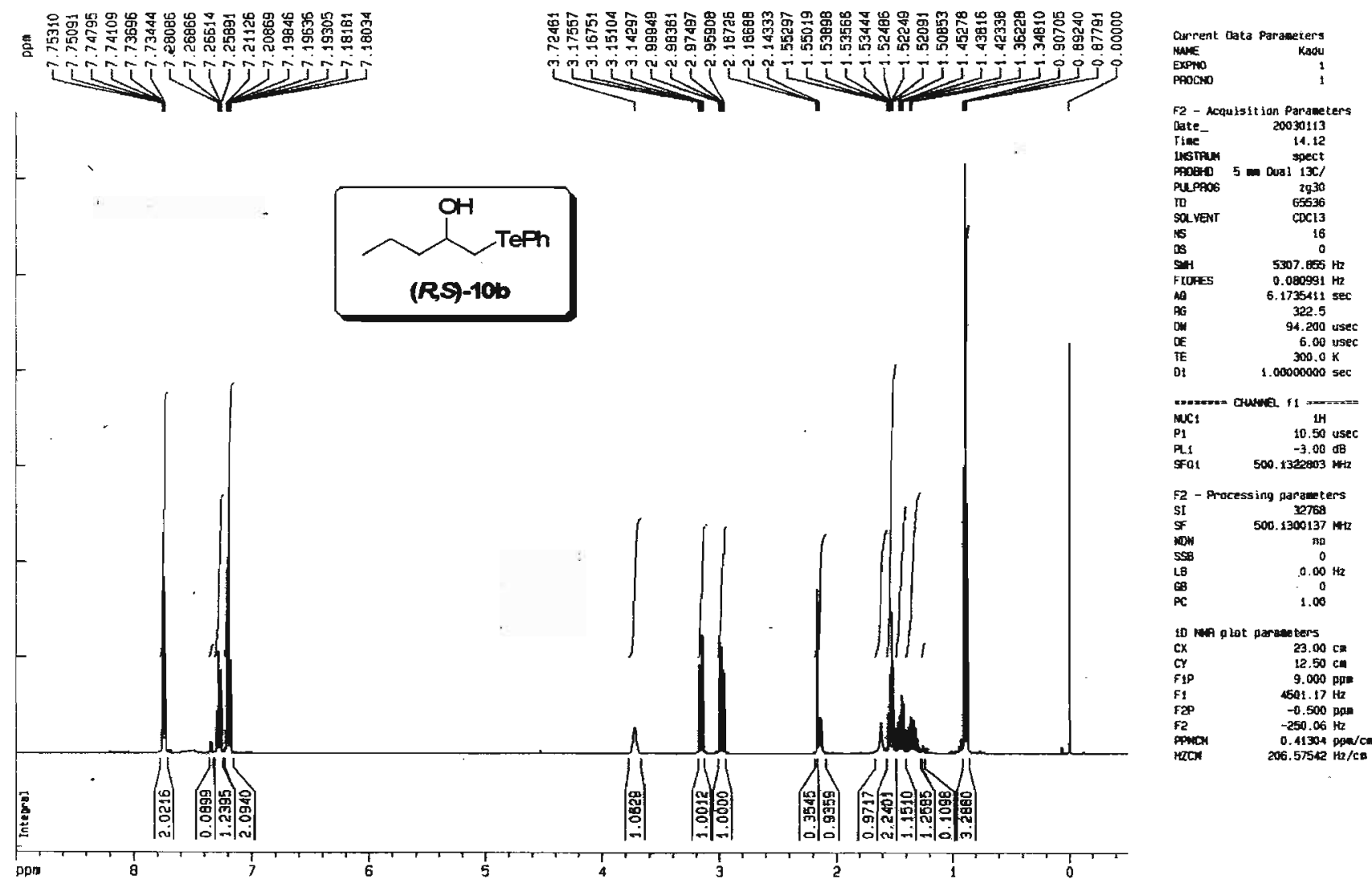

Espectro de $\mathrm{RMN}{ }^{1} \mathrm{H}$ do composto $(R, S)$-1-fenilteluro-2-pentanol $[(R, S)-10 \mathrm{~b}]$ 


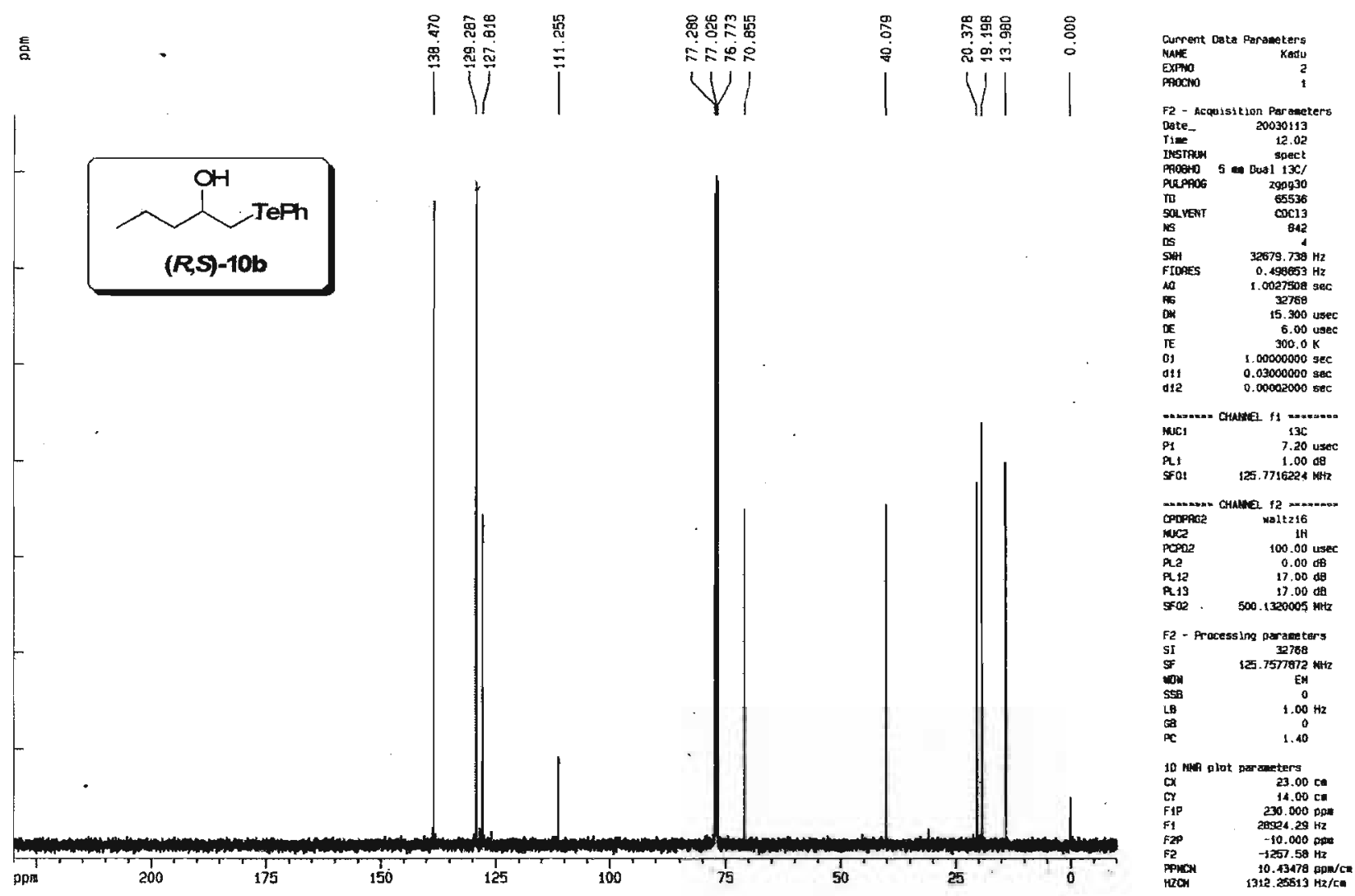

Espectro de $\mathrm{RMN}^{13} \mathrm{C}$ do composto $(R, S)$-1-fenilteluro-2-pentanol $[(R, S)-10 \mathrm{~b}]$

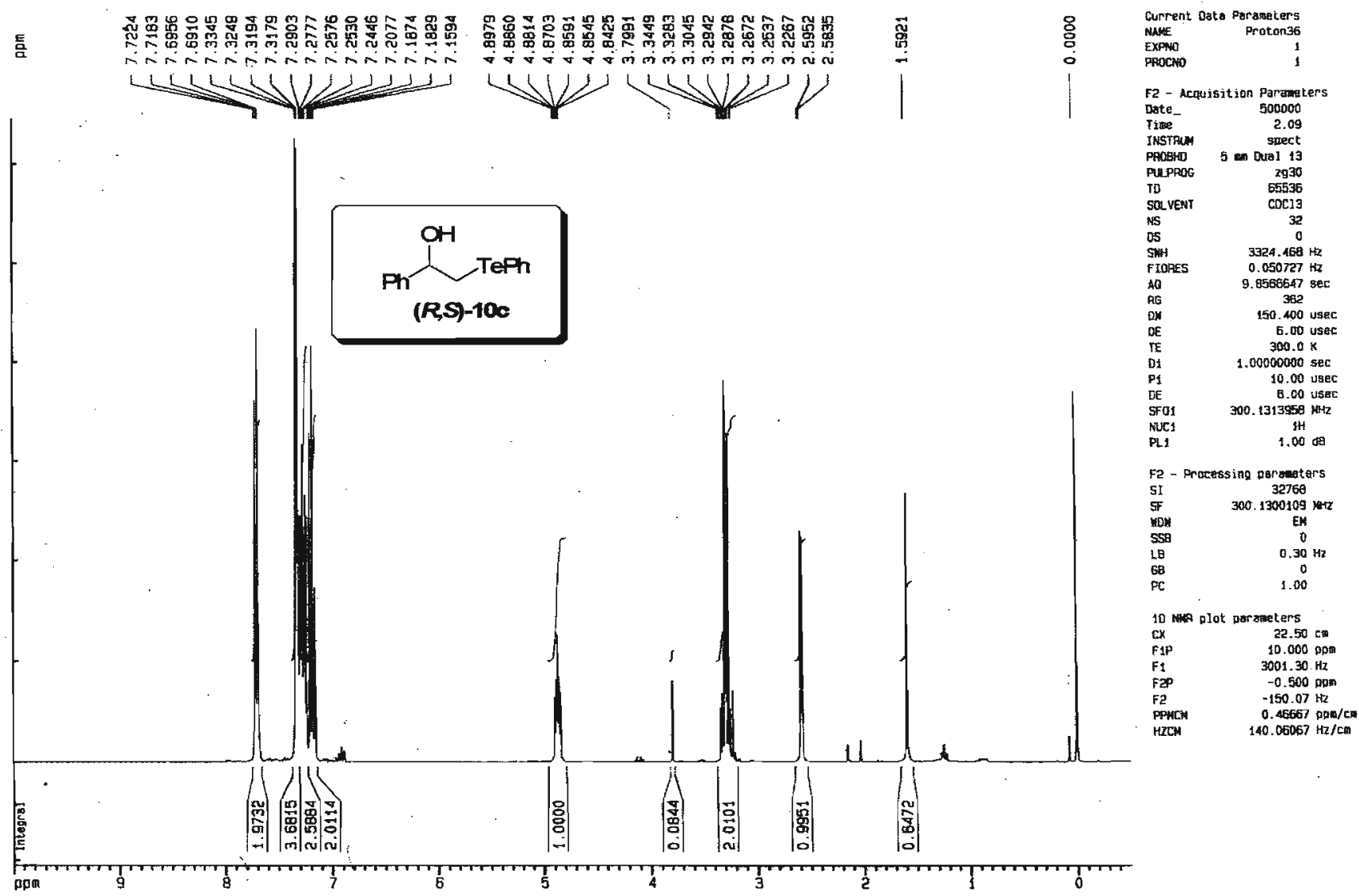

Espectro de $\mathrm{RMN}{ }^{\dagger} \mathrm{H}$ do composto $(R, S)$-1-fenil-2-fenilteluro-etanol $[(R, S)-10 \mathrm{C}]$ 

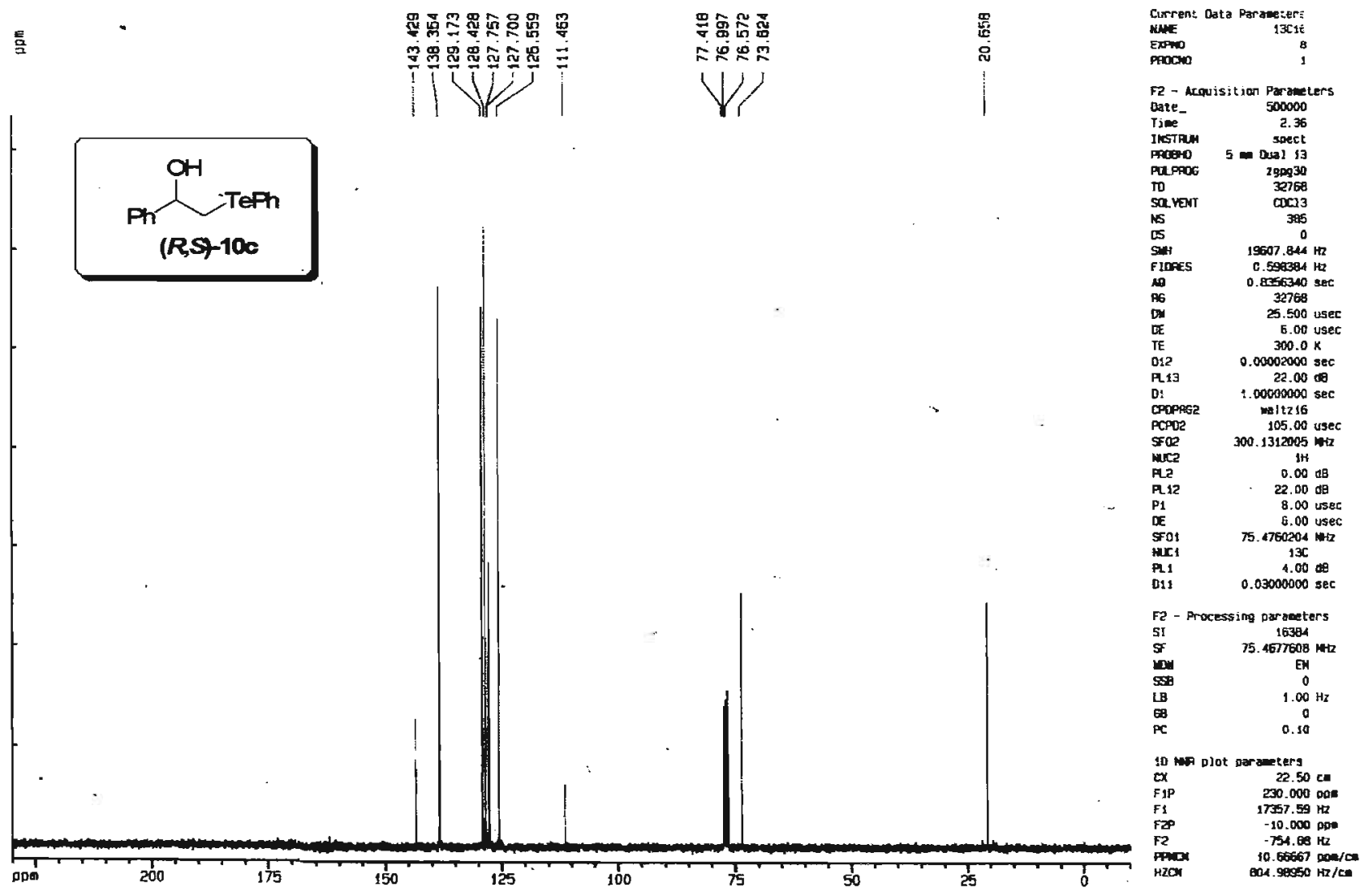

Espectro de $\mathrm{RMN}{ }^{13} \mathrm{C}$ do composto $(R, S)$-1-fenil-2-fenilteluro-etanol $[(R, S)-10 \mathrm{C}]$

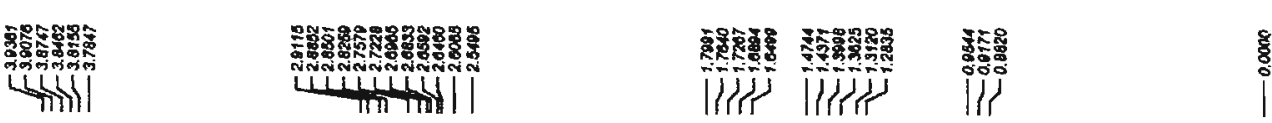

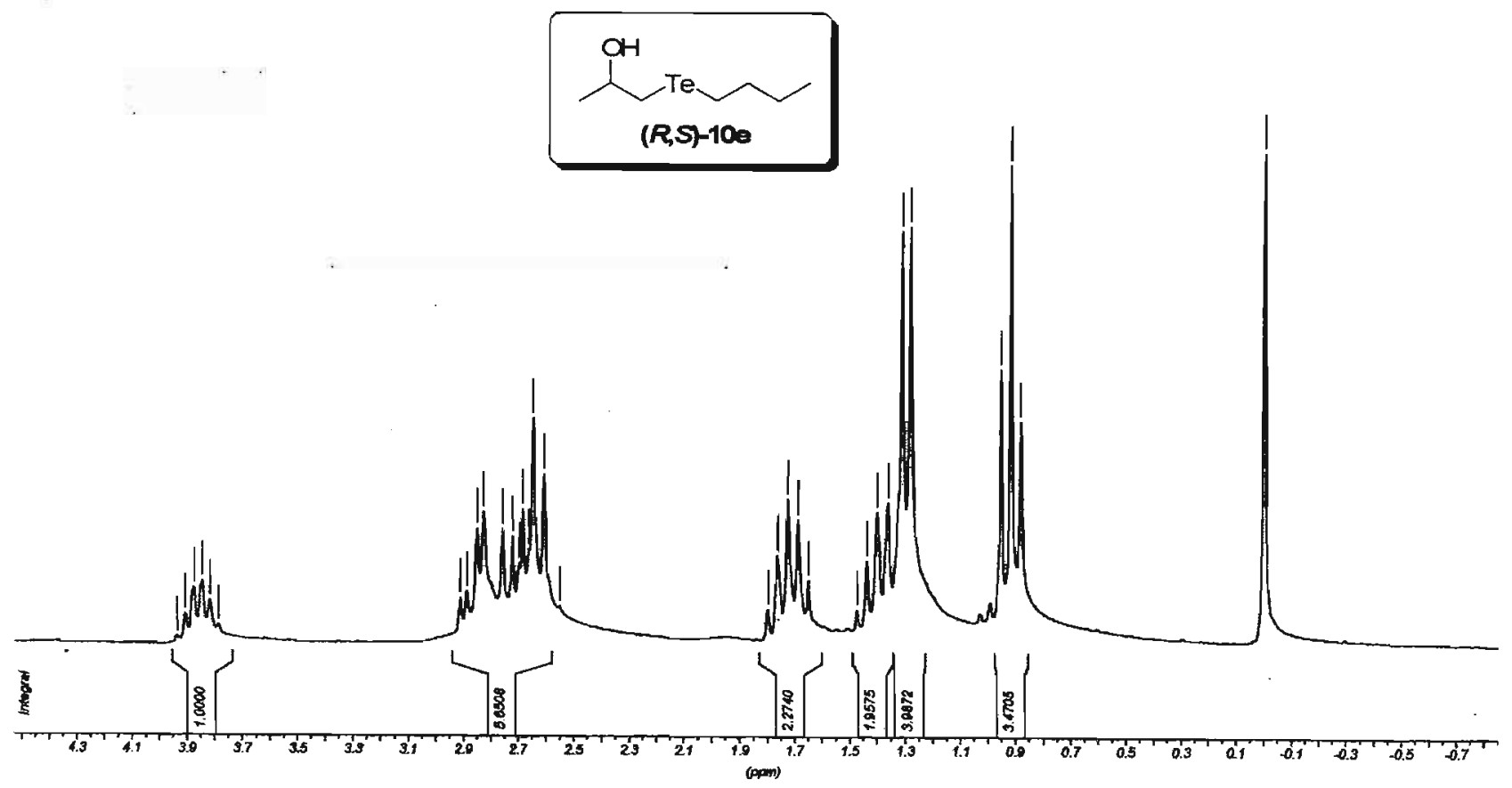

Espectro de RMN ${ }^{1} \mathrm{H}$ do composto $(R, S)$-1-(n-butilteluro)-2-propanol $[(R, S)-10 \mathrm{e}]$ 


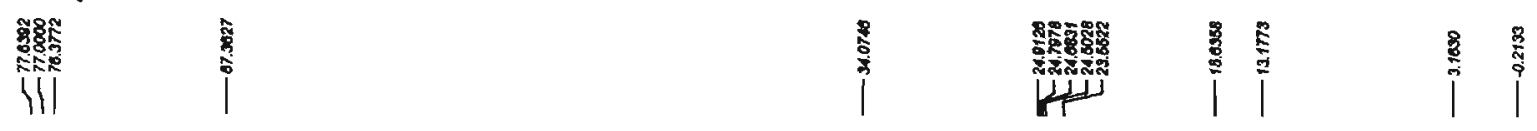

$\mathrm{OH}$

入 Te山

(R,ST-100

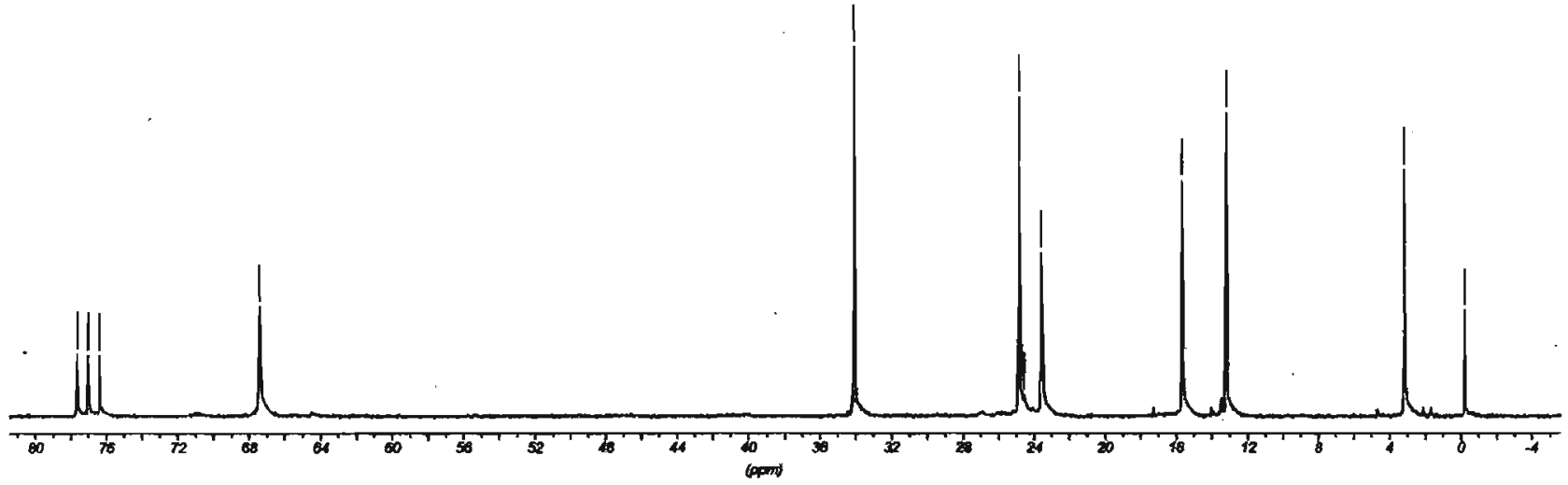

Espectro de RMN ${ }^{13} \mathrm{C}$ do composto $(R, S)-1$-( $n$-butilteluro)-2-propanol $[(R, S)-10 \mathrm{e}]$
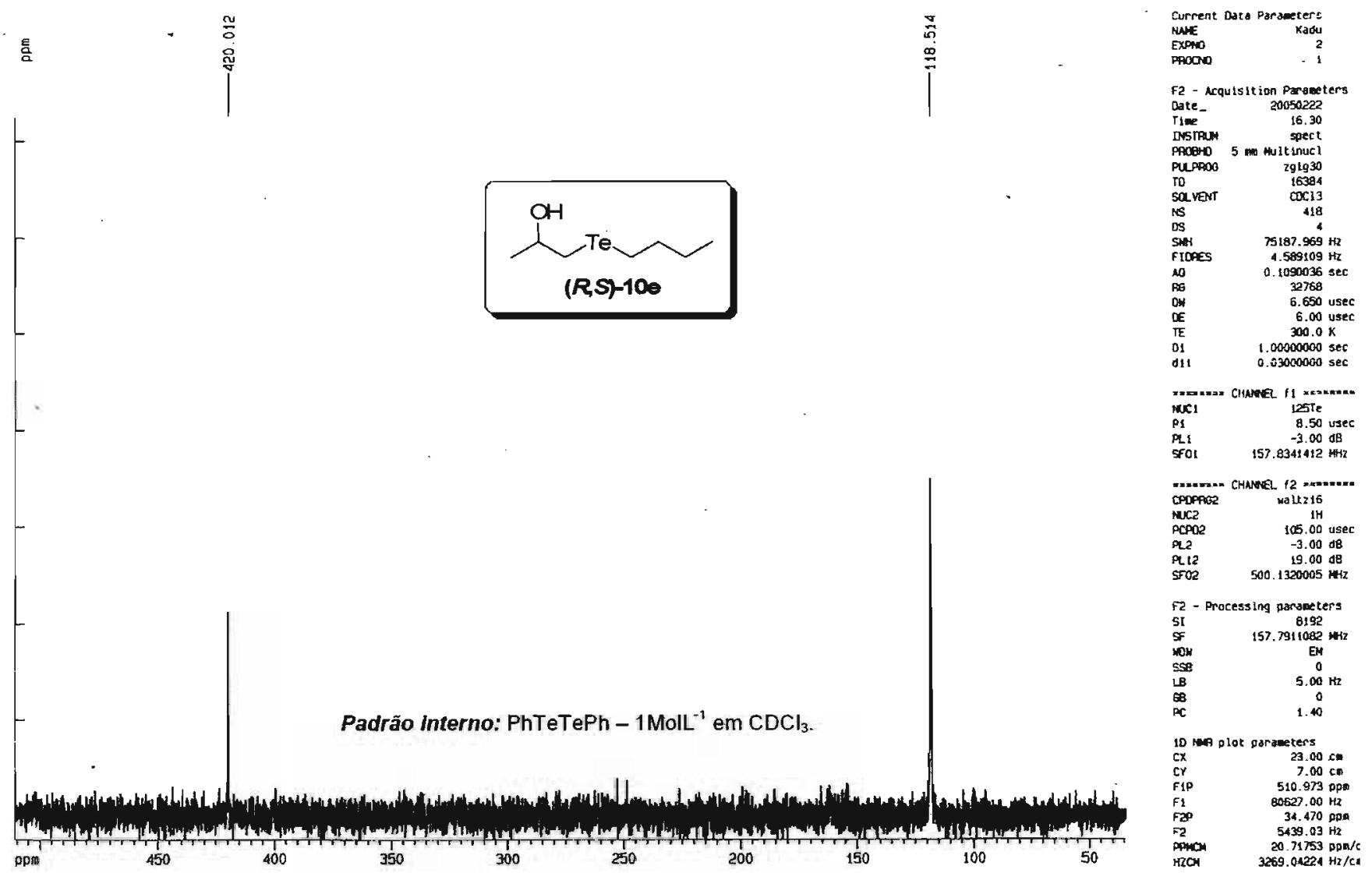

Espectro de RMN ${ }^{125} \mathrm{Te}$ do composto $(\boldsymbol{R}, \boldsymbol{S})$-1-( $\boldsymbol{n}$-butilteluro)-2-propanol [( $\left.R, \boldsymbol{S}\right)$-10e] 


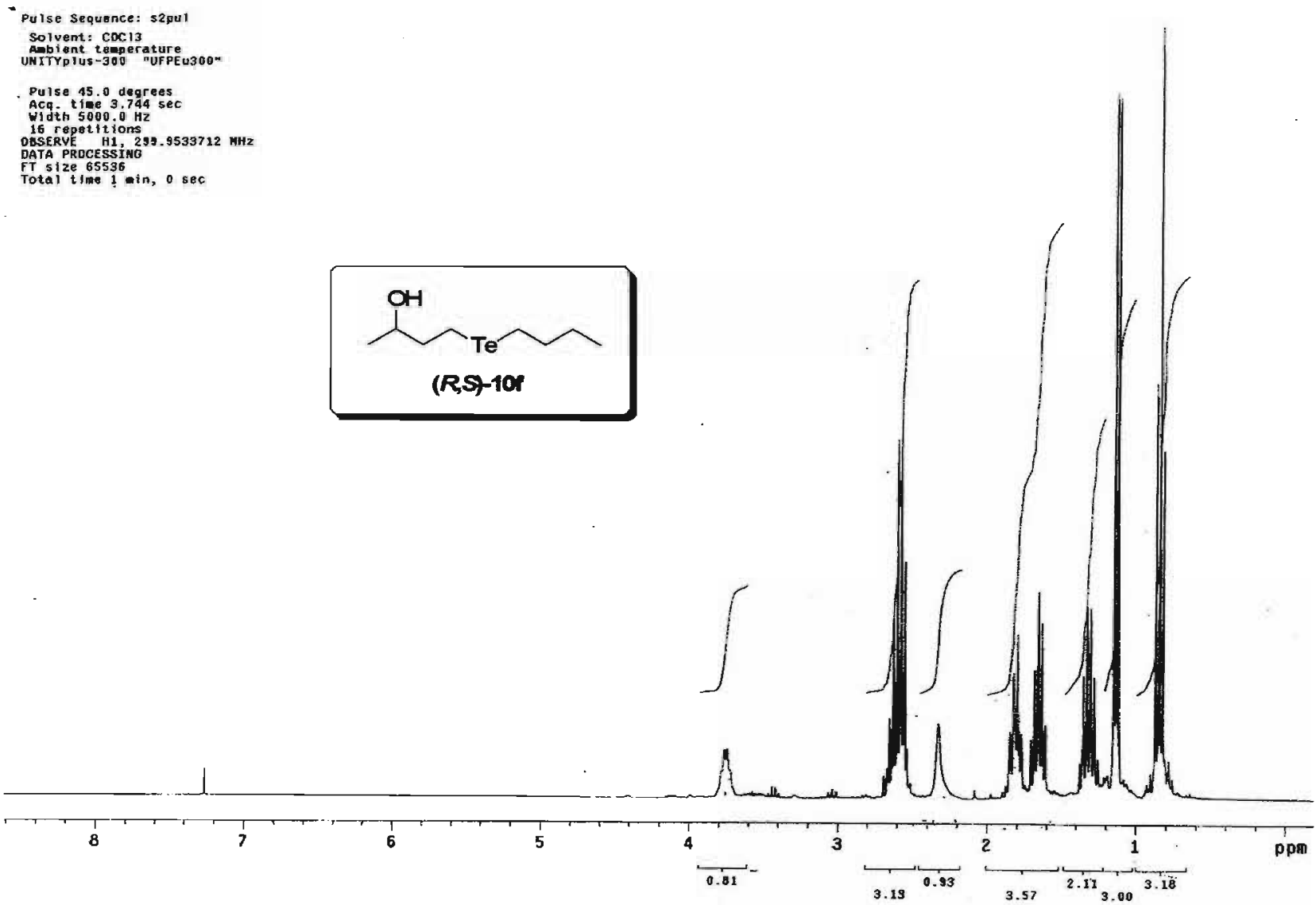

Espectro de RMN ${ }^{\dagger} \mathrm{H}$ do composto $(R, S)-4-(n$-butilteluro)-2-butanol $[(R, S)-10 f]$
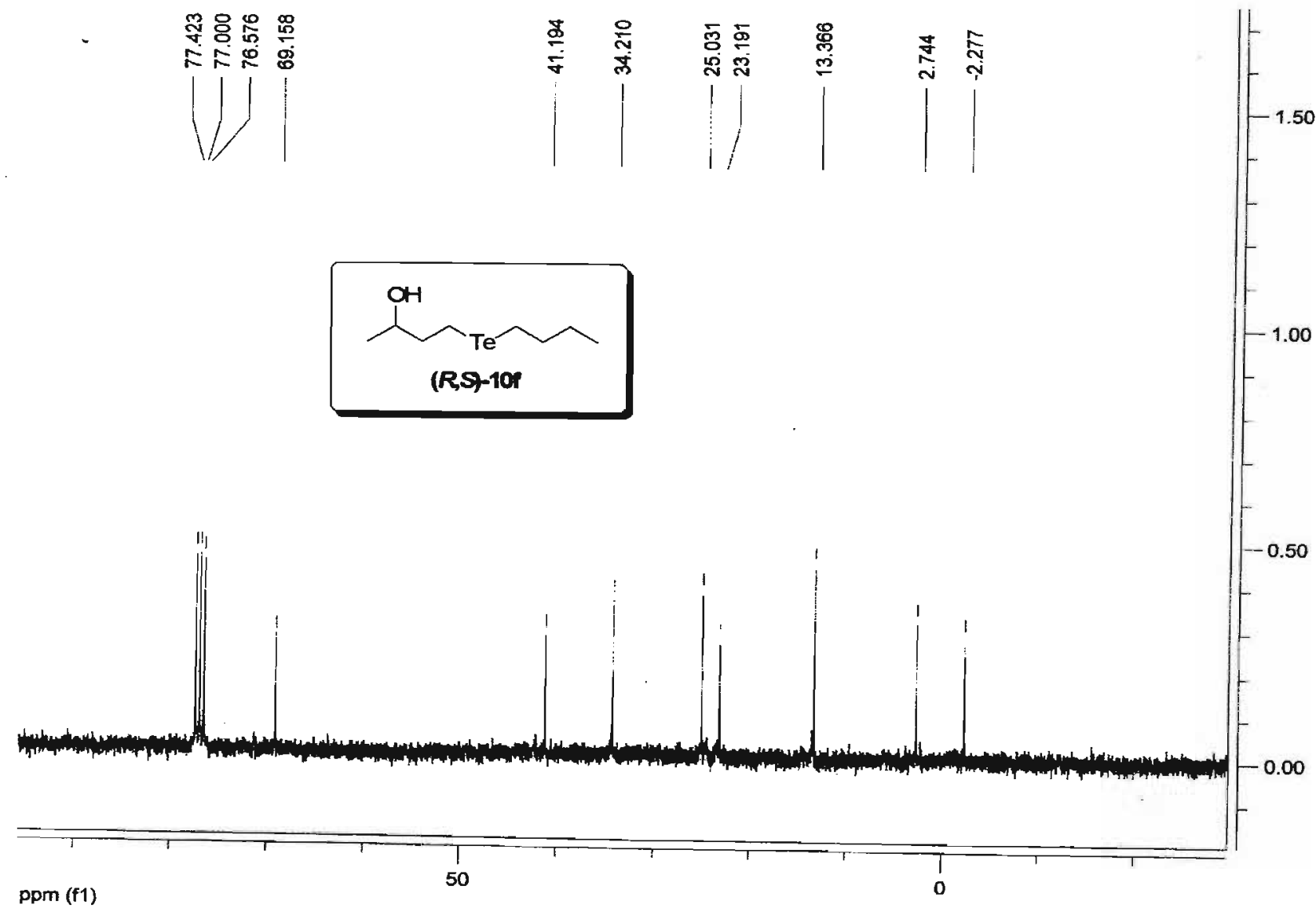


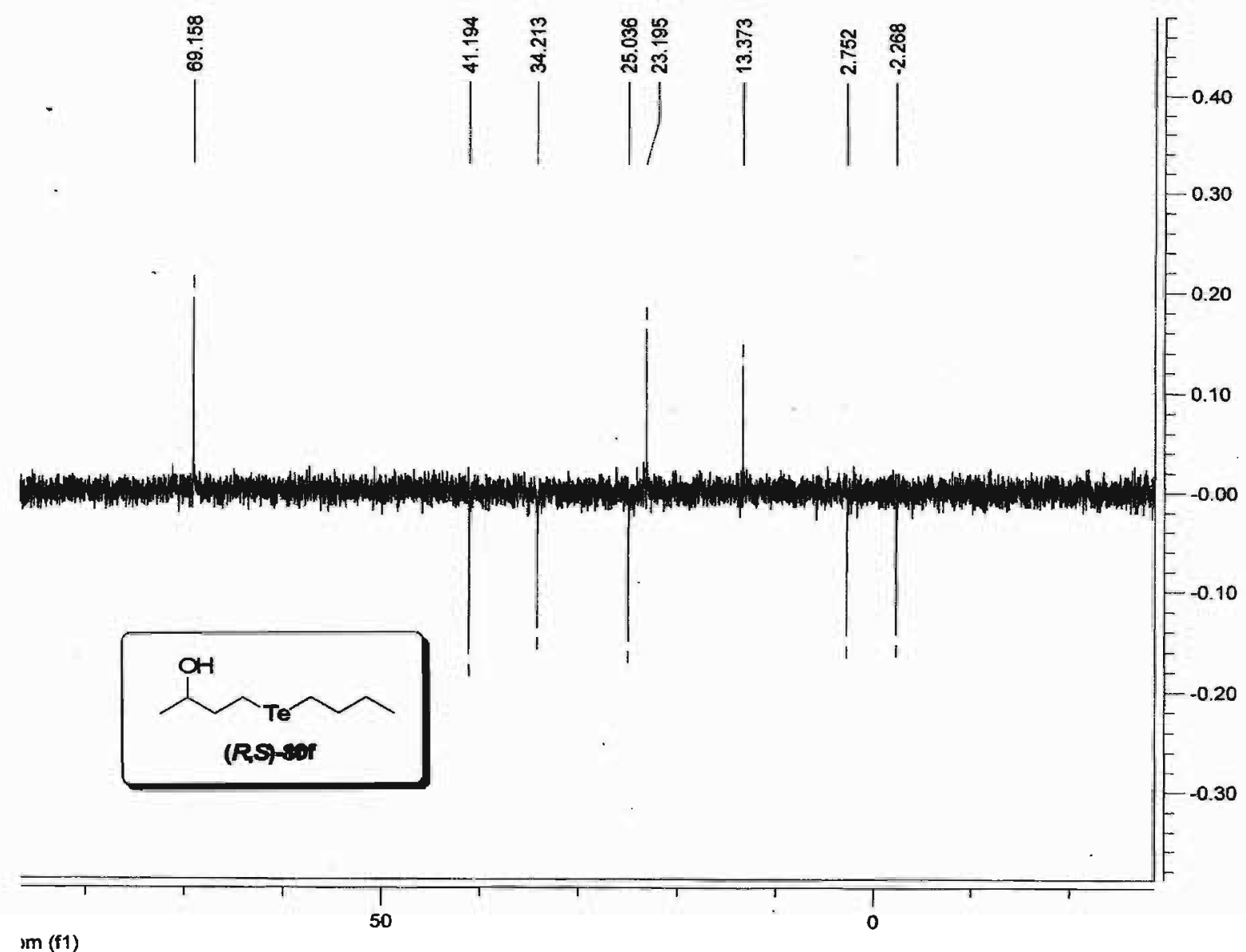

Dept do composto $(R, S)-4-(n$-butilteluro)-2-butanol [(R,S)-10f]

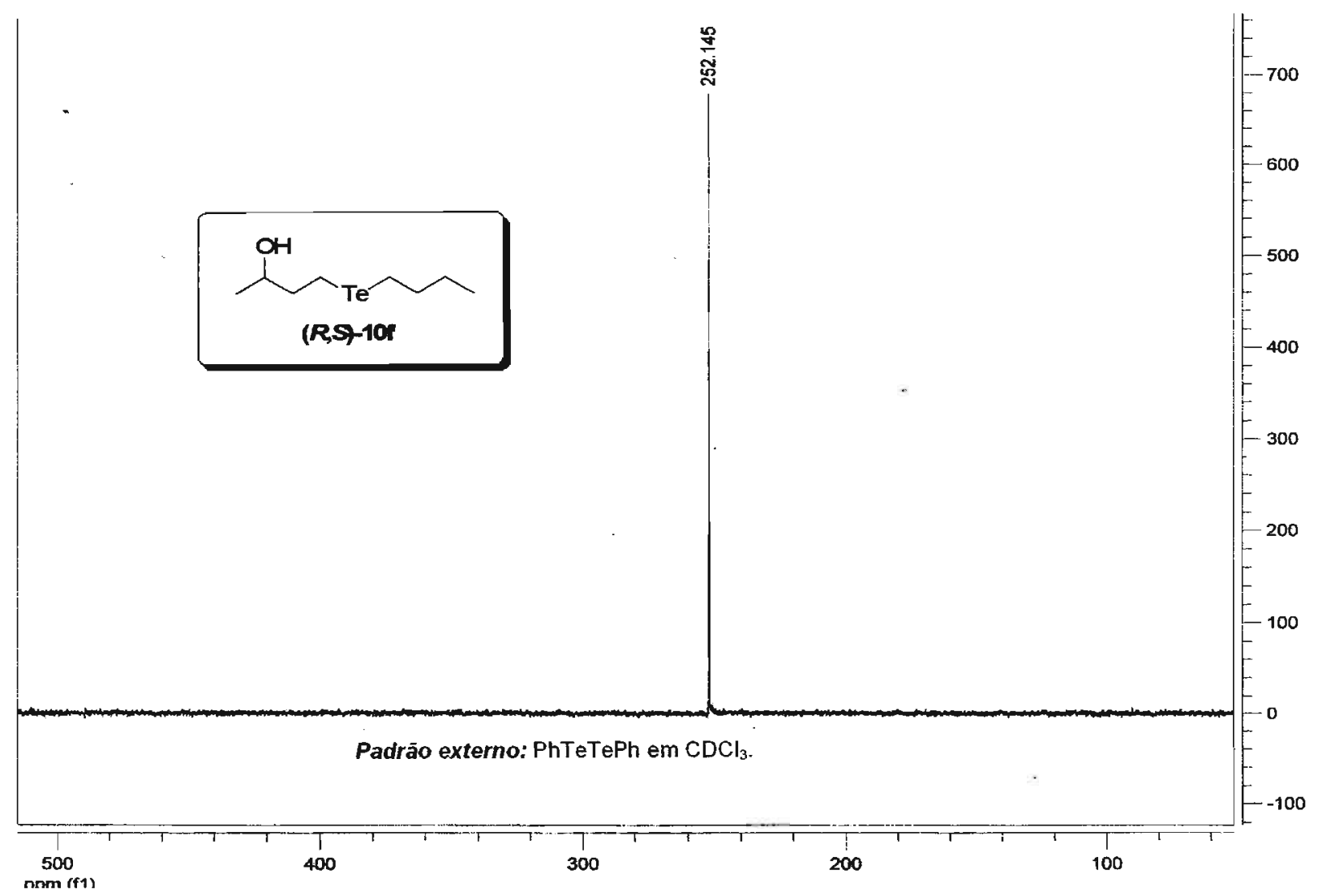

Espectro de ${ }^{i 25} \mathrm{Te}$ do composto $(\boldsymbol{R}, \boldsymbol{S})-\mathbf{4}$-( $\boldsymbol{n}$-butilteluro)-2-butanol [(R,S)-10f] 
Pulse Sequence: s2pul

Solvent: cocis

Re lax. delay 0.904 sec

Relax. 45.0 degrees

Acq t

16 repetitions

DATA PROCESSINO

Fotal time $1 \mathrm{~min}, 20 \mathrm{sec}$

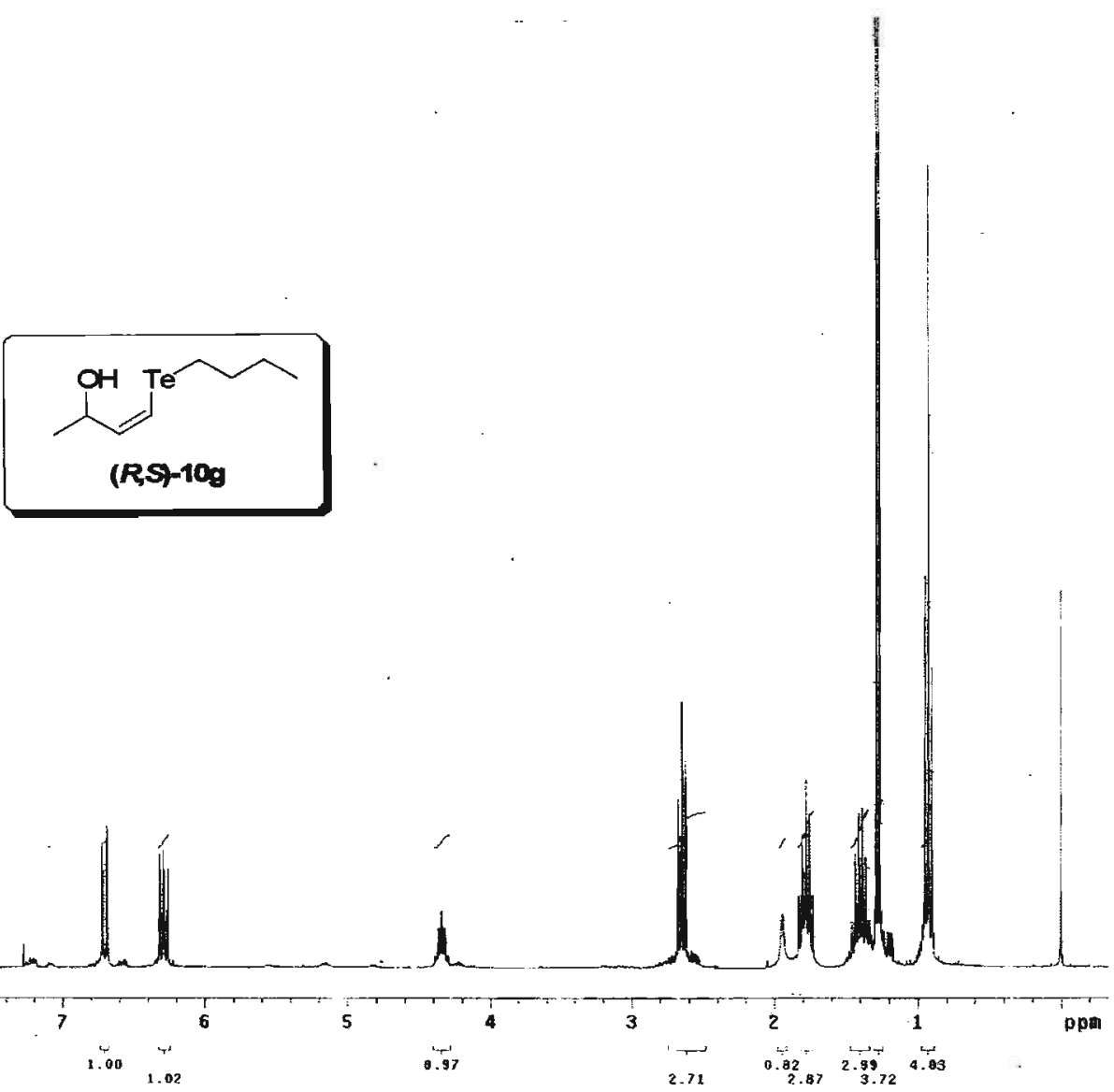

Espectro de $\mathrm{RMN}{ }^{1} \mathrm{H}$ do composto $(R, S)-(Z)-4$-(n-butilteluro)-but-3-en-2-ol $[(R, S)-10 \mathrm{~g}]$

Relax delay $0.235 \mathrm{sec}$

Acq tiae 1 . 765 sec

OBSERE C13. $75.4217006 \mathrm{KHZ}$

Power 35 dB:

Power 35 dB
Cont inuous ly on
WAL TZ-16 podulated

Line broadenting $1.0 \mathrm{~Hz}$

Fotat 1310 ing 34 in, $17 \mathrm{sec}$
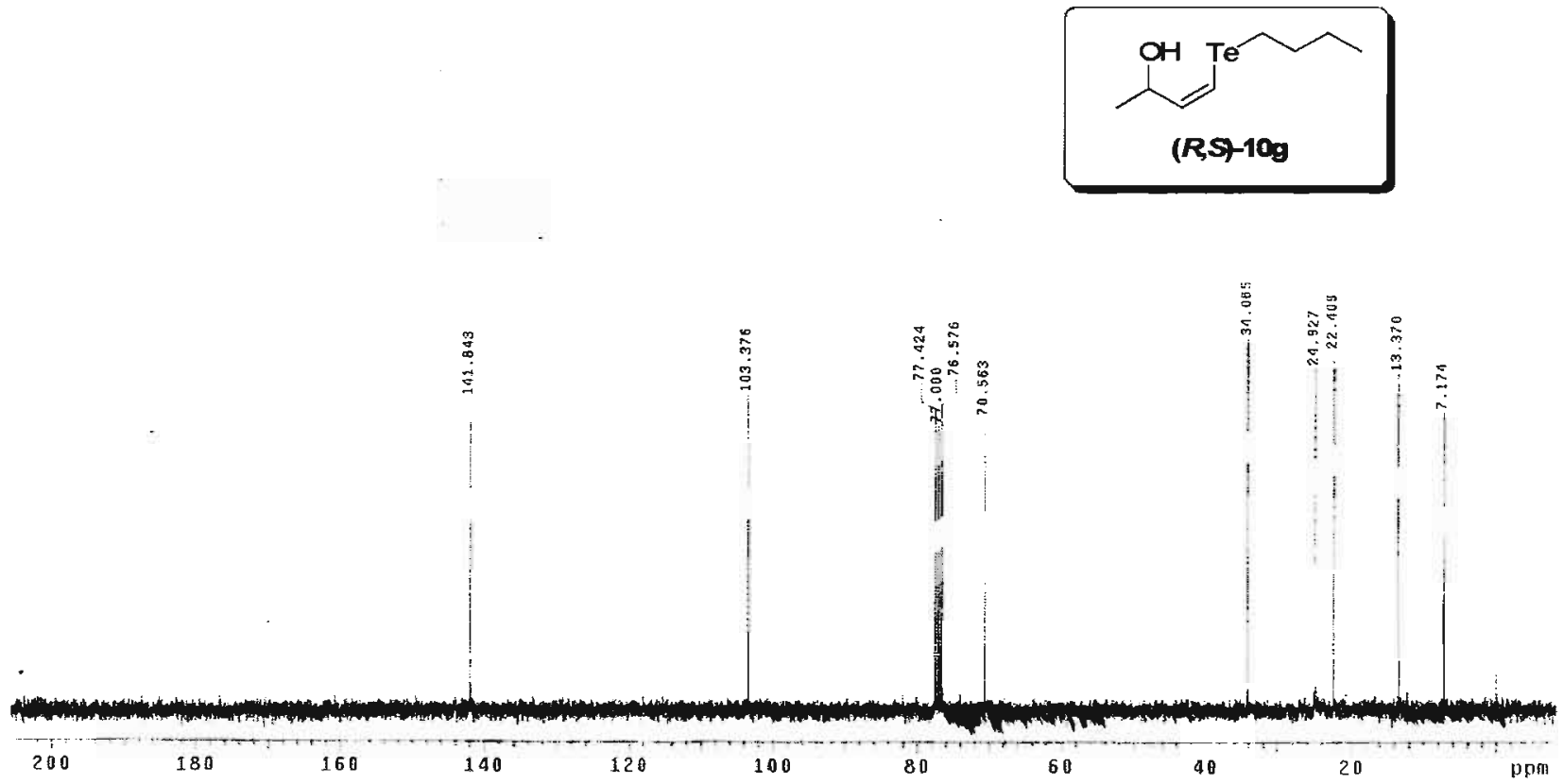

Espectro de $\mathrm{RMN}{ }^{13} \mathrm{C}$ do composto $(R, S)-(Z)-4-(n$-butilteluro)-(but-3-pn-2-ol $[(R, S)-10 \mathrm{~g}]$ 


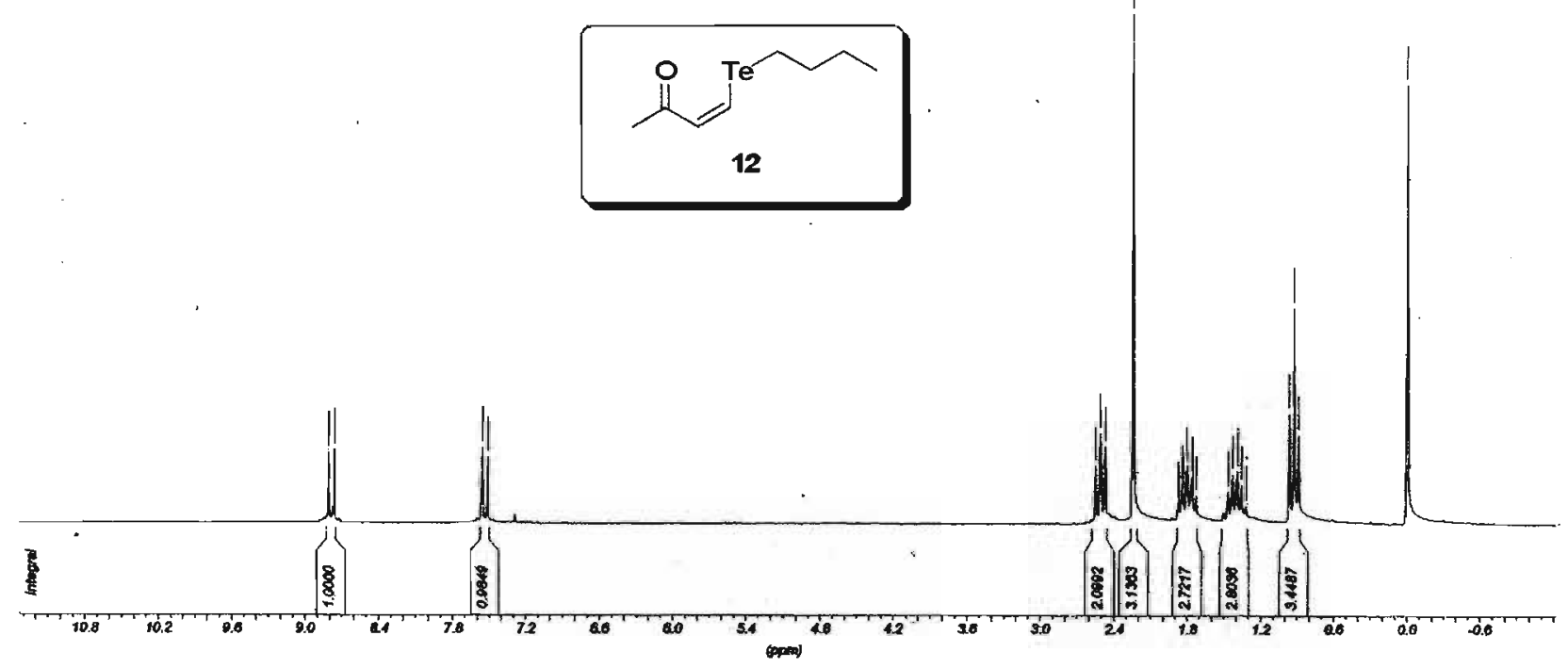

Espectro de $\mathrm{RMN}^{1} \mathrm{H}$ do composto (Z)-4-(n-butilteluro)-but-3-en-2-ona (12)
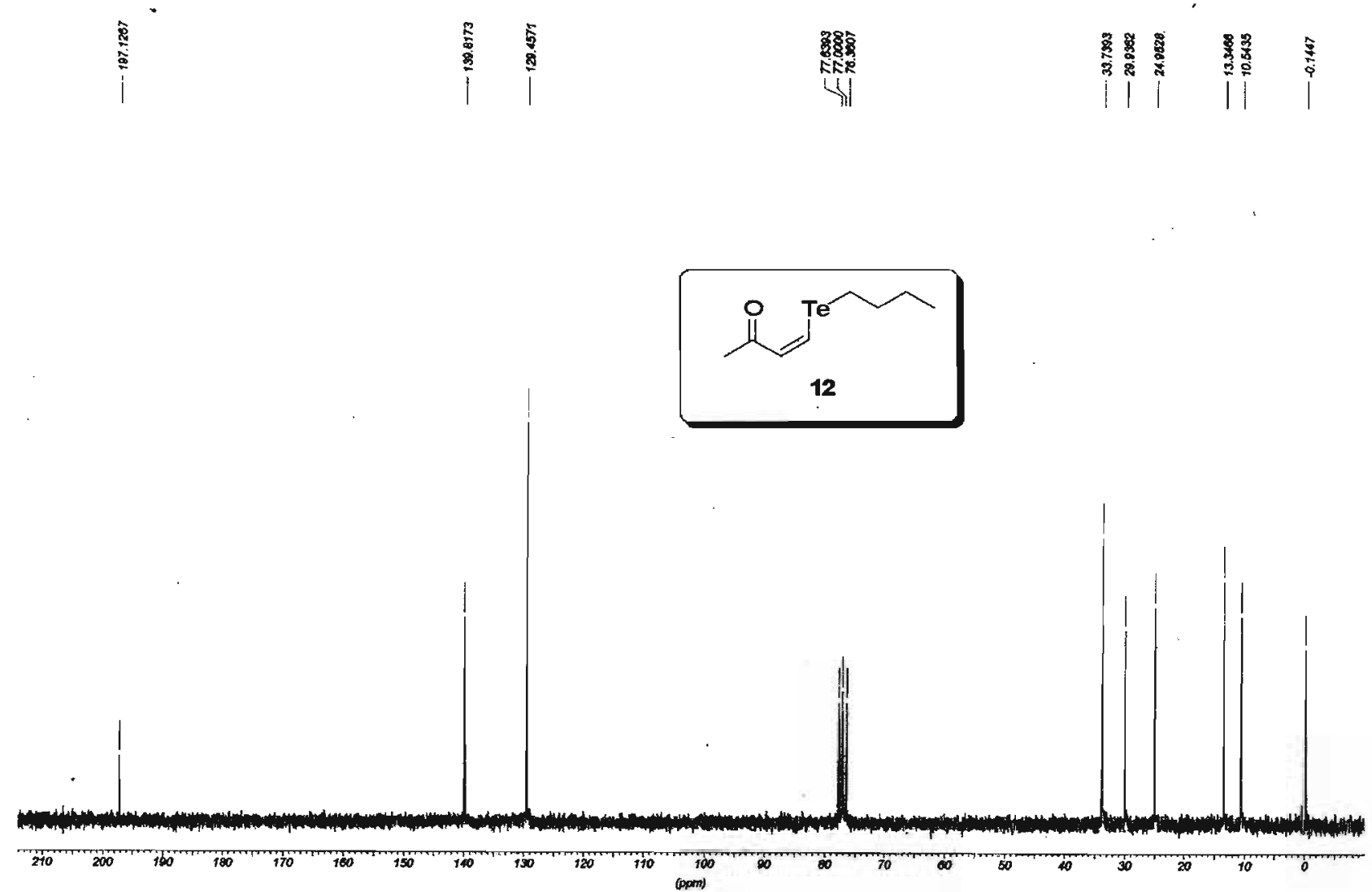

Espectro de RMN ${ }^{13} \mathrm{C}$ do composto (Z)-4-(n-butilteluro)-but-3-en-2-ona (12) 


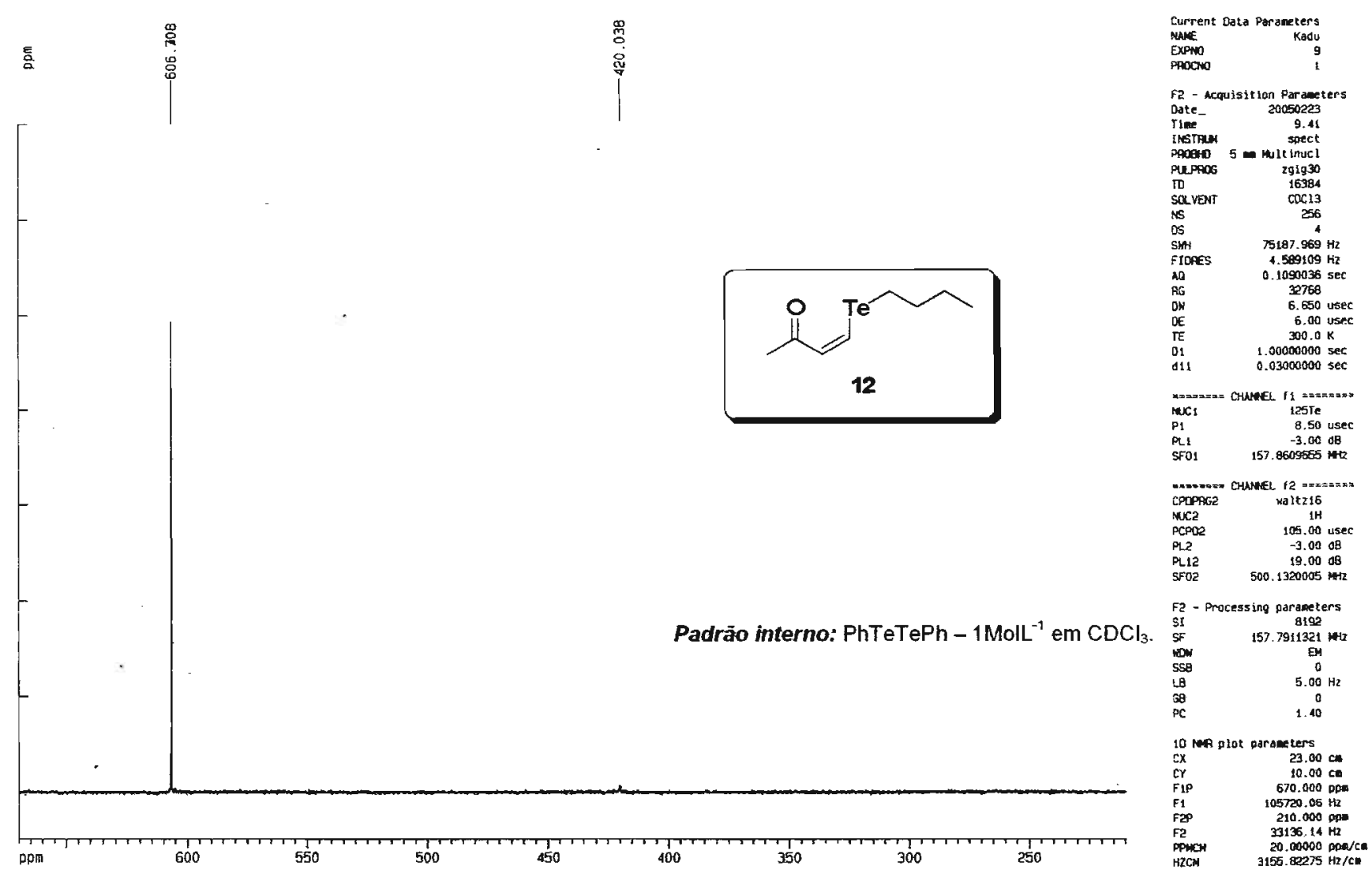

Espectro de RMN ${ }^{125}$ Te do composto (Z)-4-(n-butilteluro)-but-3-en-2-ona (12)
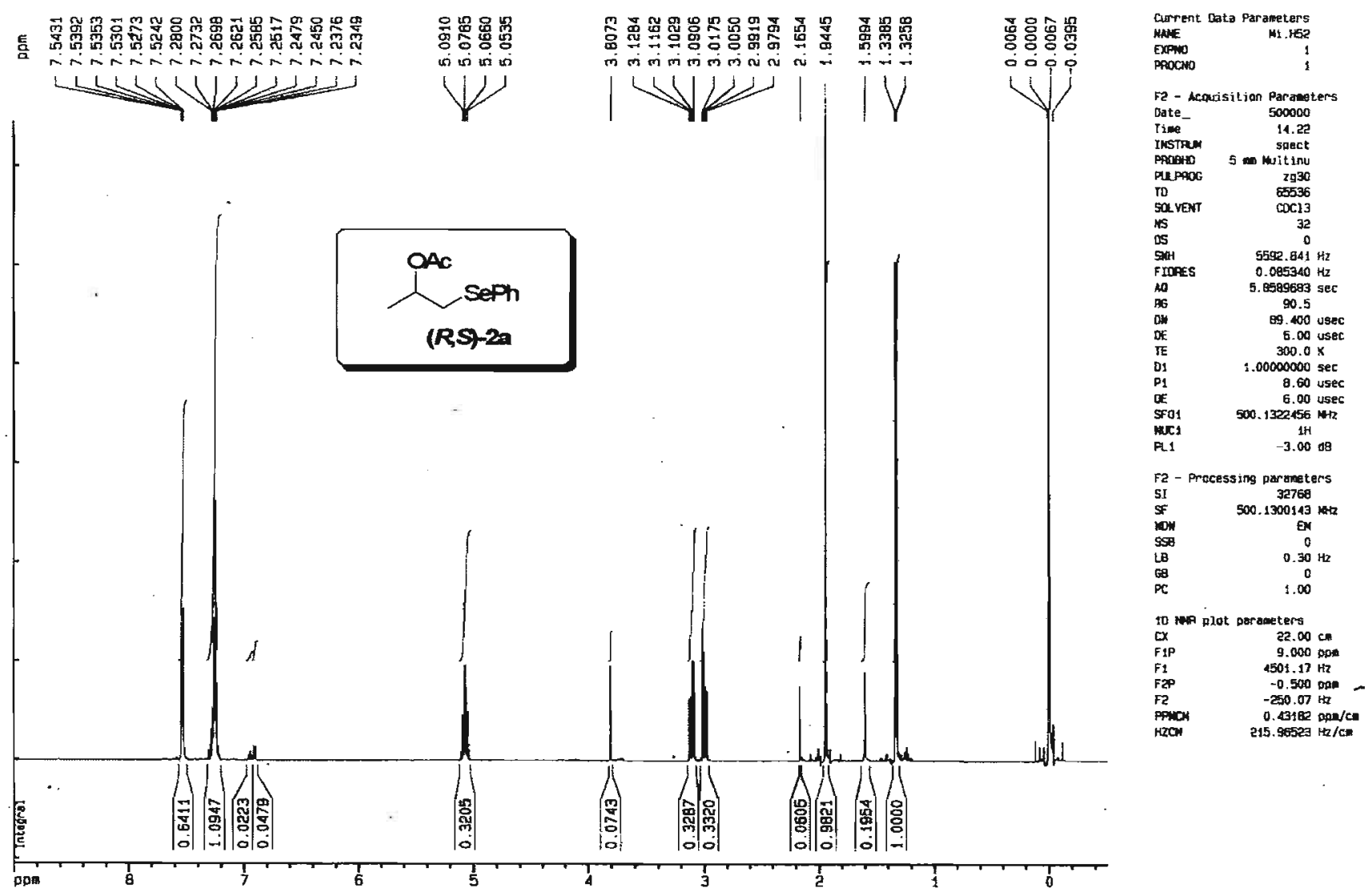

Espectro de RMN ${ }^{1} \mathrm{H}$ do composto $(R, S)$-O-acetil-1-fenilsseleno-2-propanol $[(R, S)-2 \mathrm{a}]$ 


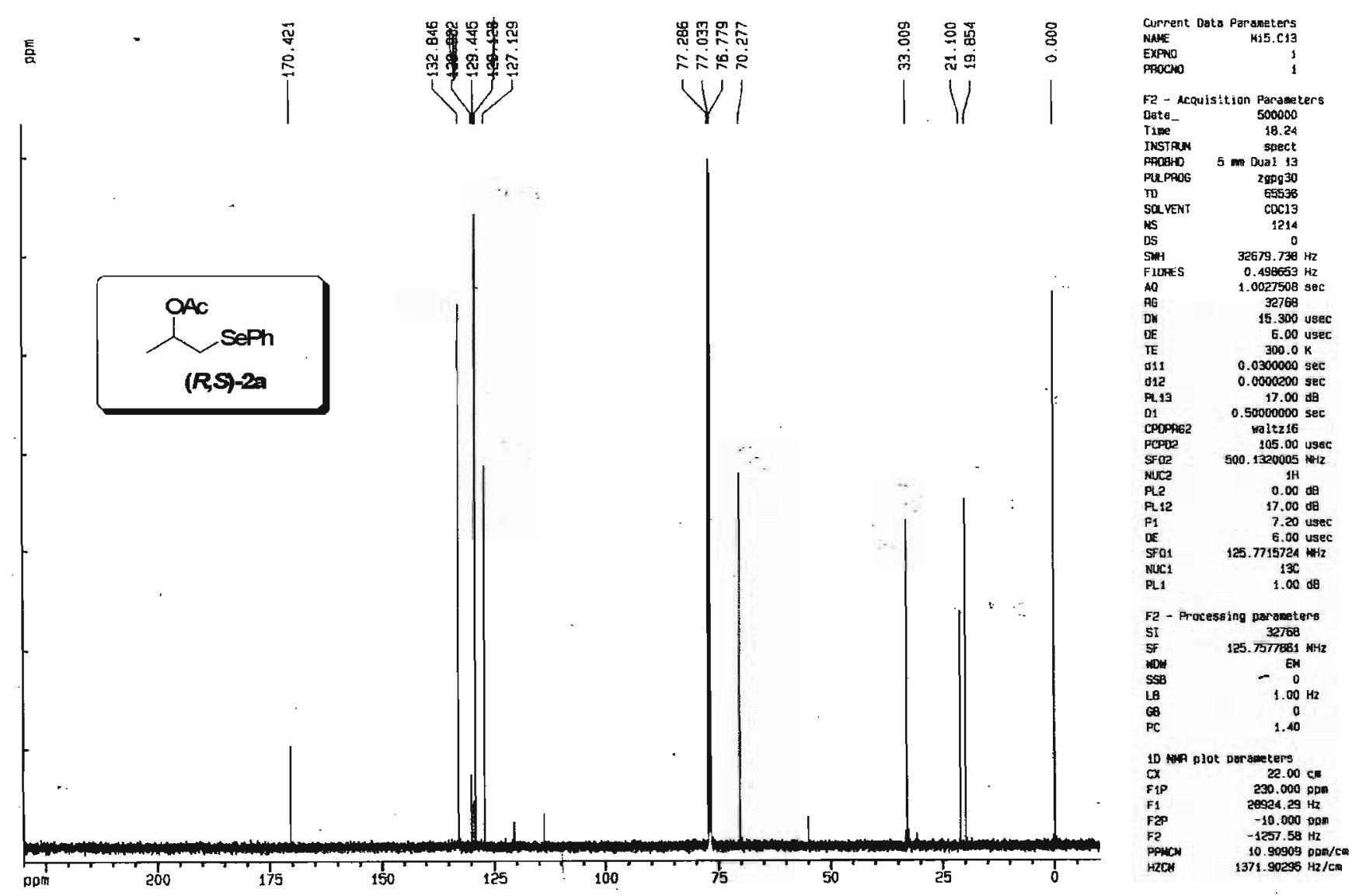

Espectro de RMN ${ }^{13} \mathrm{C}$ do composto $(R, S)$-O-acetil-1-fenilsseleno-2-propanol [(R,S)-2a]
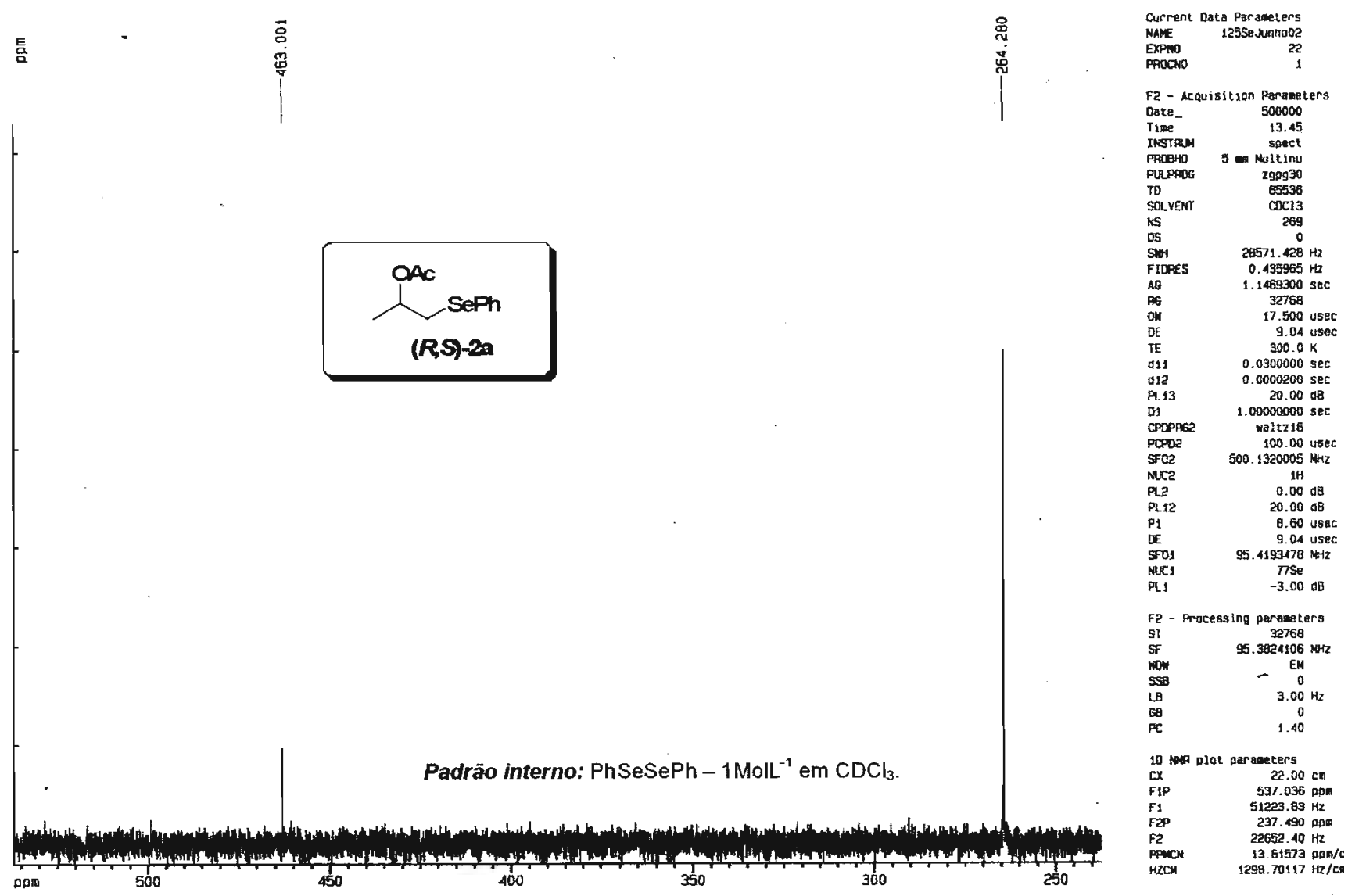

Espectro de $\mathrm{RMN}{ }^{77}$ Se do composto $(\boldsymbol{R}, \mathbf{S})$-O-acetil-1-fenilsseleno-2-propanol [( $\left.R, S\right)$-2a] 


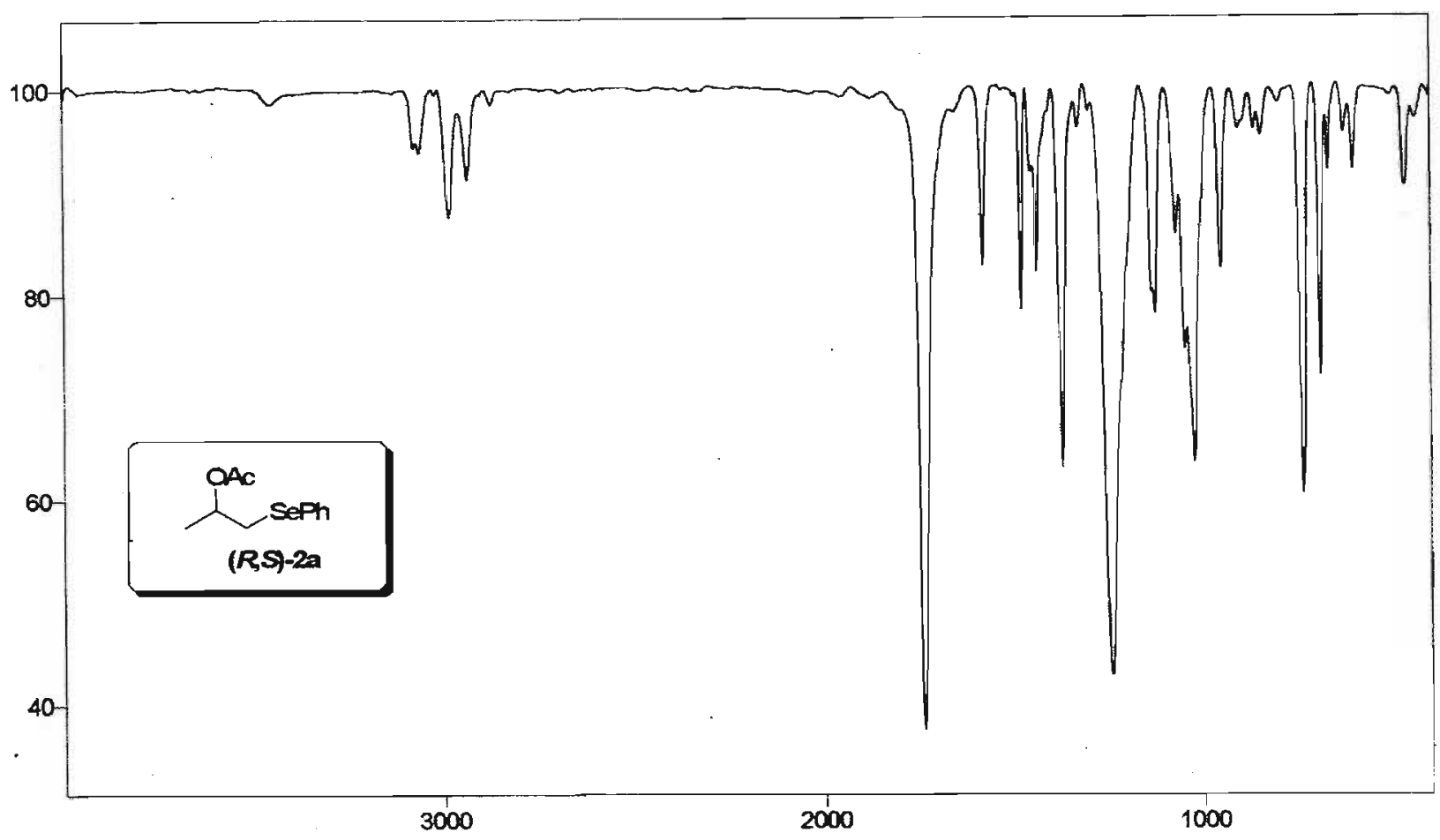

Transmittance / Wavenumber (cm-1)

Espectro de I.V. do composto $(R, S)$-O-acetil-1-fenilsseleno-2-propanol [(R,S)-2a]

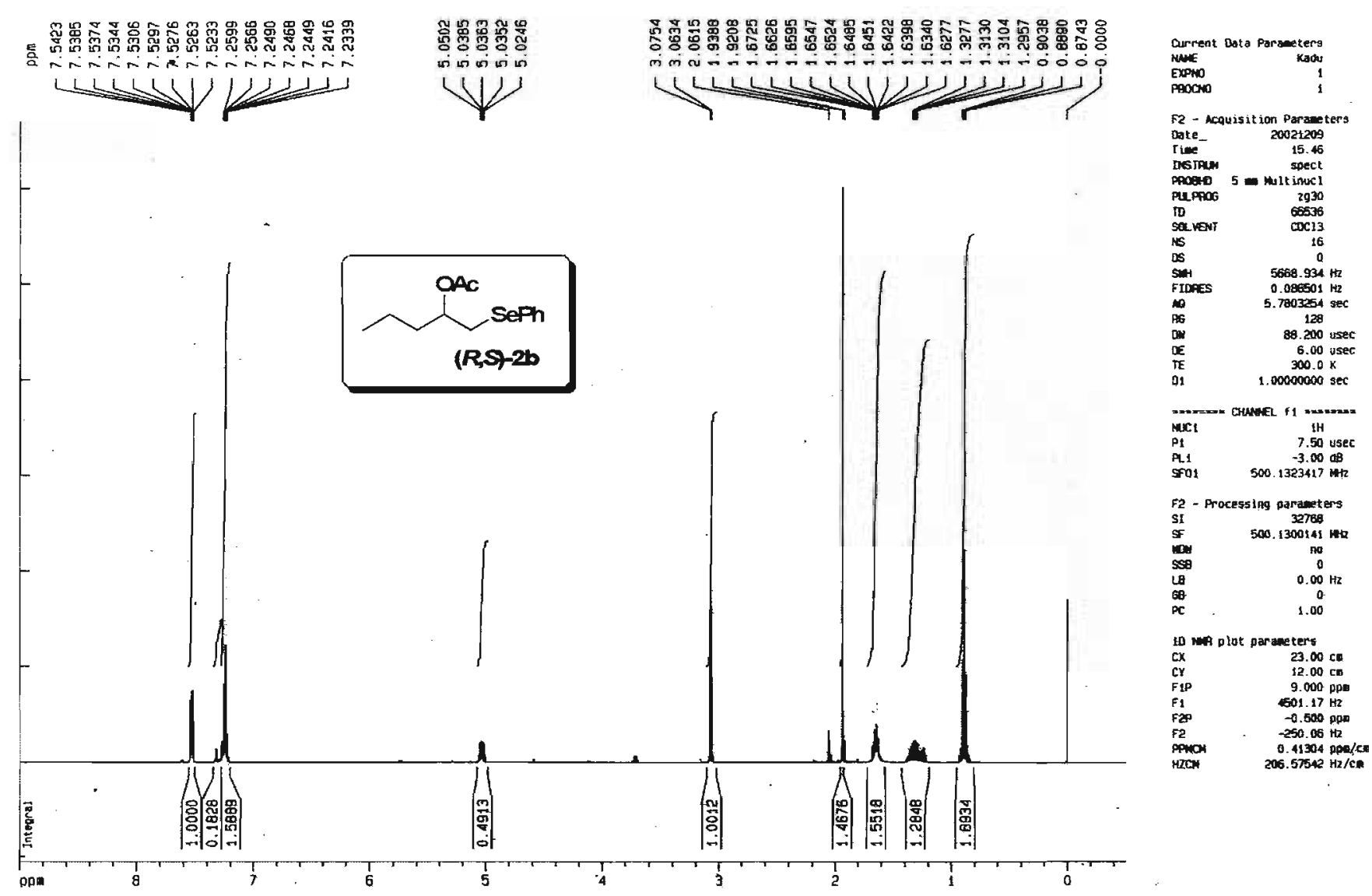

Espectro de $\mathrm{RMN}^{1} \mathrm{H}$ do composto $(R, S)$-O-acetil-1-fenilsseleno-2-pentanol [(R,S)-2b] 


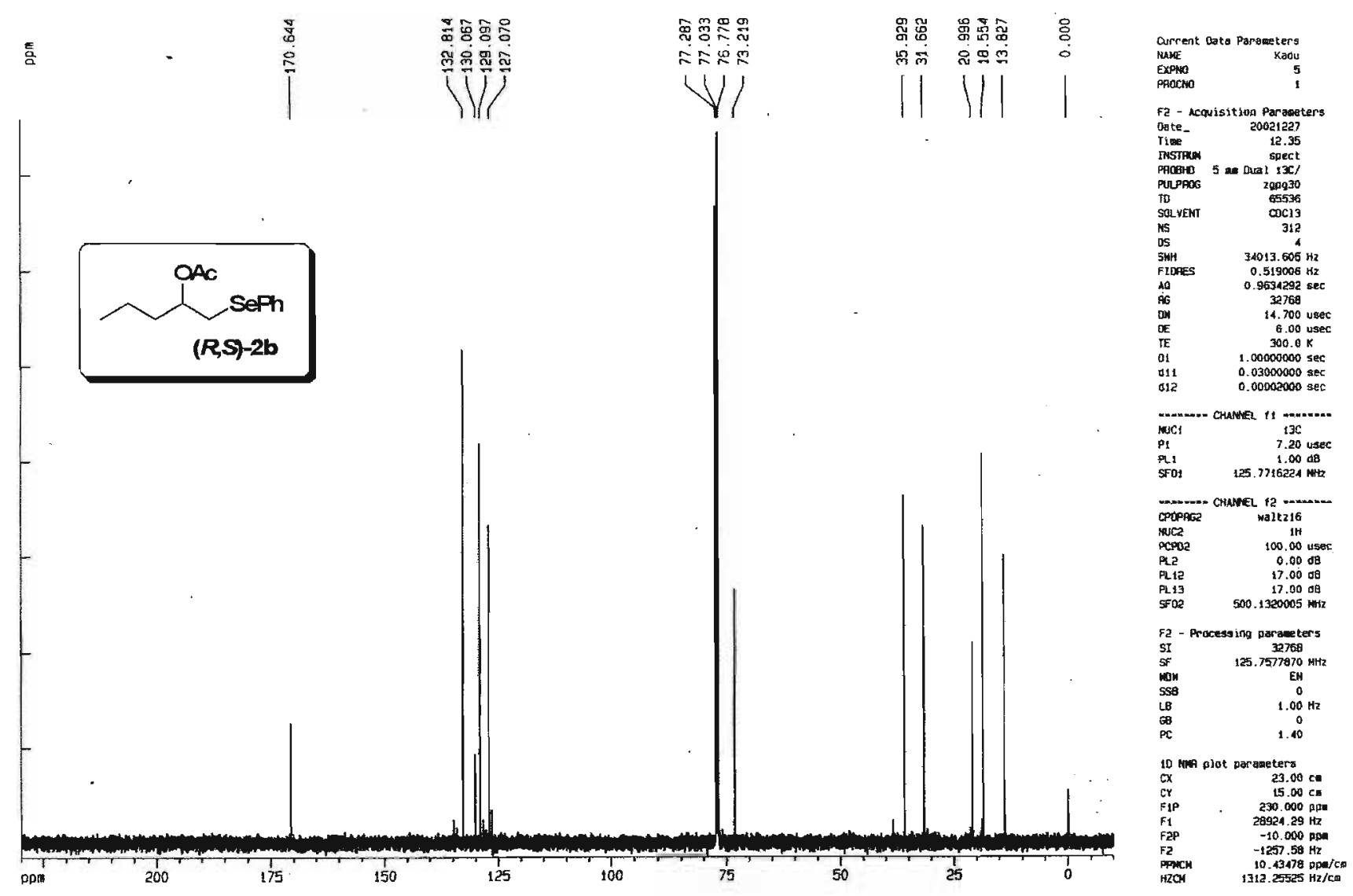

Espectro de $\mathrm{RMN}^{13} \mathrm{C}$ do composto $(R, S)$-O-acetil-1-fenilsseleno-2-pentanol [(R,S)-2b]
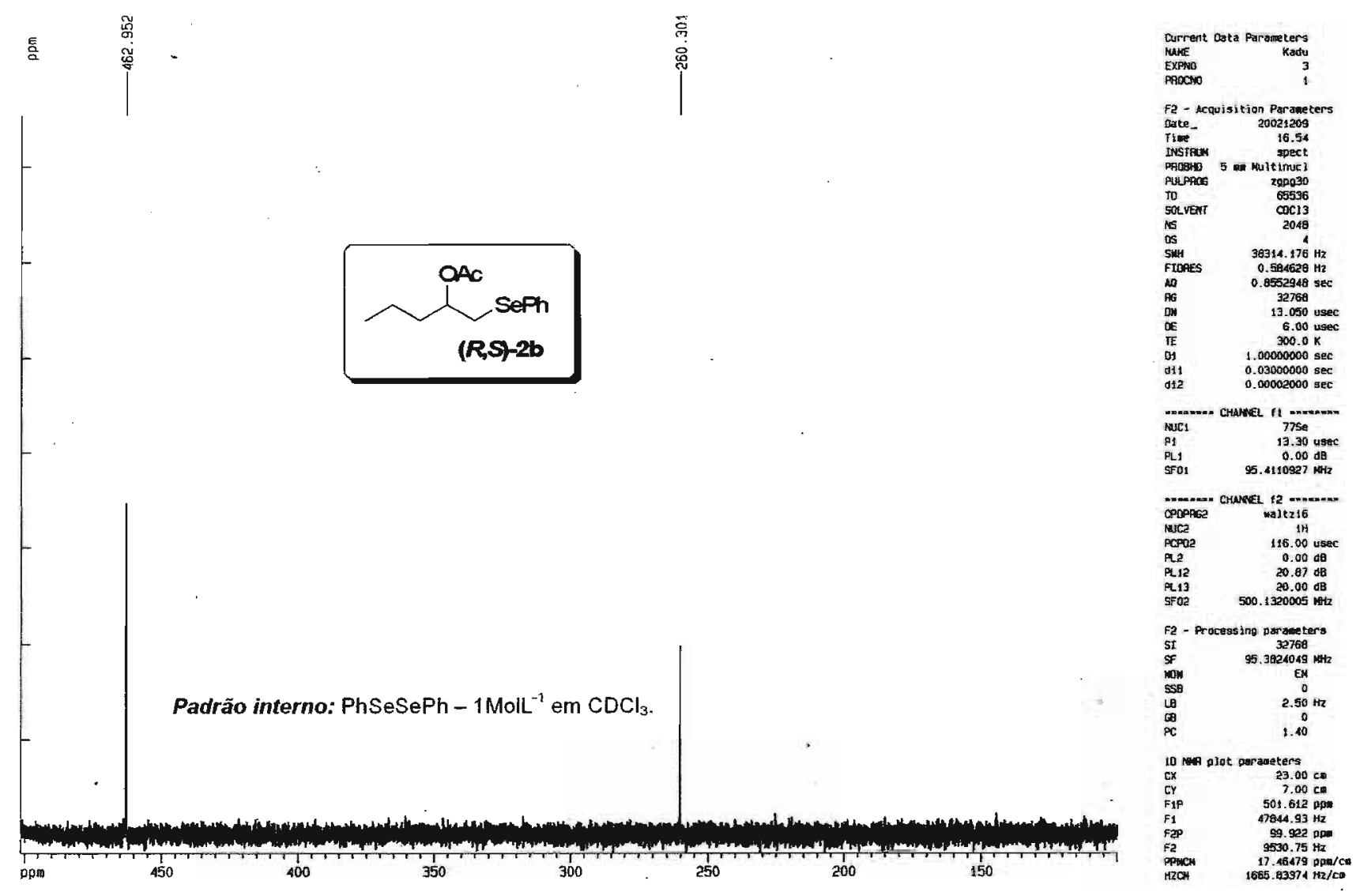

Espectro de RMN ${ }^{77}$ Se do composto $(R, S)$-O-acetil-1-fenilsseleno-2-pentanol [(R,S)-2b] 

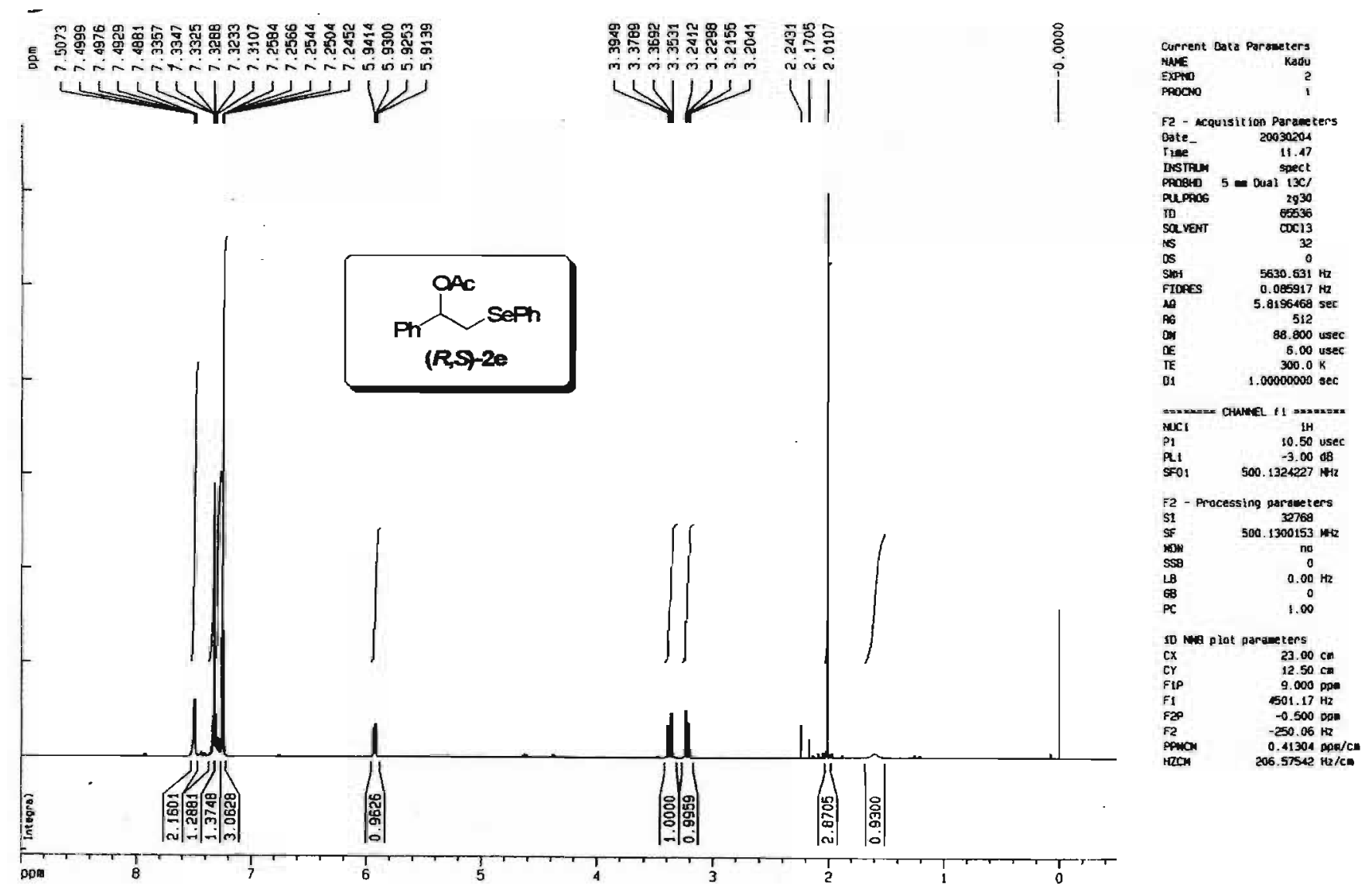

Espectro de RMN ${ }^{1} \mathrm{H}$ do composto $(R, S)$-O-acetil-1-fenil-2-fenilsseleno-2-etanol $[(R, S)-2 e]$
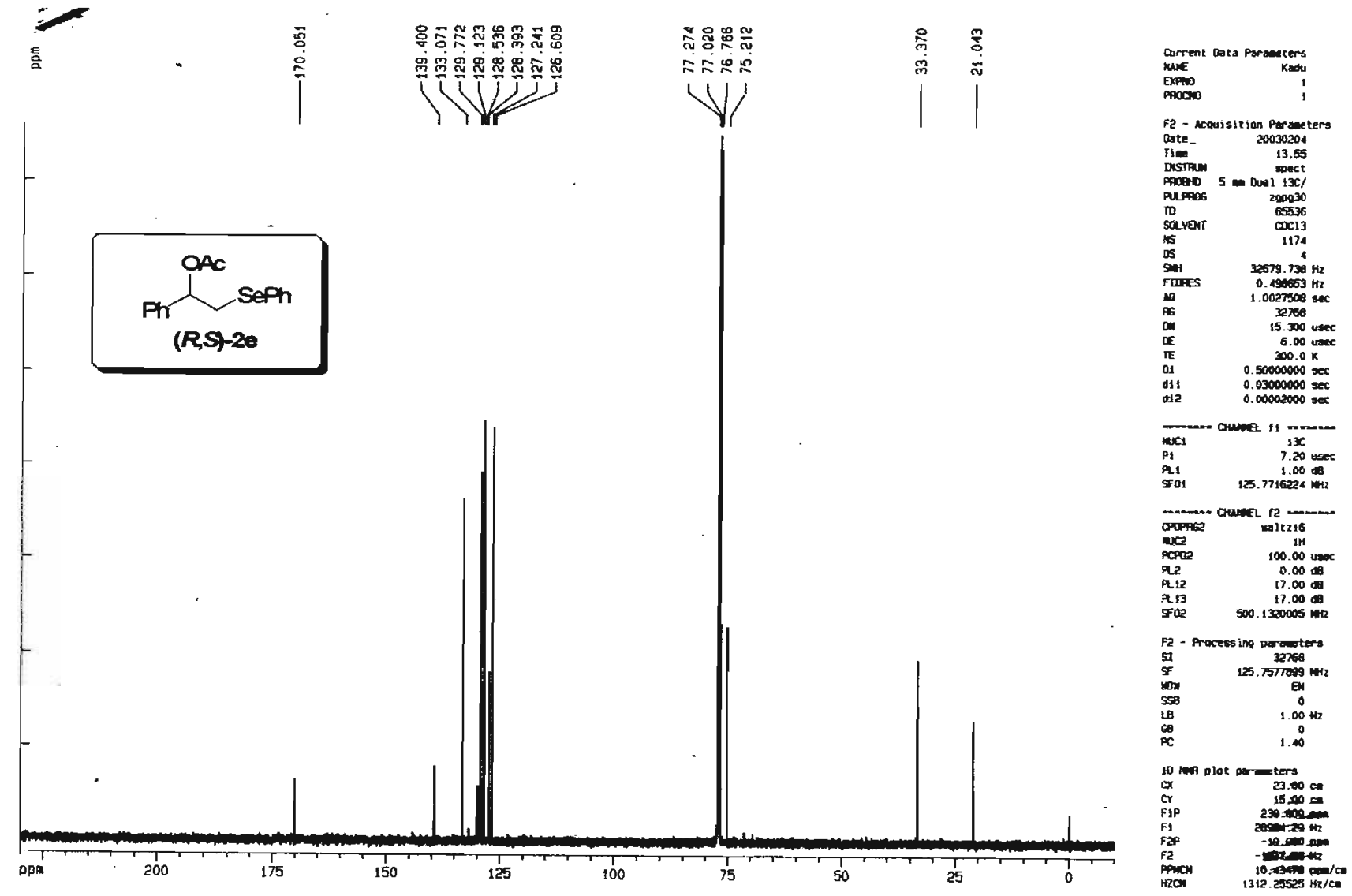

Espectro de $\mathrm{RMN}{ }^{13} \mathrm{C}$ do composto $(R, S)$-O-acetil-1-fenil-2-fenilsseleno-2-etanol $[(R, S)$-2e] 


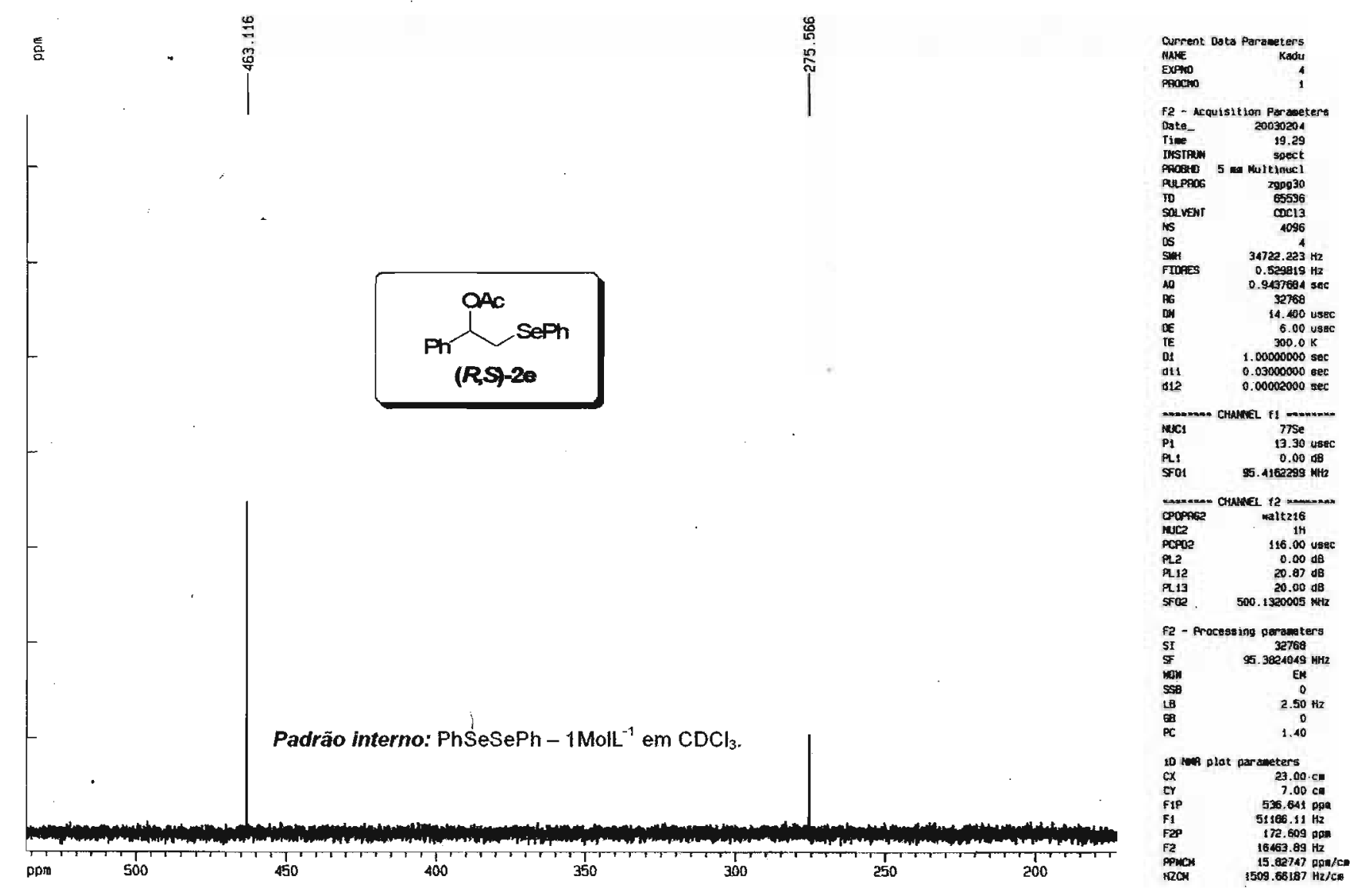

Espectro de $\mathrm{RMN}{ }^{77}$ Se do composto $(R, S)$-O-acetil-1-fenil-2-fenilsseleno-2-etanol $[(R, S)-2 \mathrm{e}]$

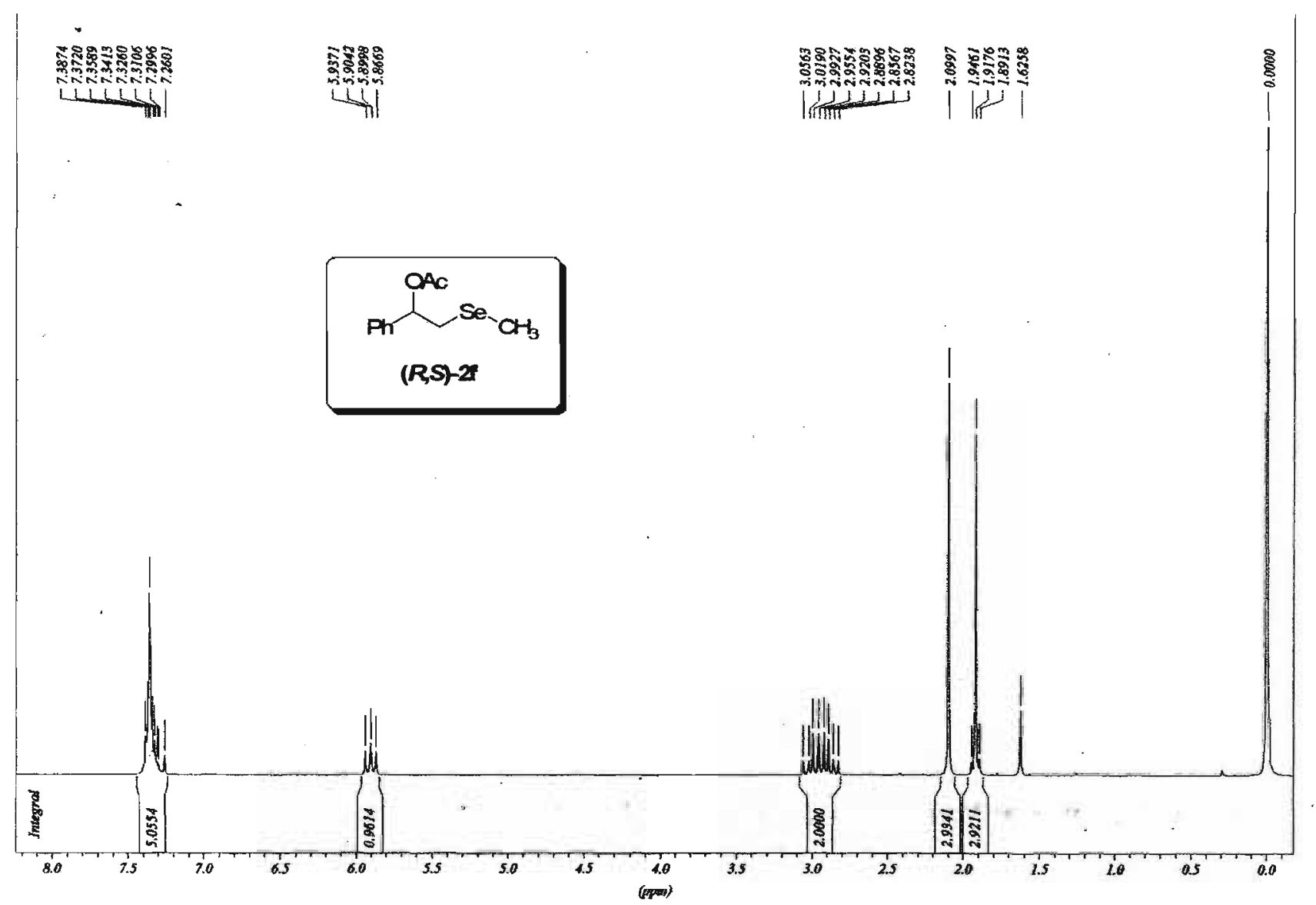

Espectro de $\mathrm{RMN}{ }^{1} \mathrm{H}$ do composto $(R, S)$-O-acetil-1-metilsseleno-2-fenil-2-etanol [(R,S)-2f] 


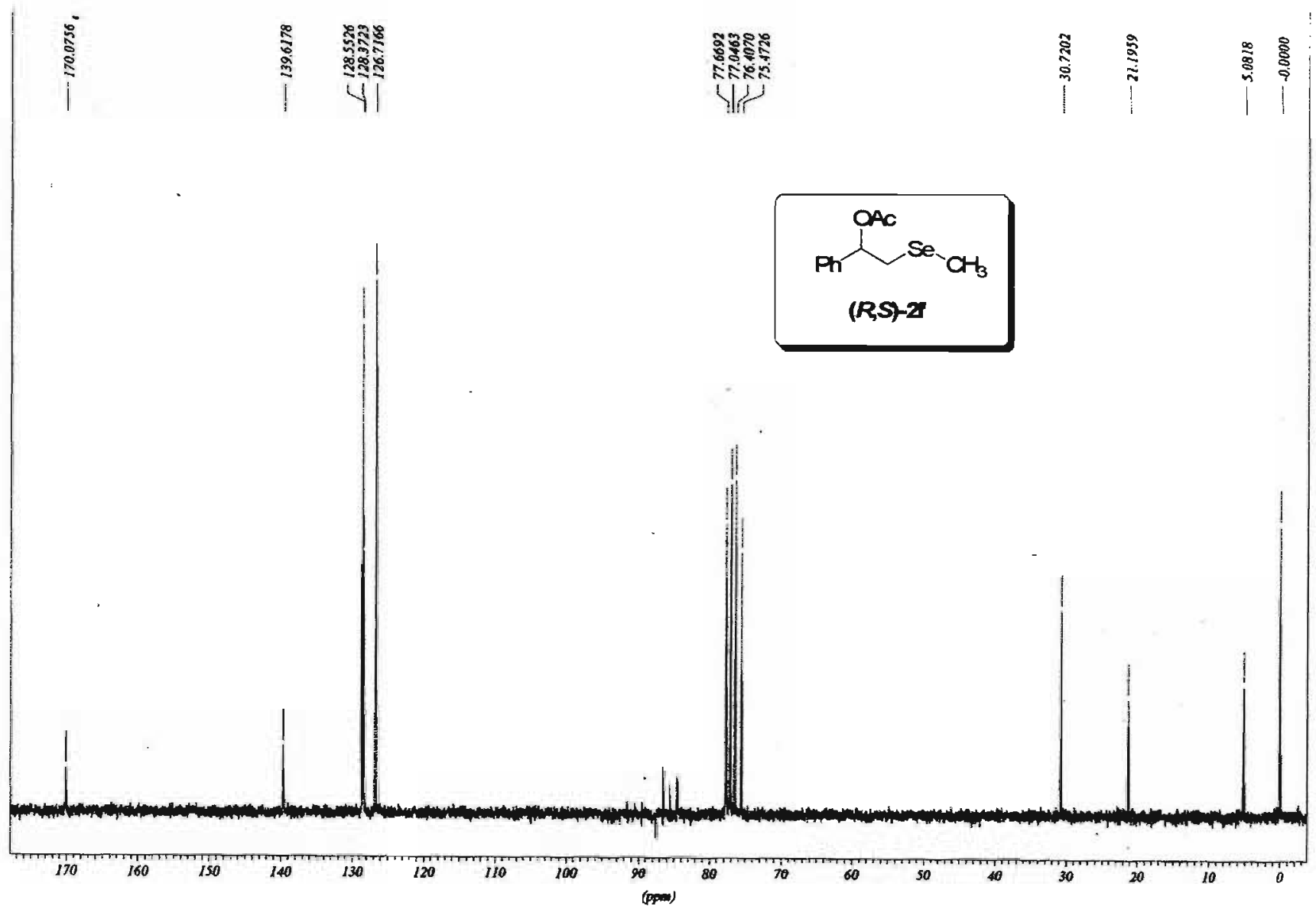

Espectro de RMN ${ }^{13} \mathrm{C}$ do composto $(R, S)$-O-acetil-1-metilsseleno-2-fenil-2-etanol $[(R, S)-2 f]$
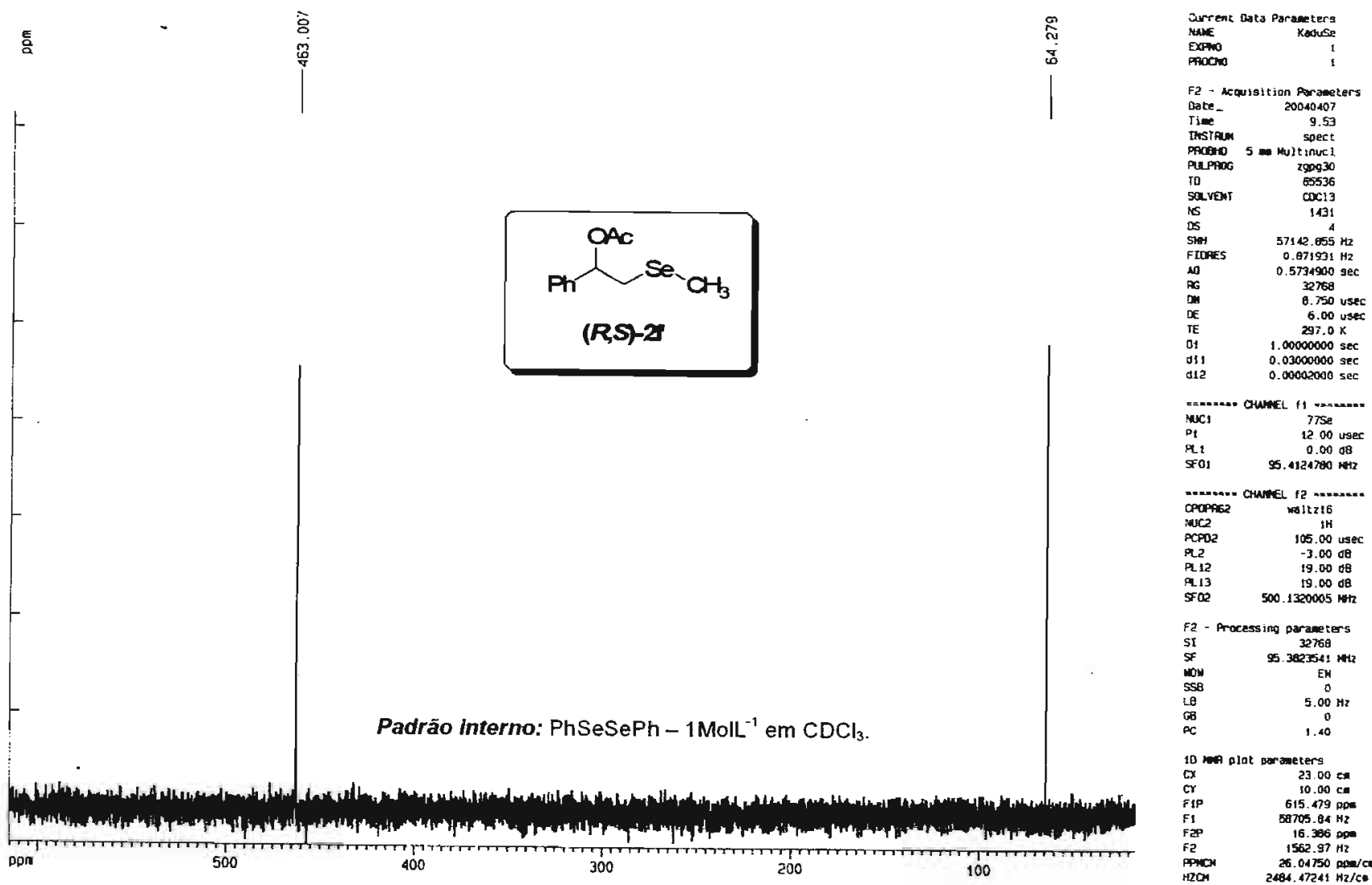

Espectro de RMN ${ }^{77}$ Se do composto $(R, S)$-O-acetil-1-metilsseleno-2-fenil-2-etanol [(R,S)-2f] 


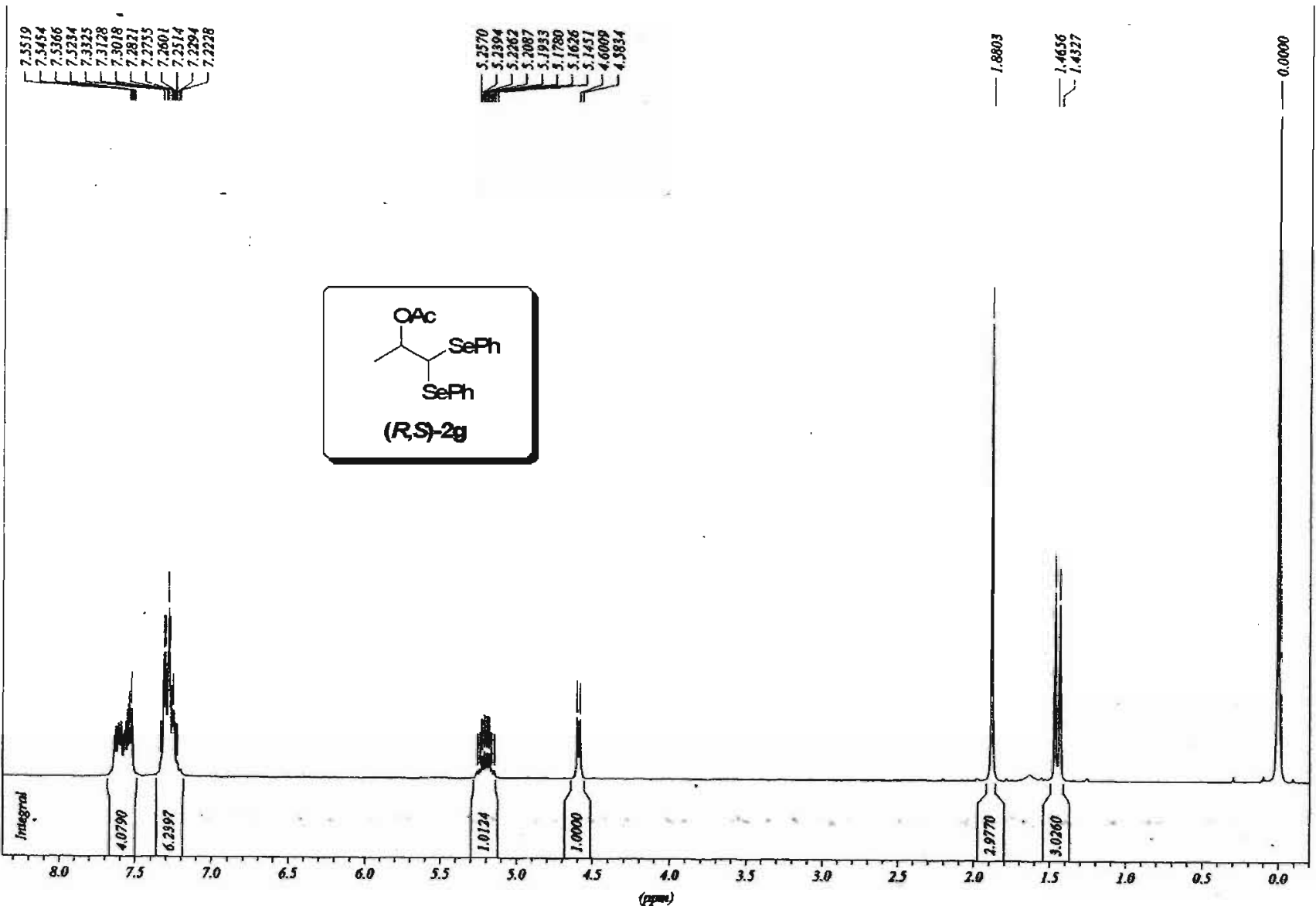

Espectro de RMIN ${ }^{1} \mathrm{H}$ do composto $(R, S)$-O-acetil-1,1-difenilsseleno-2-propanol $[(R, S)$-2g]

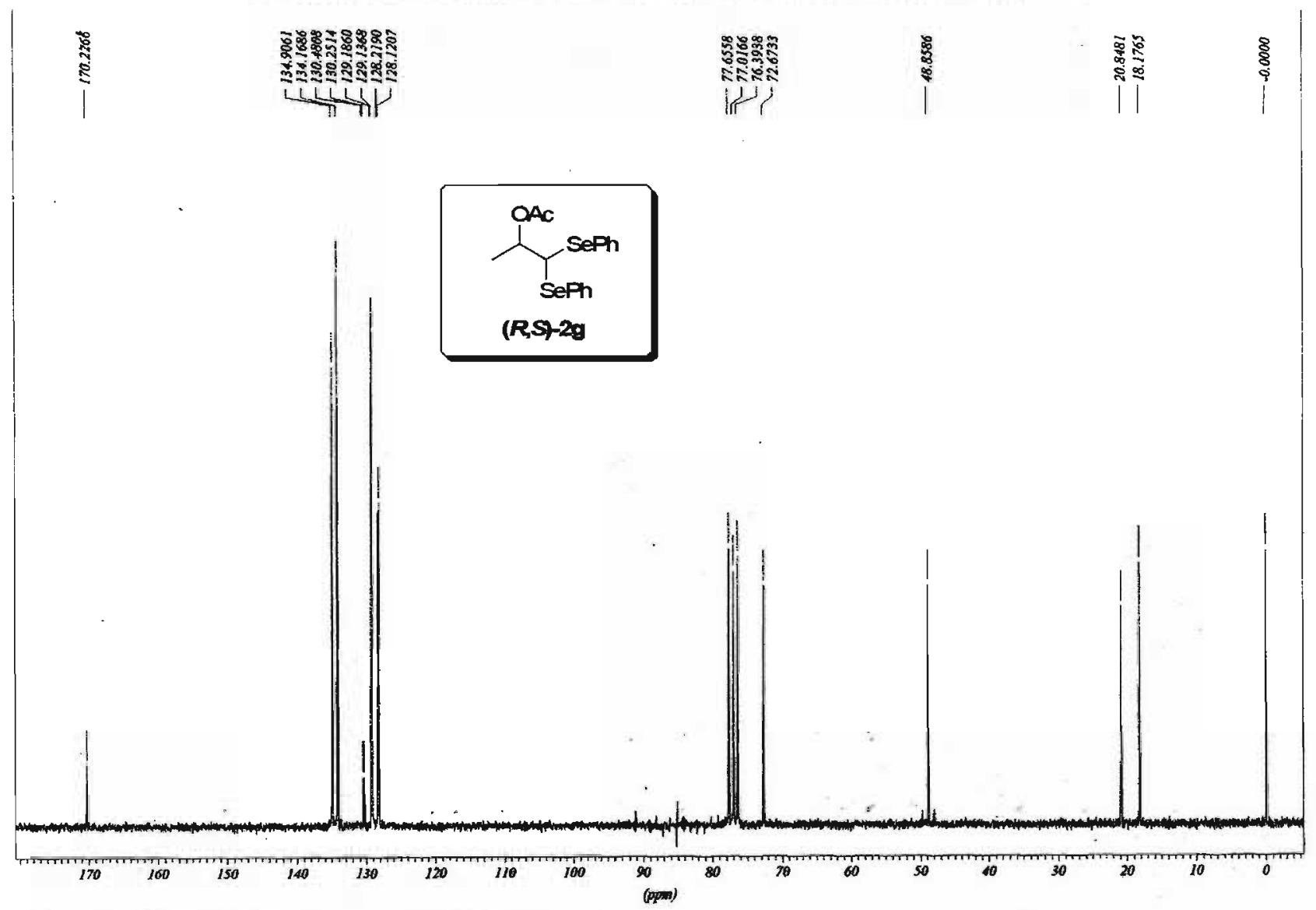

Espectro de $\mathrm{RMN}{ }^{13} \mathrm{C}$ do composto $(R, S)$-O-acetil-1,1-difenilsseleno-2-propanol $[(R, S)-2 \mathrm{~g}]$ 


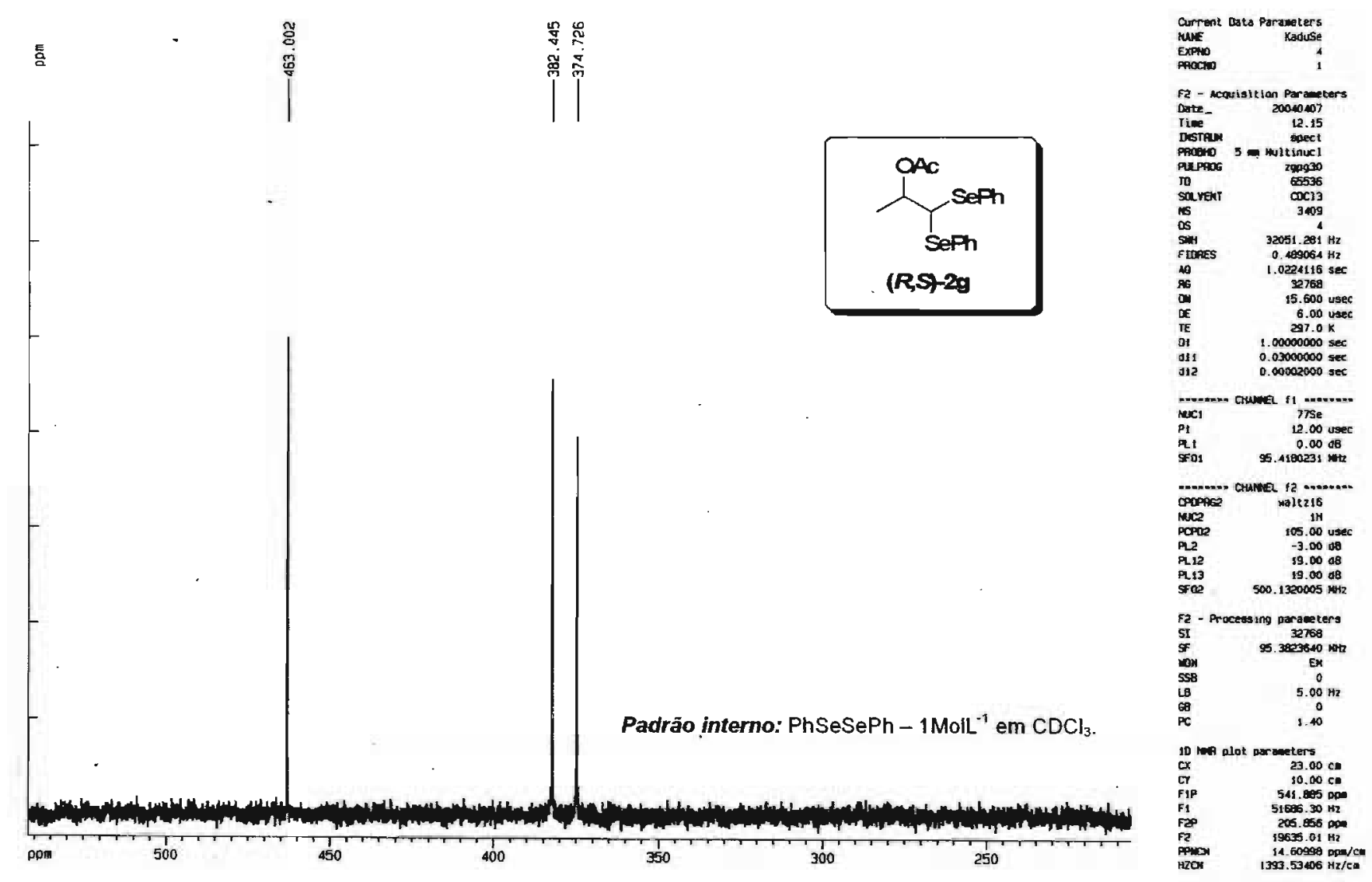

Espectro de RMN ${ }^{7 \overline{ }}$ Se do composto $(R, S)$-O-acetil-1,1-difenilsseleno-2-propanol $[(R, S)-2 \mathrm{~g}]$
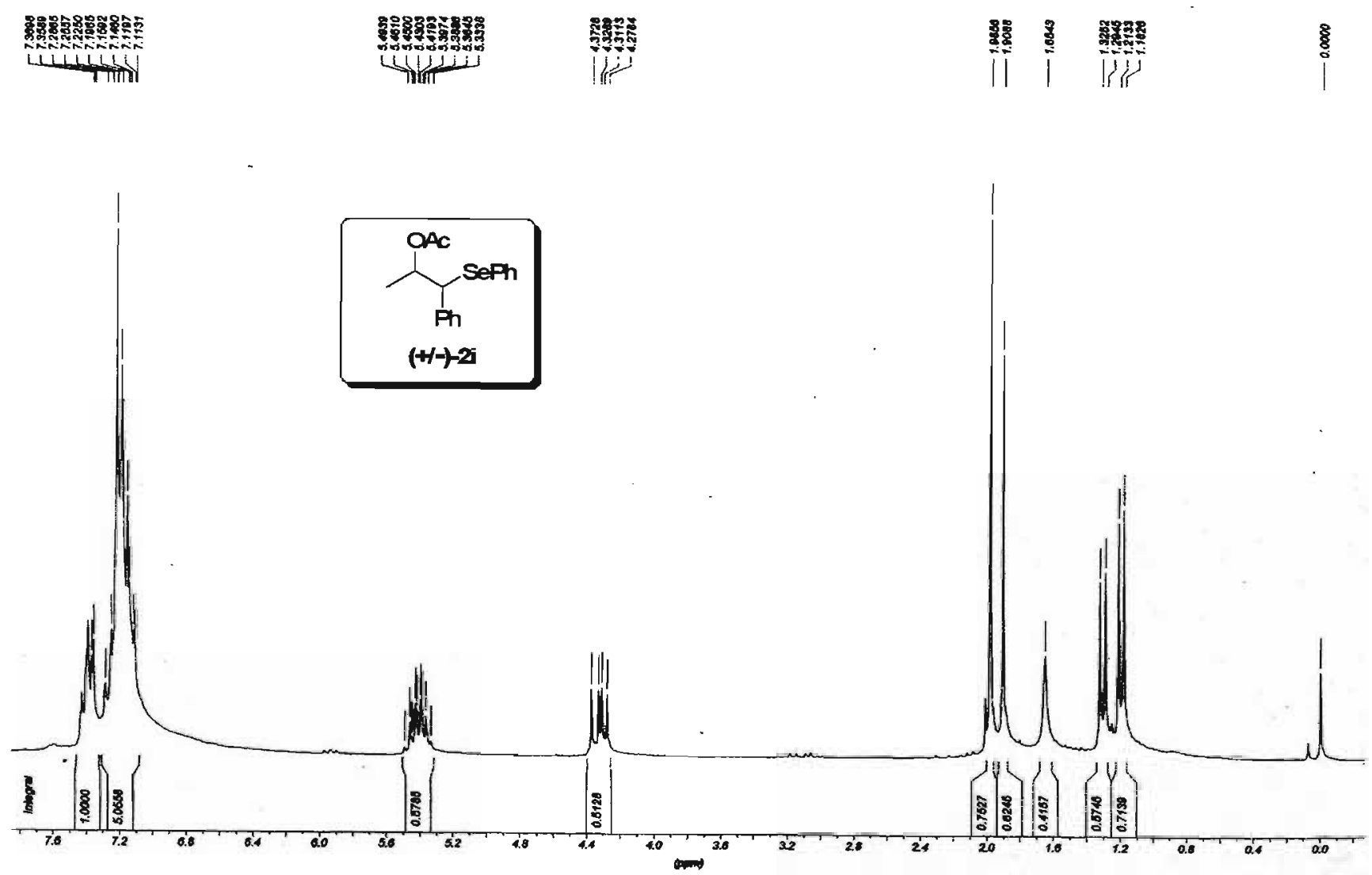

Espectro de RMN ${ }^{1} \mathrm{H}$ do composto ( \pm )-O-acetil-1-fenil-1-(fenilsseleno-2-propanol) [( \pm )-2i] 

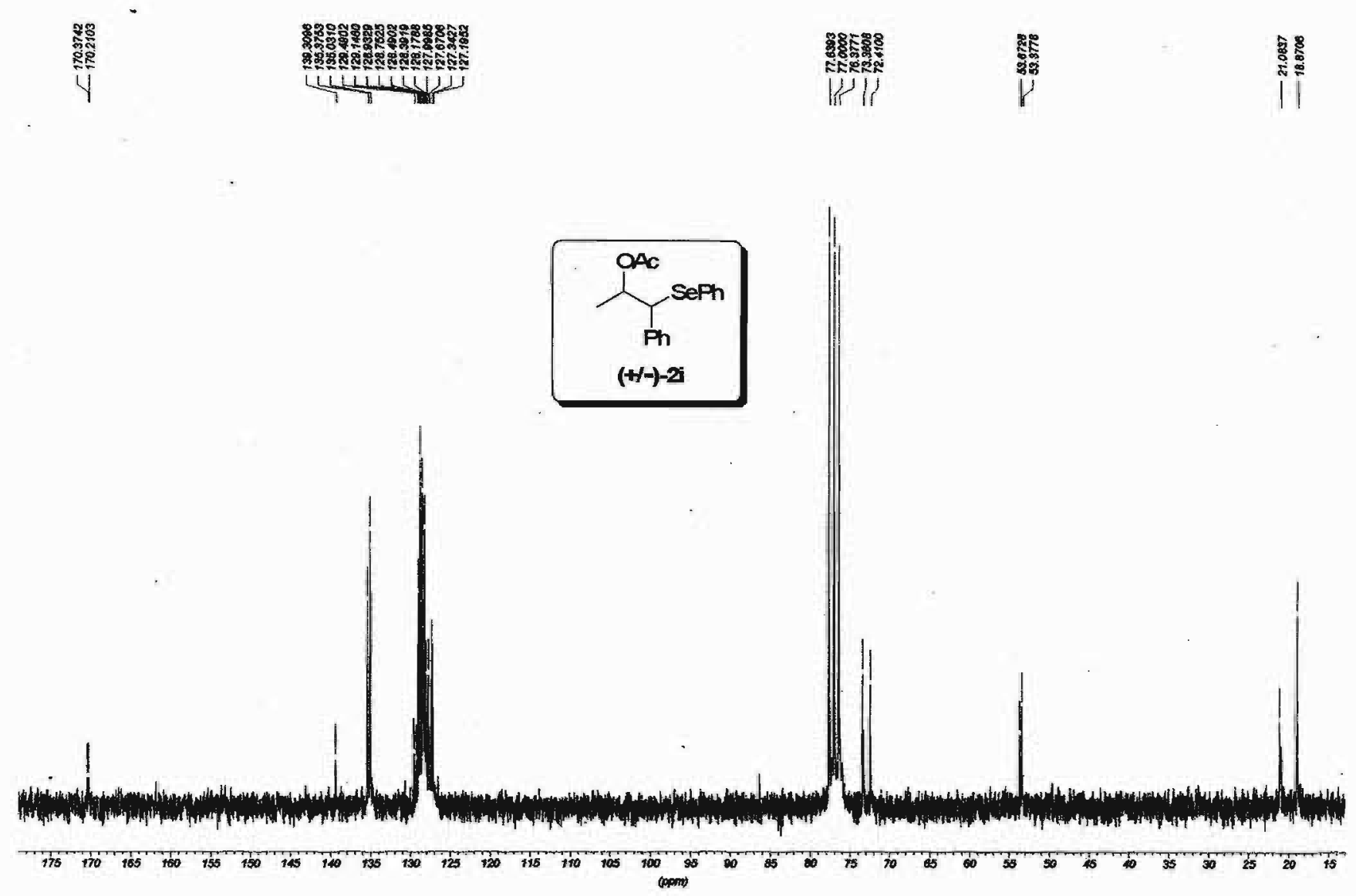

Espectro de RMN ${ }^{13} \mathrm{C}$ do composto ( \pm )-O-acetil-1-fenil-1-(fenilsseleno-2-propanol) [( \pm )-2i]

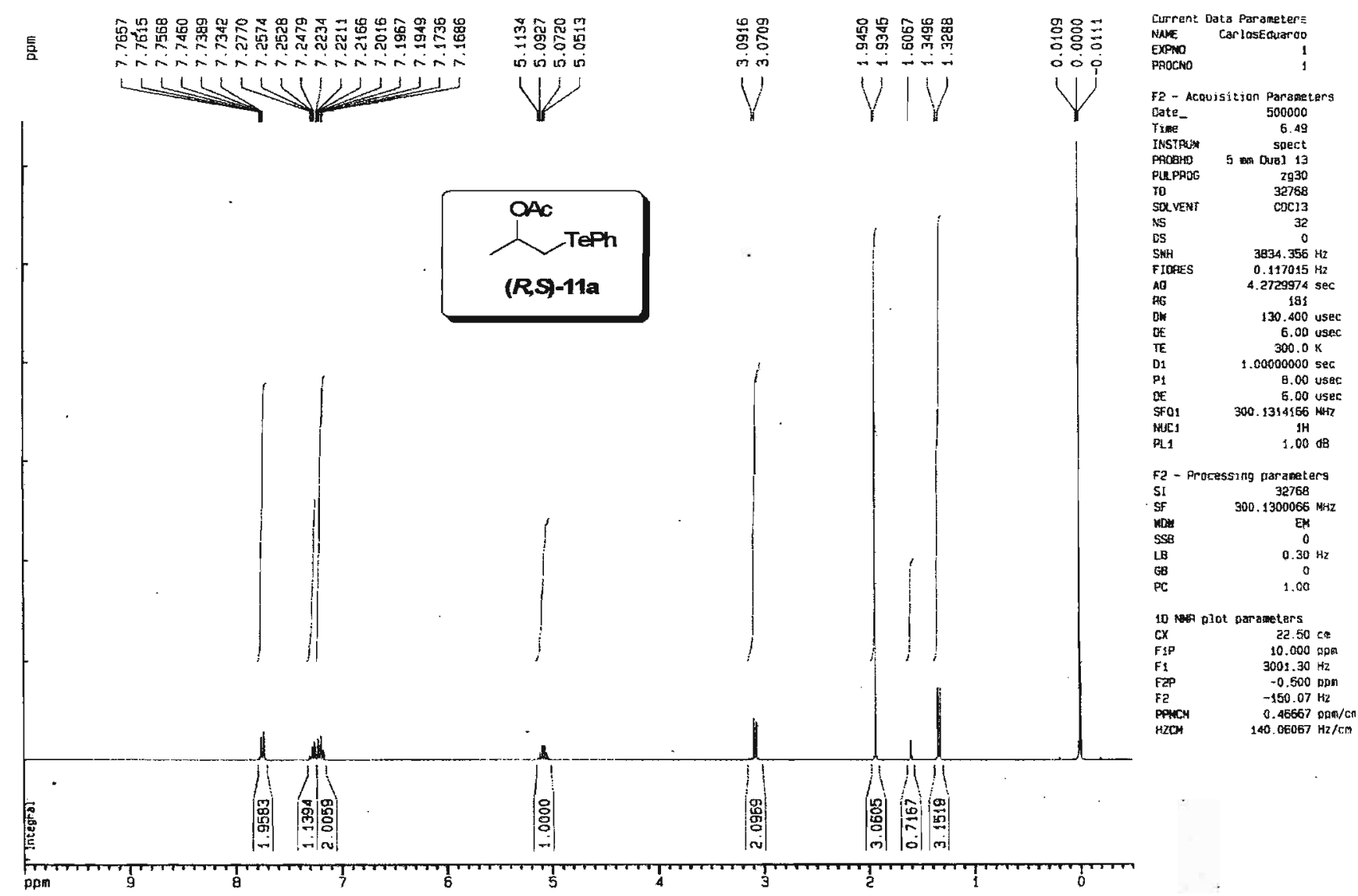

Espectro de RMN ${ }^{1} \mathrm{H}$ do composto $(R, S)-O$-acetil-1-fenilteluro-2-propanol $[(R, S)-11 \mathrm{a}]$ 


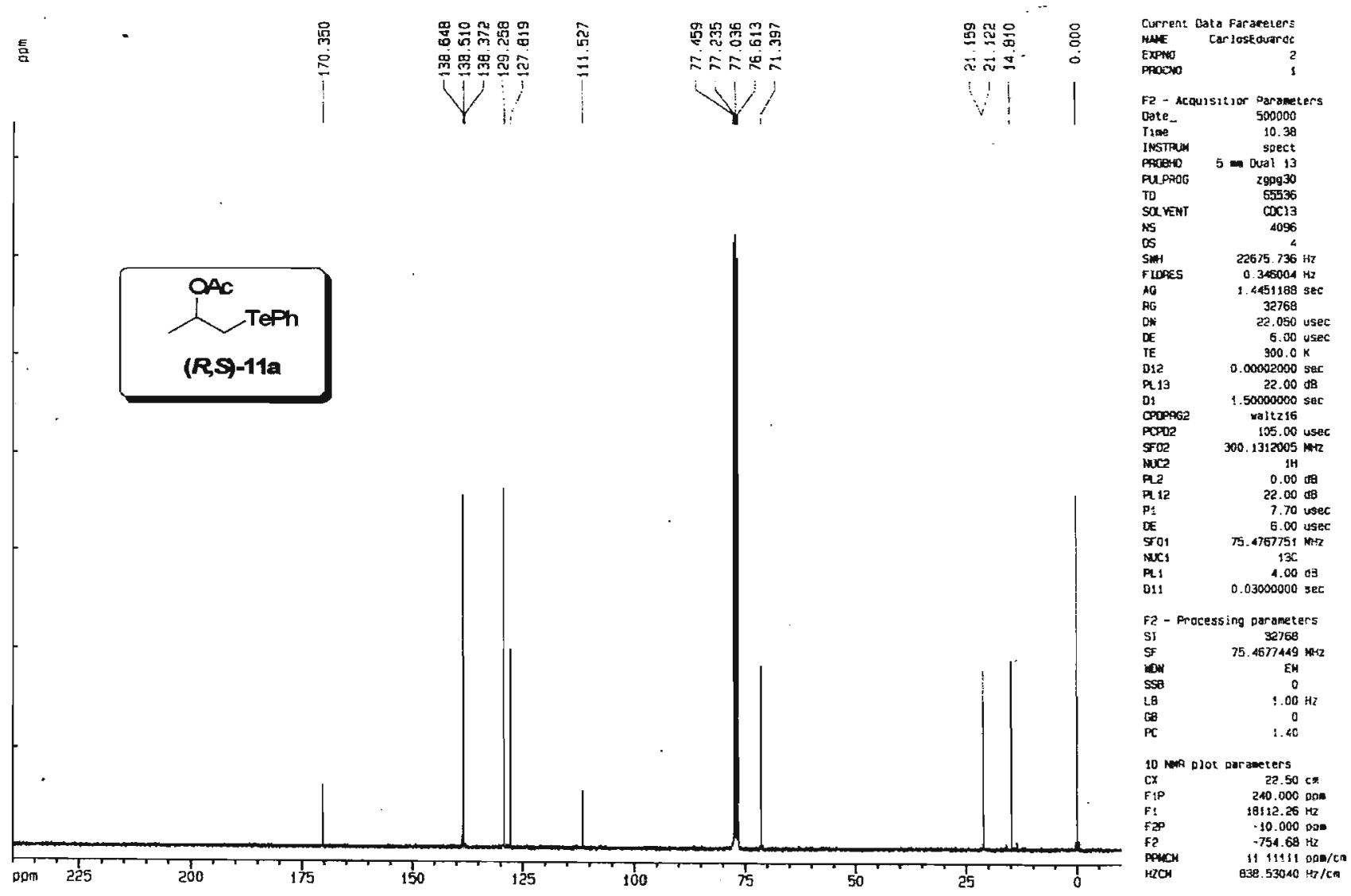

Espectro de RMN ${ }^{15} \mathrm{C}$ do composto $(R, S)$-O-acetil-1-fenilteluro-2-propanol [(R,S)-11a]

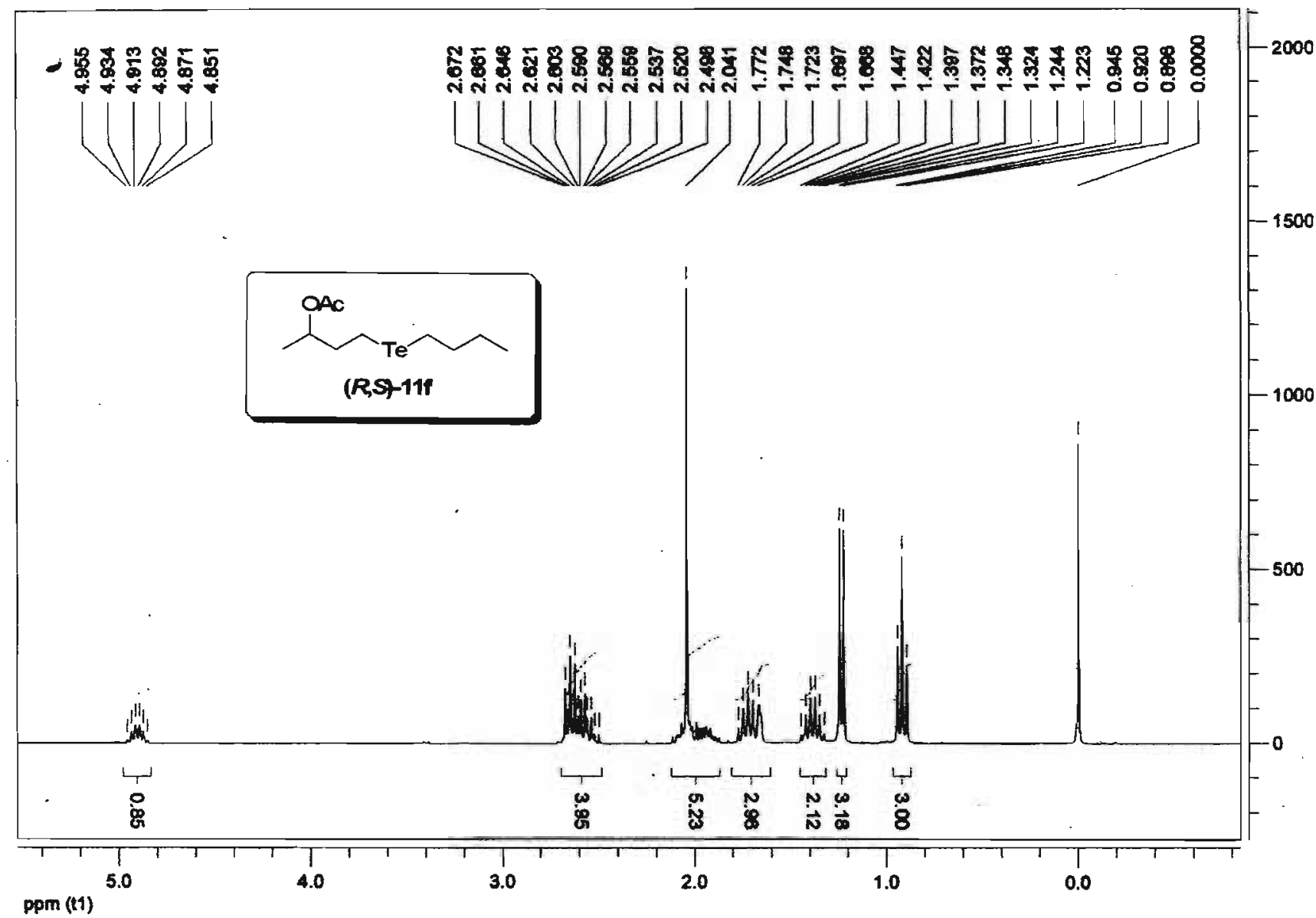

Espectro de RMN ${ }^{1} \mathrm{H}$ do composto $(\boldsymbol{R}, S)-O$-acetil-4-(n-butilteluro)-2-butanol $[(\boldsymbol{R}, \mathbf{S})-11 \mathrm{f}]$ 


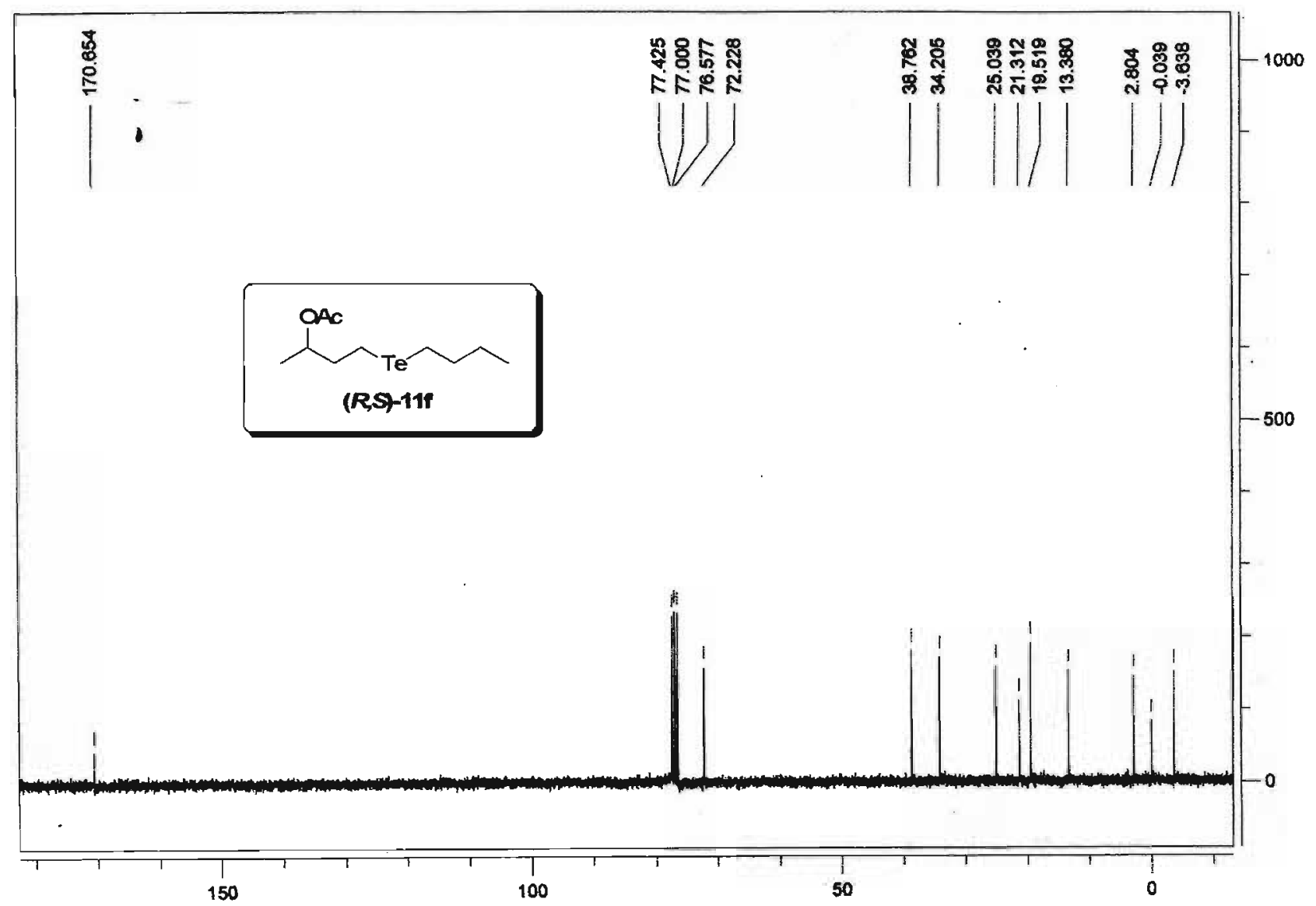

ppm (t1)

Espectro de $\mathrm{RMN}{ }^{13} \mathrm{C}$ do composto $(R, S)$-O-acetil-4-(n-butilteluro)-2-butanol $[(R, S)-11 \mathrm{f}]$

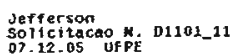

Puise Sequence: 52pol

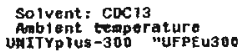

Relax- delay $3.000 \mathrm{sec}$

Pulso. 90.0 dogress

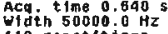

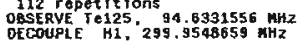

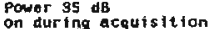

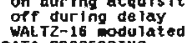

DAfA Processing
Line broadening $5.0 \mathrm{~Hz}$

Fotal 24 ing 24 min, 20 sec

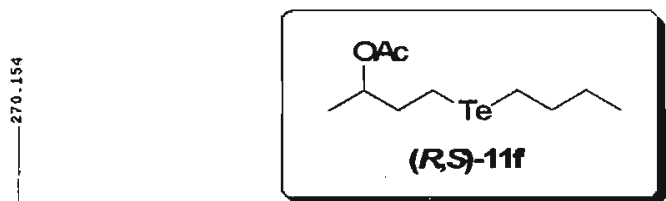

Padrão externo: PhTeTePh em $\mathrm{CDCl}_{3}$

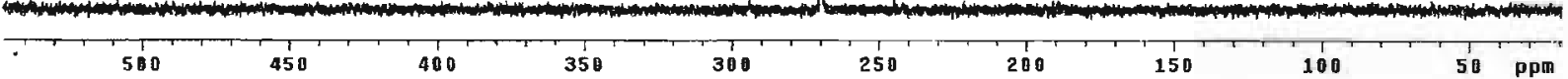




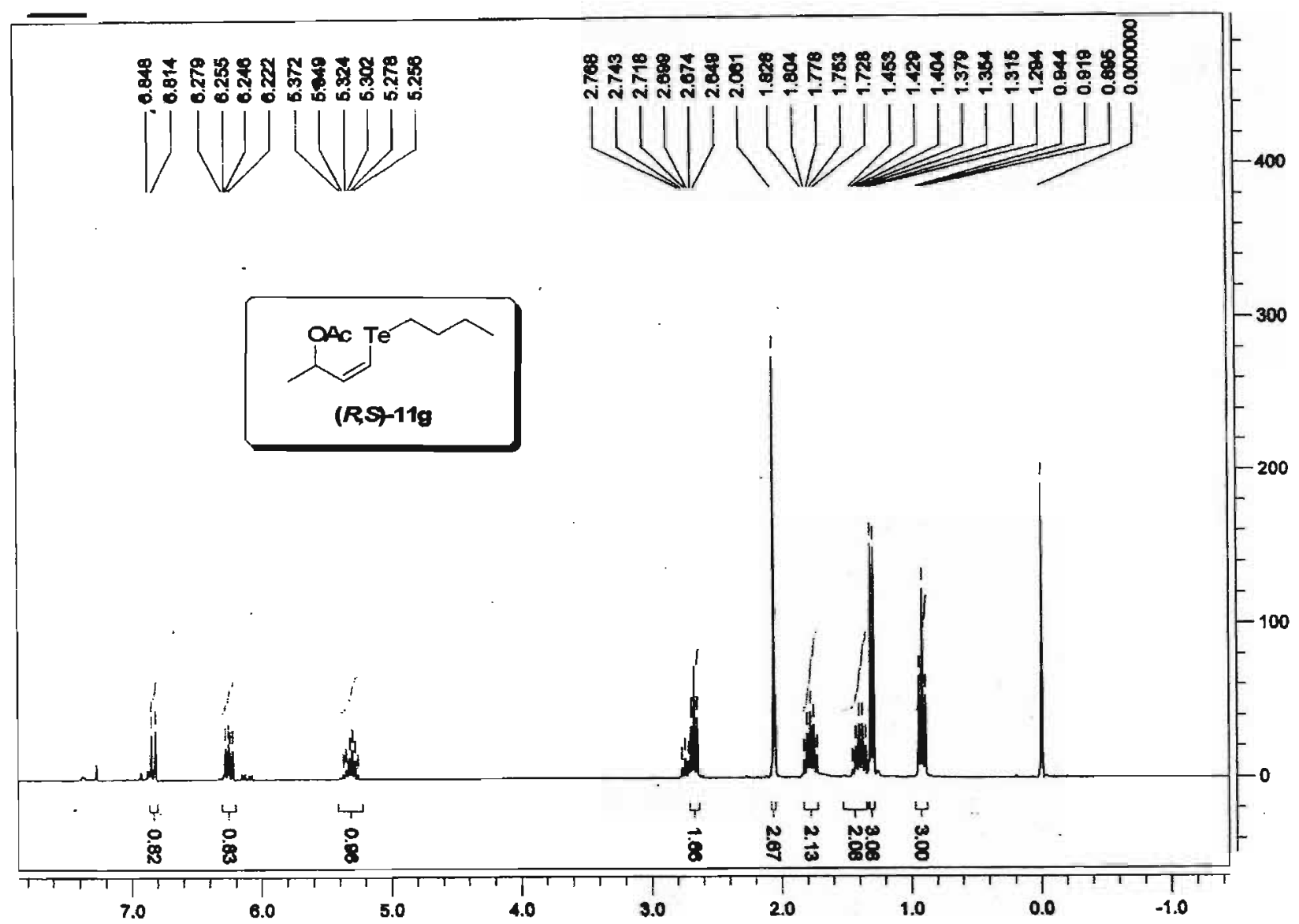

ppm (t1)

Espectro de $R M N{ }^{1} H$ do composto $(R, S)-O$-acetil-4-(n-butilteluro)but-3-em-2-ol $[(R, S)-11 \mathrm{~g}]$

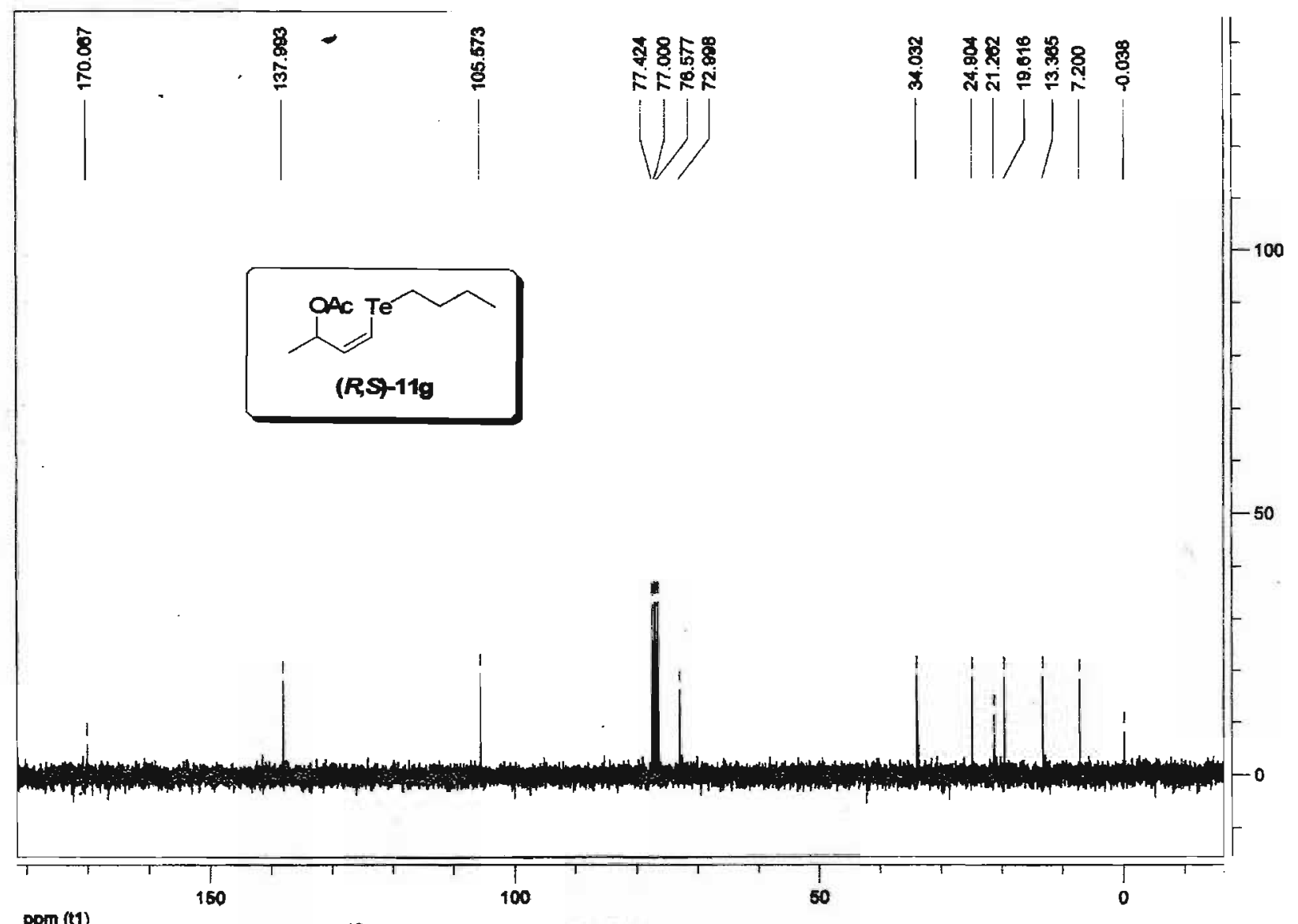

DPm (it) Espectro de RMN ${ }^{13} \mathrm{C}$ do composto $(R, S)$-O-acetil-4-(n-butilteluro)but-3-em-2-ol [(R,S)-11g] 158 


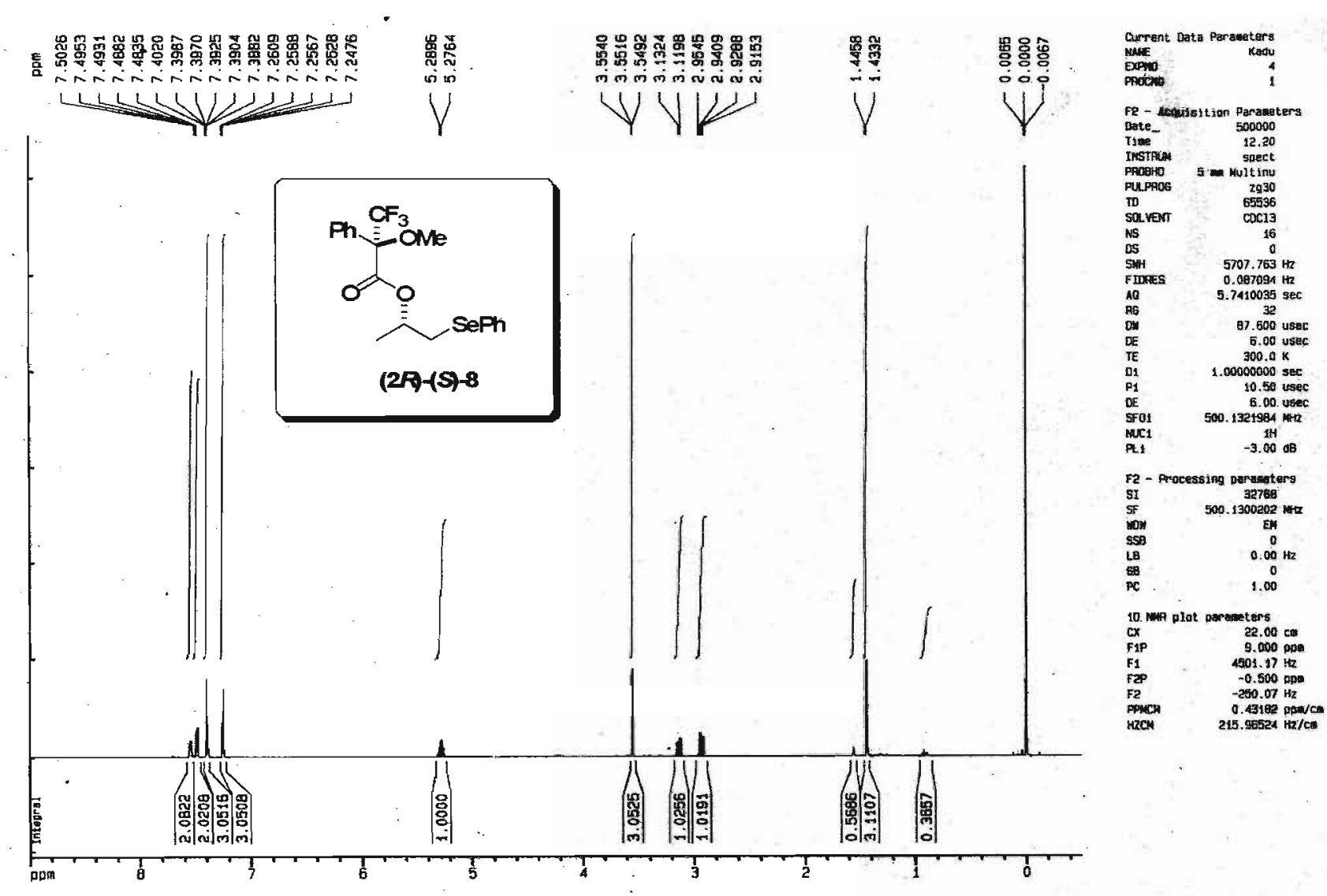

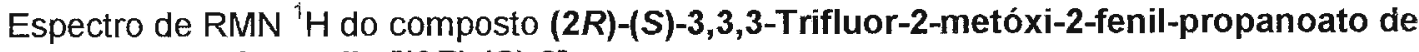
1-fenilseleno-2-propila [(2R)-(S)-8]
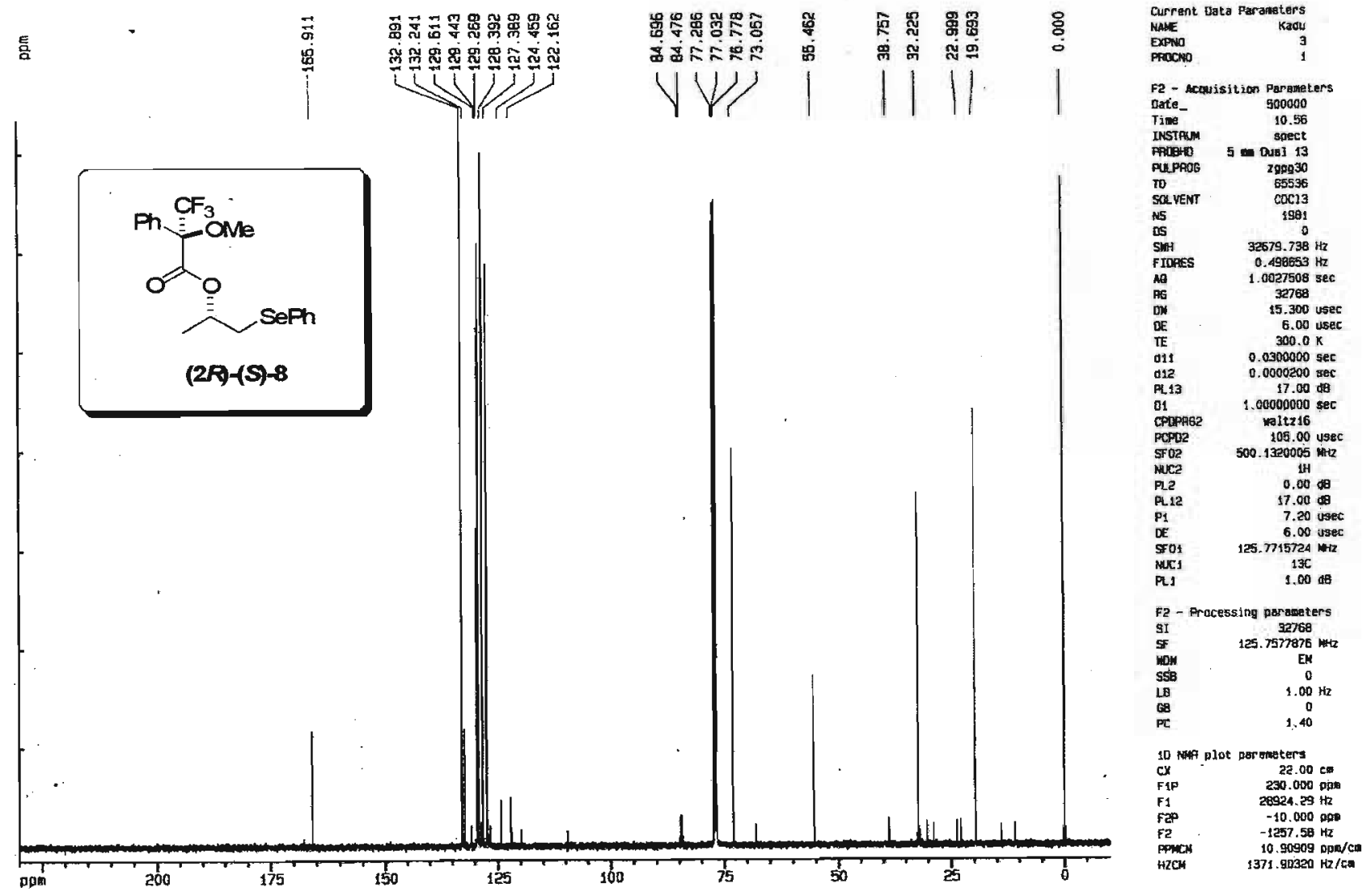


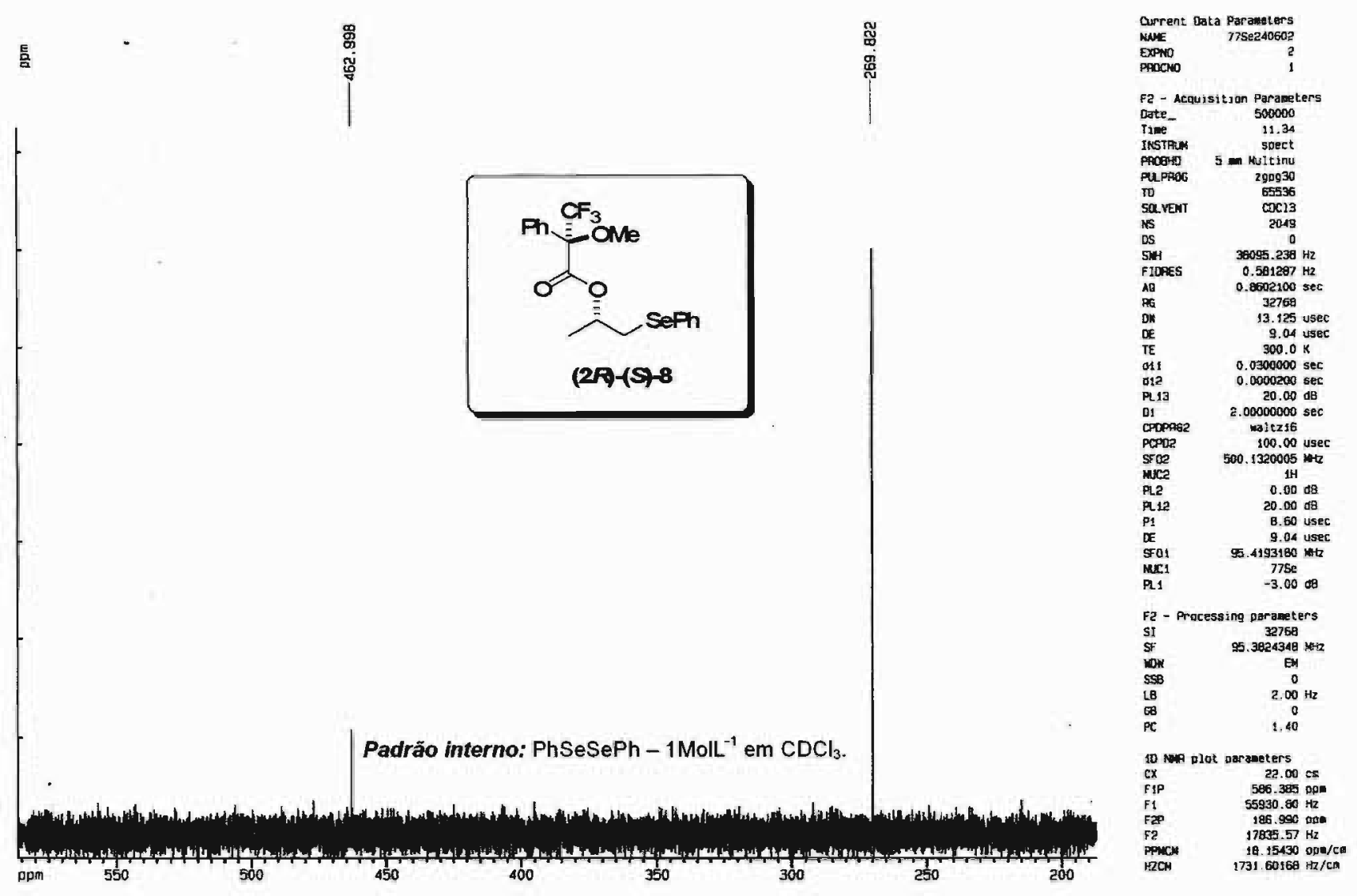

Espectro de RMN ${ }^{7 \bar{i}}$ Se do composto (2R)-(S)-3,3,3-Trifluor-2-metóxi-2-fenil-propanoato de 1-fenilseleno-2-propila [(2R)-(S)-8]

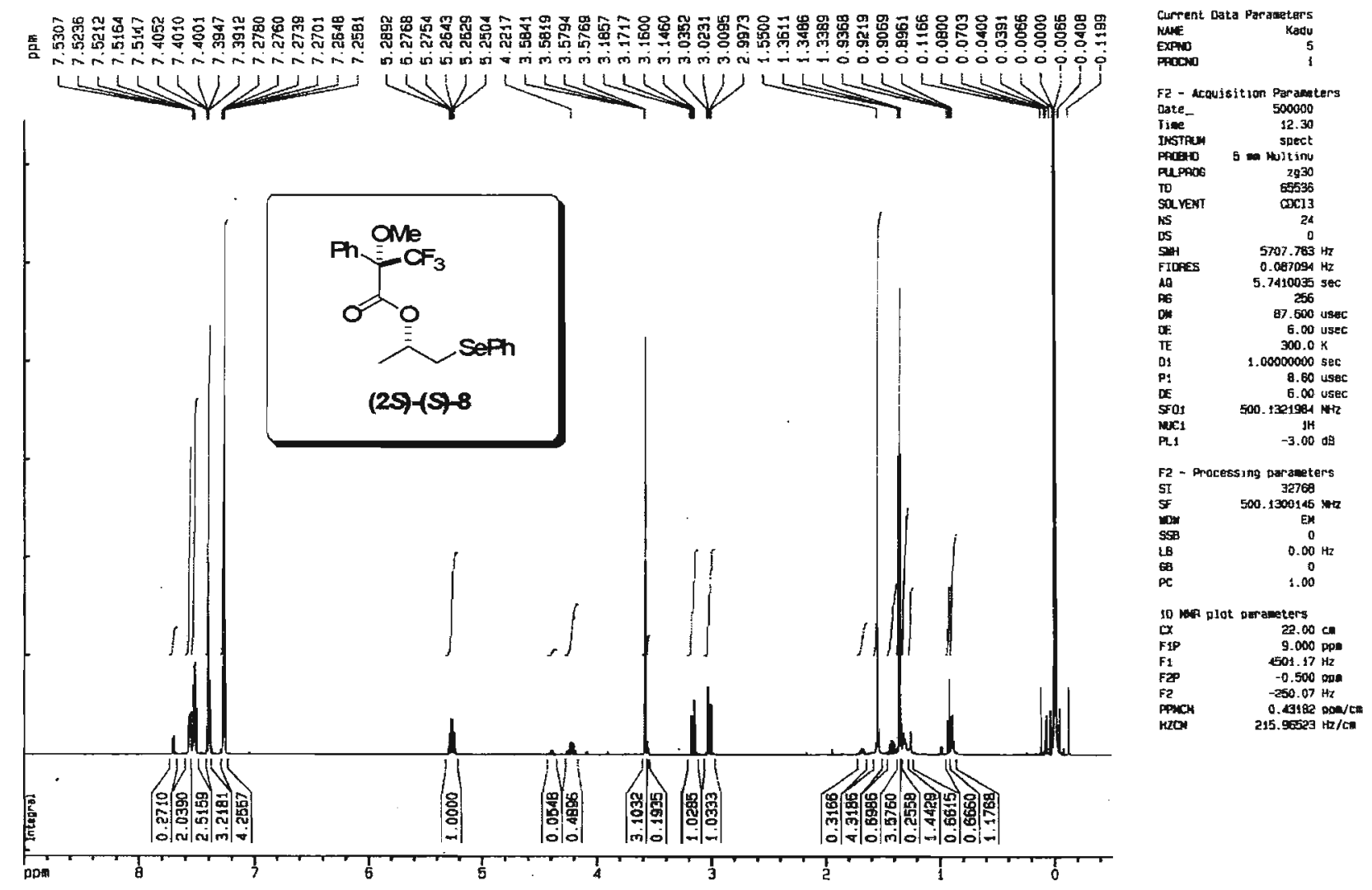

Espectro de RMN ${ }^{1} \mathrm{H}$ do composto (2S)-(S)-3,3,3-Trifluor-2-metóxi-2-fenil-propanoato de 1-fenilseleno-2-propila [(2S)-(S)-8] 


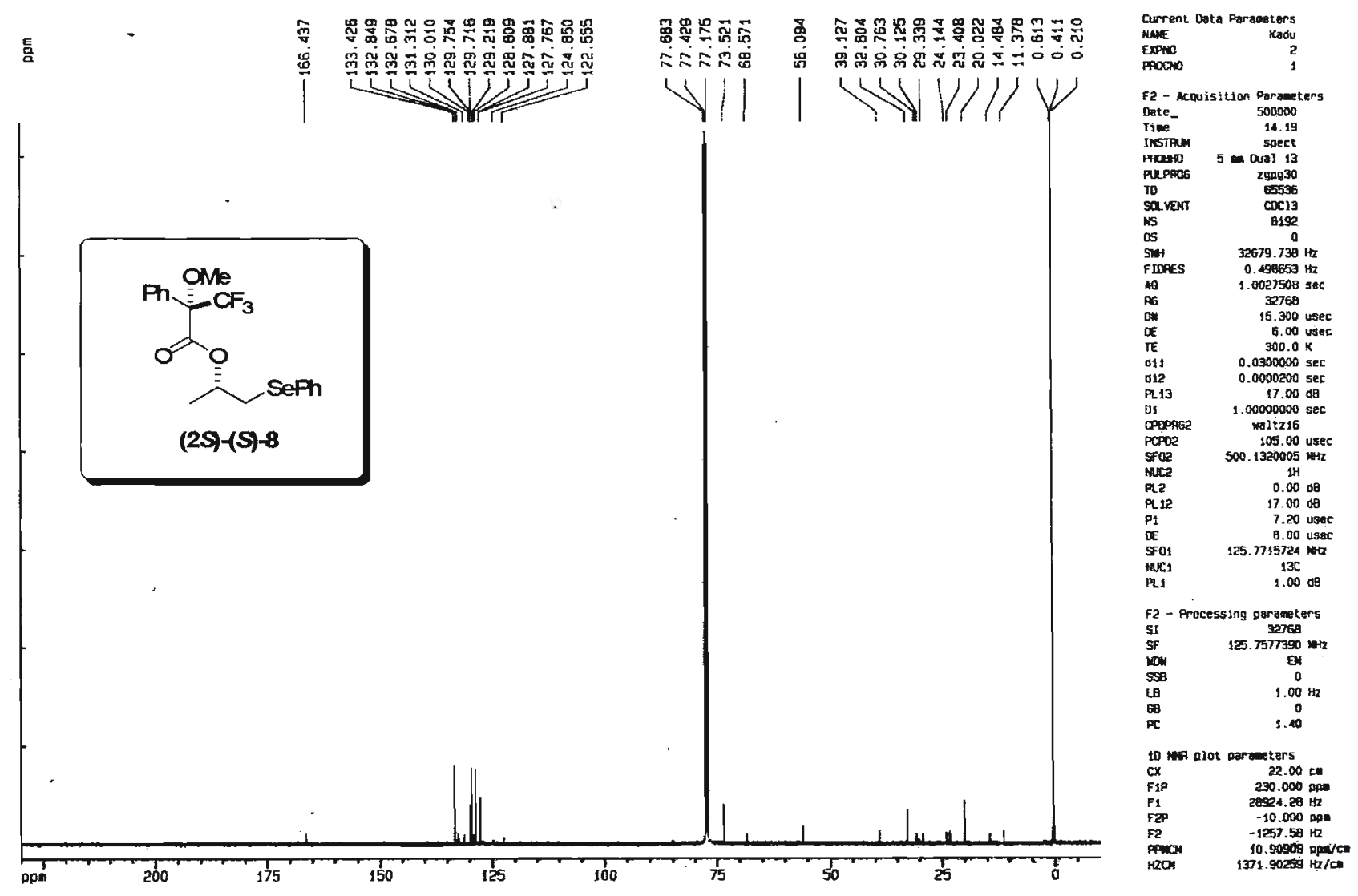

Espectro de RMN ${ }^{13} \mathrm{C}$ do composto (2S)-(S)-3,3,3-Trifluor-2-metóxi-2-fenil-propanoato de 1-fenilseleno-2-propila [(2S)-(S)-8]

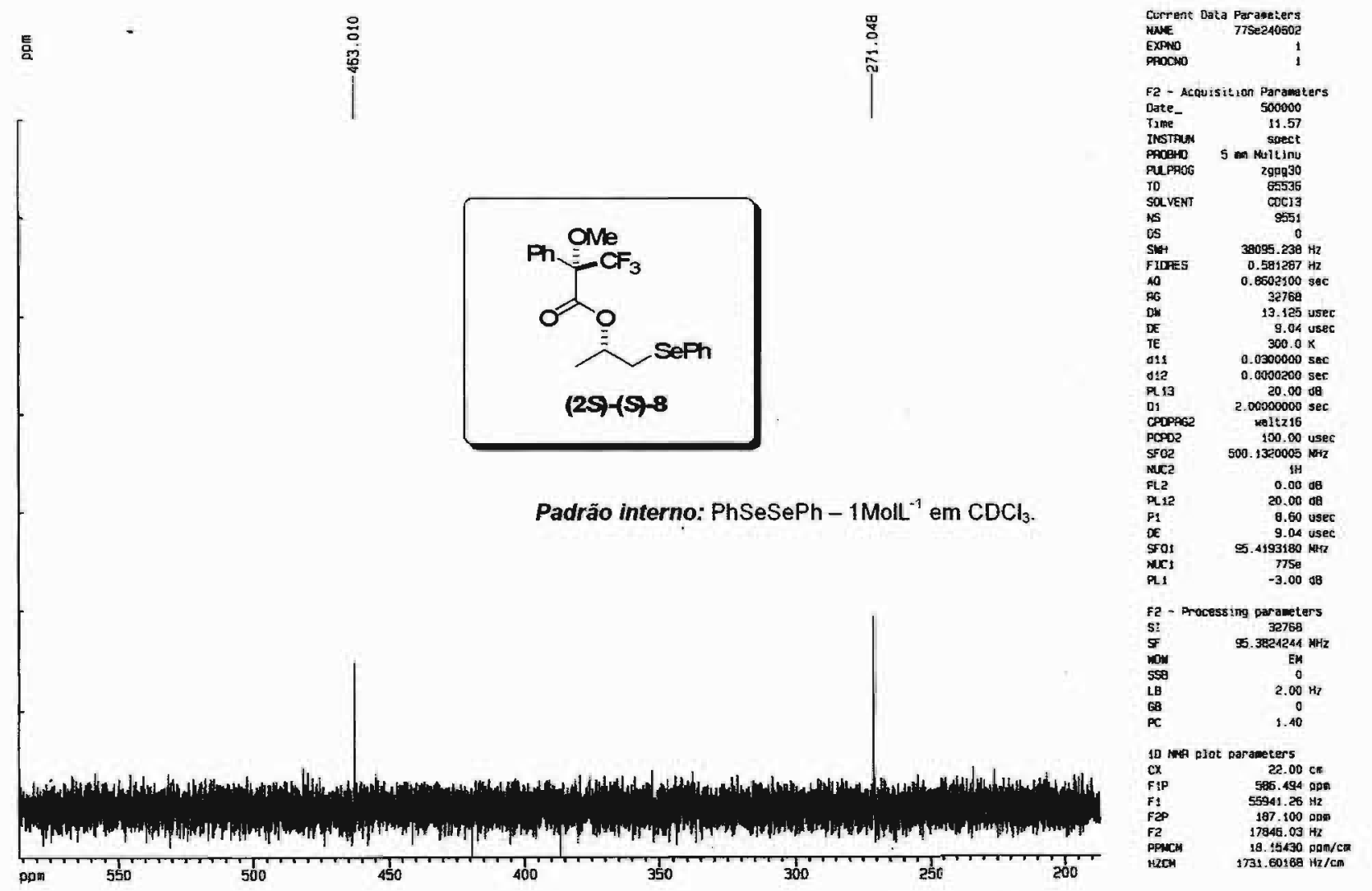

Espectro de RMIN ${ }^{i 7}$ Se do composto (2S)-(S)-3,3,3-Trifluor-2-metóxi-2-fenil-propanoato de 1-fenilseleno-2-propila [(2S)-(S)-8] 


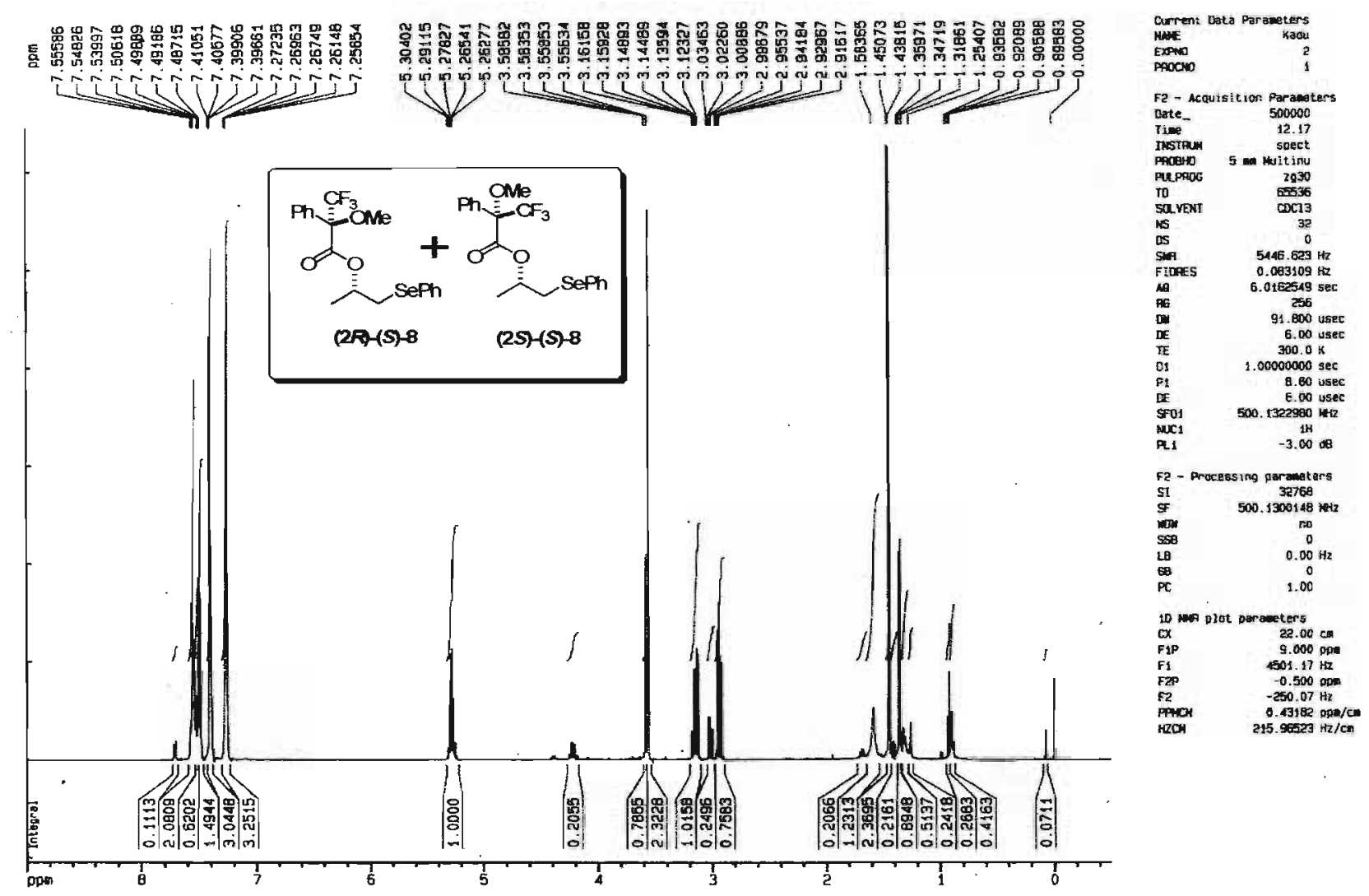

Espectro de $\mathrm{RMN}{ }^{1} \mathrm{H}$ da mistura dos compostos (2R)-(S)-3,3,3-Trifluor-2-metóxi-2-fenilpropanoato de 1-fenilseleno-2-propila [(2R)-(S)-8] e (2S)-(S)-3,3,3-Trifluor-2-metóxi-2-fenilpropanoato de 1-fenilseleno-2-propila [(2S)-(S)-8]
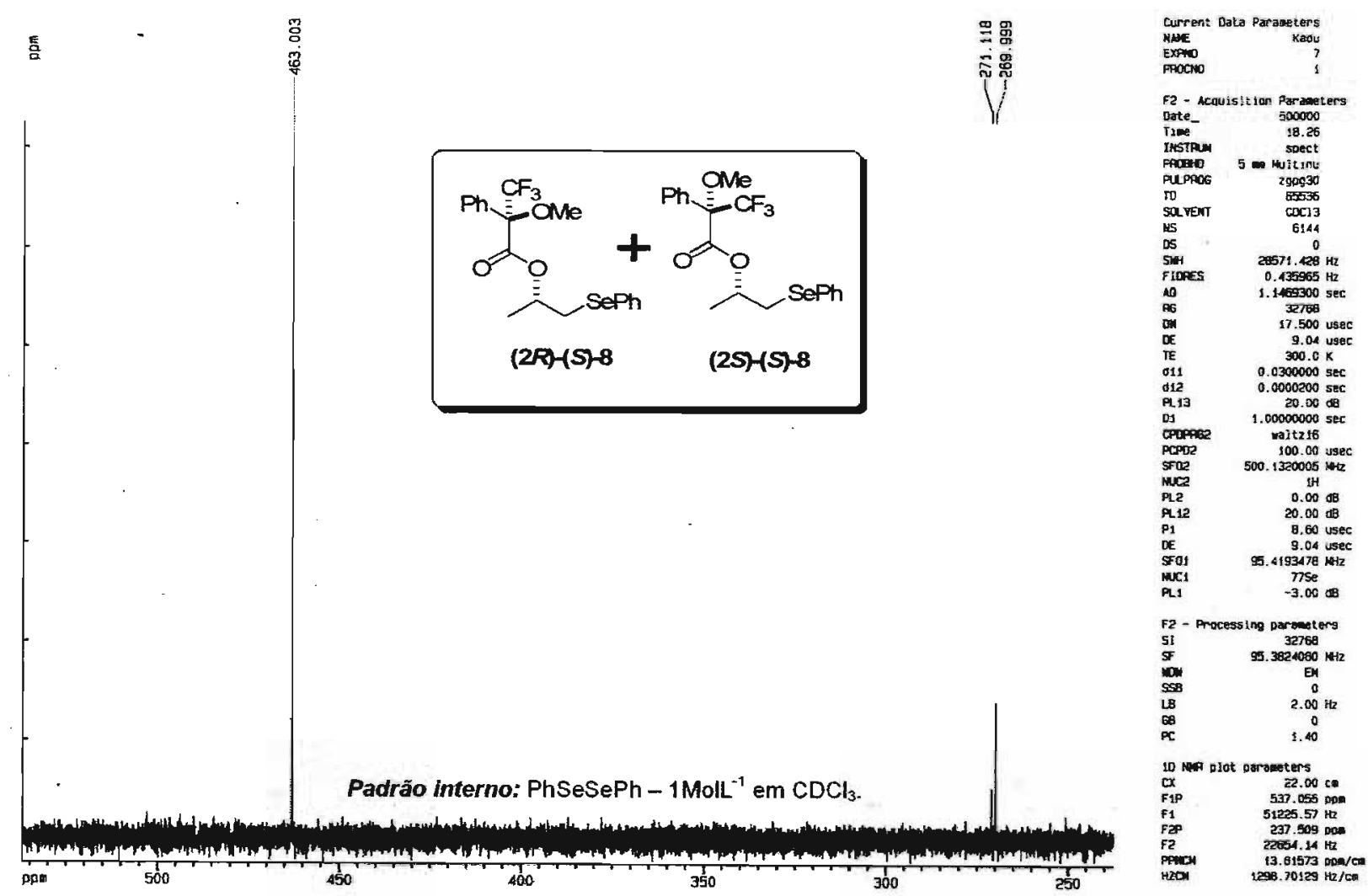

Espectro de RMN "TSe da mistura dos compostos (2R)-(S)-3,3,3-Trifluor-2-metóxi-2-fenilpropanoato de 1-fenilseleno-2-propila $[(2 R)-(S)-8]$ e (2S)-(S)-3,3,3-Trifluor-2-metóxi-2-fenilpropanoato de 1-fenilseleno-2-propila [(2S)-(S)-8] 


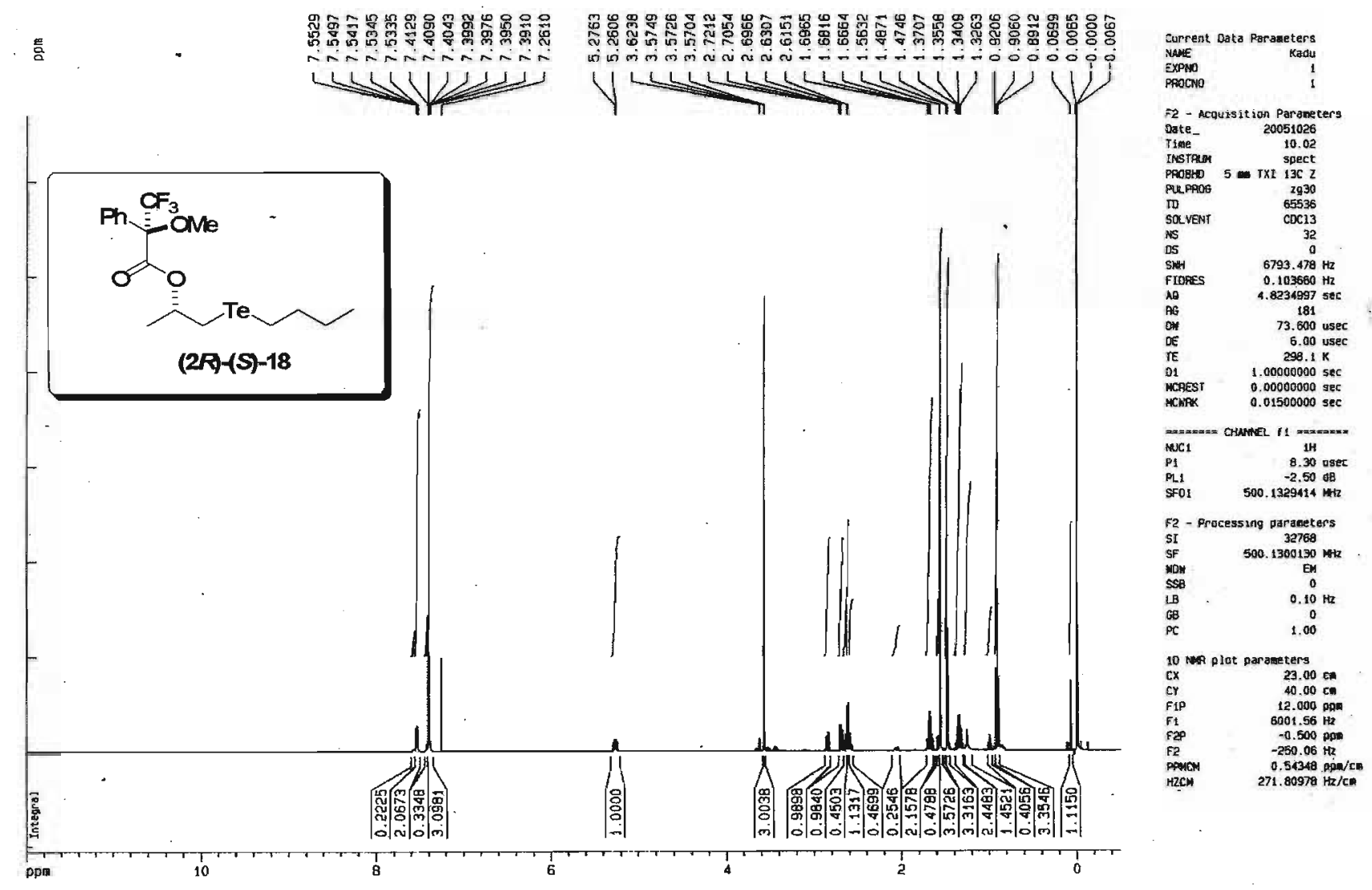

Espectro de RMN ${ }^{1} \mathrm{H}$ do composto (2R)-(S)-3,3,3-Trifluor-2-metóxi-2-fenil-propanoato de 1-(n-butilteluro)-2-propila [(2R)-(S)-18]

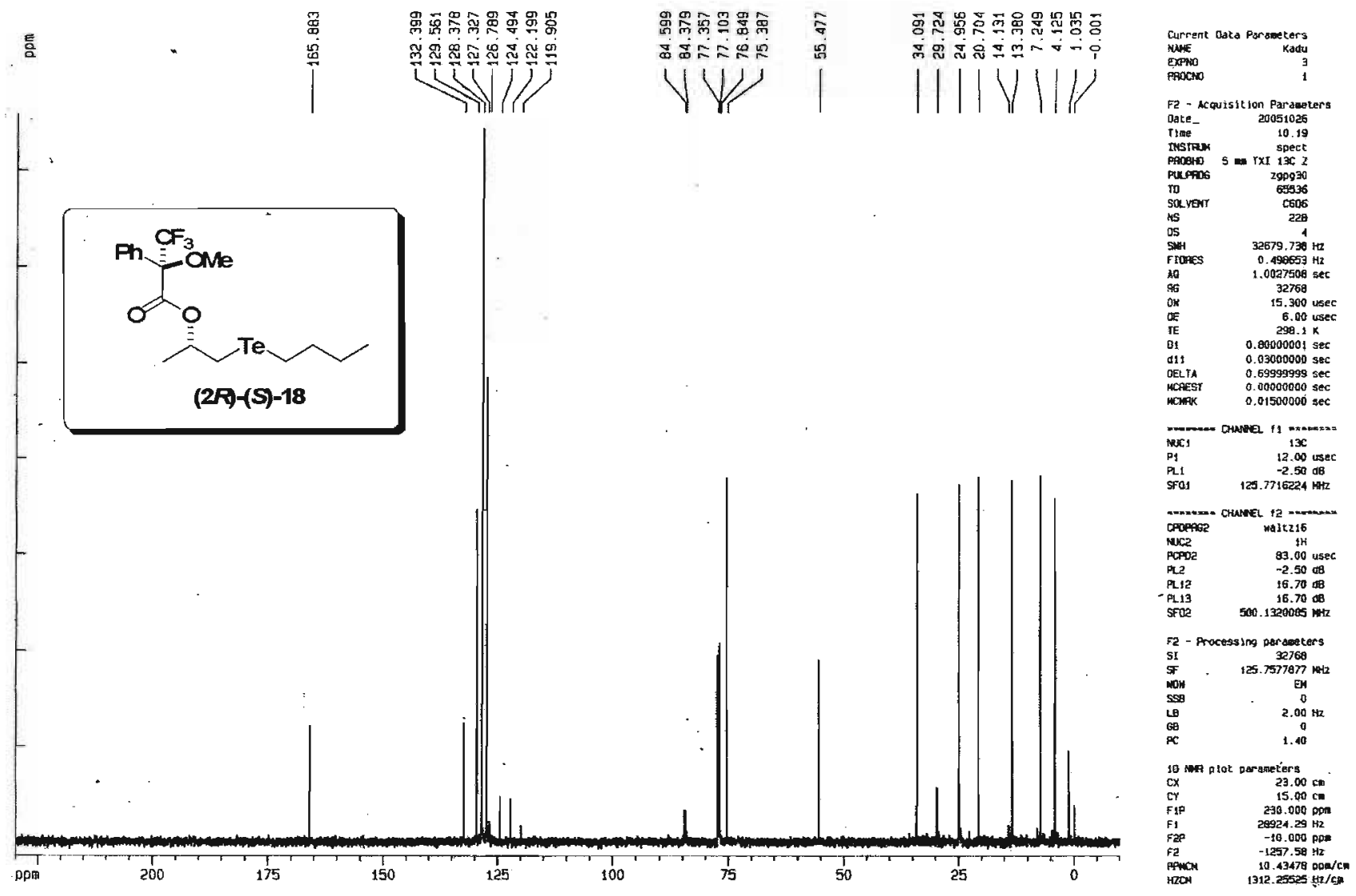

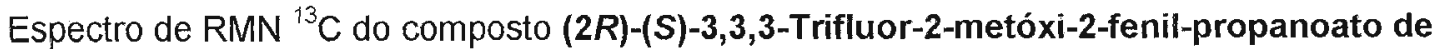
1-(n-butilteluro)-2-propila [(2R)-(S)-18] 


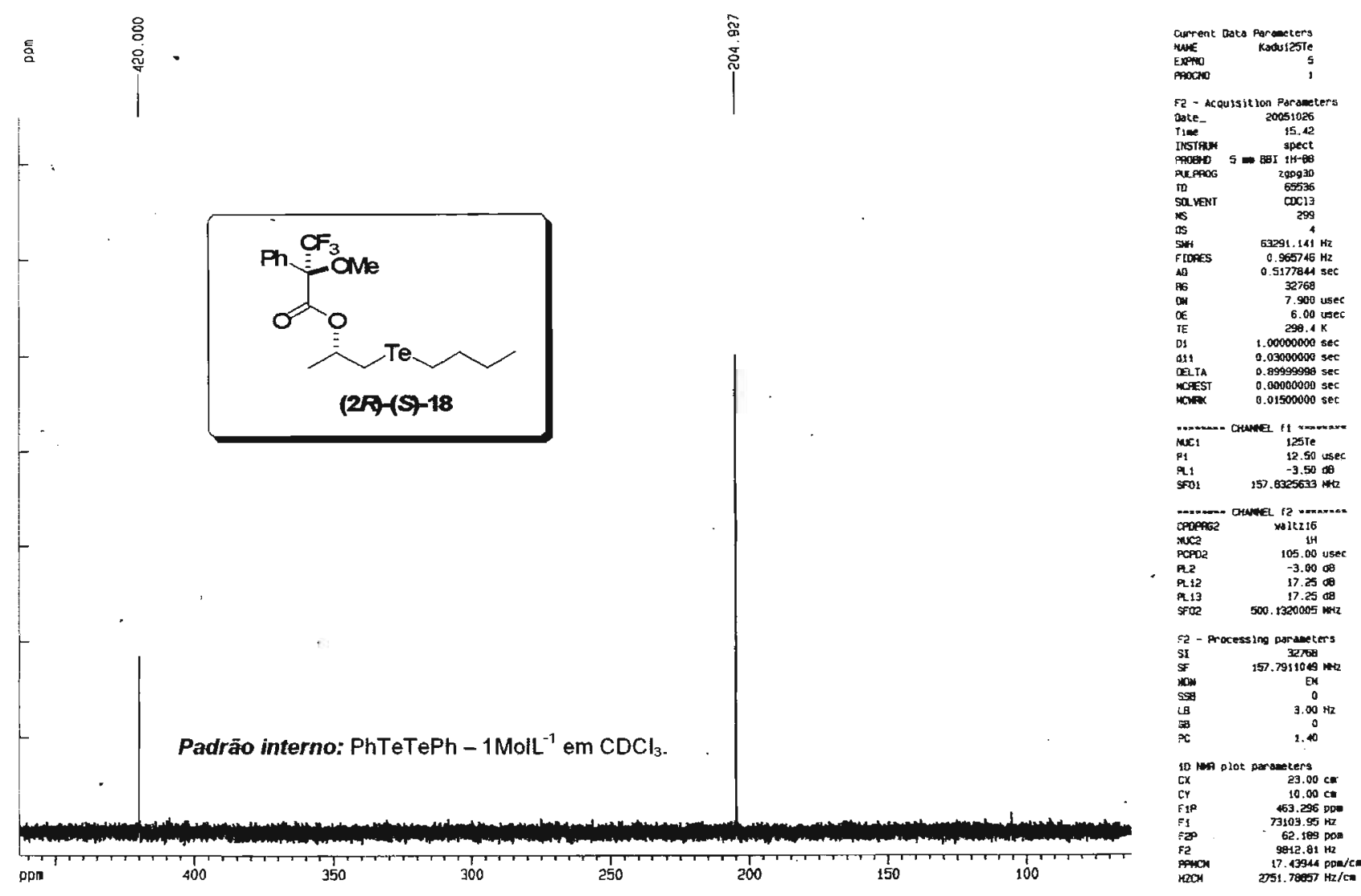

Espectro de RMIN ${ }^{125} \mathrm{Te}$ do composto (2R)-(S)-3,3,3-Trifluor-2-metóxi-2-fenil-propanoato de 1 -(n-butilteluro)-2-propila [(2R)-(S)-18]
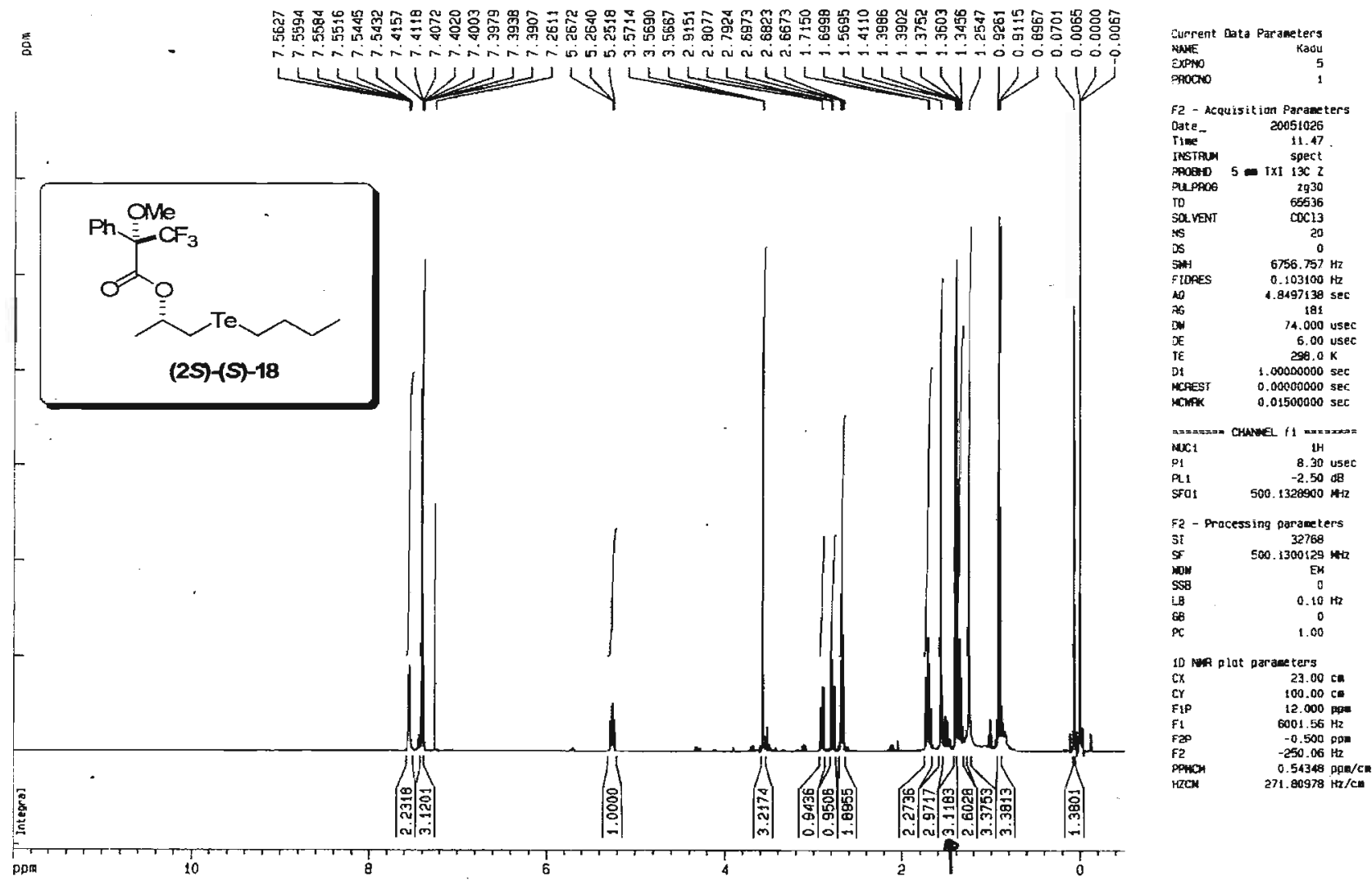

Espectro de RMN ${ }^{1} \mathrm{H}$ do composto (2S)-(S)-3,3,3-Trifluor-2-metóxi-2-fenil-propanoato de 1-(n-butilteluro)-2-propila [(2S)-(S)-18] 


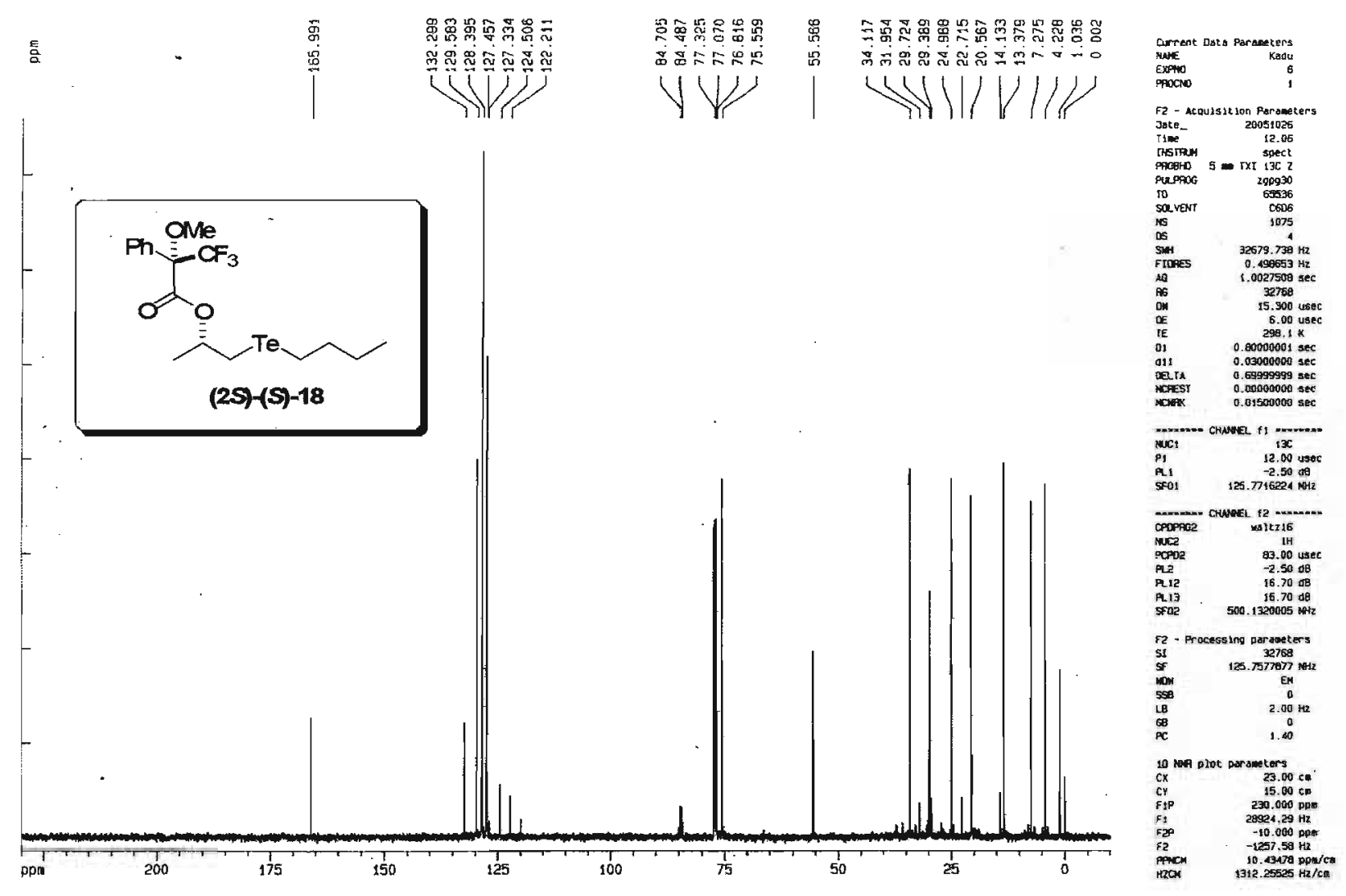

Espectro de RMN ${ }^{13} \mathrm{C}$ do composto (2S)-(S)-3,3,3-Trifluor-2-metóxi-2-fenil-propanoato de 1-(n-butilteluro)-2-propila [(2S)-\{S)-18]
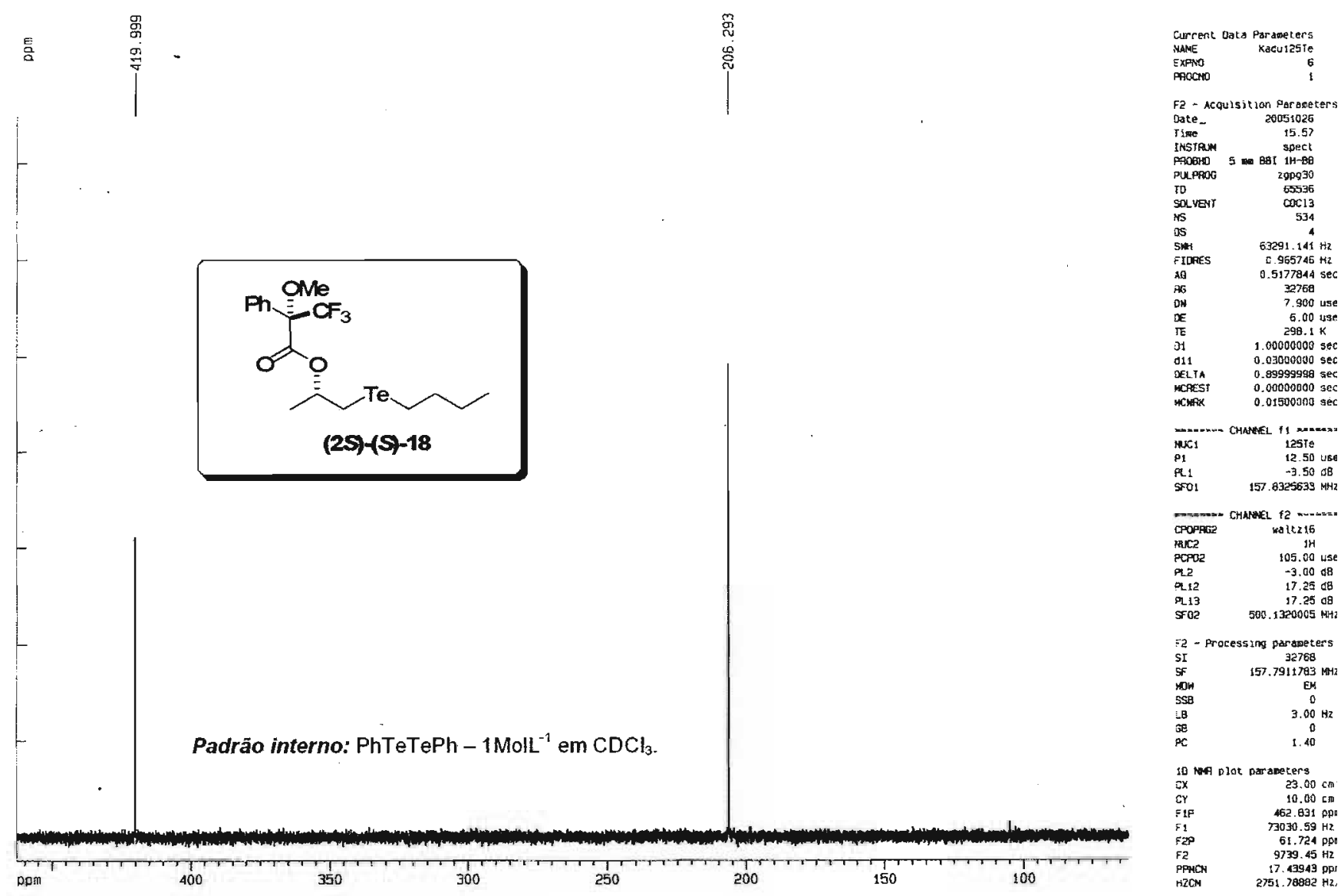

Espectro de RMN ${ }^{425} \mathrm{Te}$ do composto (2S)-(S)-3,3,3-Trifluor-2-metóxi-2-fenil-propanoato de 1 -(n-butilteluro)-2-propila [(2S)-(S)-18] 

5. Bibliografia 

(1) Coelho, F. A. S. Cadernos Temáticos de Química Nova na Escola 2001, 3, 23.

(2) Tumlinson, J. H.; Klein, M. G.; Doolitle, R. E.; Ladd, T. L.; Proveaux, A. T. Science 1977, 197, 789.

(3) Mori, K. Chirality 1998, 10, 578.

(4) a) Nilson, D.L.; Cox, M.M. Lehninger Principles of Biochemistry, 3th ed.; W.H. Freeman: New York, 2000. b)

http://quark.qmc.ufsc.br/qmcweb/artigos/drogas_quirais.html.

(5) http://www.spq.pt/boletim/docs/boletimSPQ_096_072_11.pdf.

(6) Stinson, S. C. Chem. \& Eng. 2001, 40, 79.

(7) Borman, S. C\&EN 2001, 79, 5.

(8) http://academic.scranton.edu/faculty/CANNM1/introport.html.

(9) Faber, K. Biotransformations in Organic Chemistry, 4th ed.; SpringerVerlag: Berlin, 2000.

(10) Ghanem, A.; Hassan, Y. A. Tetrahedron:Asymmetry 2004, 15, 3331.

(11) Liese, A.; Filho, M. V. Chemical Biotechnol 1999, 10, 595.

(12) Roberts, S. M. J. Chem. Soc. Perkin Trans 2000, 1, 611.

(13) Straathof, A. J. J.; Schmid, A.; Panke, S. Curr Opin Biotechnol 2002, 13, 548.

(14) Fulkul, T.; Soda, K. Molecular Aspects of Enzyme Catalysis; Kadansha: Toquio, 1994.

(15) Fischer, E. Ber. Dtsch. Chem. Ges. 1894, 27, 2985.

(16) Kosland, D. E.; Neet, K. E. Ann. Rev. Biochem. 1968, 37, 359.

(17) Dewar, M. S. J. Enzyme 1986, 36, 8.

(18) Warshel, A.; Aqvist, J.; Creighton, S. Proc. Natl. Acad. Sci. 1989, 86 5820 .

(19) Ongston, A. G. Nature 1948, 162, 963.

(20) Hirs, C. H. W.; Moore, S.; Stein, W. H. J. Biol. Chem. 1960, 235, 633.

(21) Carrea, G.; Riva, S. Angew. Chem. Int. Ed. 2000, 39, 2226.

(22) Holland, H. L. Nat. Prod. Rep. 2001, 18, 171.

(23) Roberts, S. M. (ed.); Biocatalysts for Fine Chemicals Synthesis John Wiley \& Sons: Chichester, 1999.

(24) Ching-Shih, C.; Cahrles, J. S. Angew. Chem. Int. Engl. 1989, 28, 695.

(25) Koskinem, A. M.; Klibanov, A. M. Enzymatic Reactions in Organic Media, 1st ed; Chapman \& Hall: New York, 1995.

(26) Wong, C.; Whitesides, G. M. Enzymes in synhetic organic chemistry; Pergamon Press: London, 1995.

(27) Cambou, B.; Klibanov, A. M. Biotechnol. and Bioeng. 1987, 26, 1449.

(28) Djeghaba, Z.; Deleuze, H.; Dejeso, B.; Messadi, D.; Maillard, B. Terahedron 1991, 32, 761.

(29) Margolin, A. L.; Klibanov, A. M. J. Am. Chem. Soc. 1987, 109, 3802.

(30) Lino, Y.; Tanaka, A; Yamashita, K. Agric. Biolog. Chem. 1972, 36, 2505.

(31) Kazlauskas, R. J.; Weissfloch, A. N. E.; Rappaport, A. T.; Cuccia, A. J. Org. Chem. 1991, 56, 2656. 
(32) Hanefeld, U. Org. Biomol. Chem. 2003, 1, 2405.

(33) Cygler, M.; Grochulski, P.; Kazlauskas, R. J.; Schrag, J. D.; Buothillier, F.; Rubin, B.; Serreqi, A. N.; Gupta, A. K. J. Am.Chem. Soc. 1994, 116, 3180.

(34) Ema, T.; Kobayashi, J.; Maeno, S.; Sakai, T.; Utaka, M.; Bull. Chem. Soc. Jpn. 1998, 71, 443

(35) Rotticci, D.; Hæffner, F.; Orrenius, C.; Norin, T.; Hult, K.; J. Mol. Catal. B:Enzym. 1998, 5, 267.

(36) Mojovic, L.; Knezevic, Z.; Popadic, R.; Jovanovic, S. Appl. Mic. Biotech 1998, 50, 676 .

(37) Comasseto, J. V. J. Organomet. Chem. 1983, 253, 131.

(38) Back, T. (ed); Organoselenium Chemistry Oxford University Press: Oxford, 1999

(39) Comasseto, J. V. Rev. Heteroatom. Chem. 1993, 9, 61.

(40) Comasseto, J. V.; Barrientos-Astigarraga, R. E. A/drichimica Acta 2000, 33,66 .

(41) Marino, J. P.; McClure, M. S.; Holub, D. P.; Comasseto, J. V.; Tucci, F. C. J. Am. Chem. Soc. 2002, 8, 1664.

(42) Ellensohn, R. M.; Tese de doutorado, Universidade de São Paulo: São Paulo, 2000.

(43) a) Comasseto, J.V. J. Organomet. Chem. 1983, 253, 131; b) Comasseto, J. V.; Lo, W. L.; Petragnani, N.; Stefani, H. A. Synthesis 1997, 373.

(44) Petragnani, N.; Stefani, H. A. Tetrahedron 2p05, 61, 1613-1679.

(45) Liotta, D. Organoselenium Chemistry; John Wiley: New York, 1987.

(46) (a) Sebach, D.; Peleties, N. Angew. Chem. Int. Ed. Engl. 1969, 8, 450-451;

(b) Dumont, W.; Bayet,P; Krief, A. Angew. Chem. Int. Ed. Engl. 1974, 13, 804.

(47) Reich, H.J.; Willis, W. W. Jr.; Clark, M. C. J. Org. Chem. 1981, 46, 2775.

(48) Clarembeau, M.; Cravador, A.; Dumont, W.; Hevesi, L.; Krief, A.; Lucchetti, J.; Vanende, D. Tetrahedron 1985, 41, 4793.

(49) (a) Weber, H.; Khorana, H. G.; J. Mol. Biol. 1972, 72, 219; (b) Zhdanov, R. I.; Zhenodarova, S. M. Synthesis 1975, 222.

(50) Queiroz, N.; Nascimento, M. G. Tetrahedron Letters 2002, 43, 5225-5227.

(51) Móris-Varas, F.; Shah, A.; Aikens, J.; Nadkarni, N.P.; Rozzell, J.D.; Demirjian, D.C. Bioorg. Med. Chem. 1999, 7, 2183.

(52) Andrade, L. H.; Porto, A. L. M.; Comasseto, J. V.; Omori, A.T.; Assis, L.F. J. Mol. Catal. B: Enzym. 2004, 29, 55.

(53) Chasteen, T. G., Bentley, R. Chem. Rev. 2003, 1,103.

(54) Clive, D.L.; Chittattu, G.J.; Farina, V.; Kiel, W.A.; Menchen, S.M.; Russel C.G.; Singh, A.; Wong, C. K.; Curtis, N. J. J. Am. Chem. Soc. 1980, 102, 4438.

(55) Dale, J.A.; Mosher, H.S. J. Am. Chem. Soc. 1973, 95:2, 512.

(56) Keinan, E.; Hafeli, E. K.; Seth, K.K.; Lamed, R. J. Am. Chem. Soc. 1986, $108,162$.

(57) Nakamura, K.; Matsuda, T. J. Org. Chem. 1998, 63, 8957. 
(58) Toshimitso, A.; Nakano, K.; Mukai, T.; Tamao, K. J. Am. Chem. Soc. 1996 $118,2756$.

(59) Ohkuma, T.; Koizumi, M.; Doucet, H.; Pham, T.; Kozawa, M.; Murata, K.; Katayama, E.; Yokozawa, T.; Ikariya, T.; Noyori, R. J. Am. Chem. Soc. 1998, 120, 13529.

(60) Comasseto, J. V.; Ling, L. W.; Petragnani, N.; Stefani, H. A. Synthesis 1997, 4, 373.

(61) Zeni, G.; Formiga, H. B.; Comasseto, J. V. Tetrahedron Lett. 2000, 41 , 1311.

(62) Seebach, D.; Beck, A. K. Chem. Ber. 1975, 108, 314.

(63) Petragnani, N.; Schill, Chem. Ber., 1970, 103, 2271.

(64) Zinn, F. K.; Righi, V. E.; Luque, S. C.; Formiga, H. B.; Comasseto, J. V. Tetrahedron Lett. 2002, 43, 1625.

(65) Princival, J. L.; Barros, S. M. G., Comasseto, J. V.; Dos Santos, A. A. Tetrahedron Lett. 2005,46, 4423.

(66) (a) Barrietos-Astigarra, R. E; Castelani, P.; Comasseto, J. V.; Formiga, H B.; Silva, N. C.; Sumida, C. Y.; Vieira, M. L. J. Organomet. Chem. 2001, 43, 623; (b) Raminelli, C.; Silva, N. C.; Dos Santos, A. A.; Porto, A. L.M.; Andrade, L. H.; Comasseto. J. V. Tetrahedron 2005, 61, 409.

(67) Vieira, M. L.; Zinn, F. K.; Comasseto, J. V. J. Braz. Chem. Soc. 2001, 12, 586.

(68) (a) Wheeler, J. W.; Chungo, R.H. J. Org. Chem. 1969, 34, 1149; (b) Johnson, M. R.; Rickborn, B. J. Org. Chem. 1970, 35, 1041.

(69) Dos Santos, A.A.; Castelani, P.; Bassora, B.K.; Junior, J.C.F.; Costa, C.E.; Comasseto, J.V. Tetrahedron, 2005, 61, 9173.

(70) Costa, C.E.; Clososki, G.C.; Barchesi, H. B.; Zanotto, S. P.; Nascimento, M.G.; Comasseto, J. V. Tetrahedron:Asymmetry 2004, 15, 3945.

(71) Clososki, G.C.; Costa, C.E.; Missio, L.J.; Cass, Q.B.; Comasseto, J.V. Synthetic Comm. 2004, 34, 817.

(72) Tsuboi, S.; Sakamoto, J.; Kawano, T. Utaka, Takeda, A. J. Org. Chem. $1991,56,7177$.

(73) Perrin, D. D.; Amarego, W.L.F. Purification of Laboratory Chemicals; Pergamon Press: London, 1980.

(74) Sharpless, K. B.; Lauer, R. F. J. Am. Chem. Soc. 1973, 95, 2697.

(75) Haller, W. S.; Irgolic, K. J. J. Organomet. Chem. 1972, 38, 97.

(76) Tatchell, A. R. Et al In Vogel's Textbook of Practical Organic Chemistry, $5^{\text {th }}$ ed., Wiley: New York, 1989, 432.

(77) Rua Latino Coelho, 1301, Parque Taquaral, CEP 13087-010 - Campinas SP - Brasil.

(78) Sir, C. J.; Wu, S. H. Topics Stereochem 1989, 19,63.

(79) Abad, J. L.; Fabriás, G.; Camps, F.; J. Org. Chem. 2000, 65, 8582. 